\title{
Pd-Catalyzed Alkene Difunctionalization Reactions of Enolates for the Synthesis of Substituted Bicyclic Cyclopentanes.
}

Evan C. Bornowski, ${ }^{\dagger}$ Elsa M. Hinds, ${ }^{\dagger}$ Derick R. White, ${ }^{\dagger}$ Yusuke Nakamura, and John P. Wolfe* Department of Chemistry, University of Michigan, 930 N. University Avenue, Ann Arbor, Michigan 48109-1055

\section{Supporting Information}

Descriptions of Stereochemical Assignments

\section{Descriptions of Stereochemical Assignments}

The relative stereochemistry of products $7 \mathrm{~d}, 7 \mathrm{c}$ (via S12), 7e, 7p, 7k, 7o, 6e, 17 and 18h was assigned on the basis of ${ }^{1} \mathrm{H}$ NMR nOe studies. The data for these studies is provided below, along with the key nOe signals. The relative stereochemistry of all other products was assigned based on analogy to 7d, 7c (via S12), 7e, 7p, 7k, 7o, 6e, 17 or 18h. 

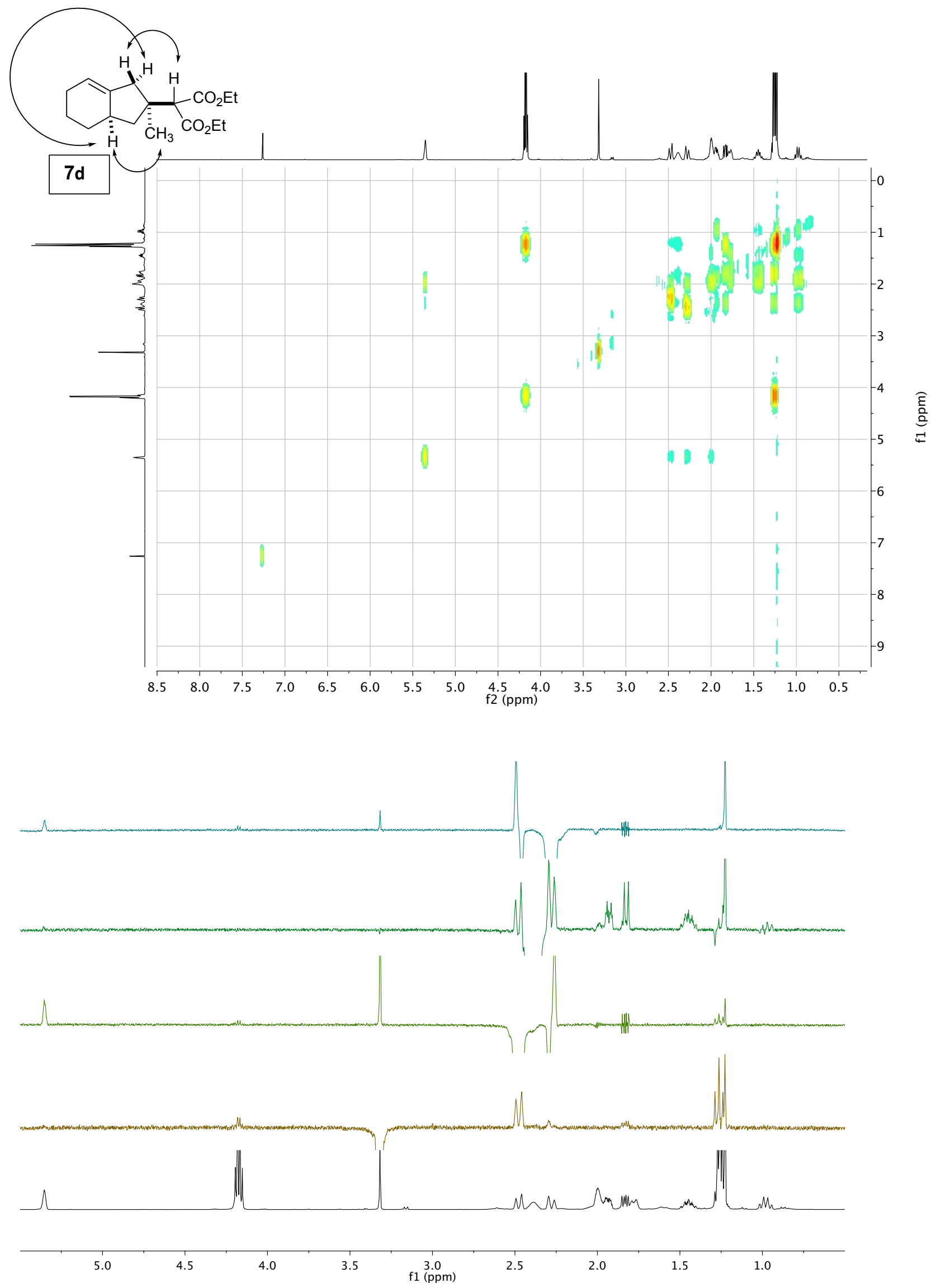

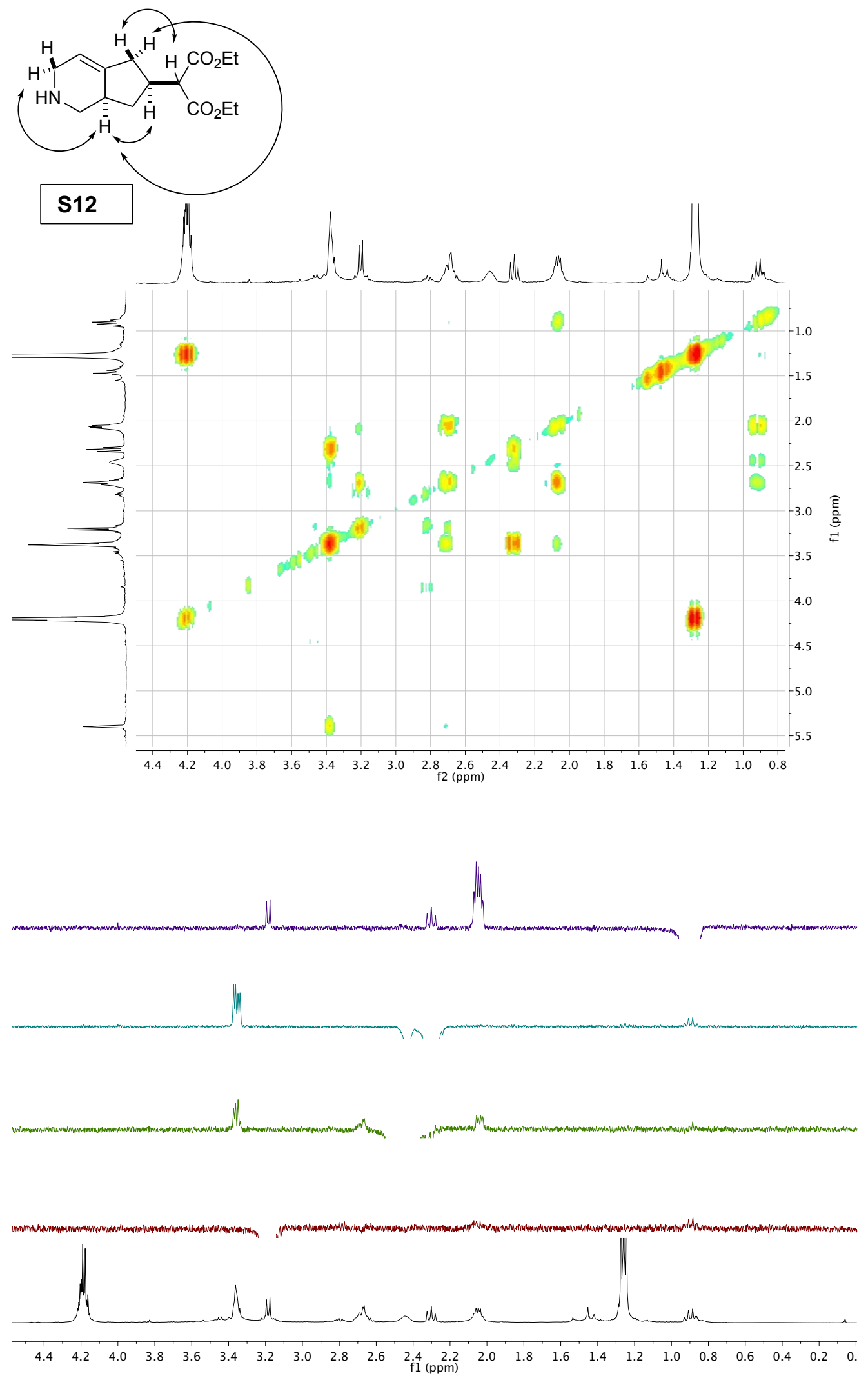

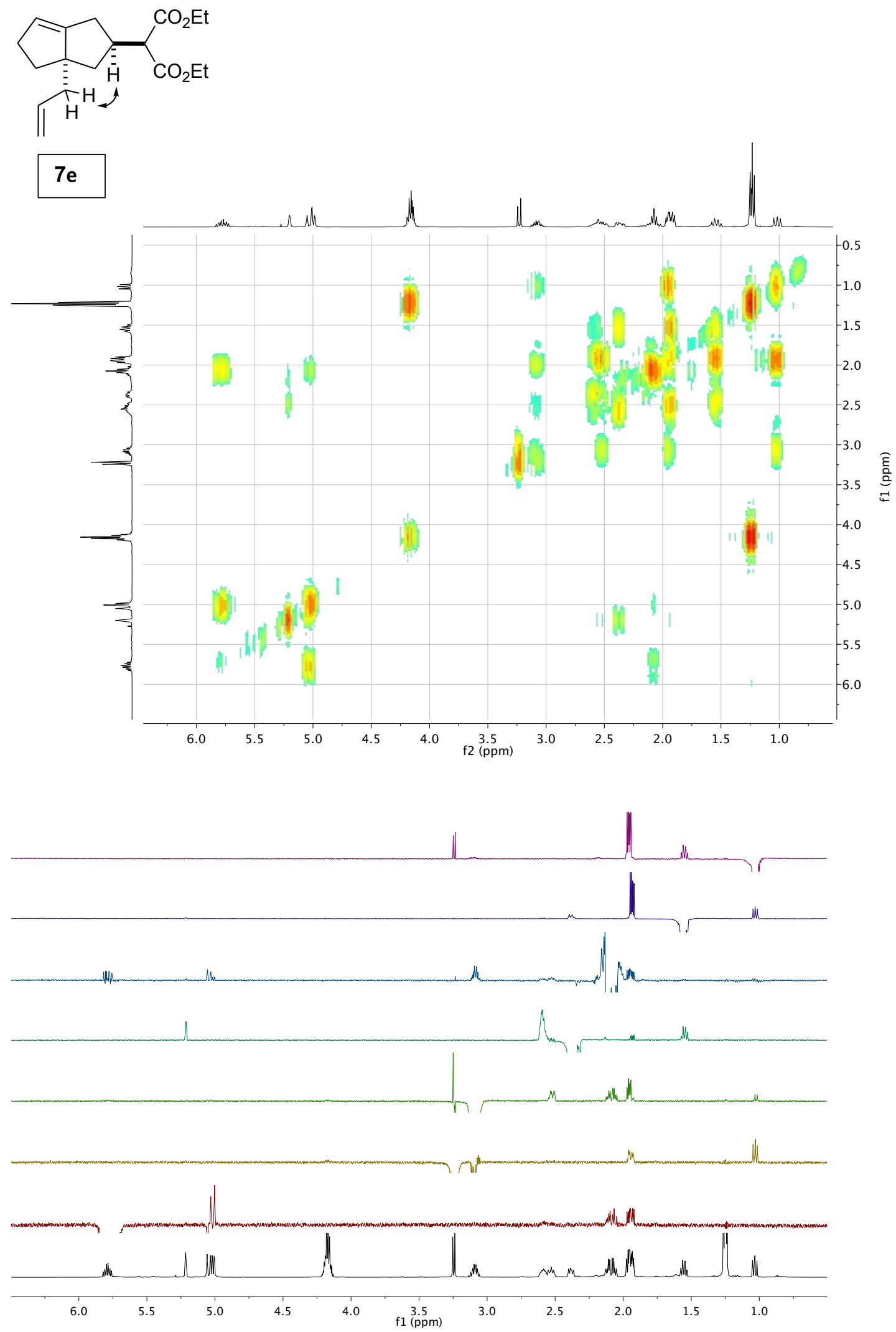

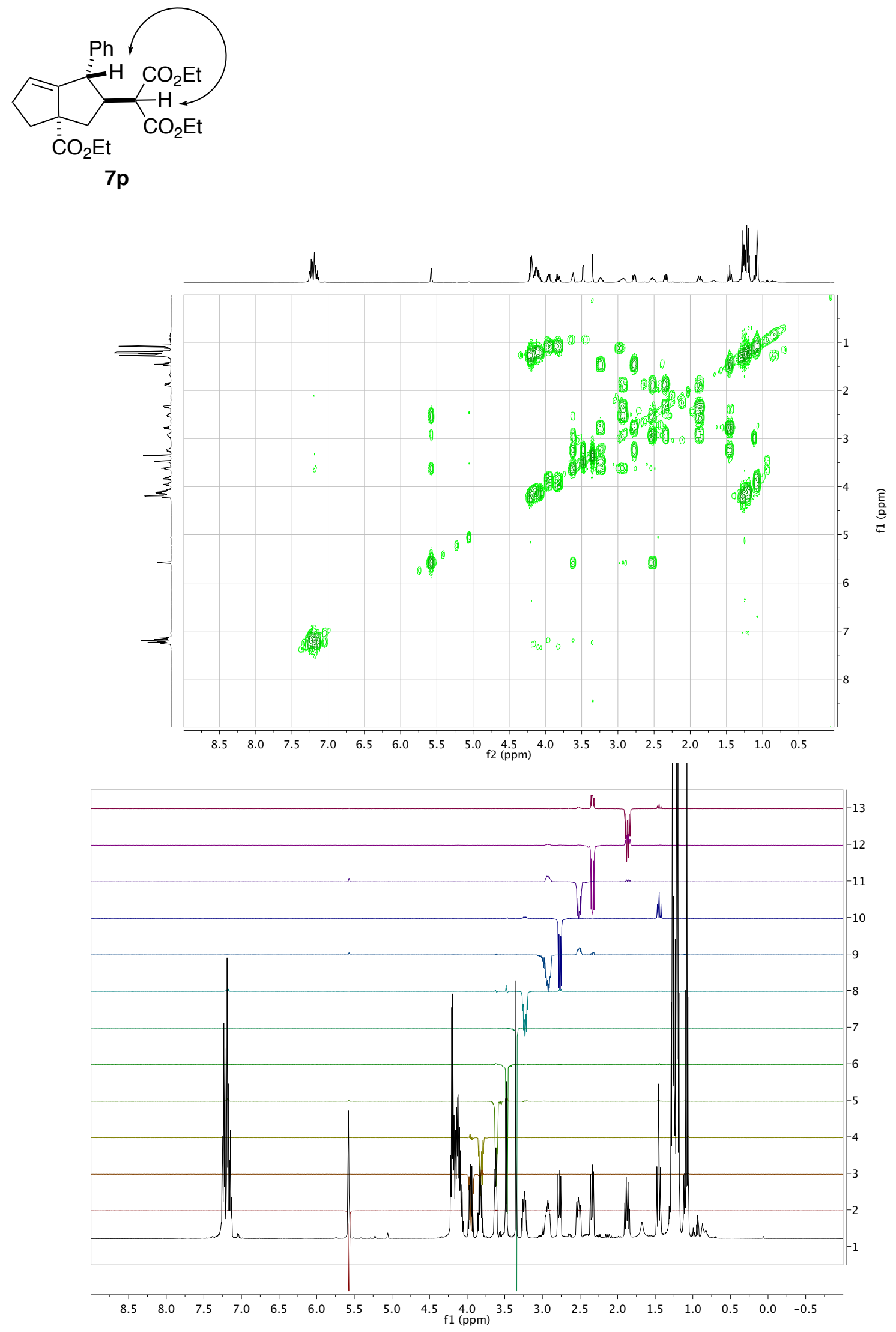


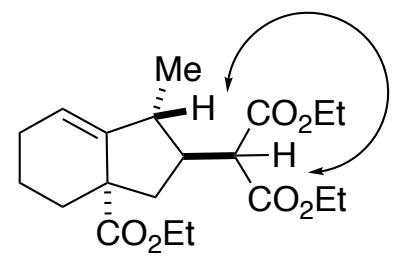

7k
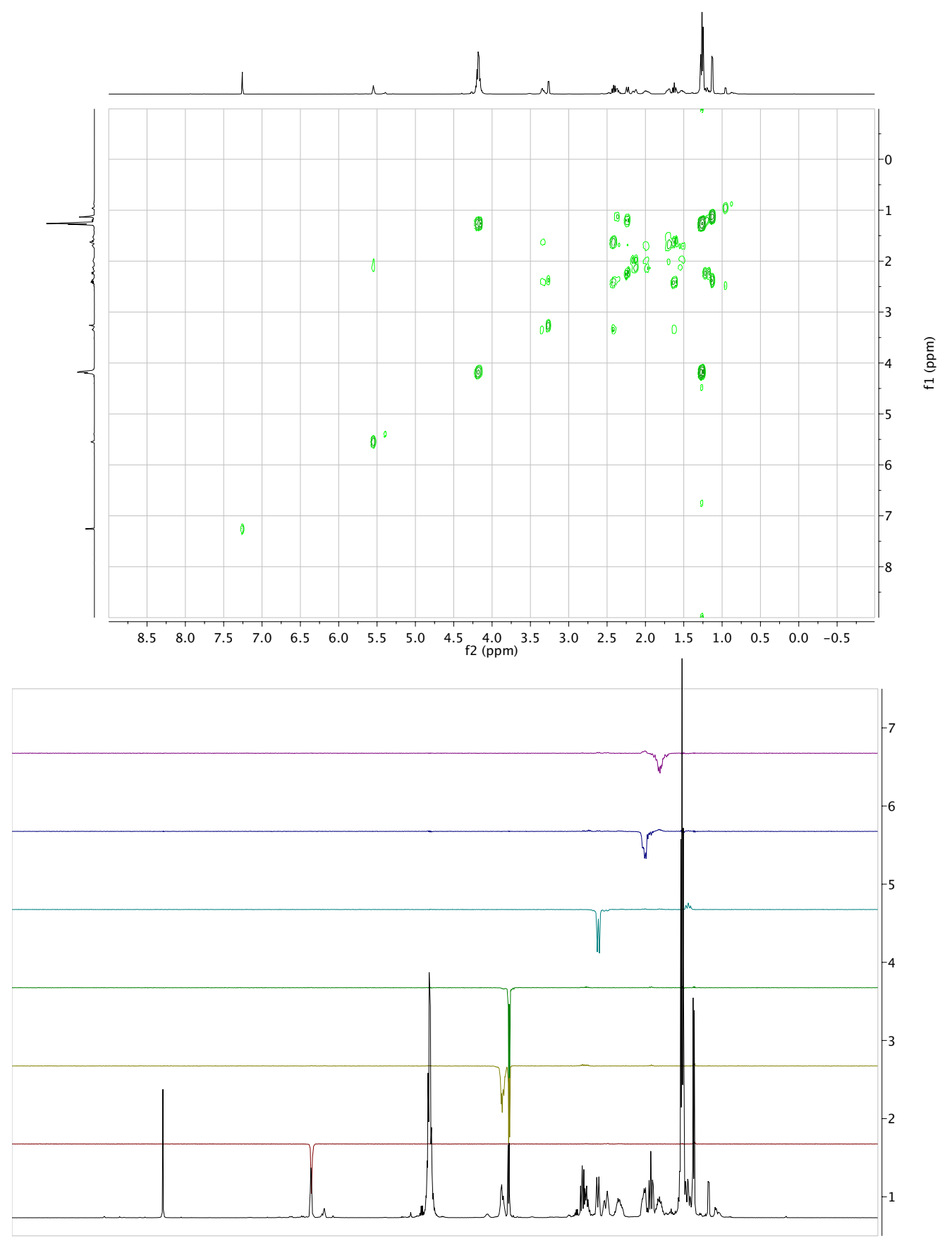

$\begin{array}{lllllllllllllllllll}8.5 & 8.0 & 7.5 & 7.0 & 6.5 & 6.0 & 5.5 & 5.0 & 4.5 & \underset{\mathrm{f} 1}{(\mathrm{ppm})}(\mathrm{ppm}) & 3.5 & 3.0 & 2.5 & 2.0 & 1.5 & 1.0 & 0.5 & 0.0 & -0.5\end{array}$ 


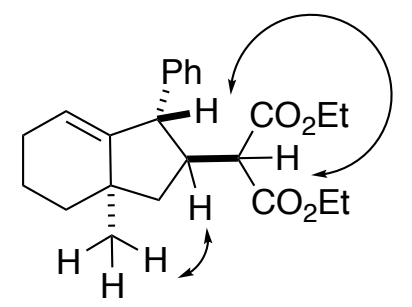

70

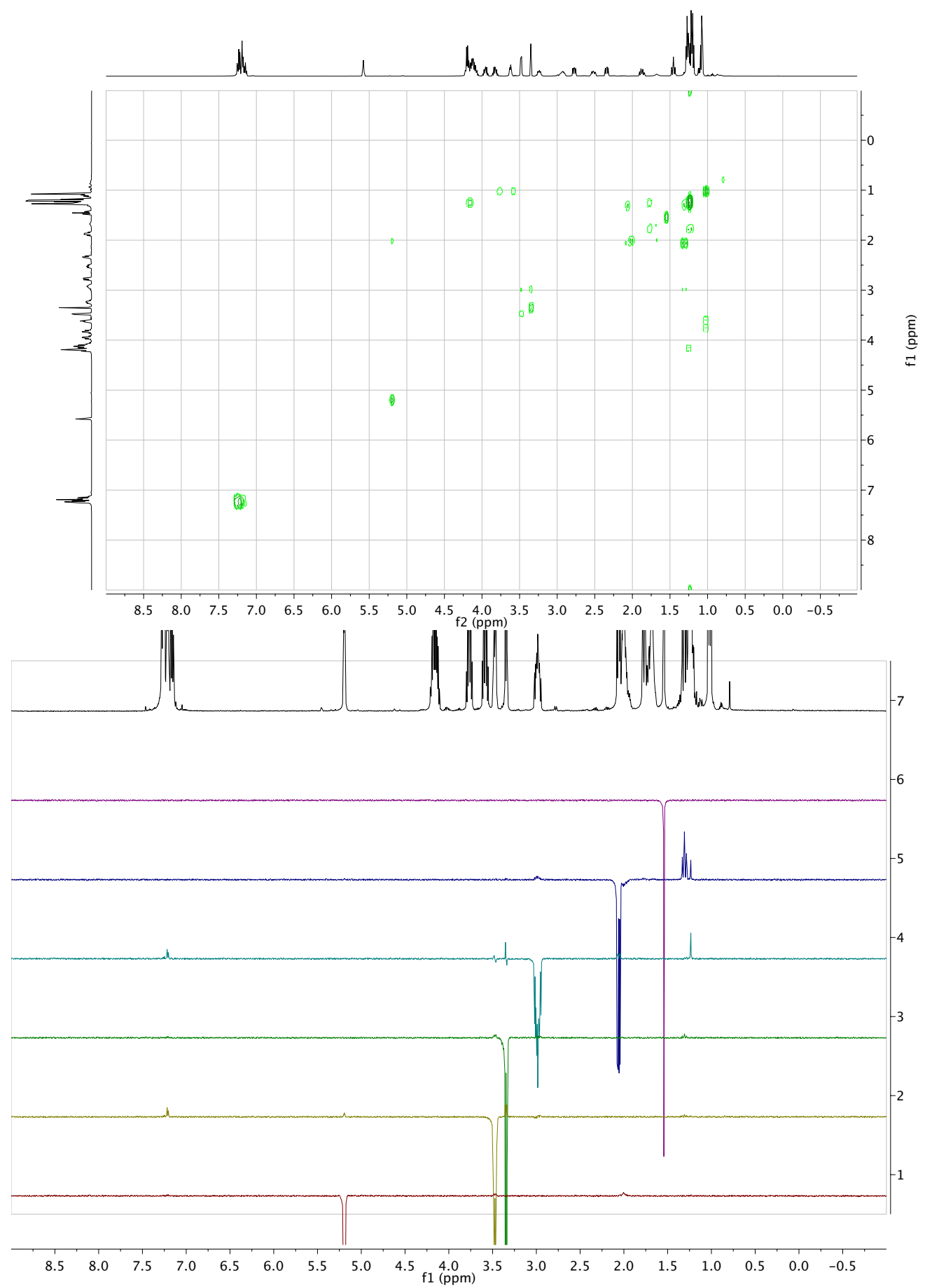



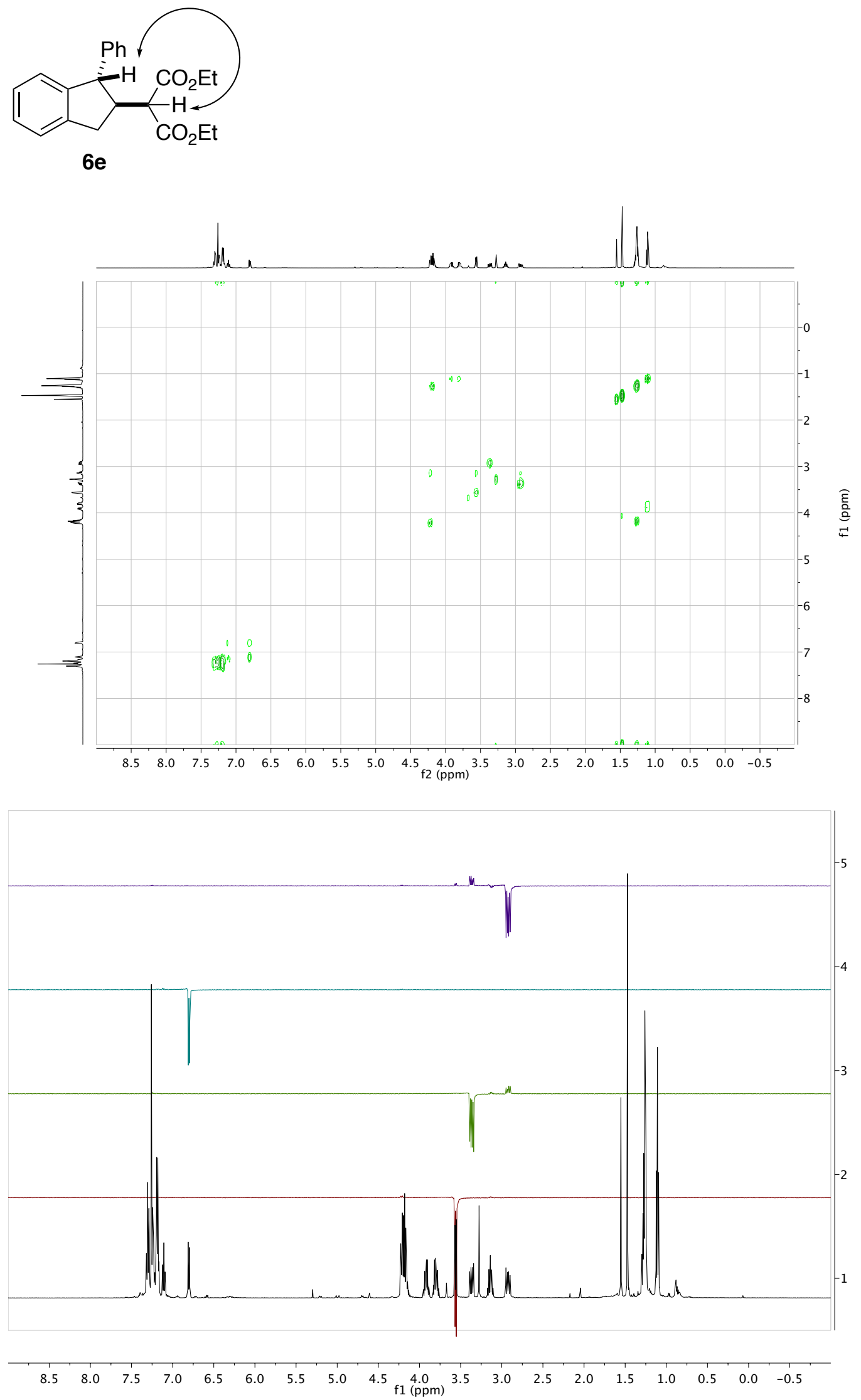


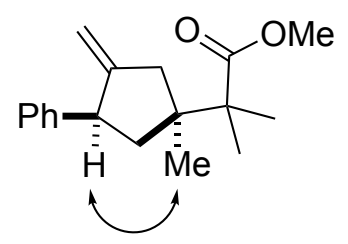

17
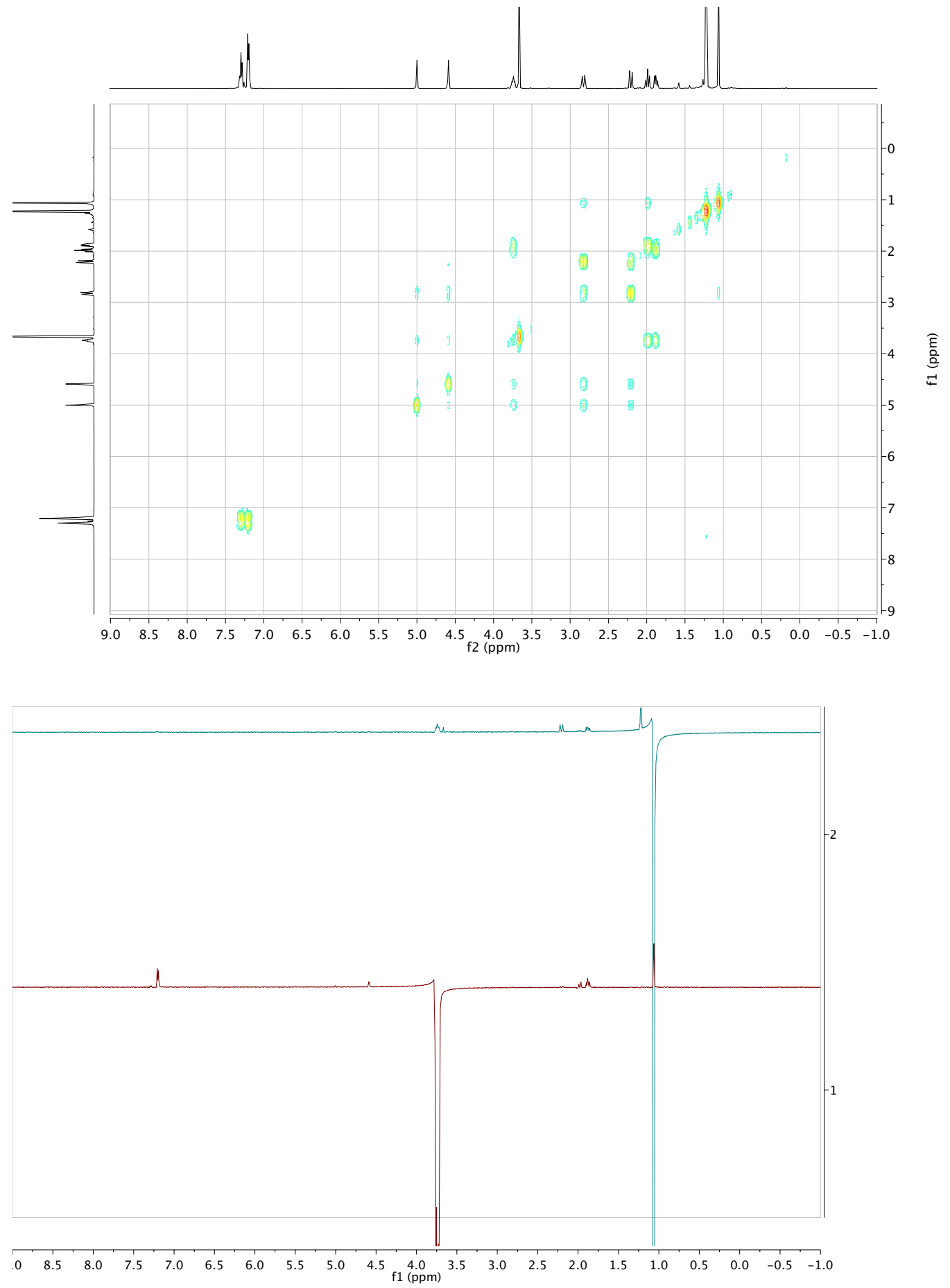


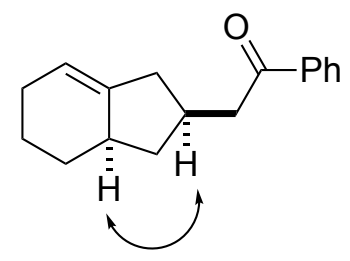

$18 \mathrm{~h}$
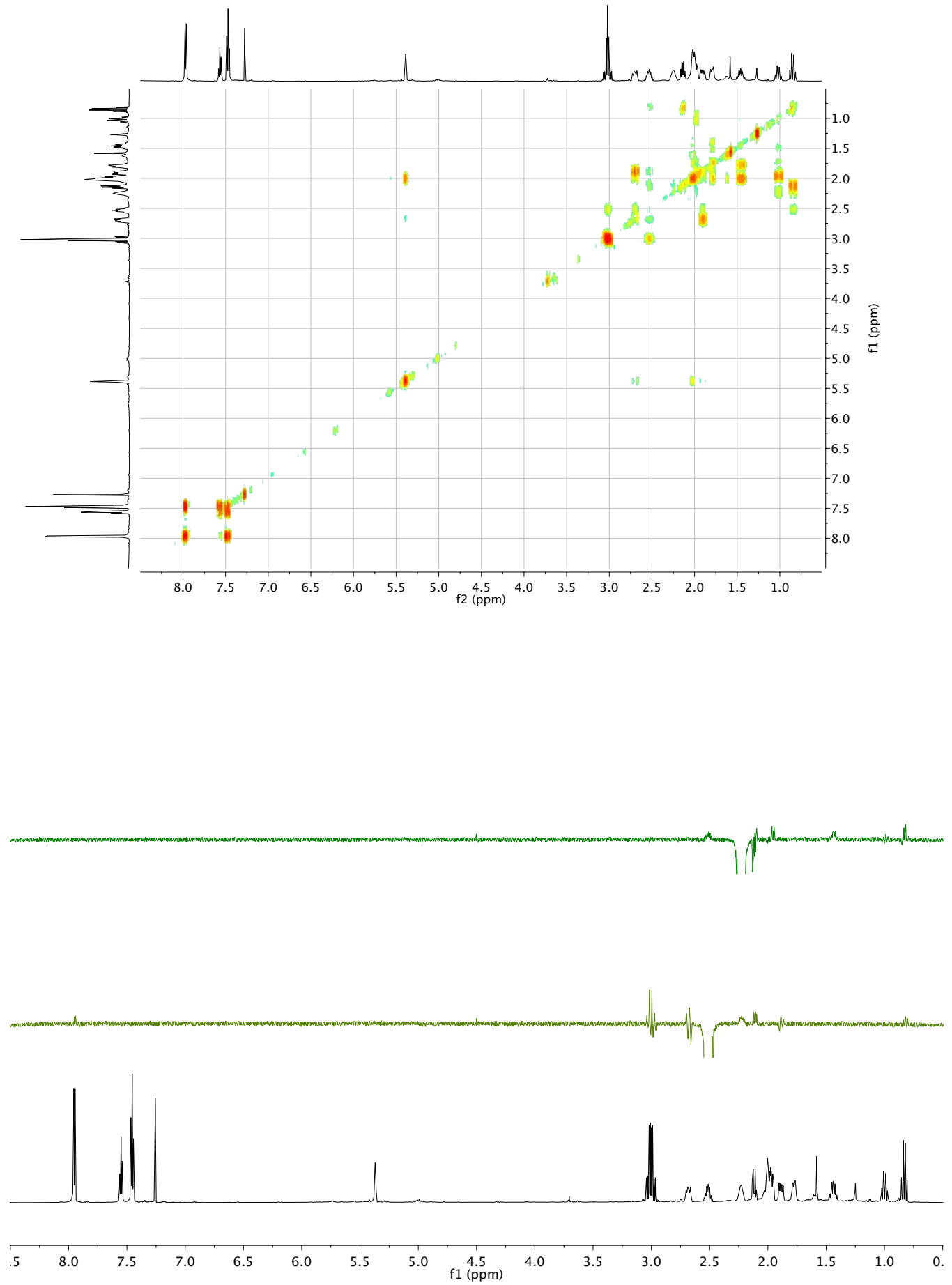


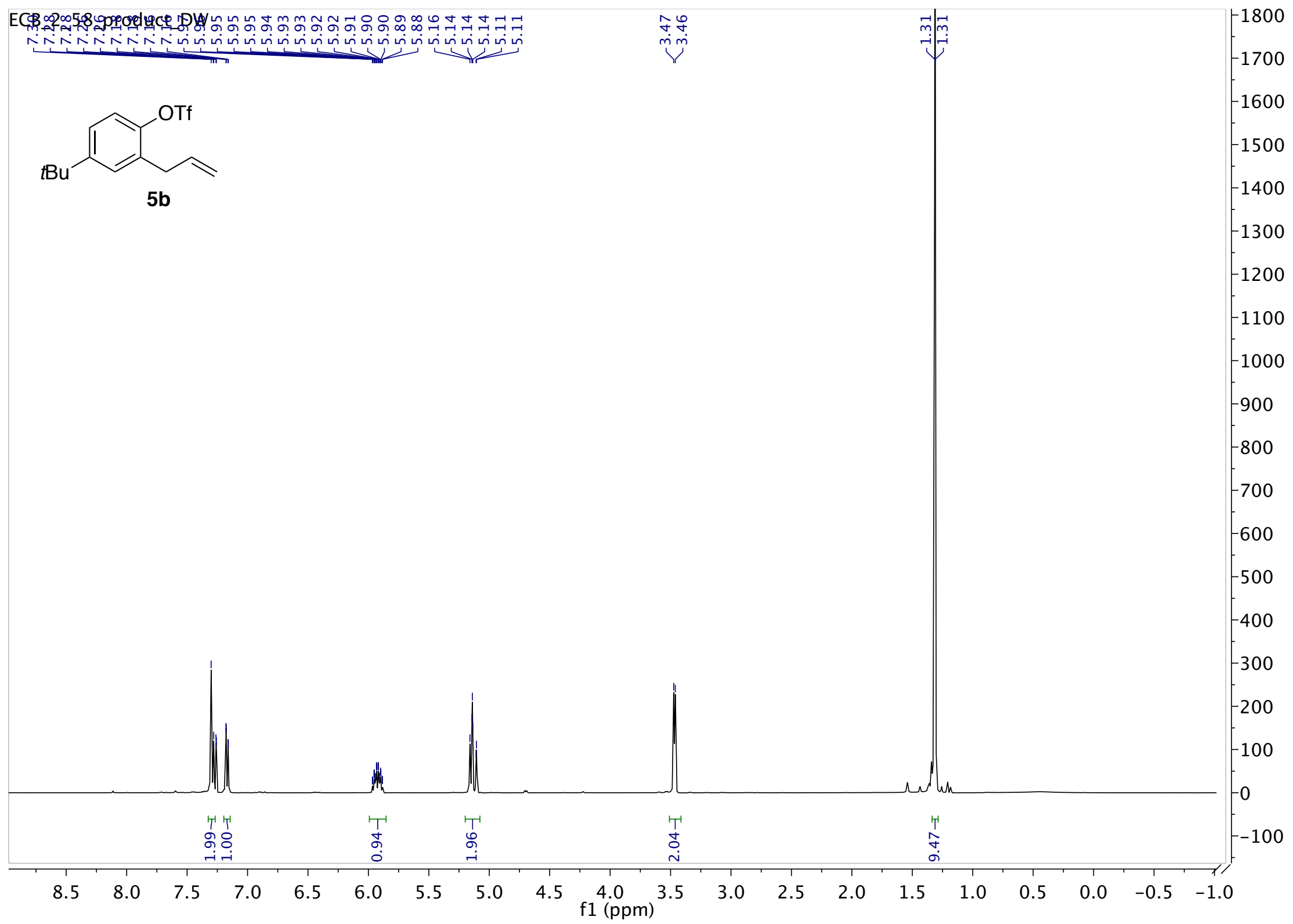




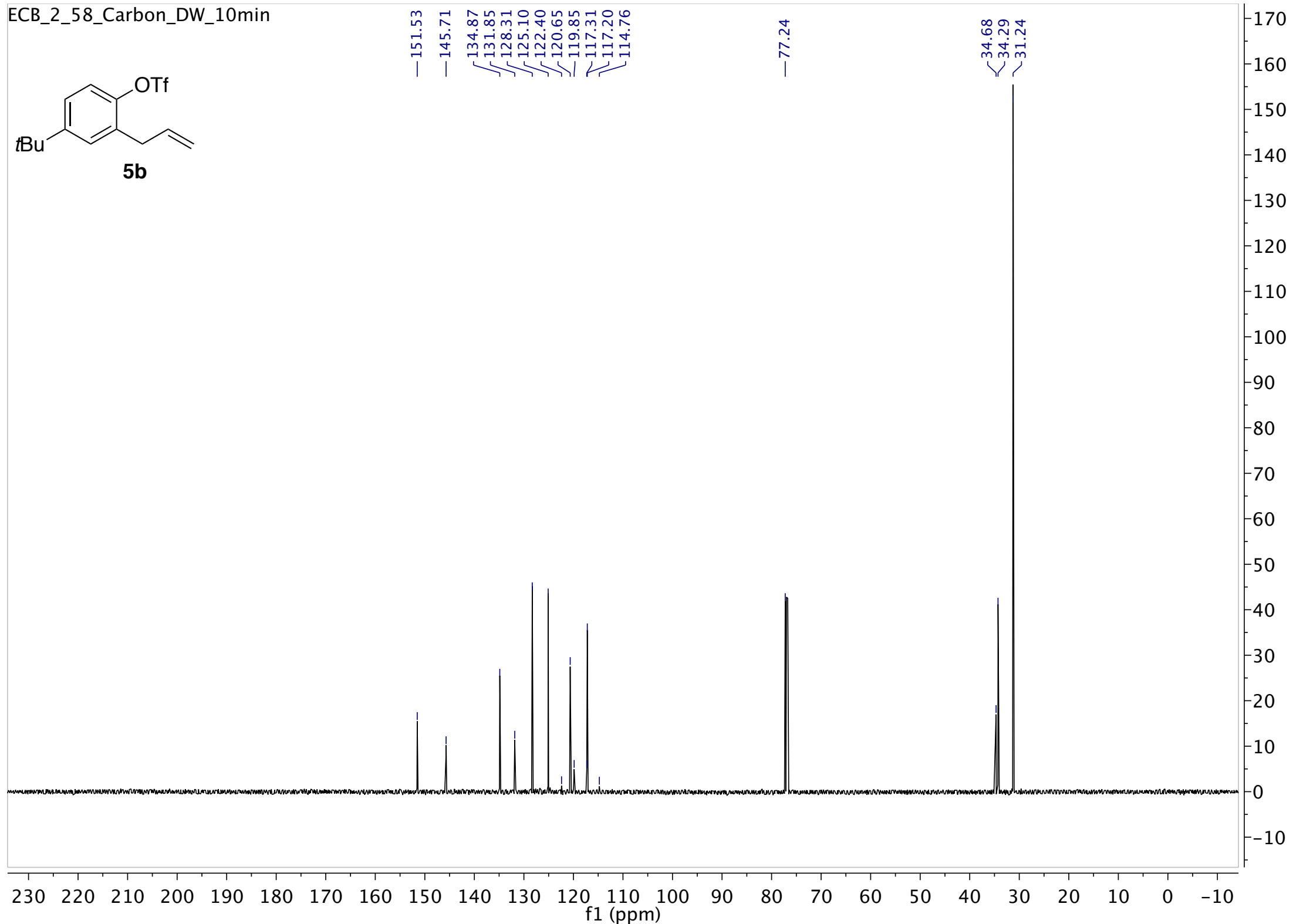




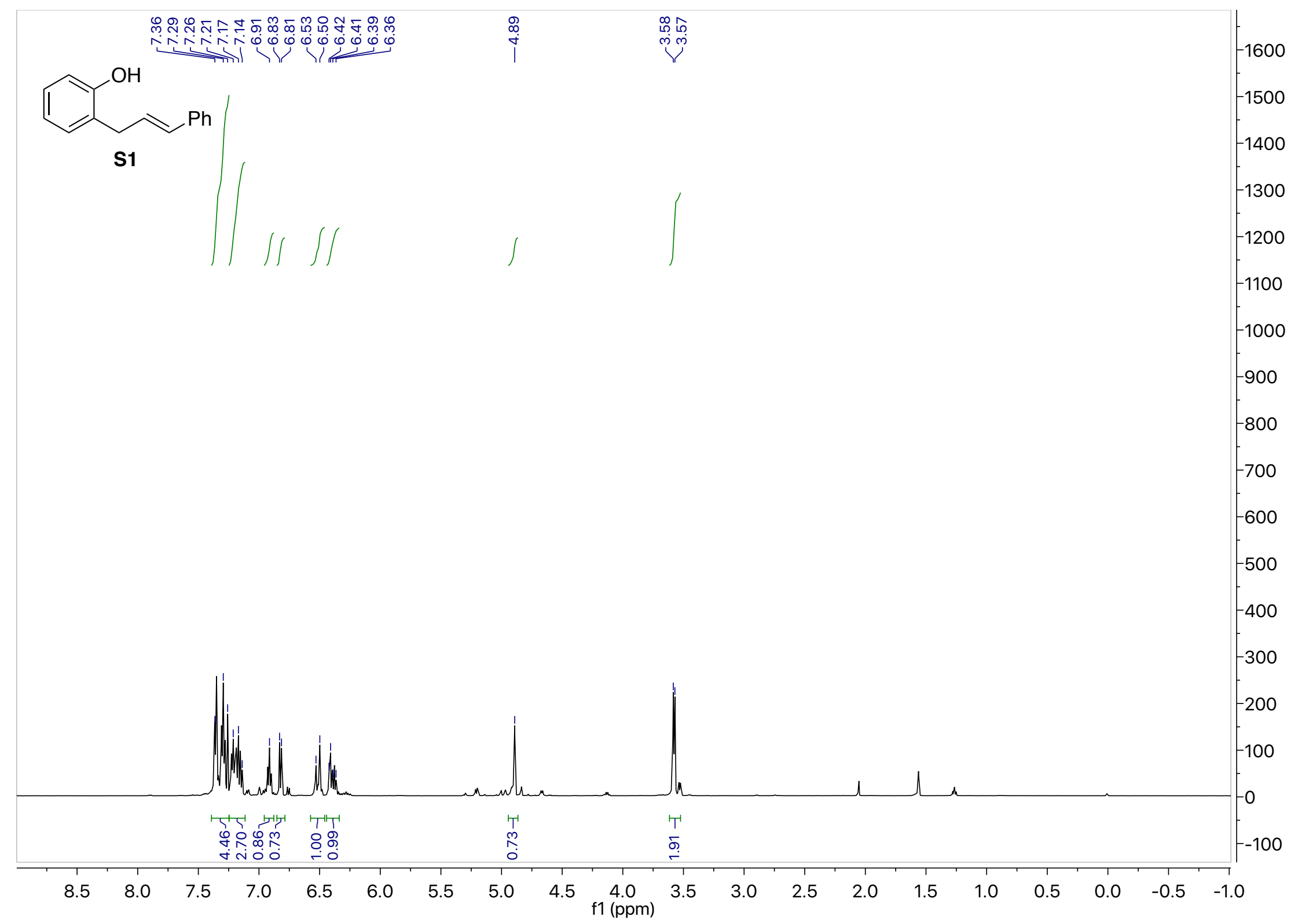




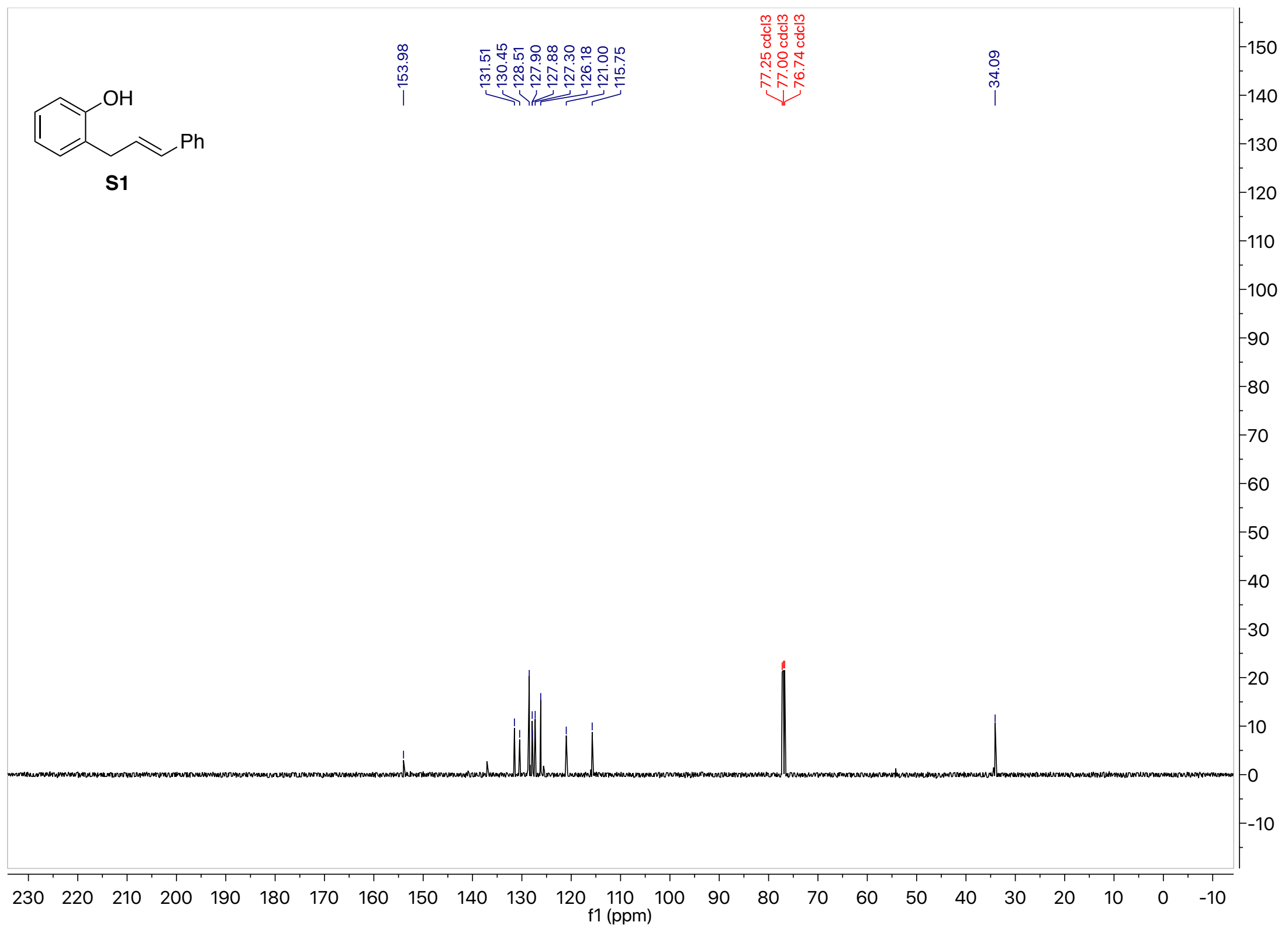




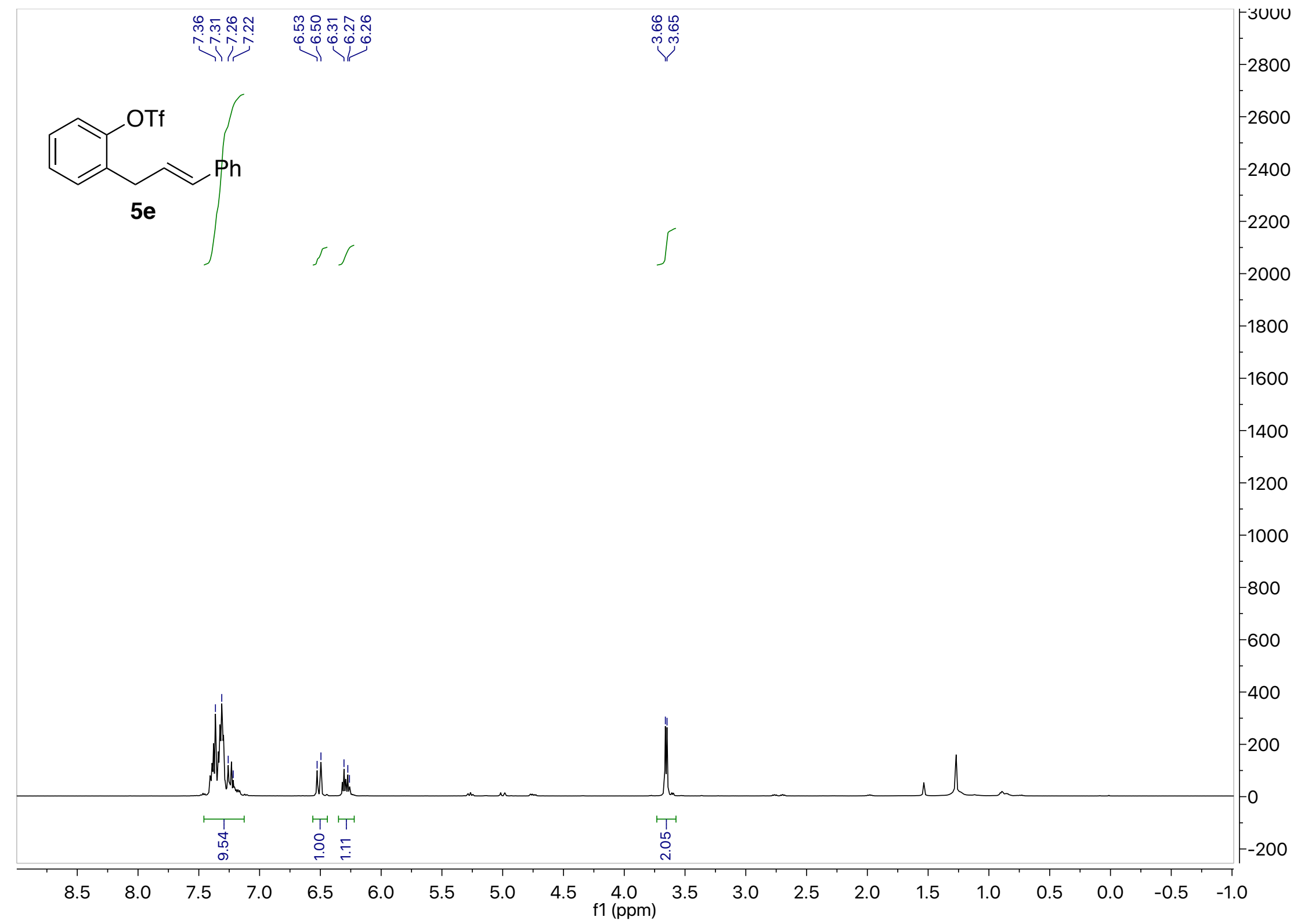




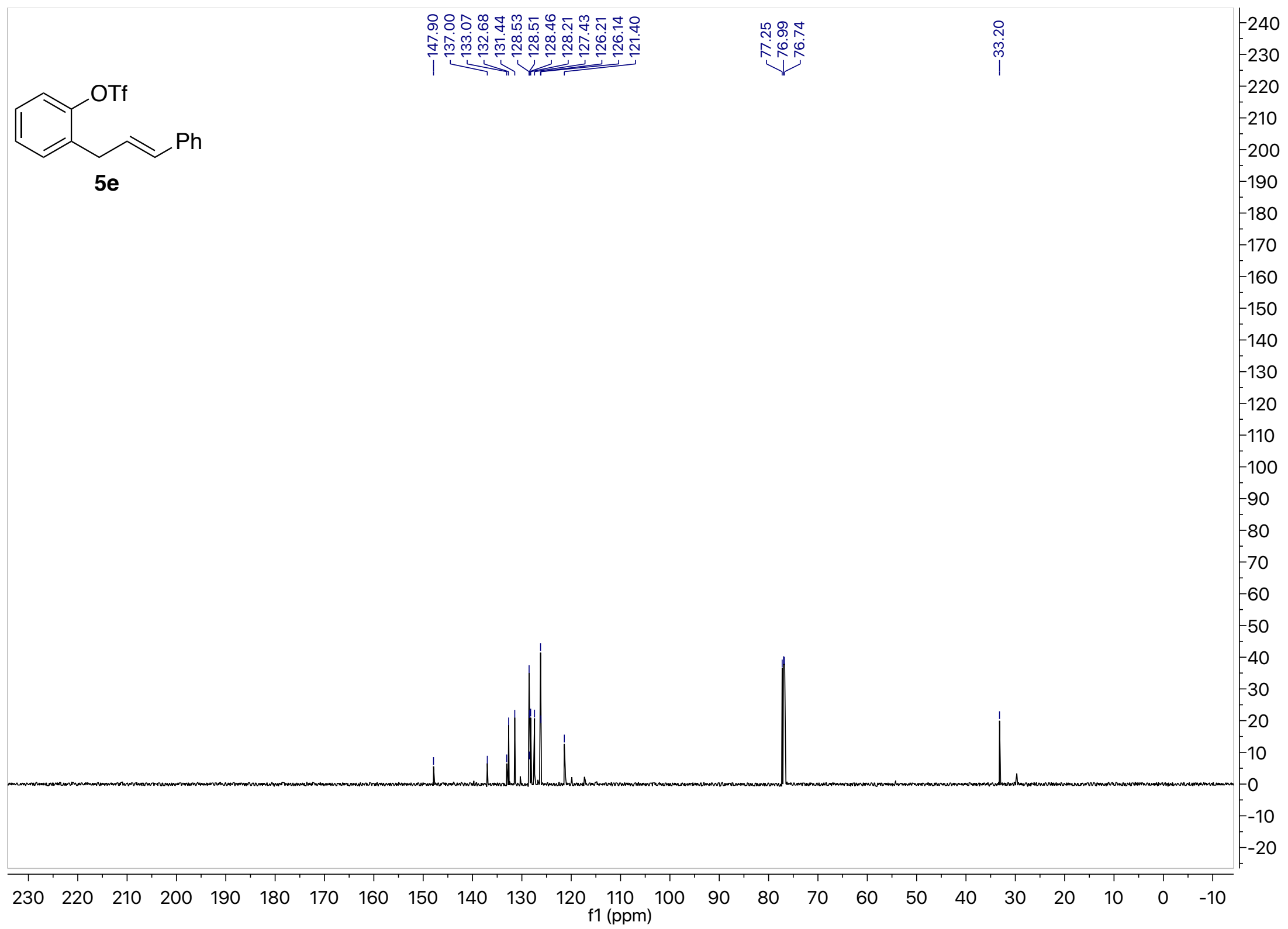




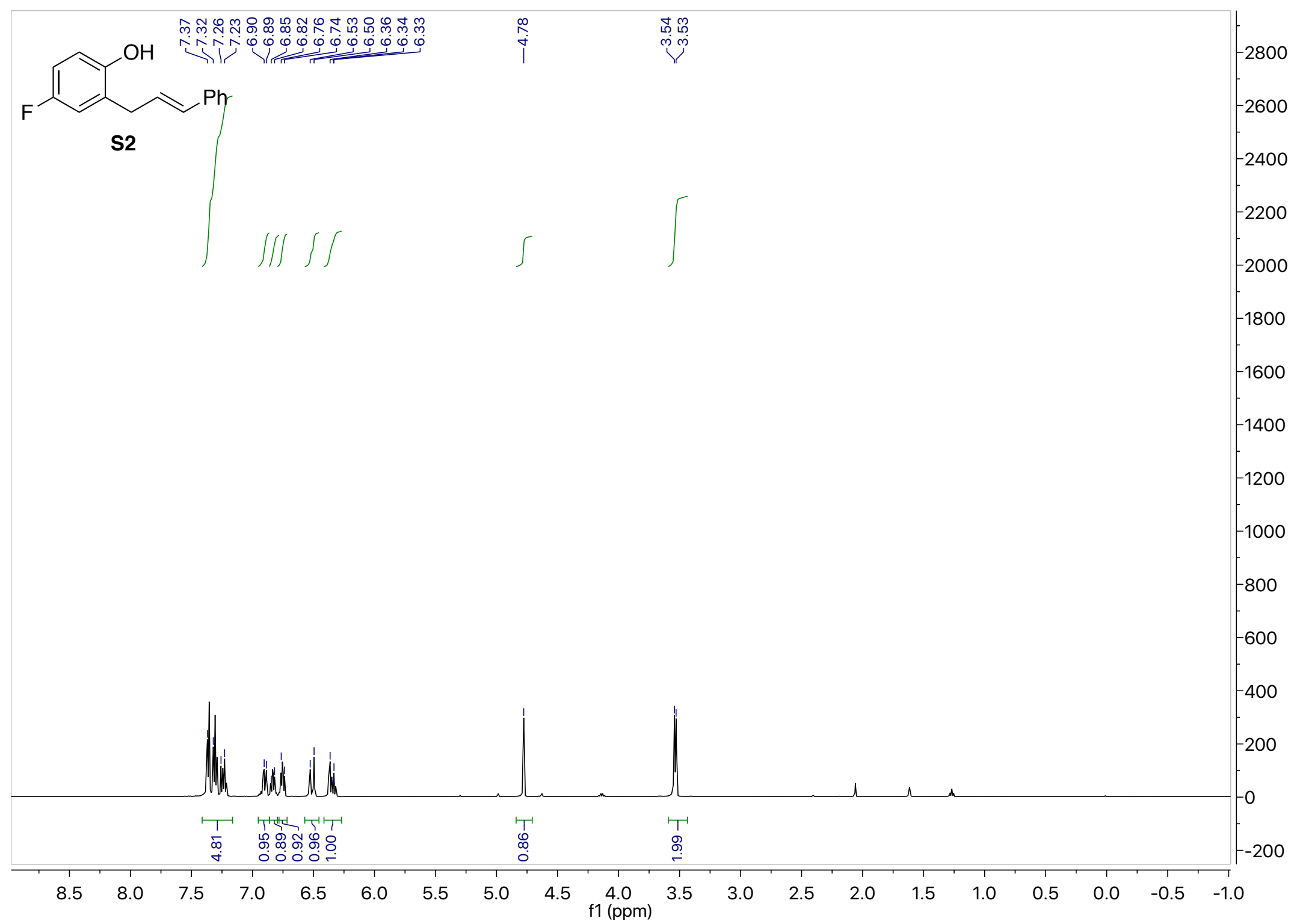




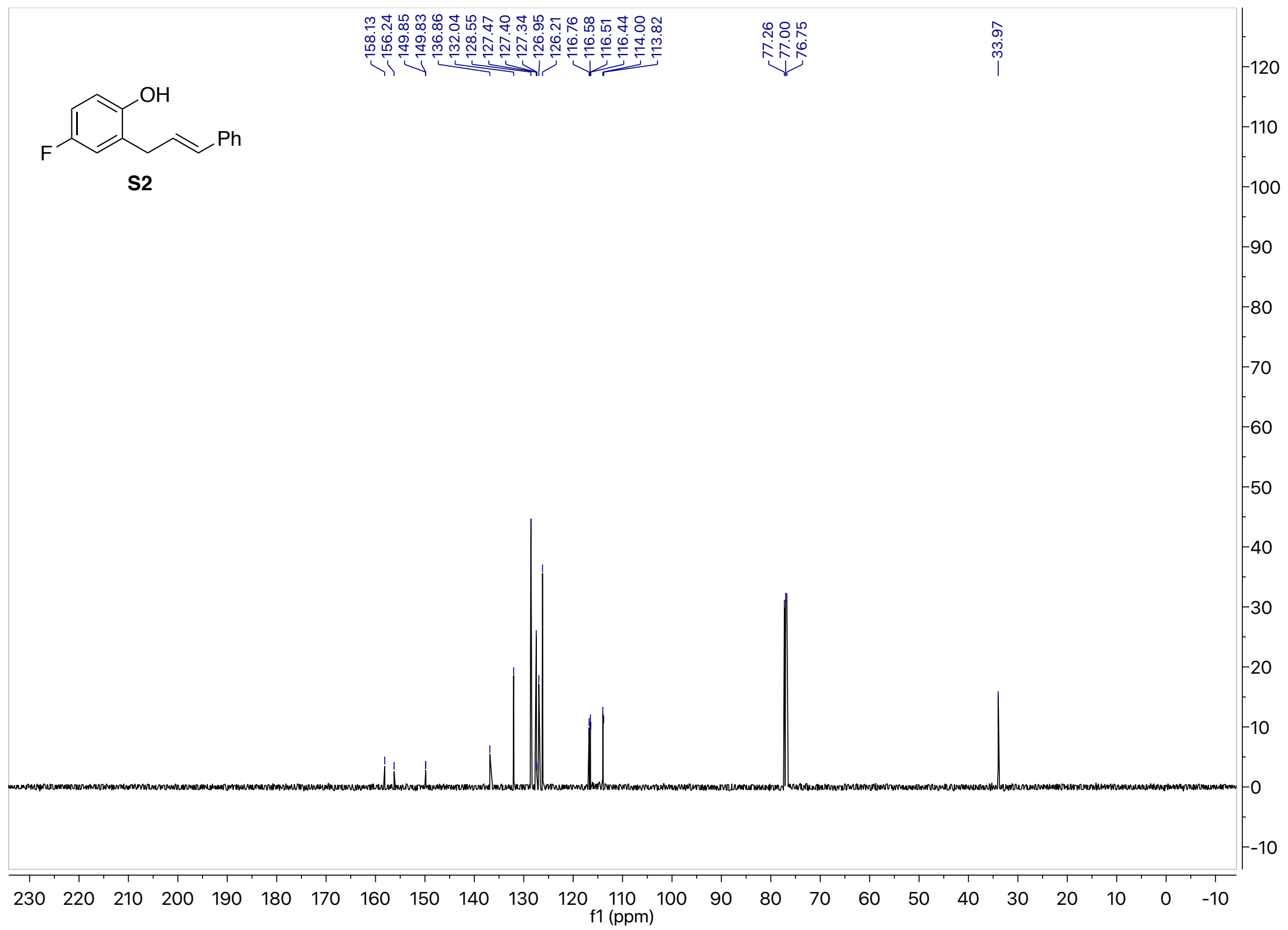




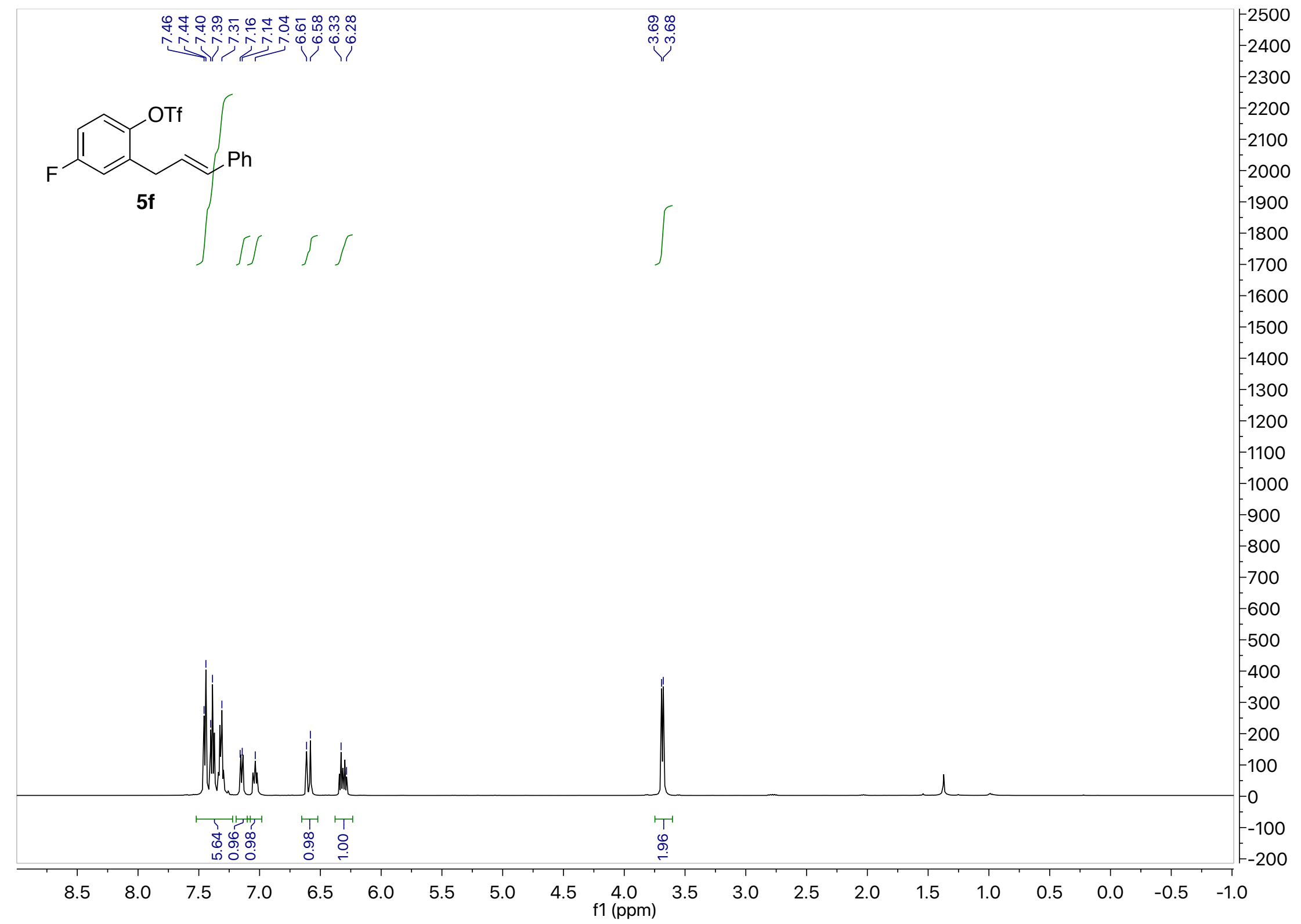




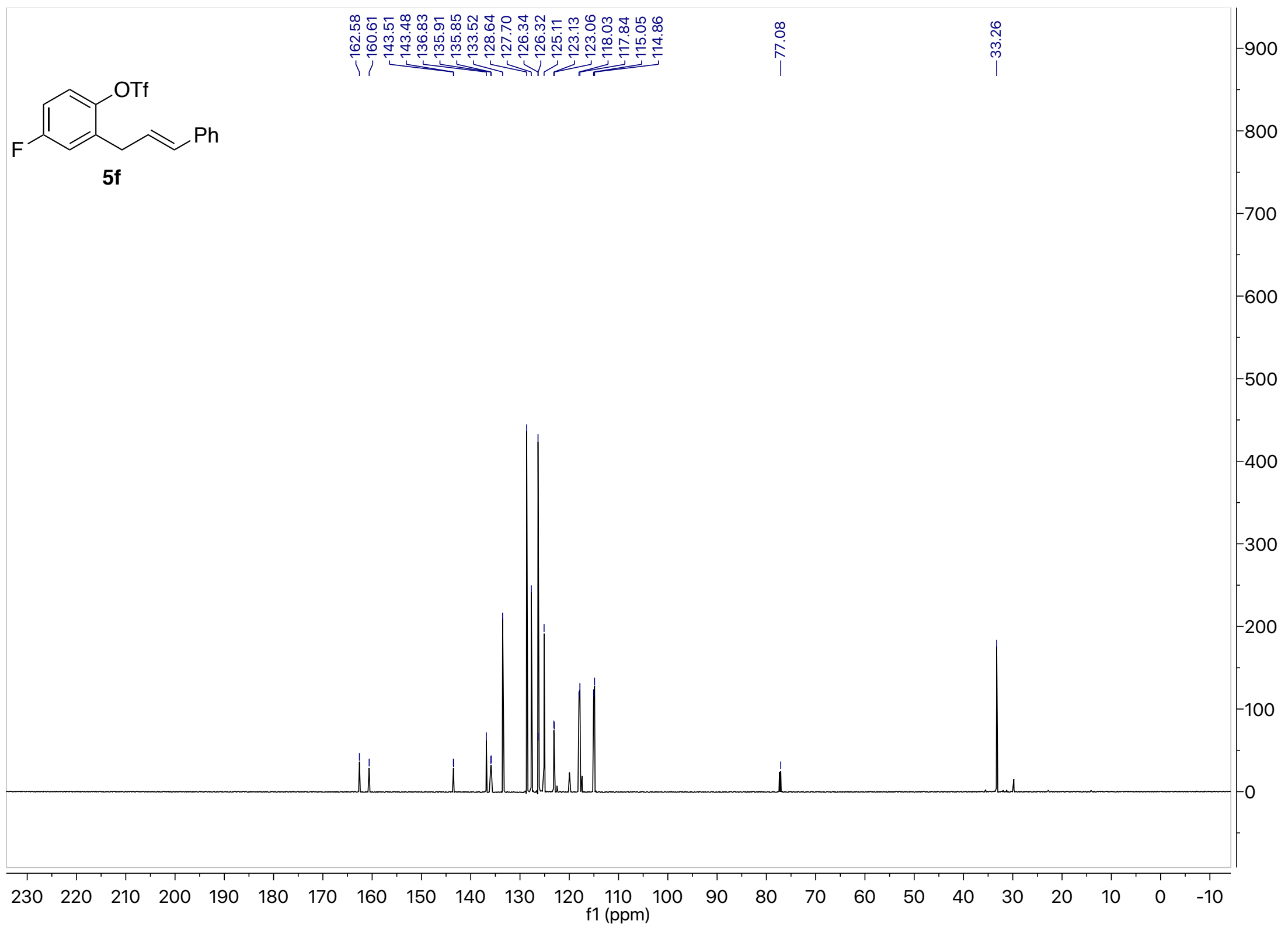




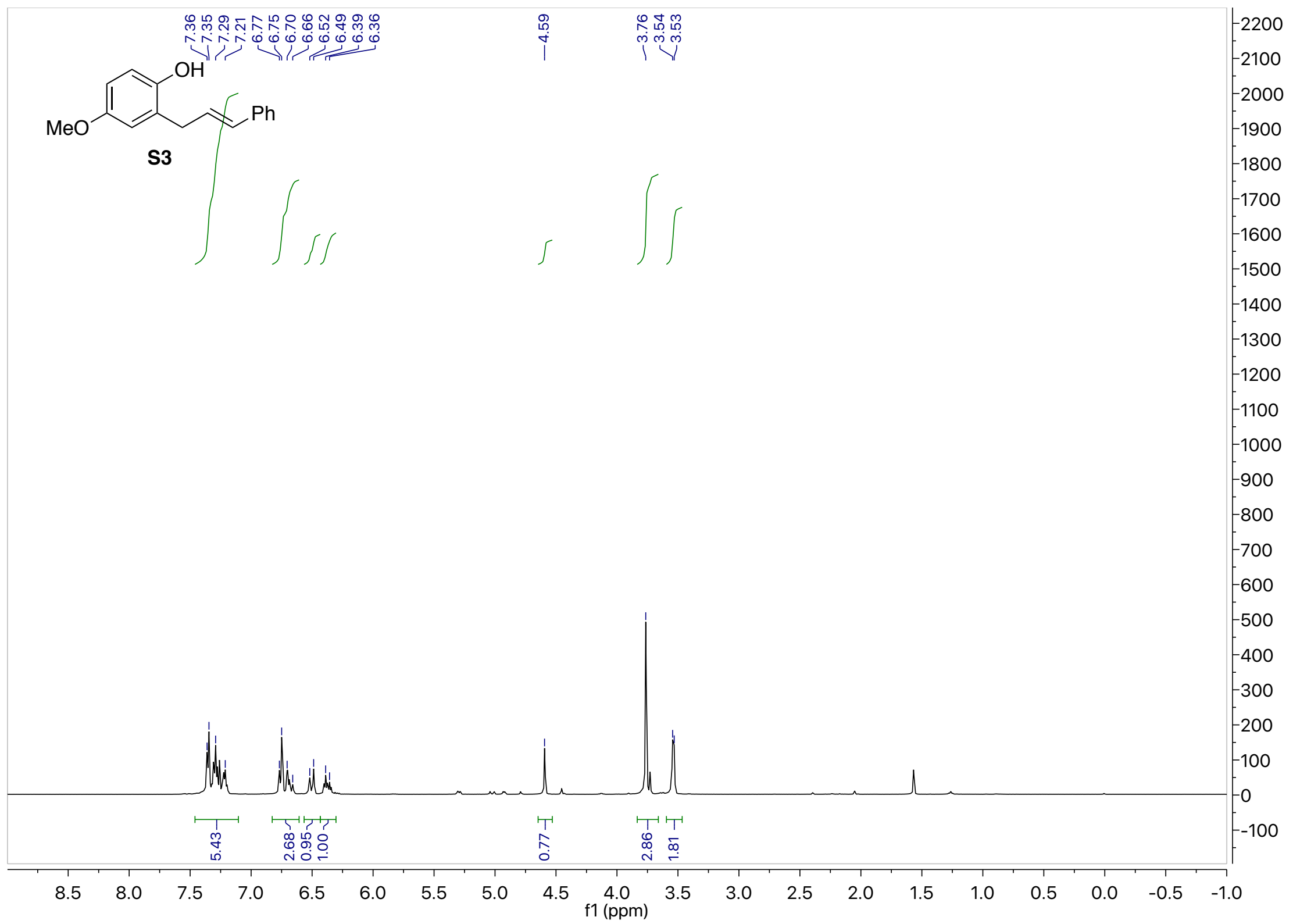




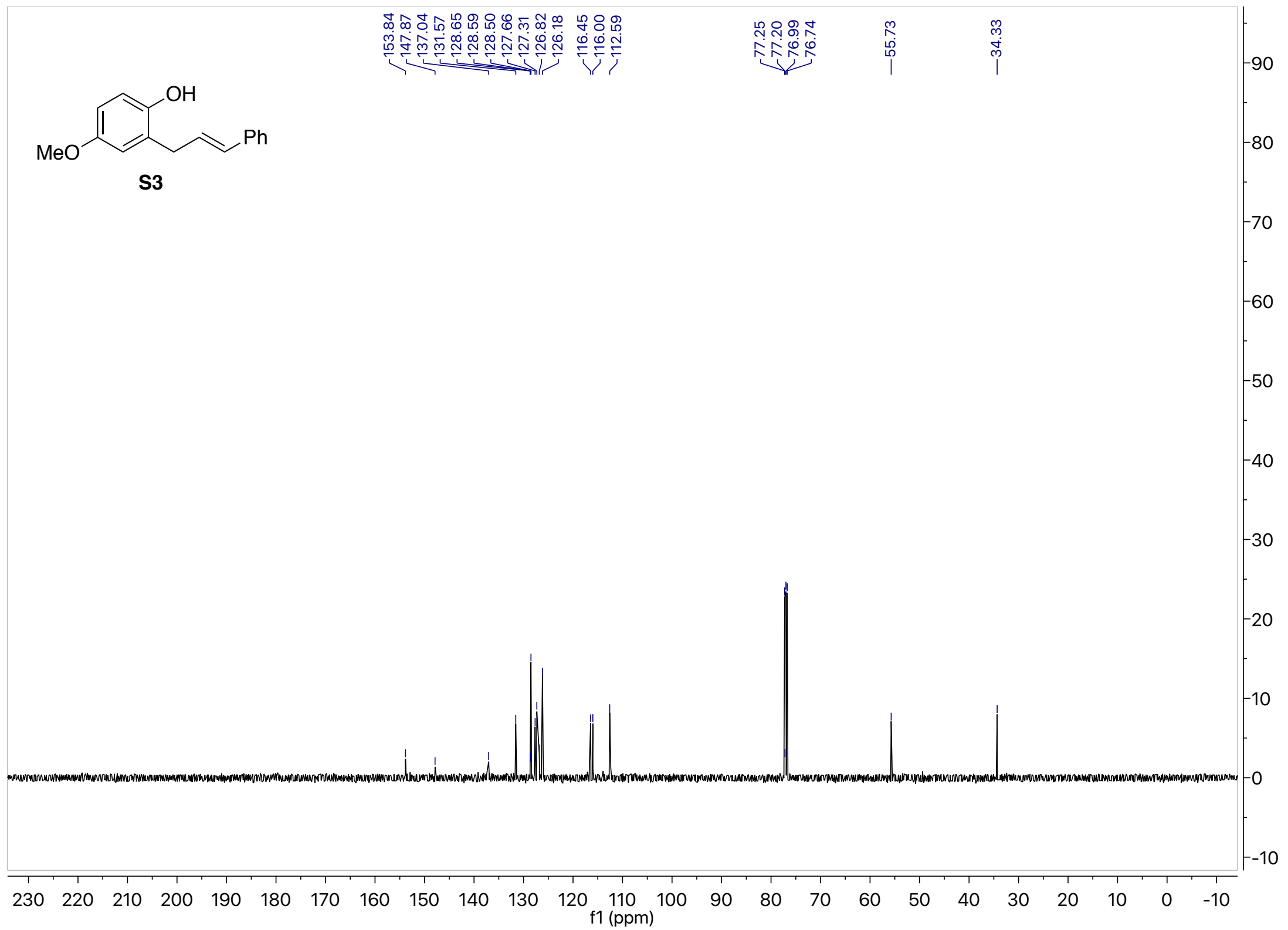




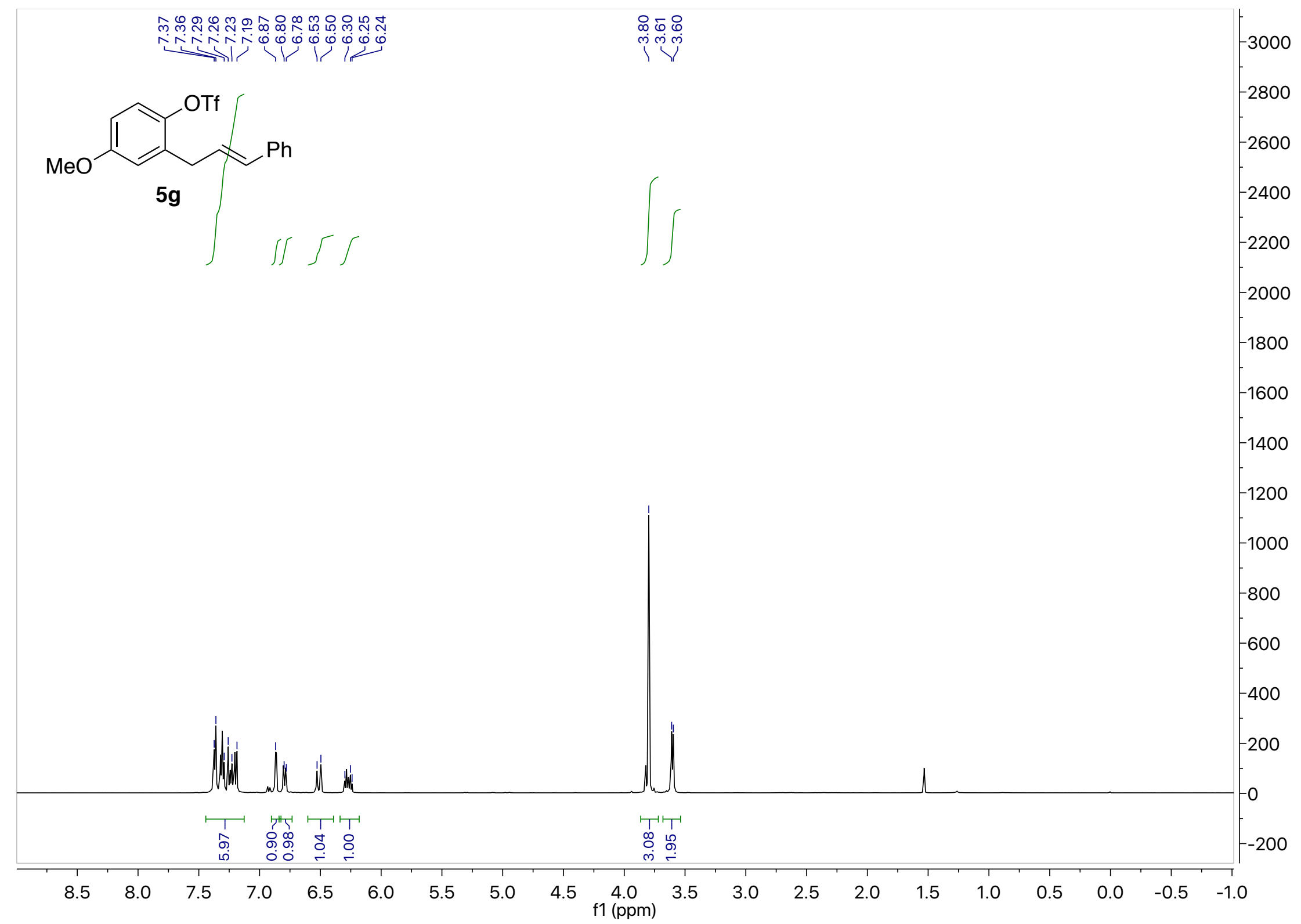




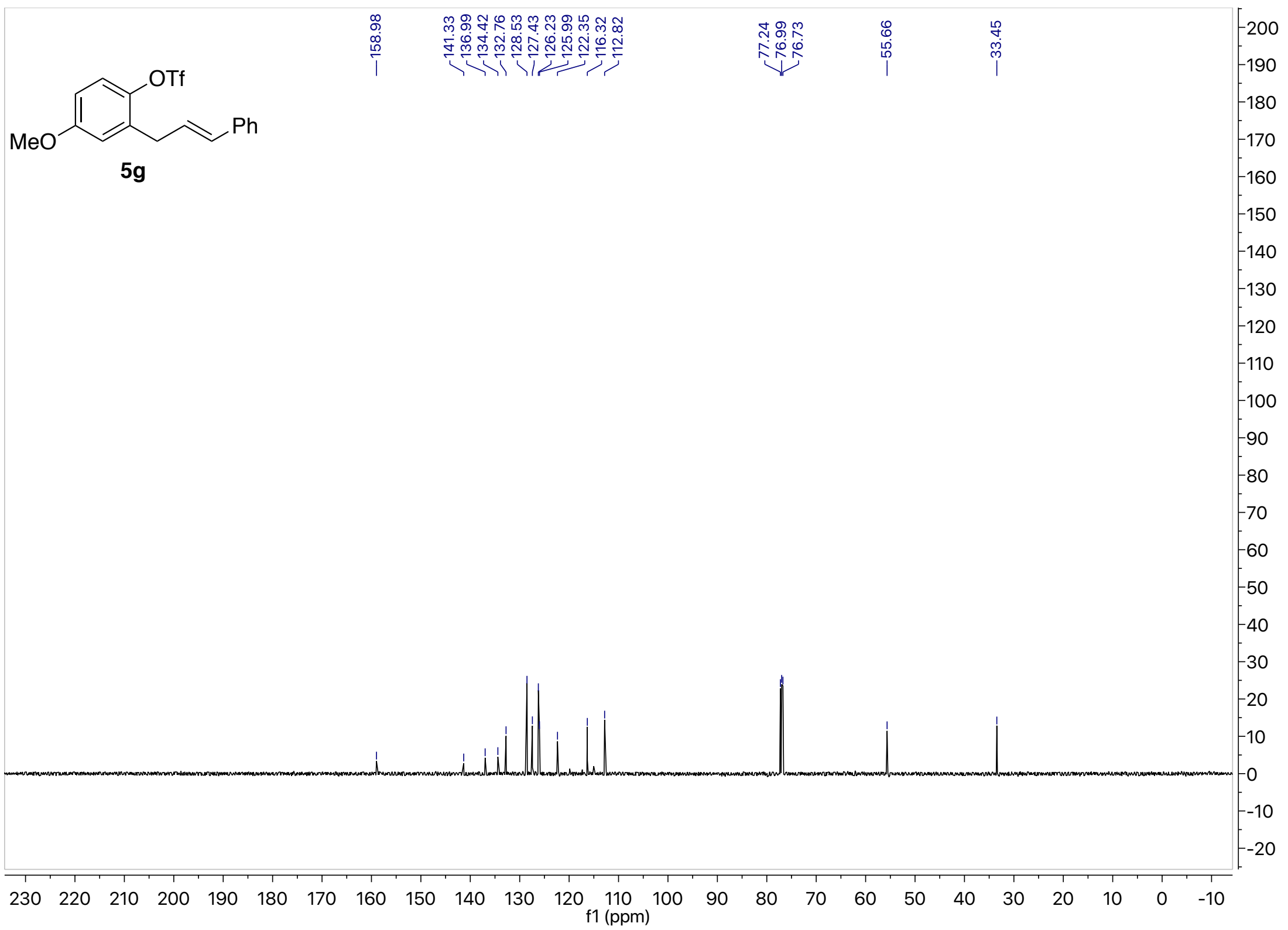




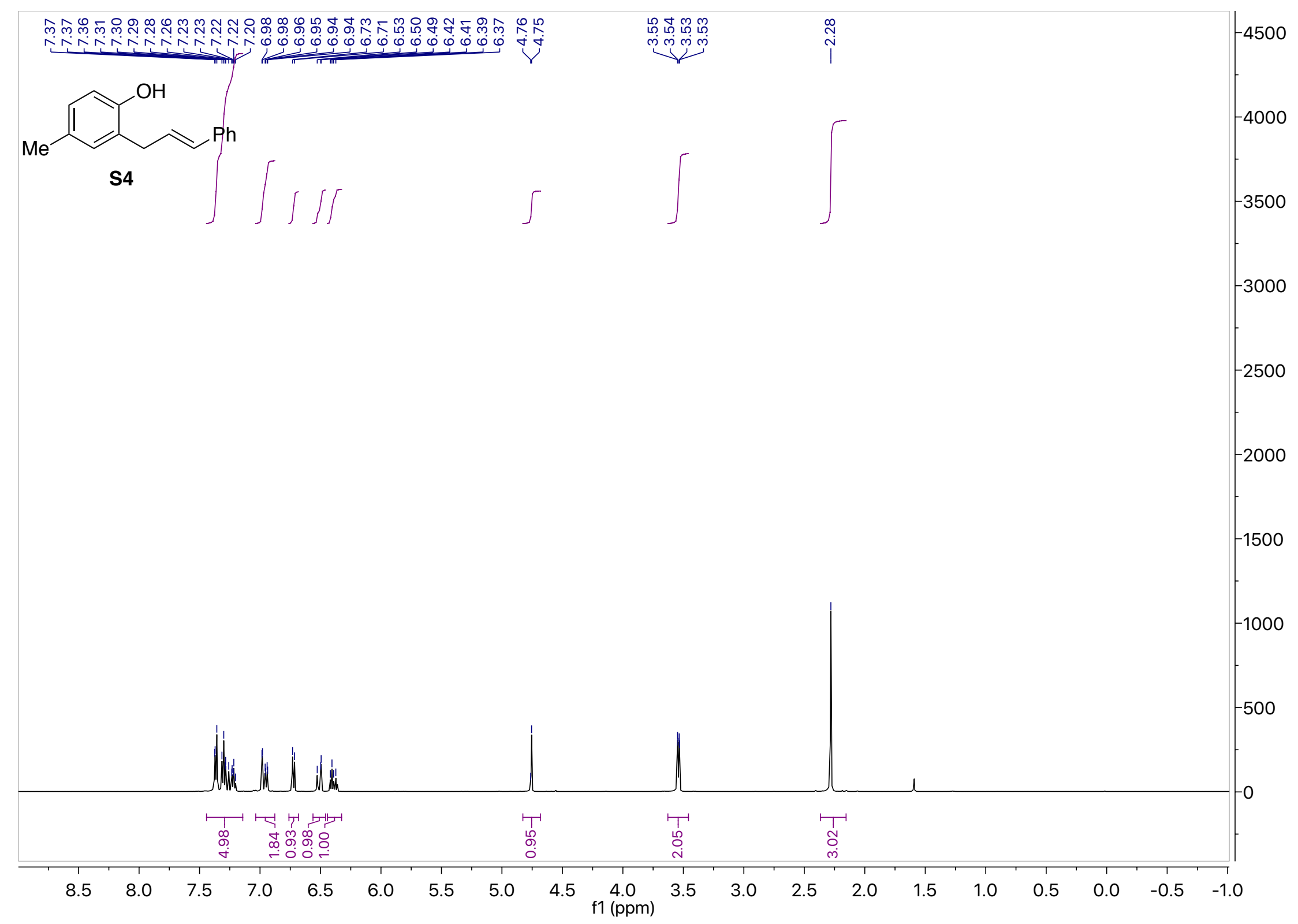




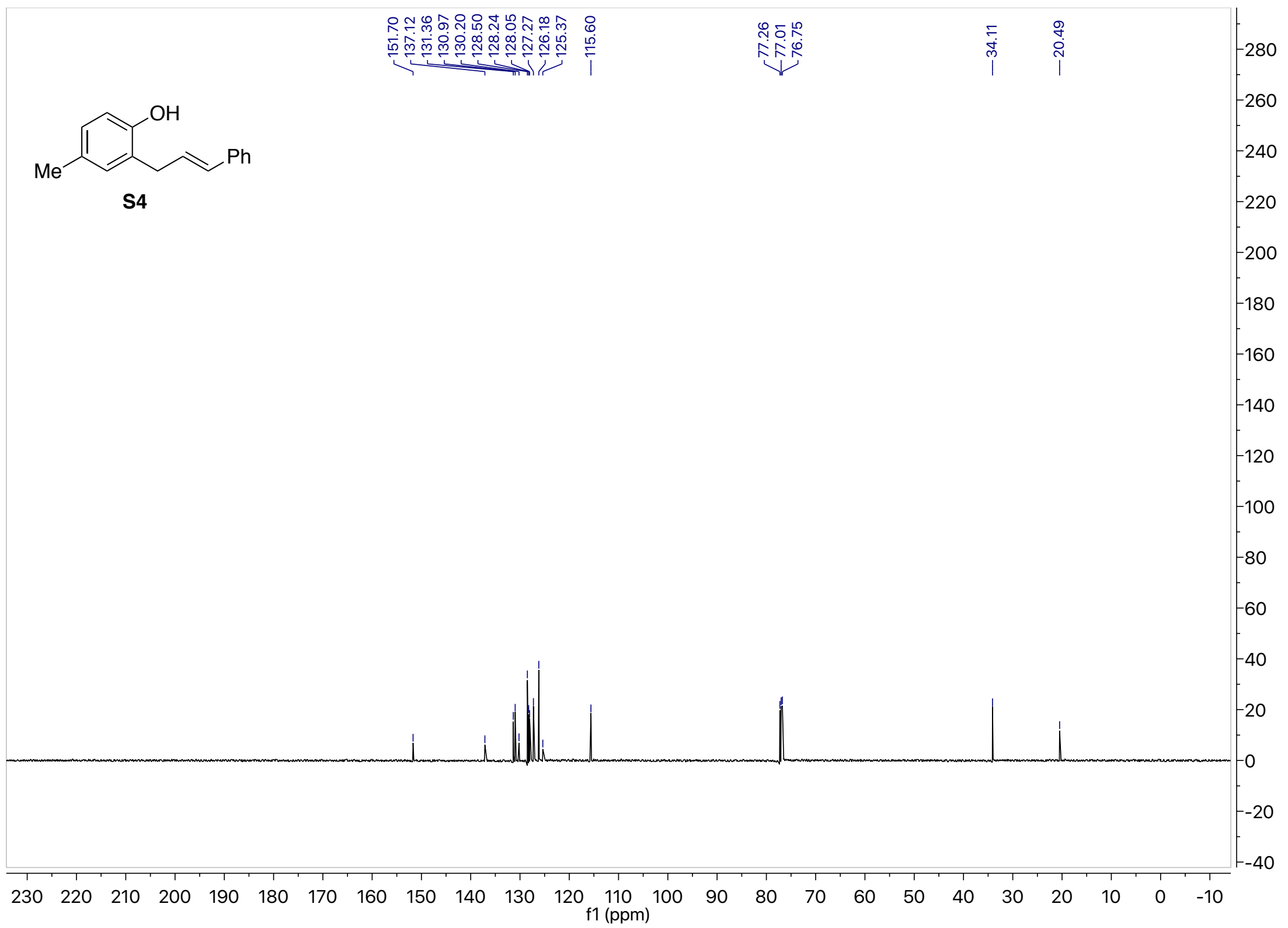




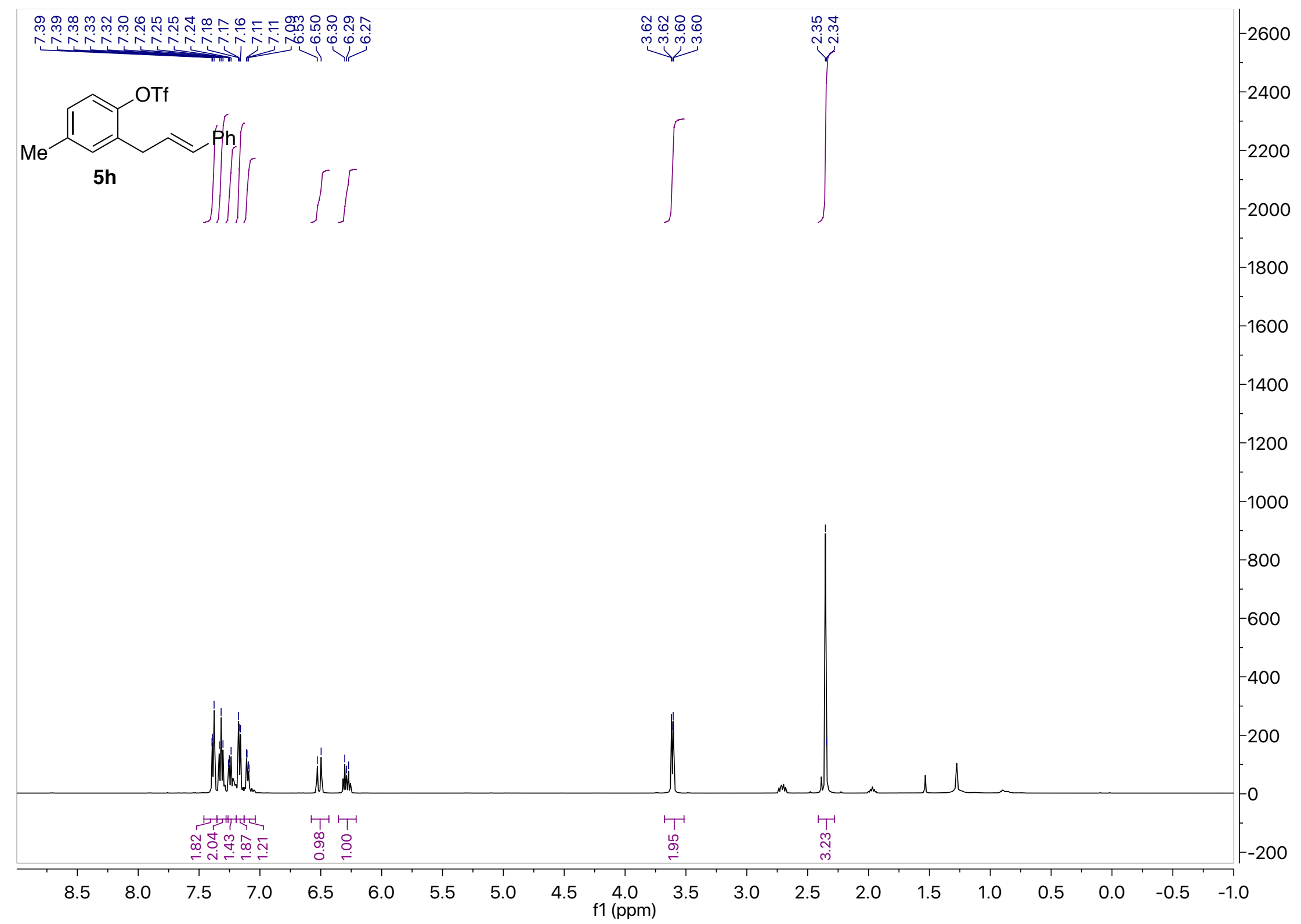




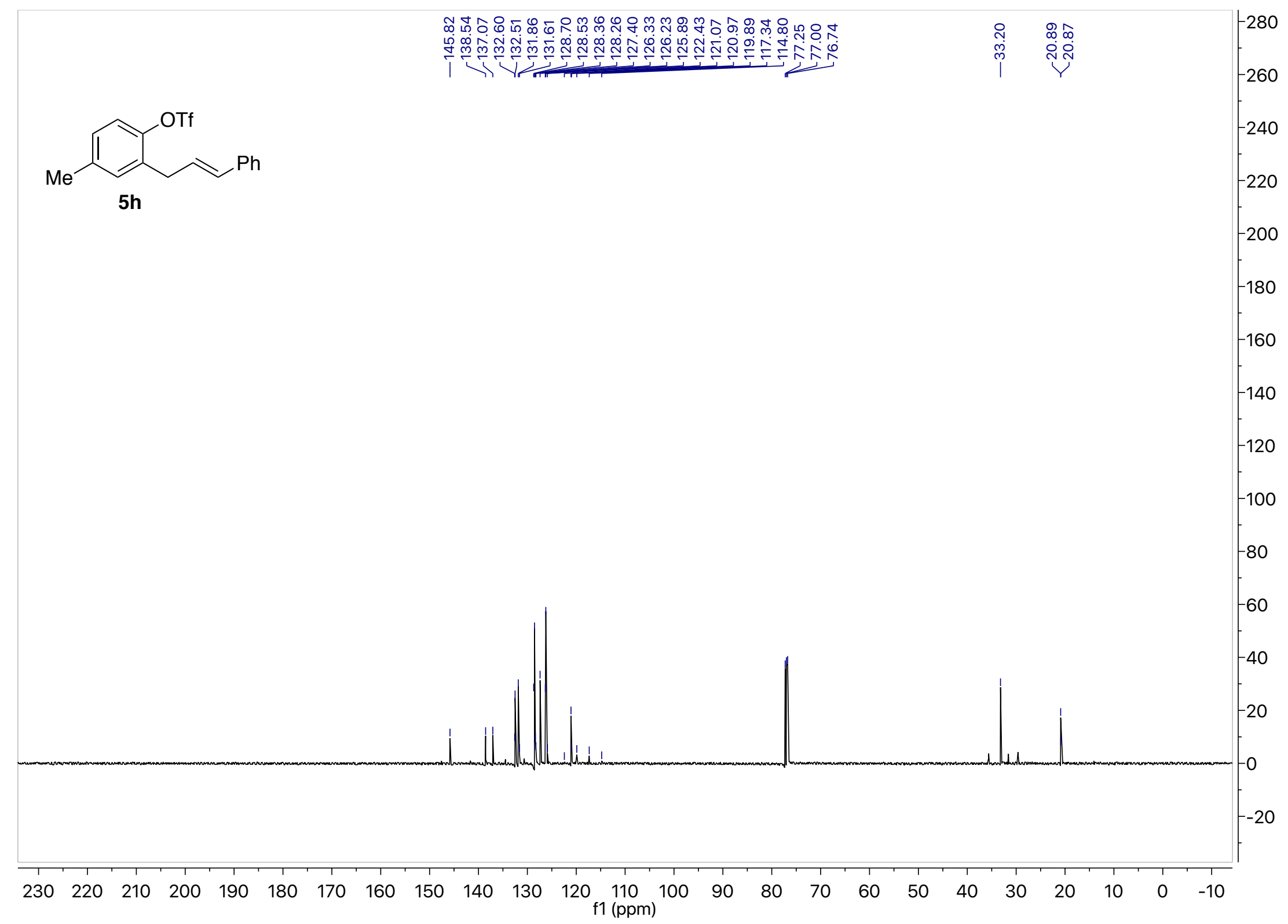




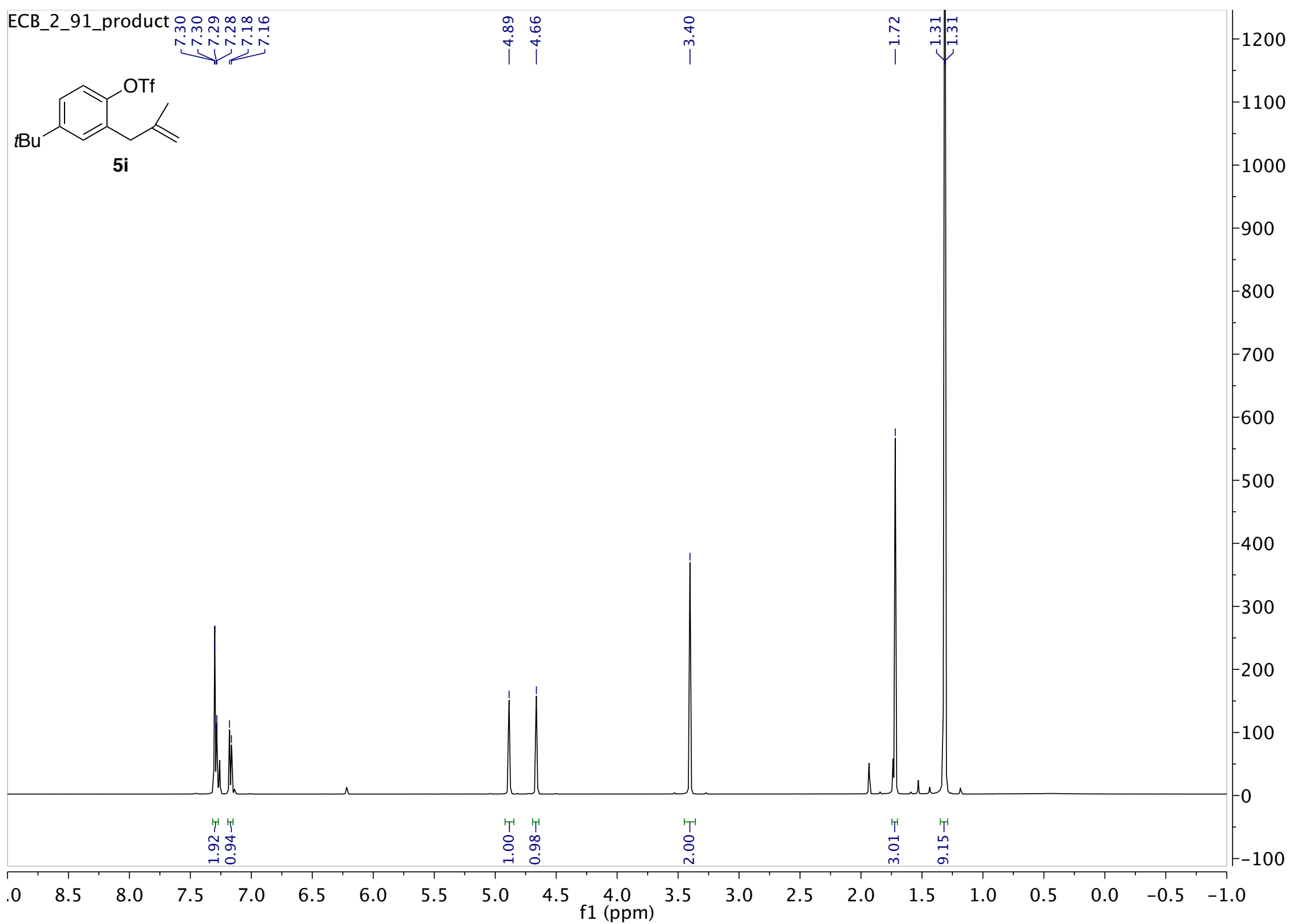




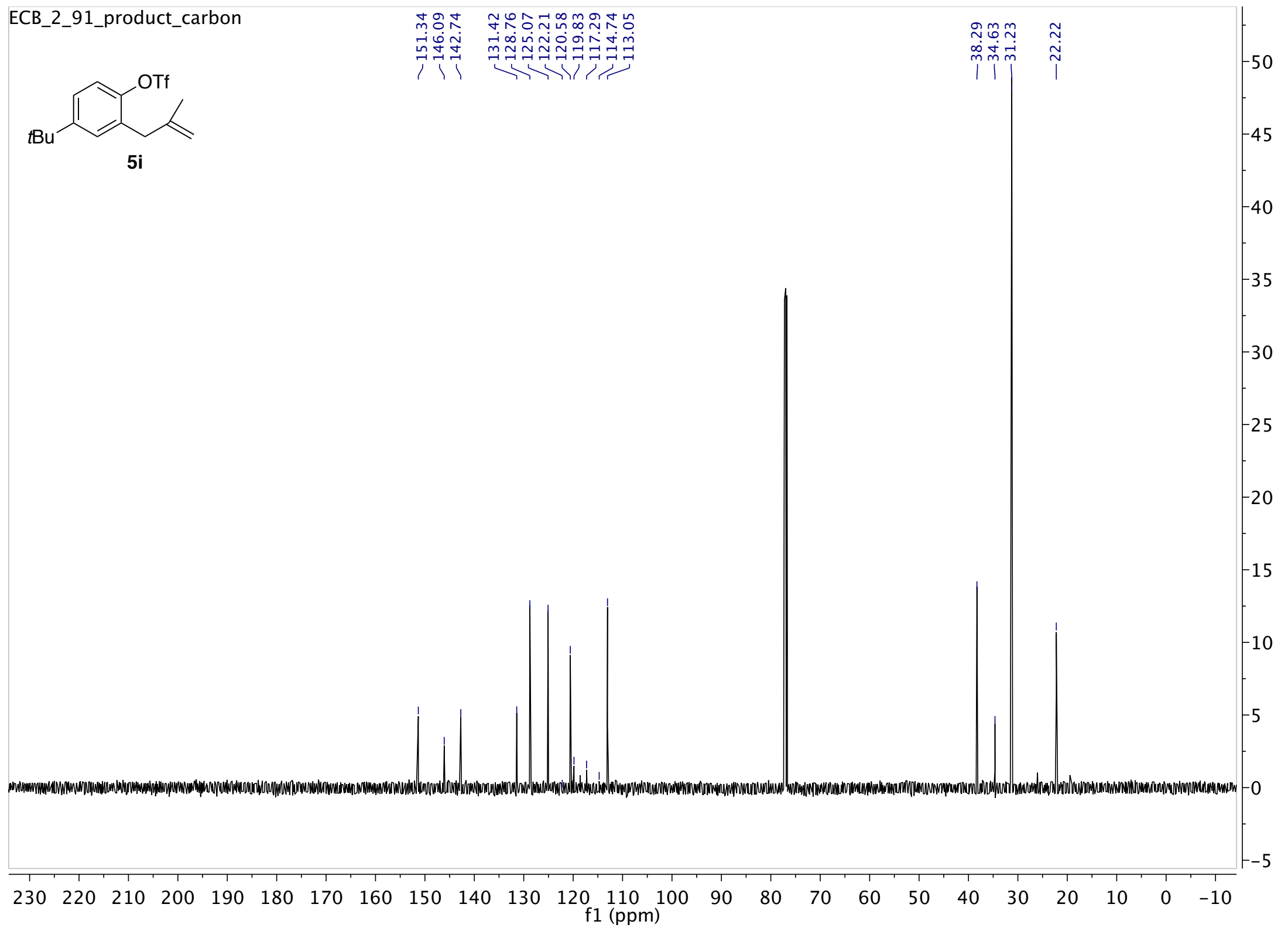




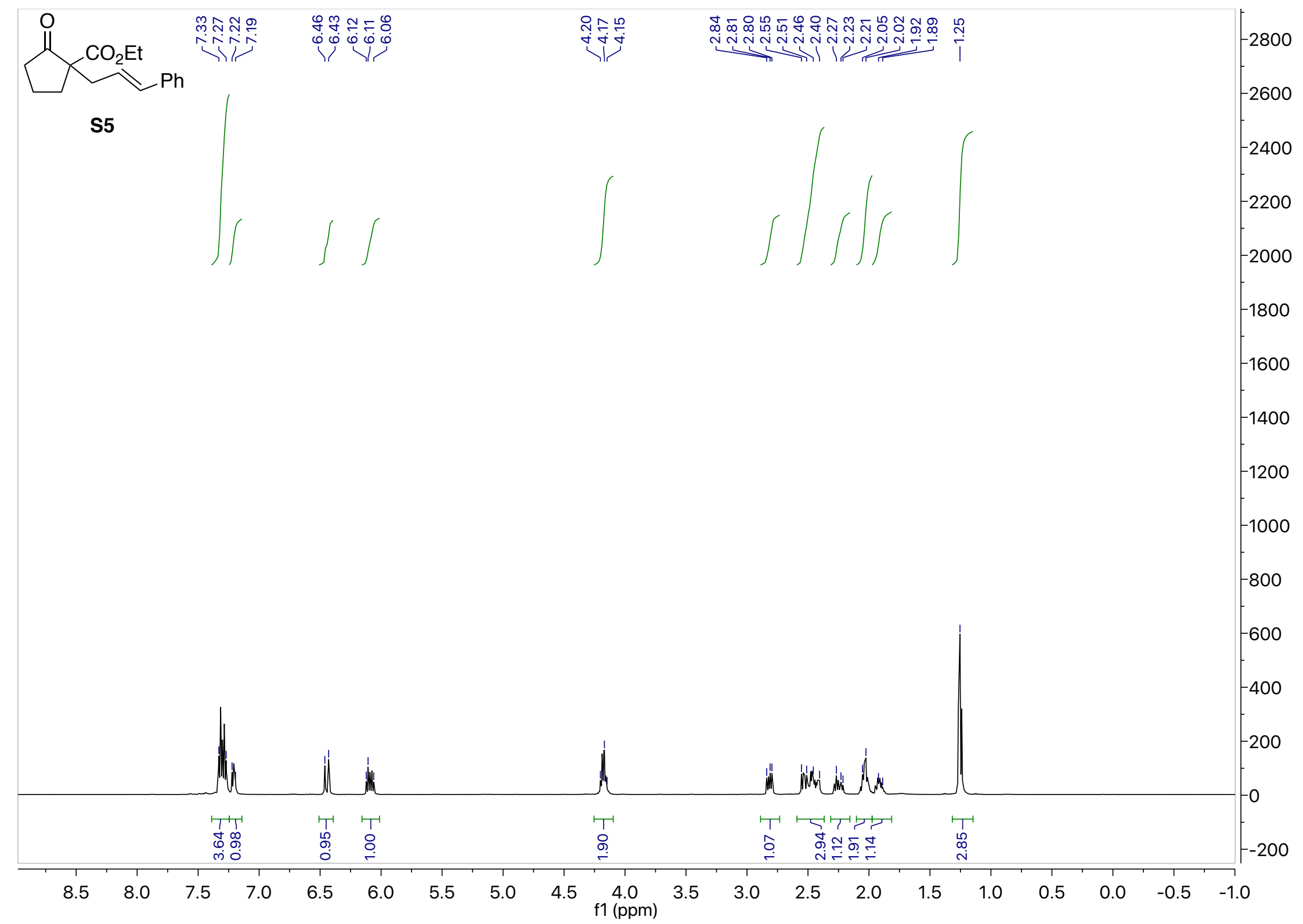




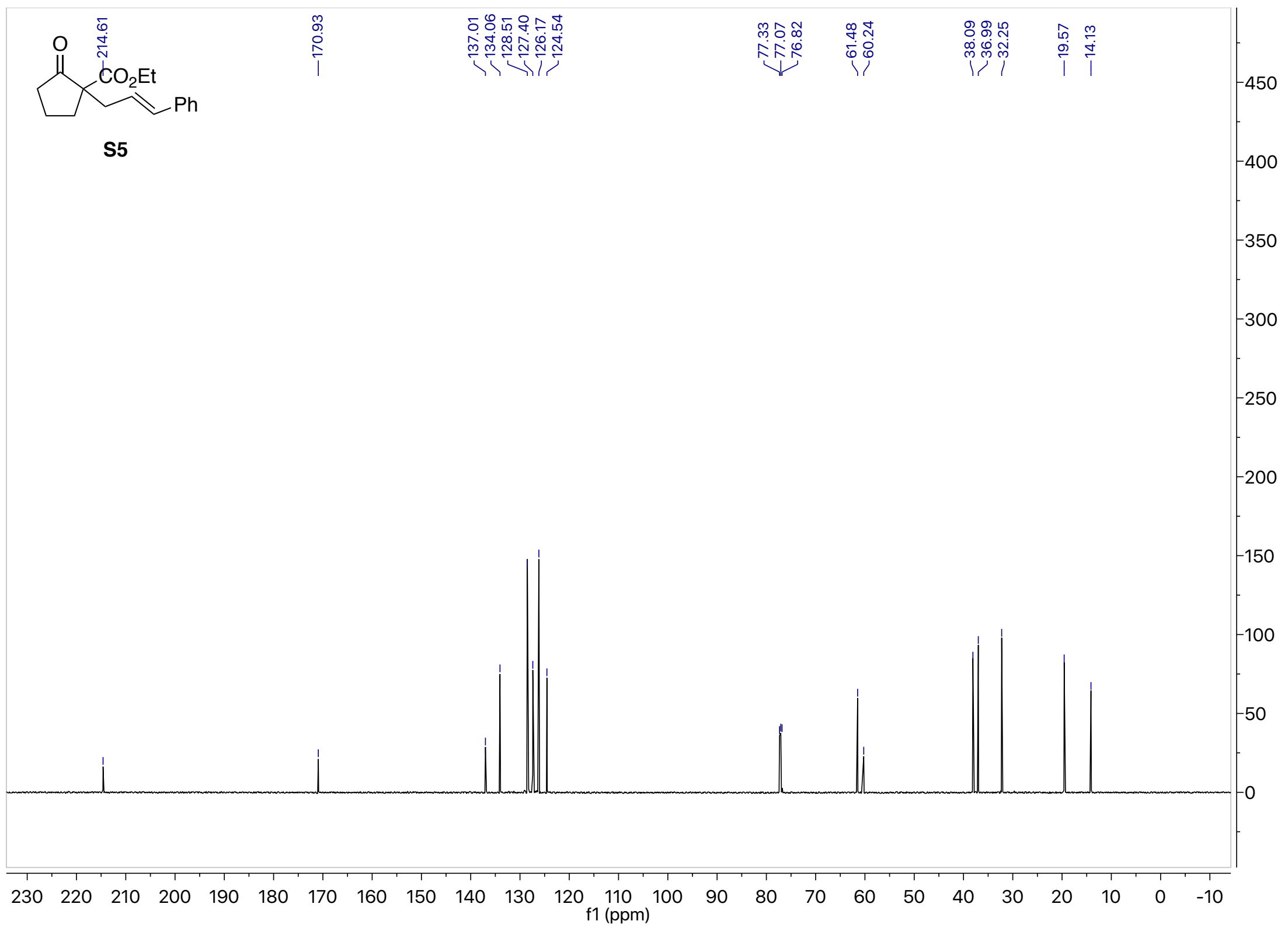




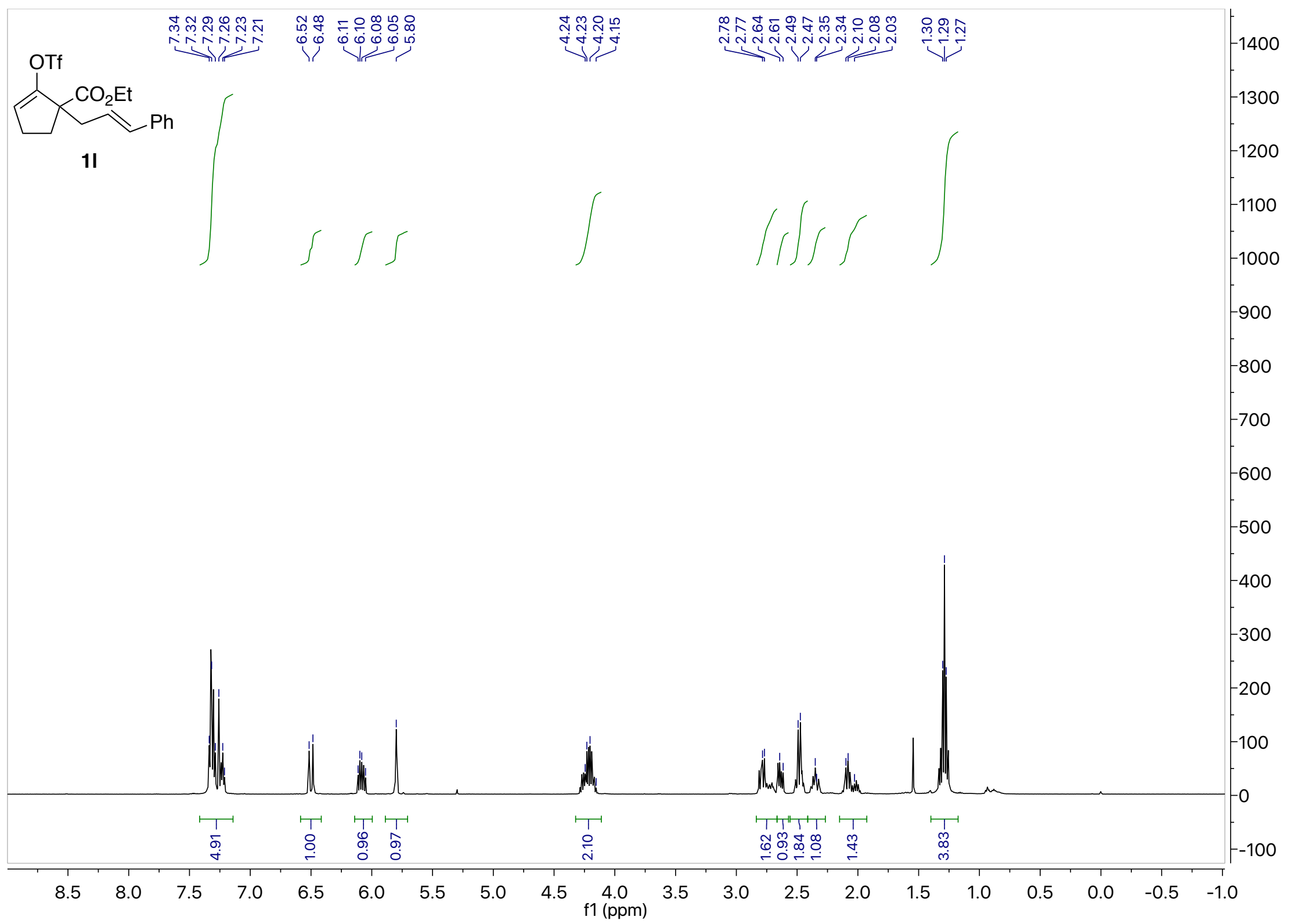




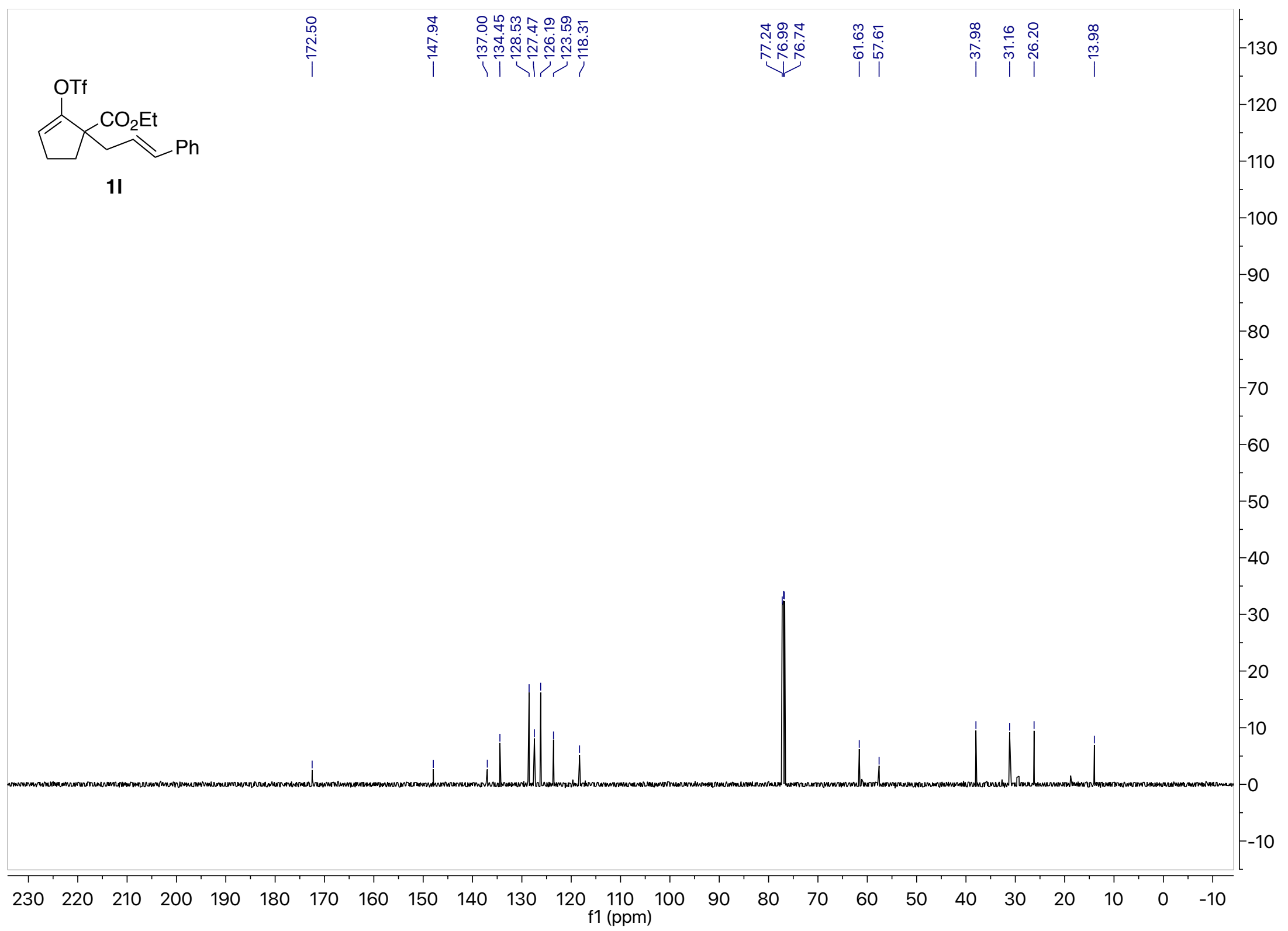




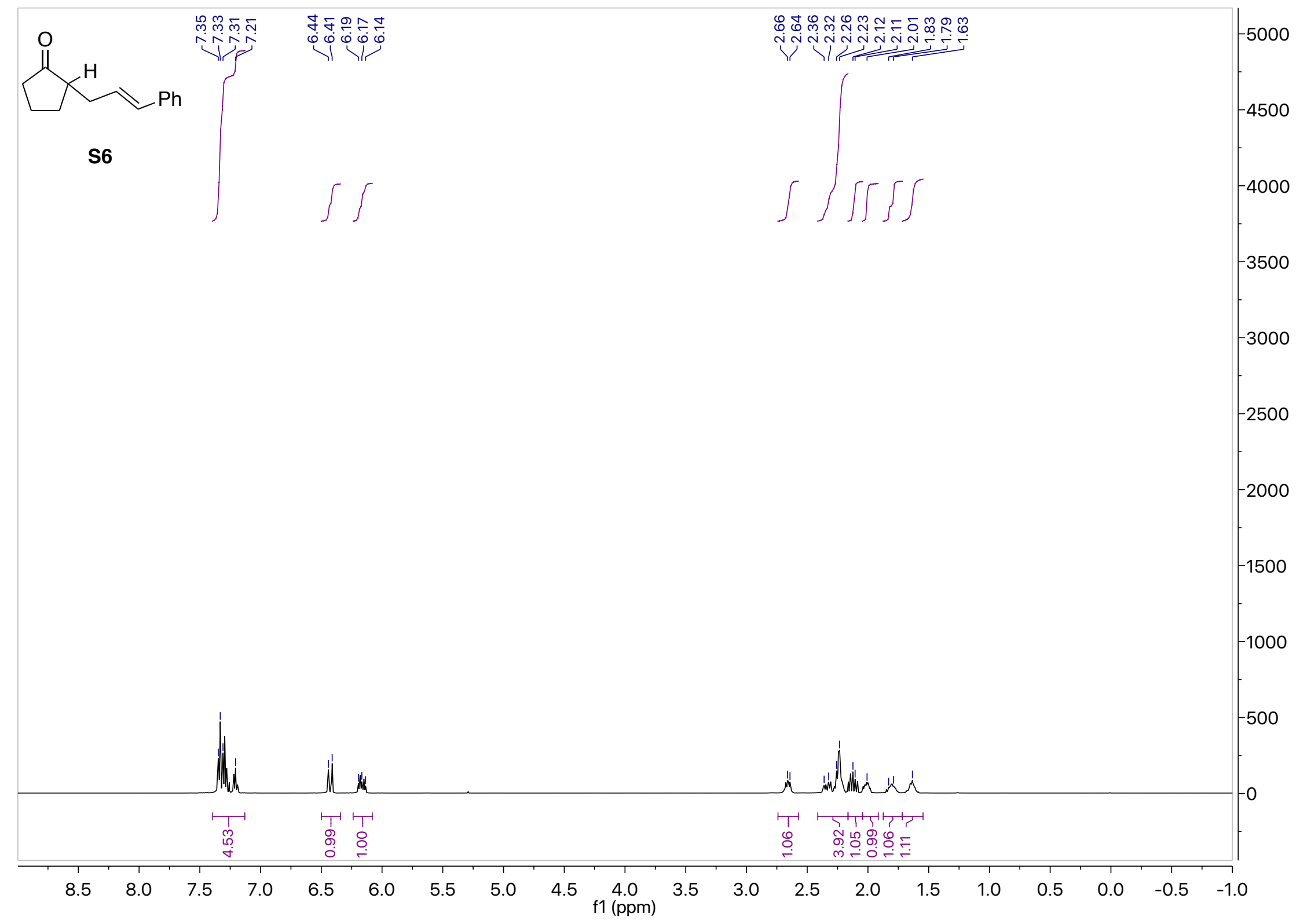




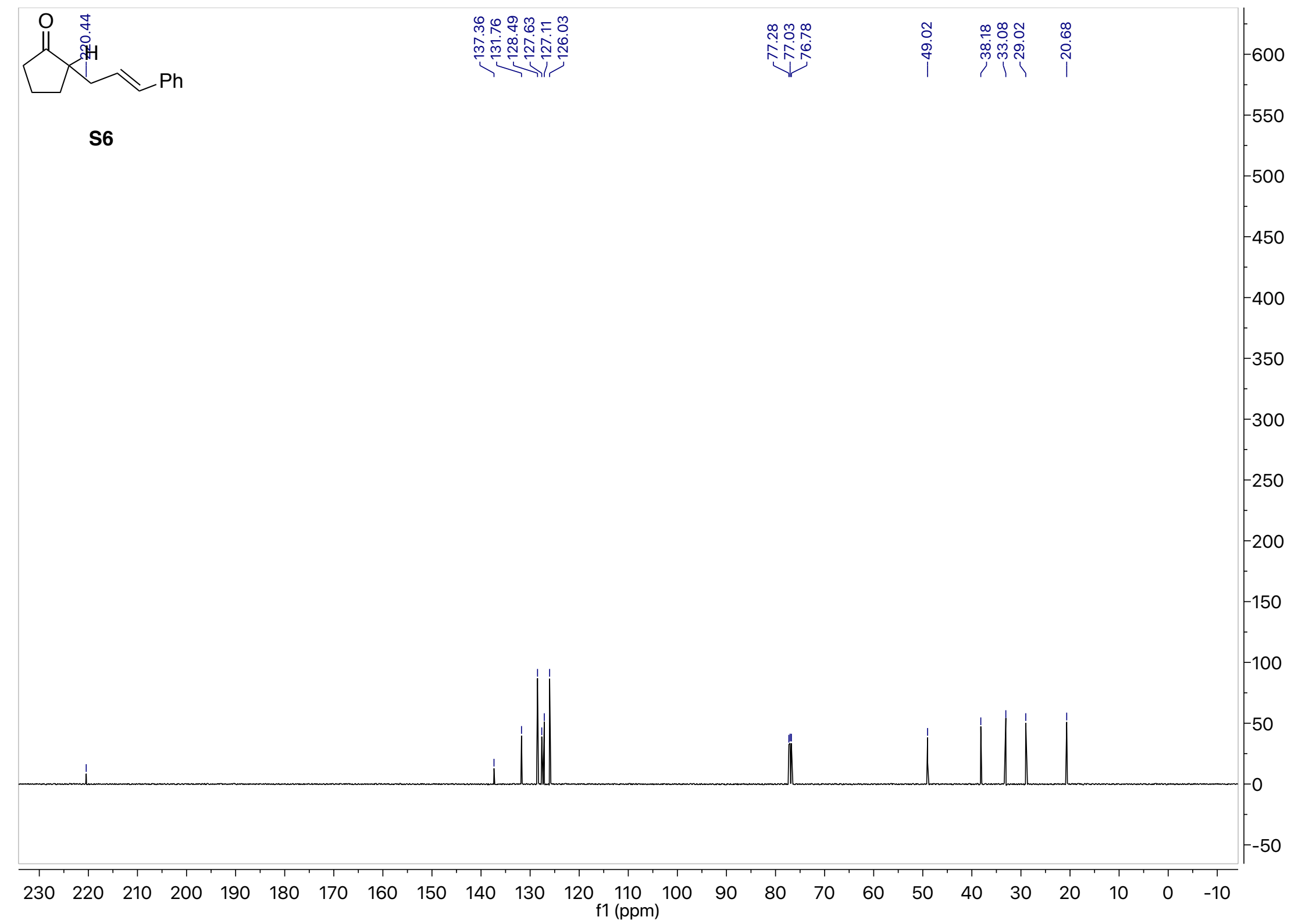




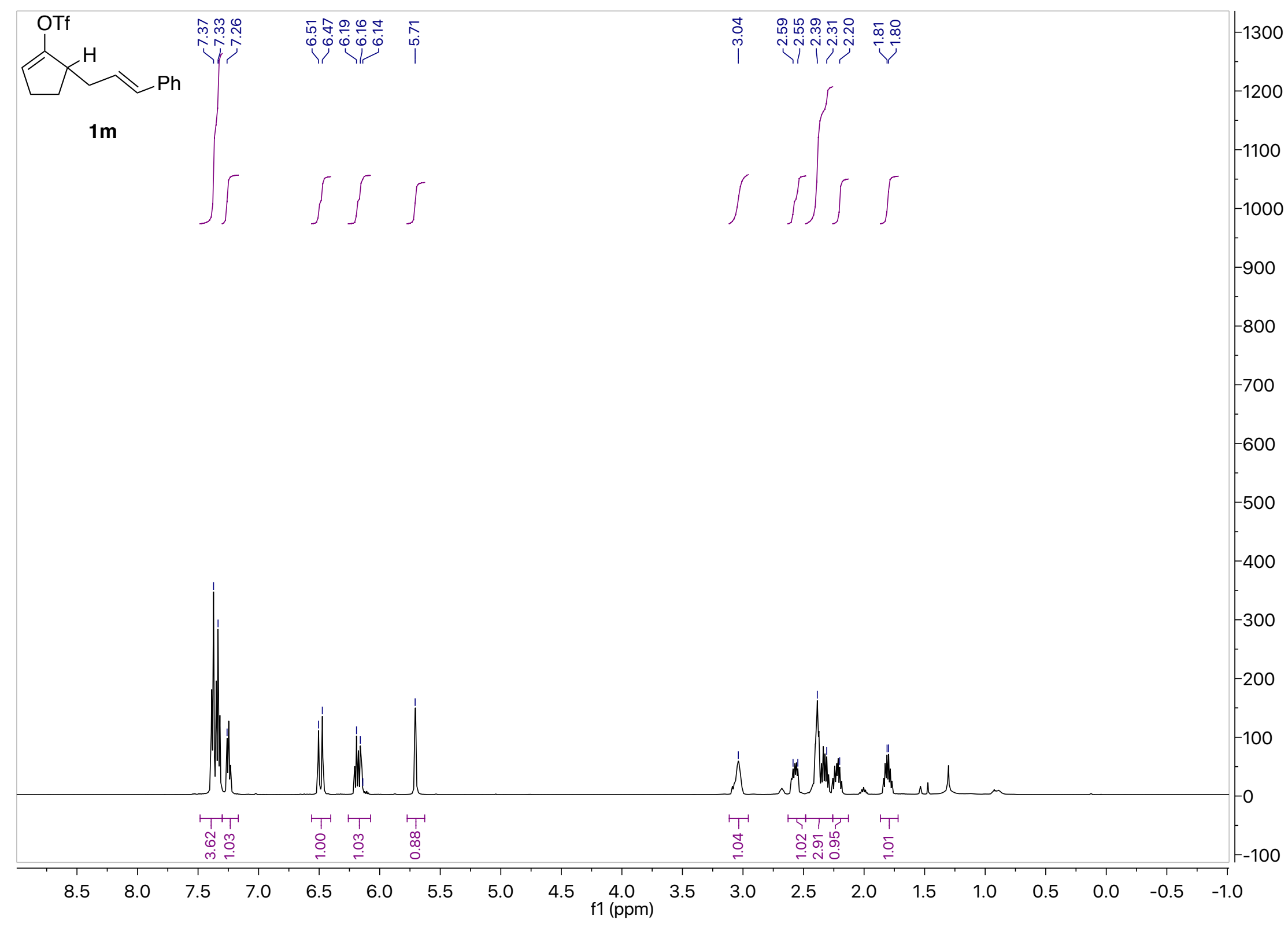




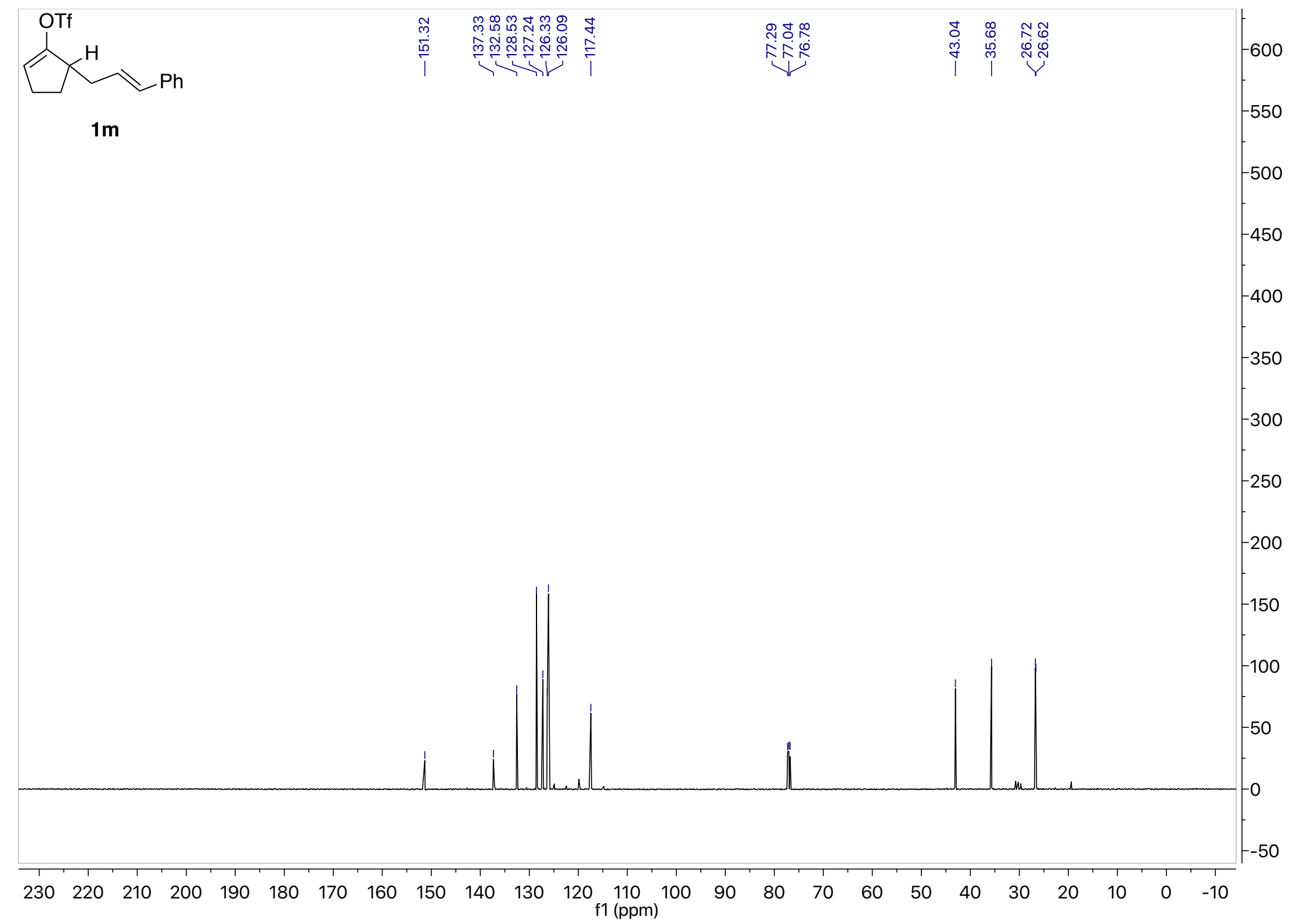




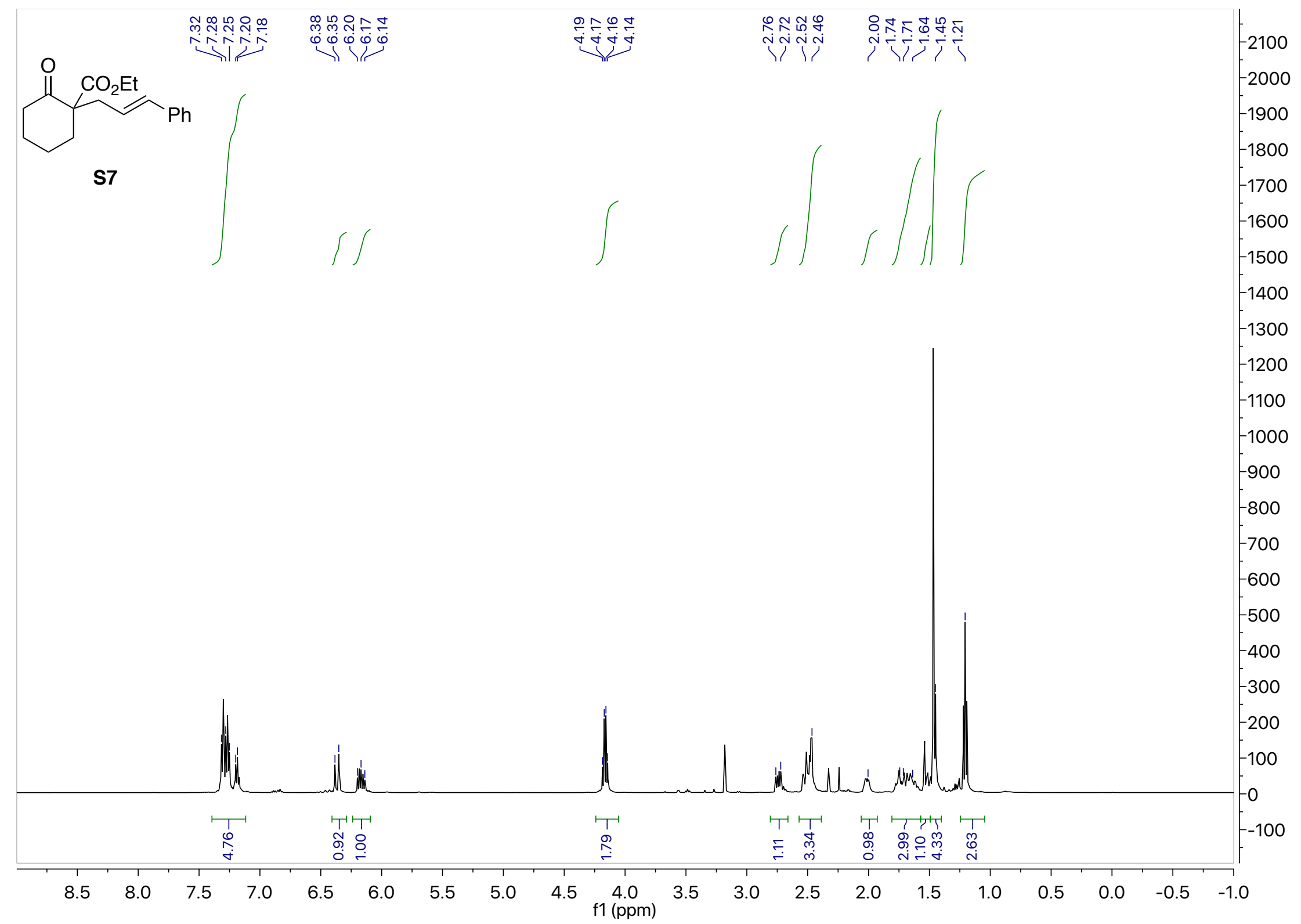




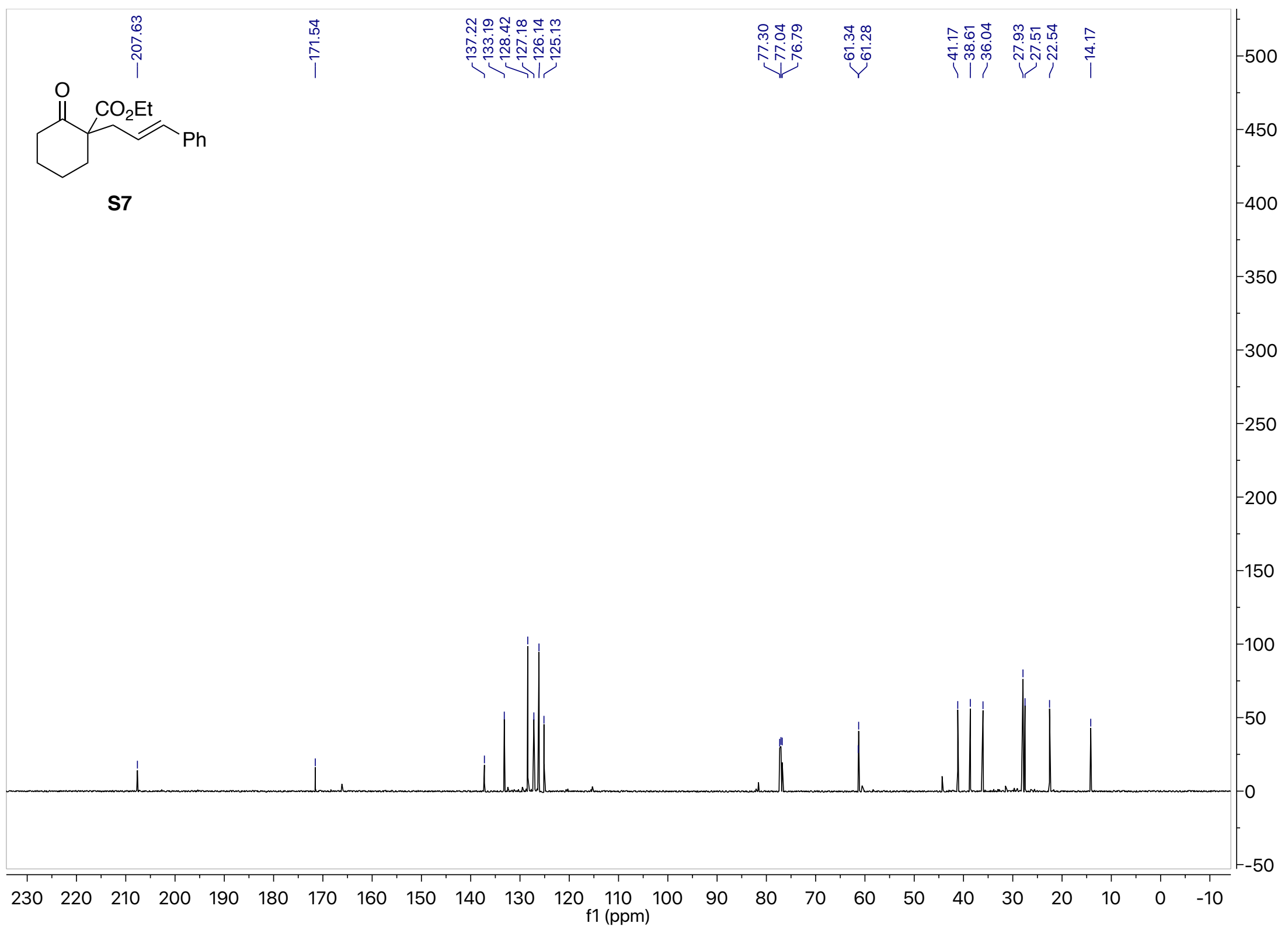




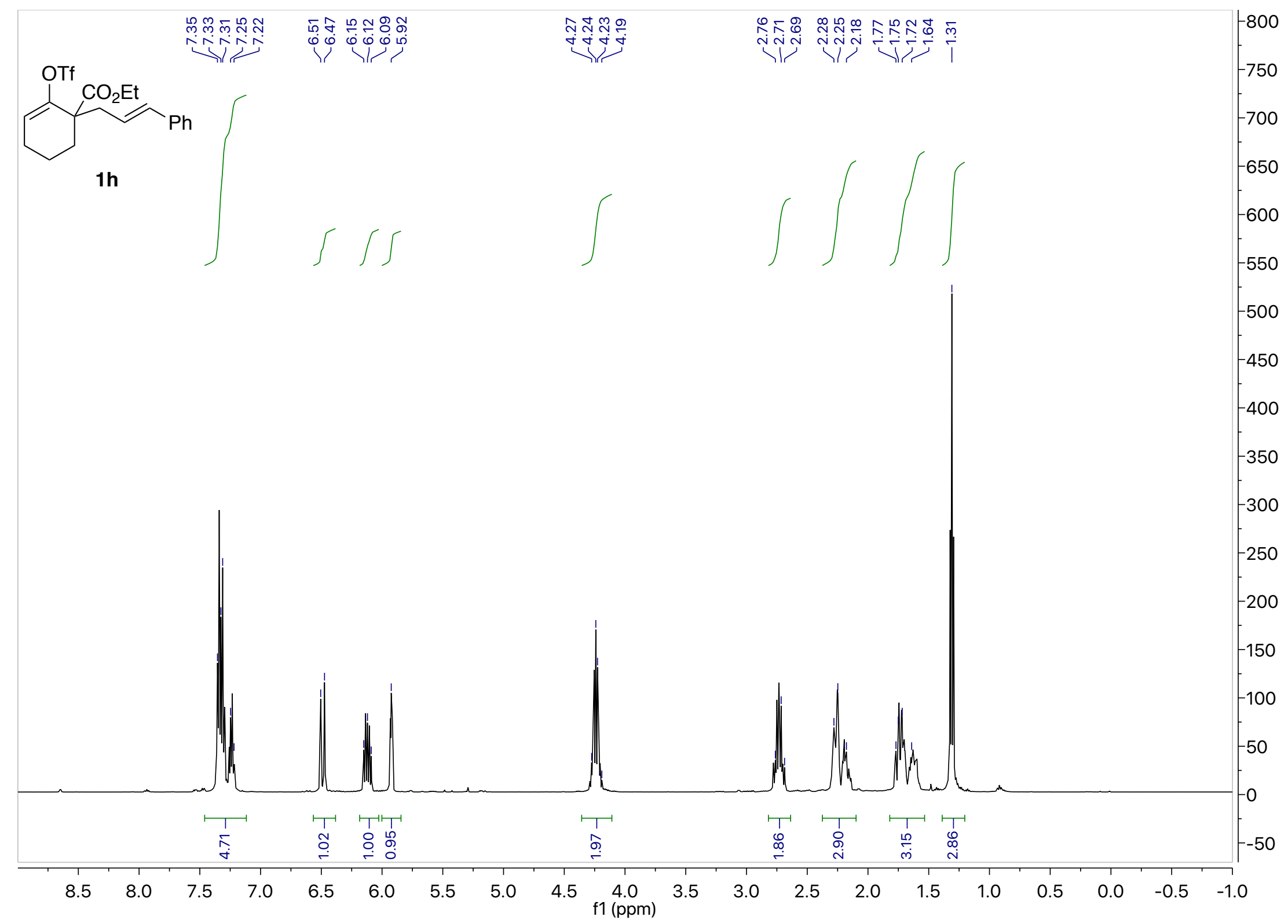




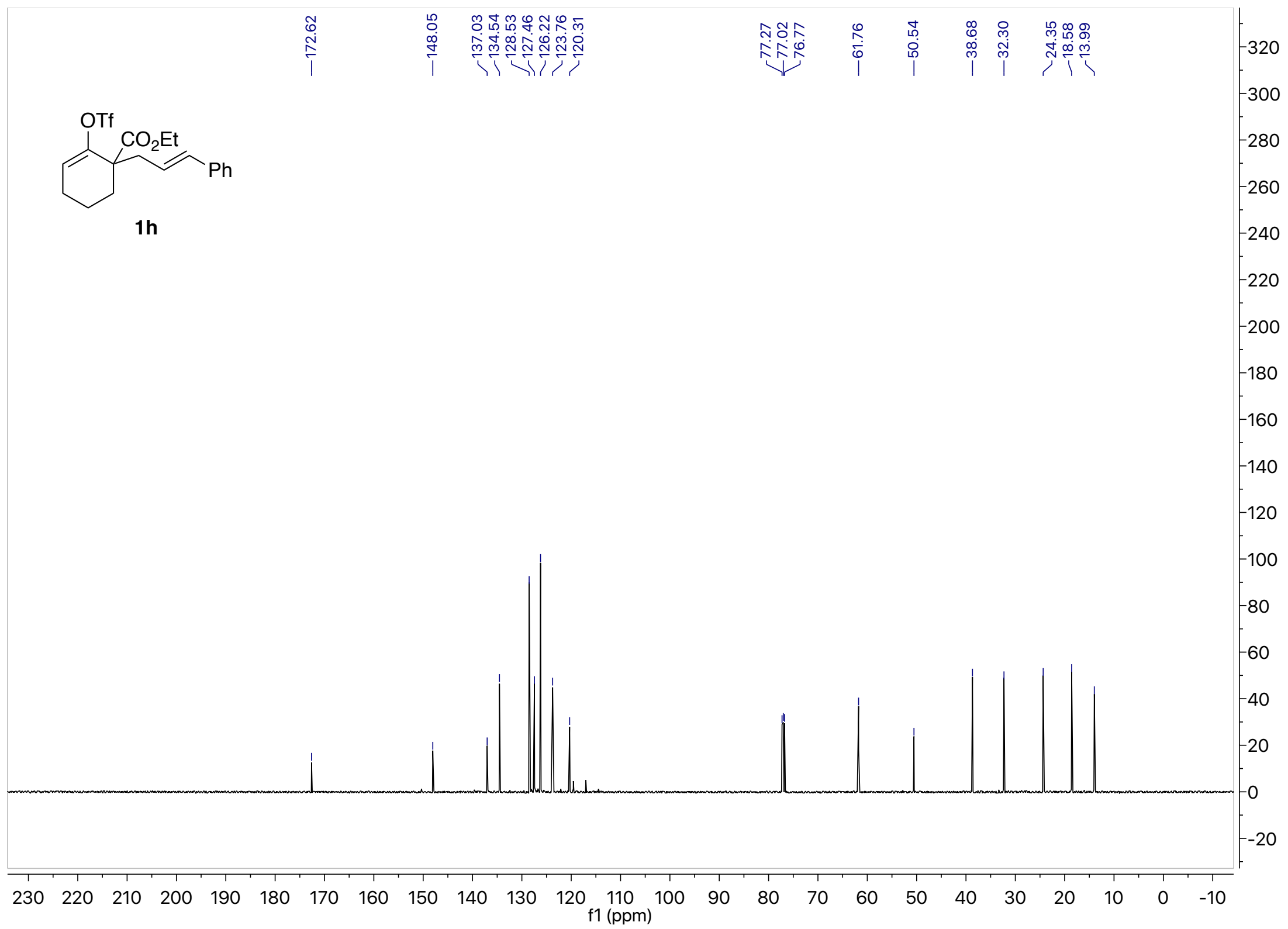




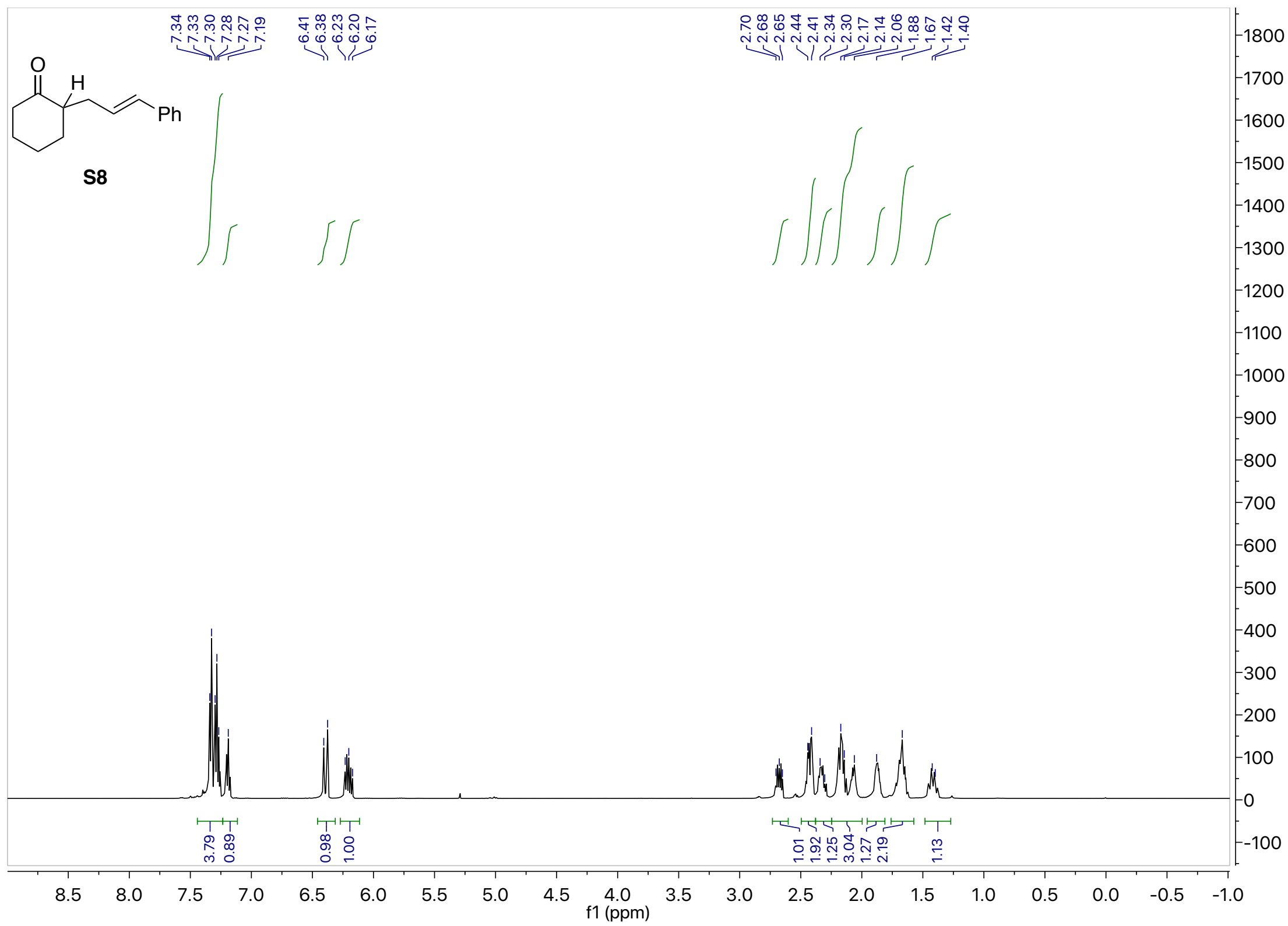




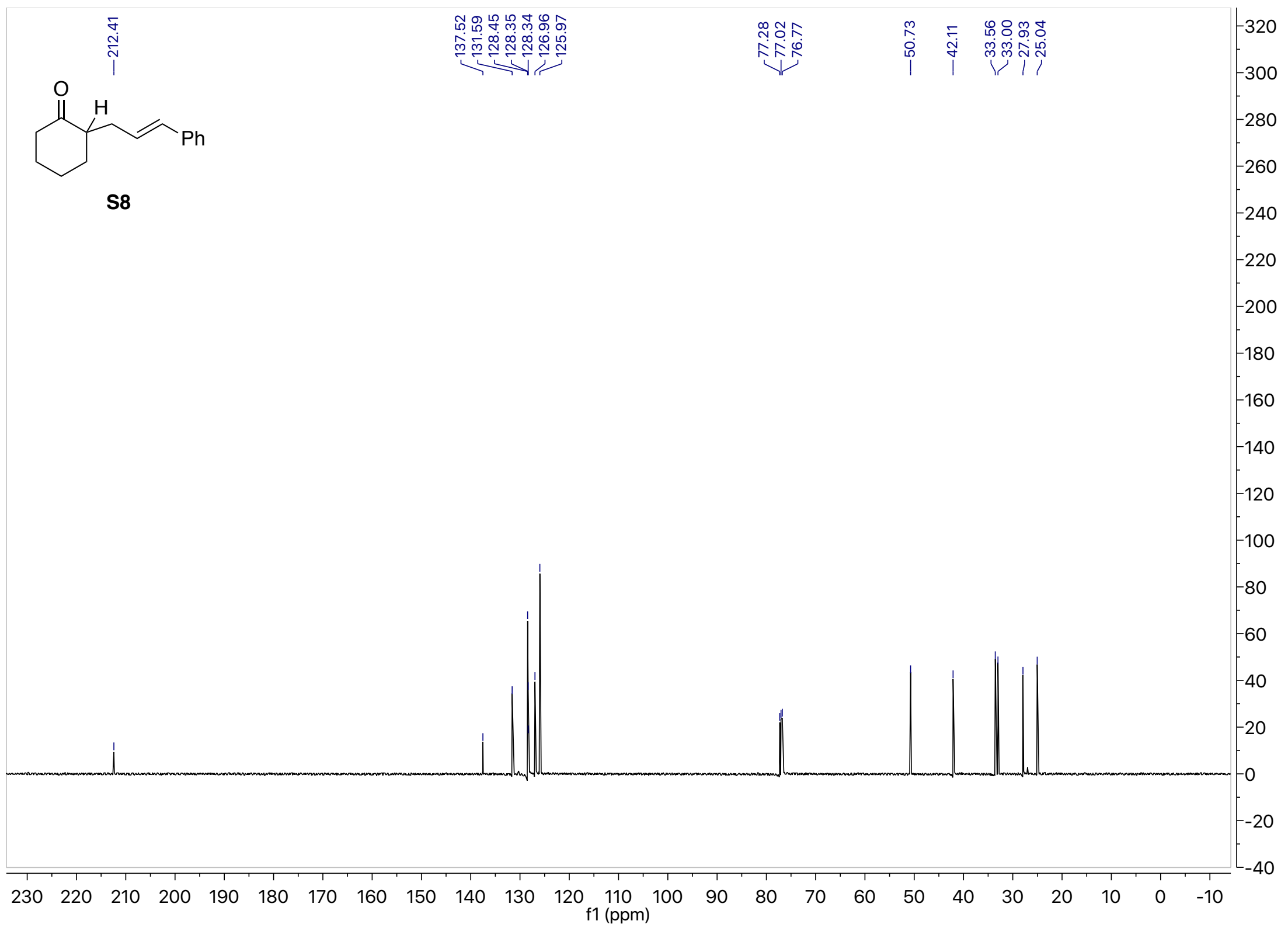




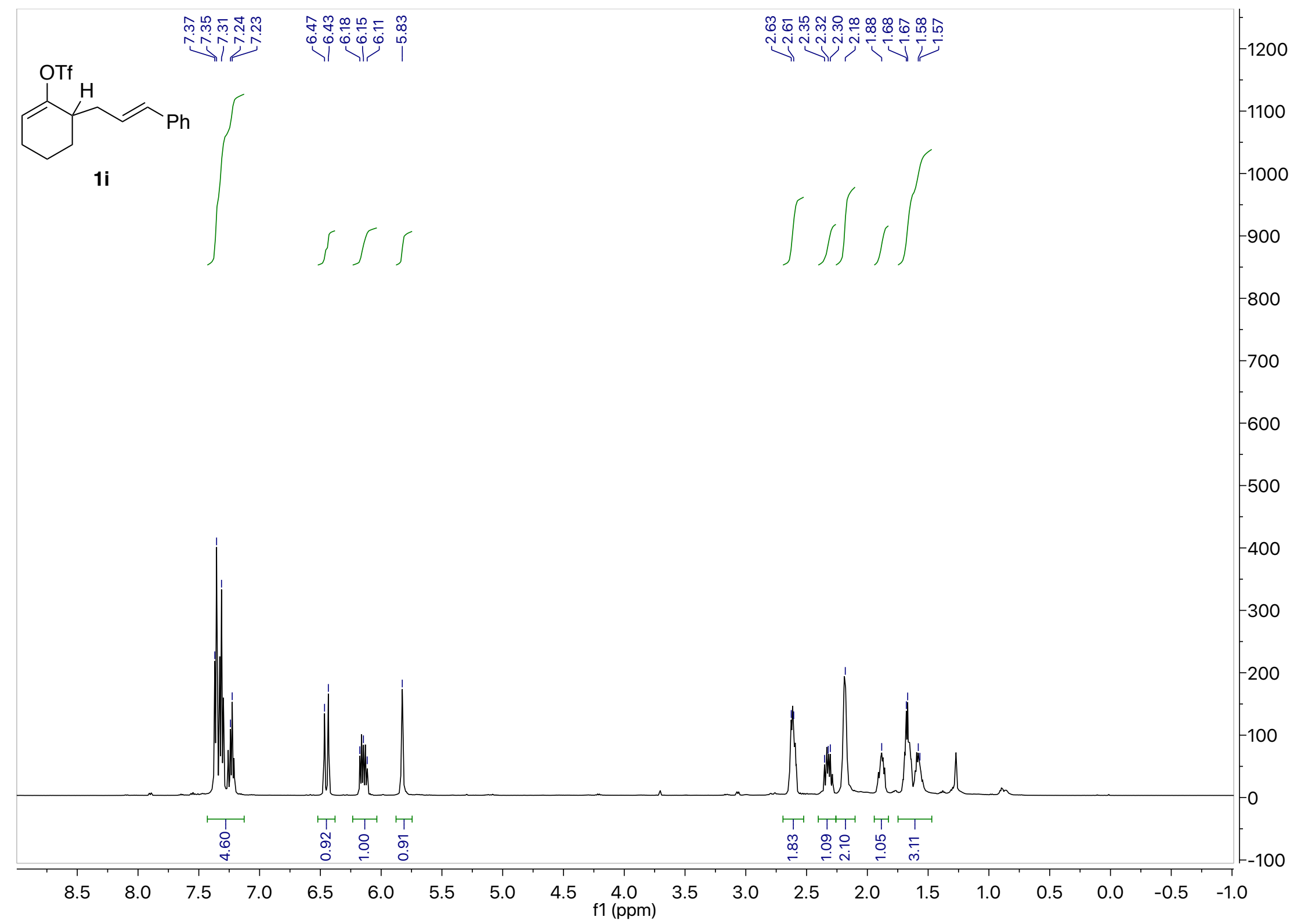




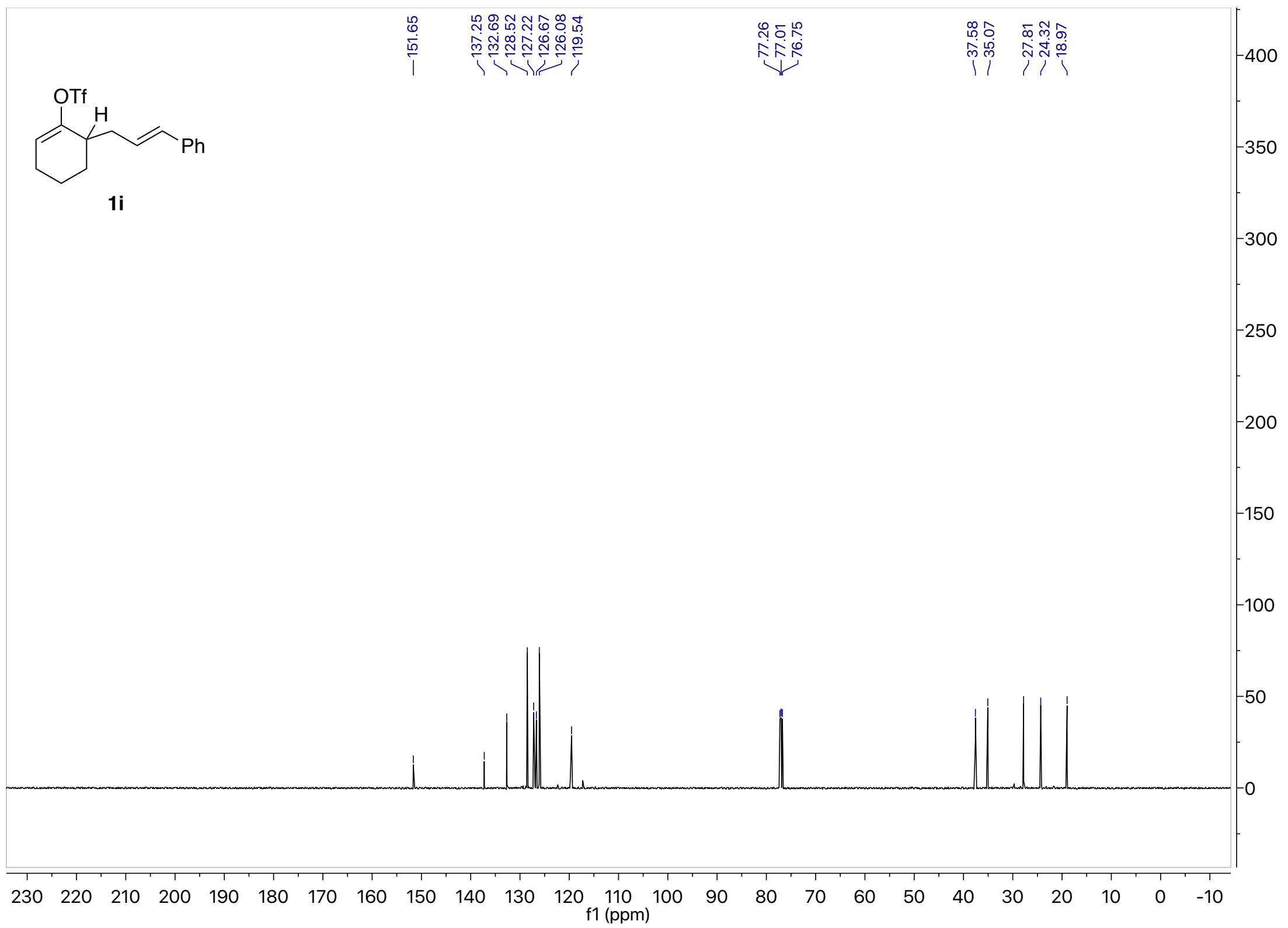




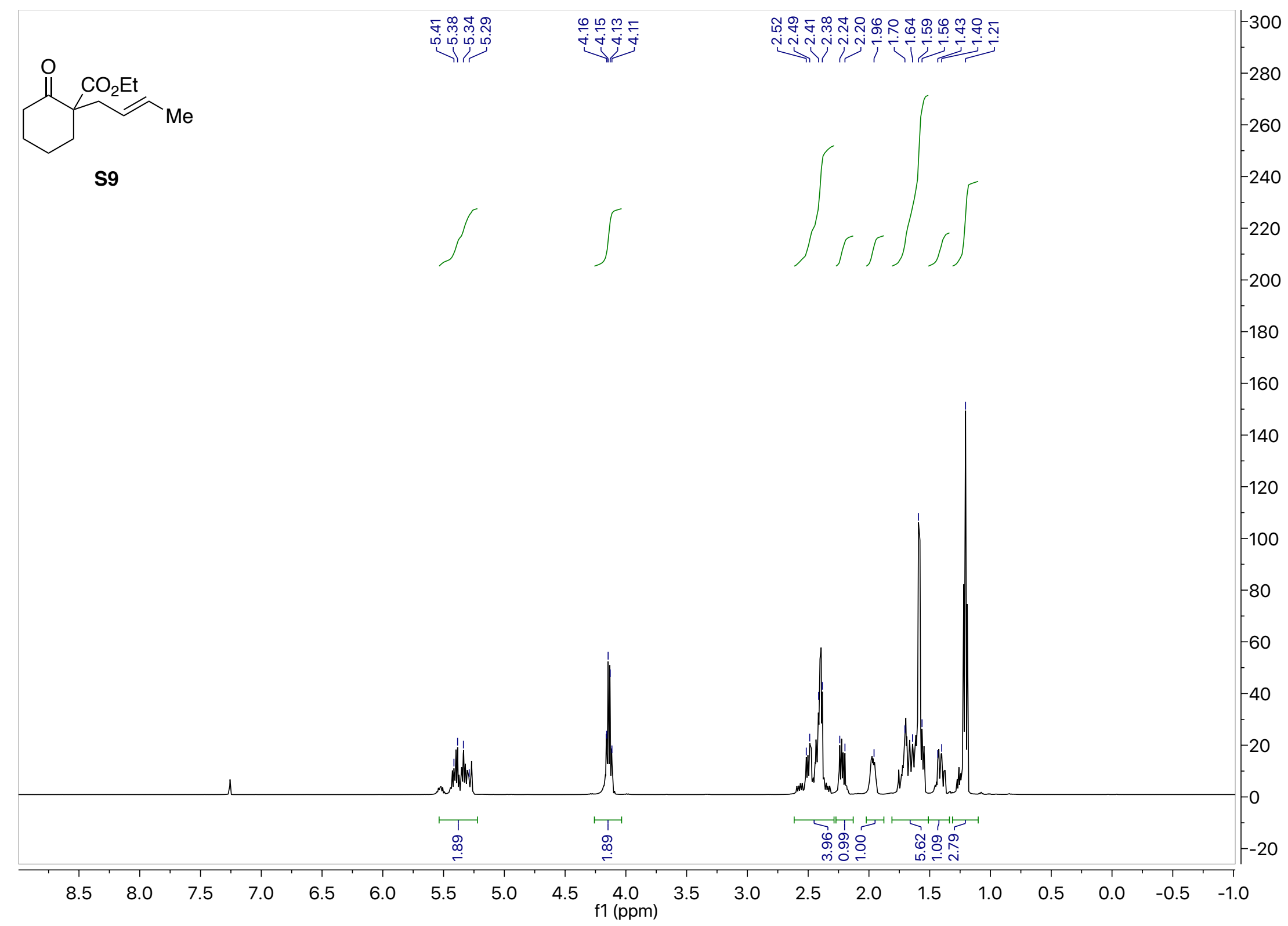




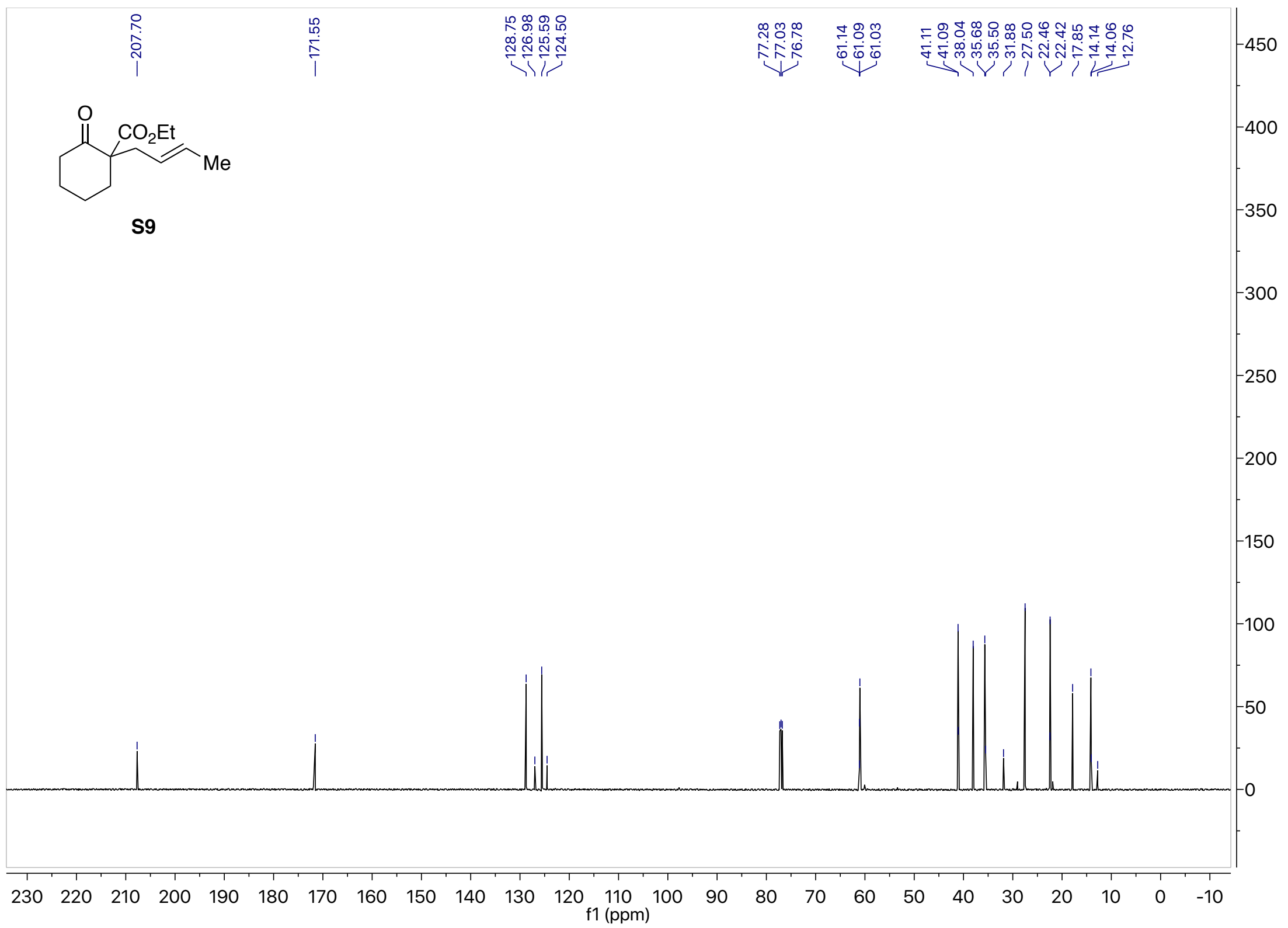




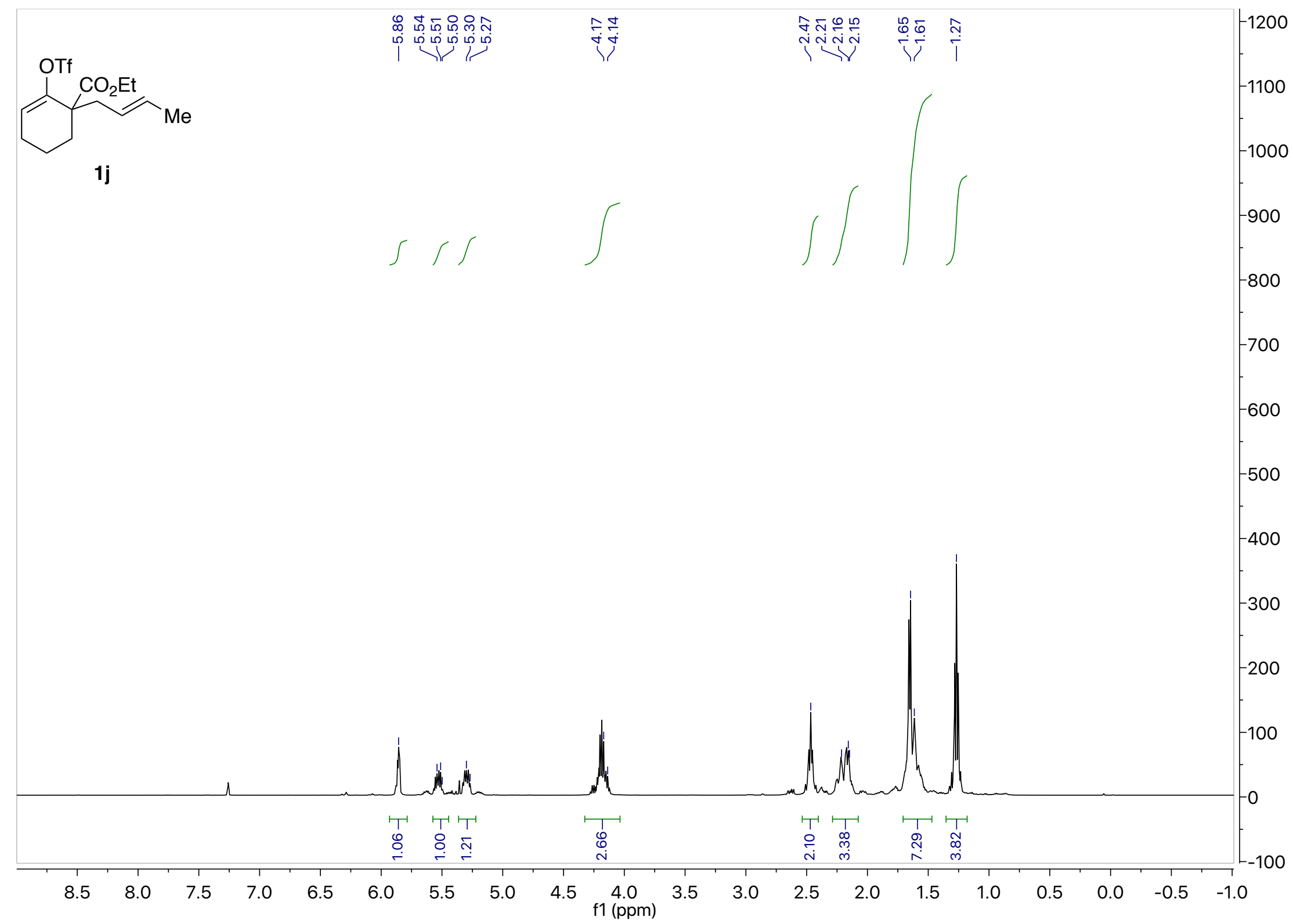




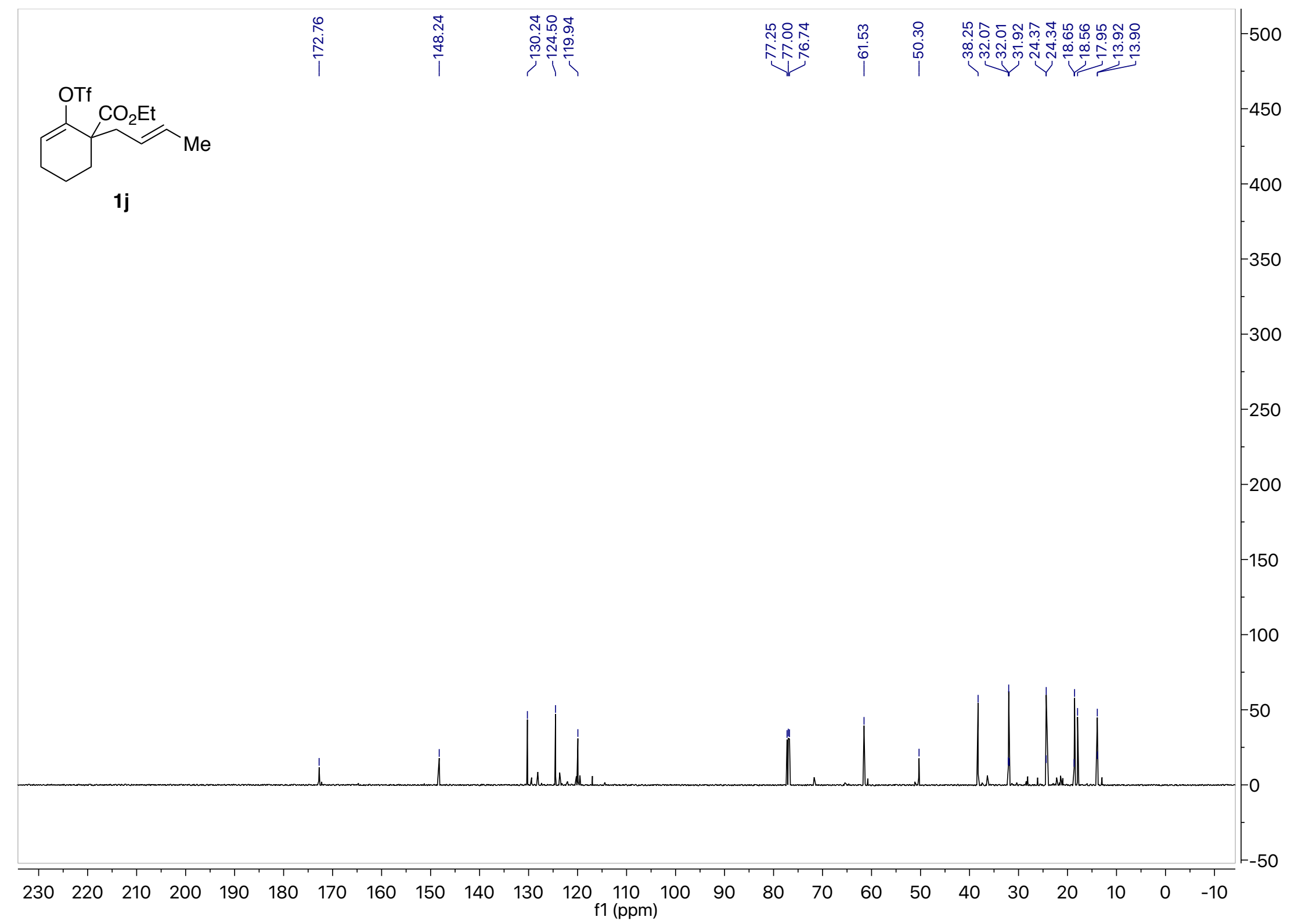




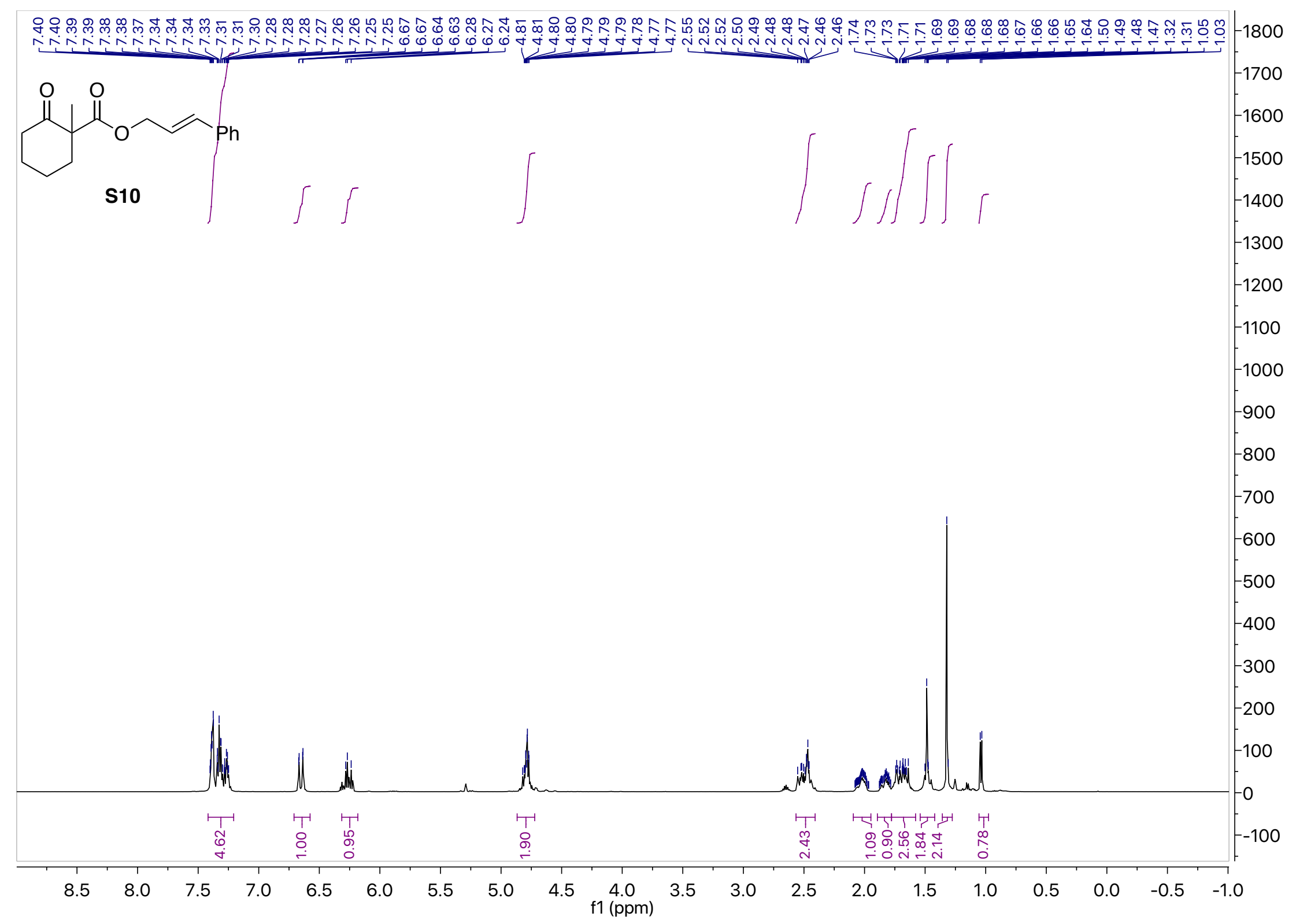




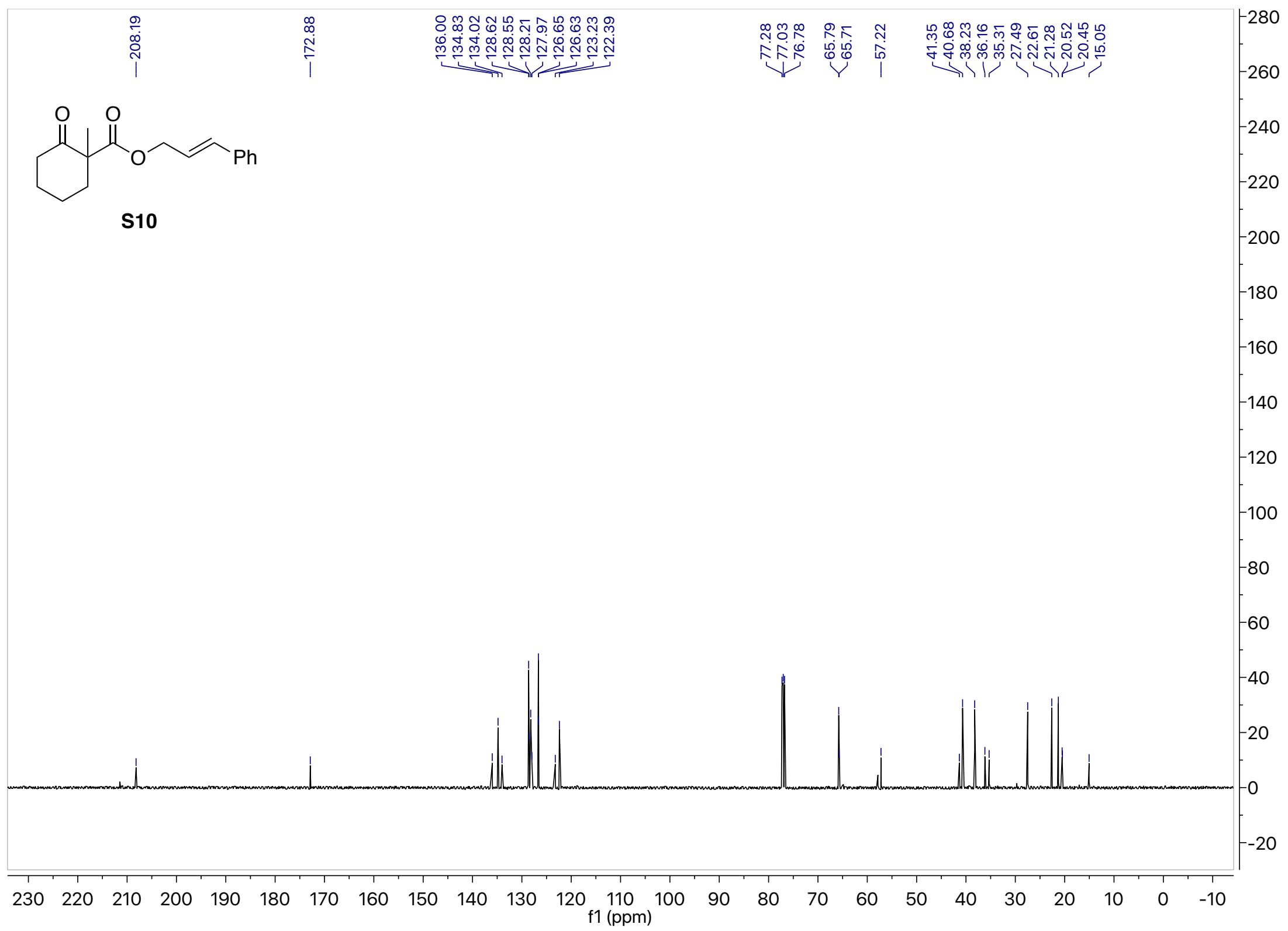




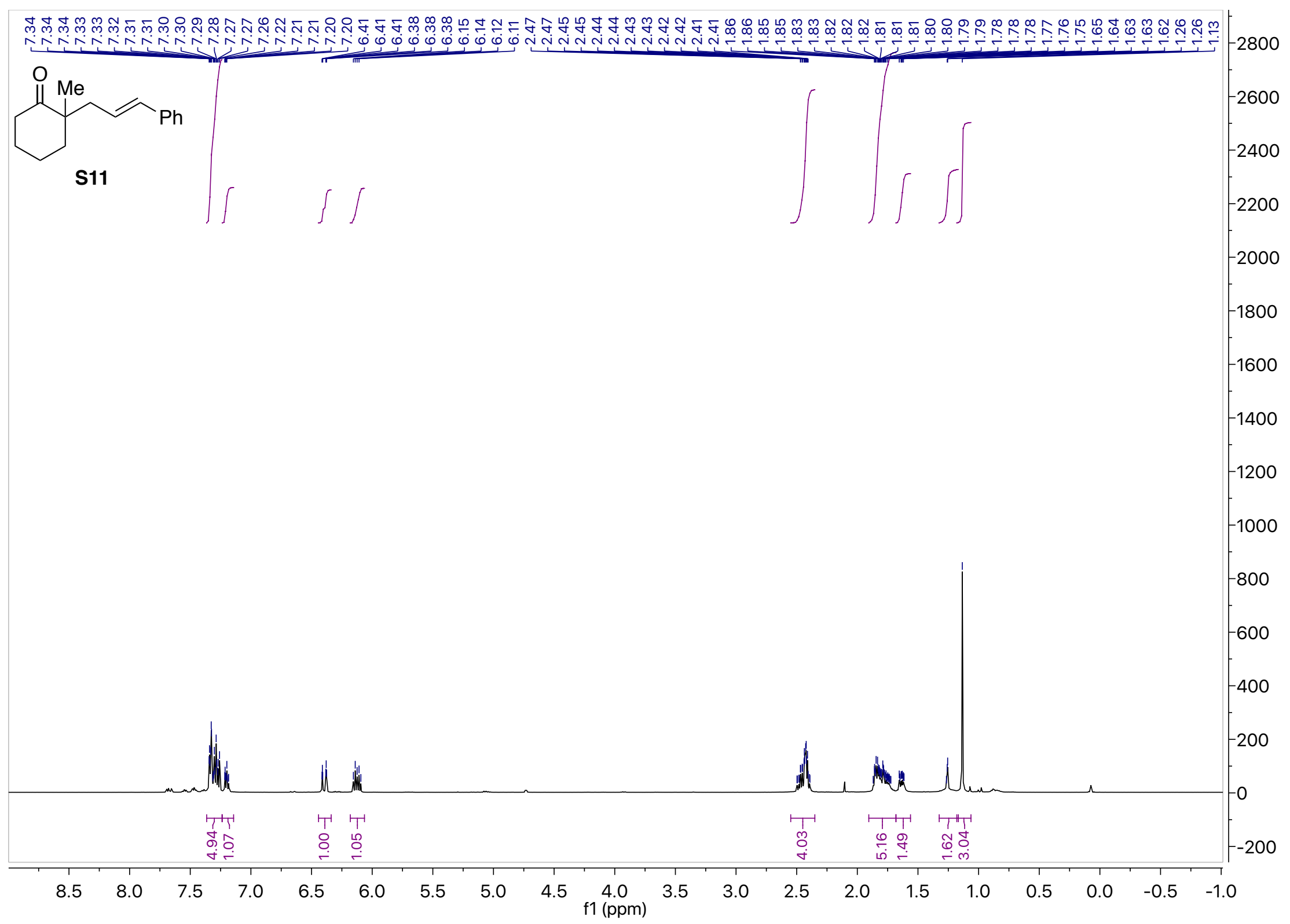




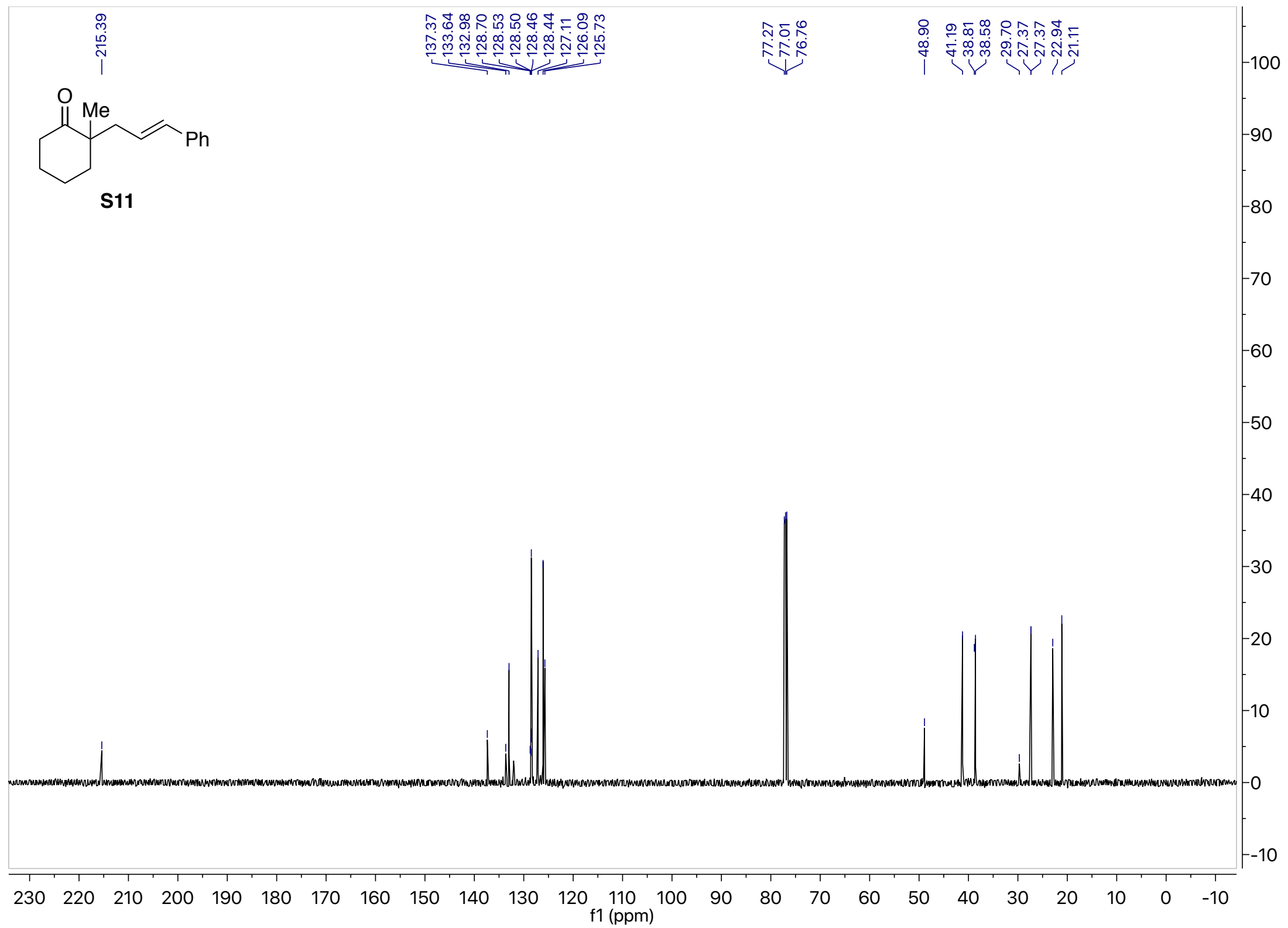




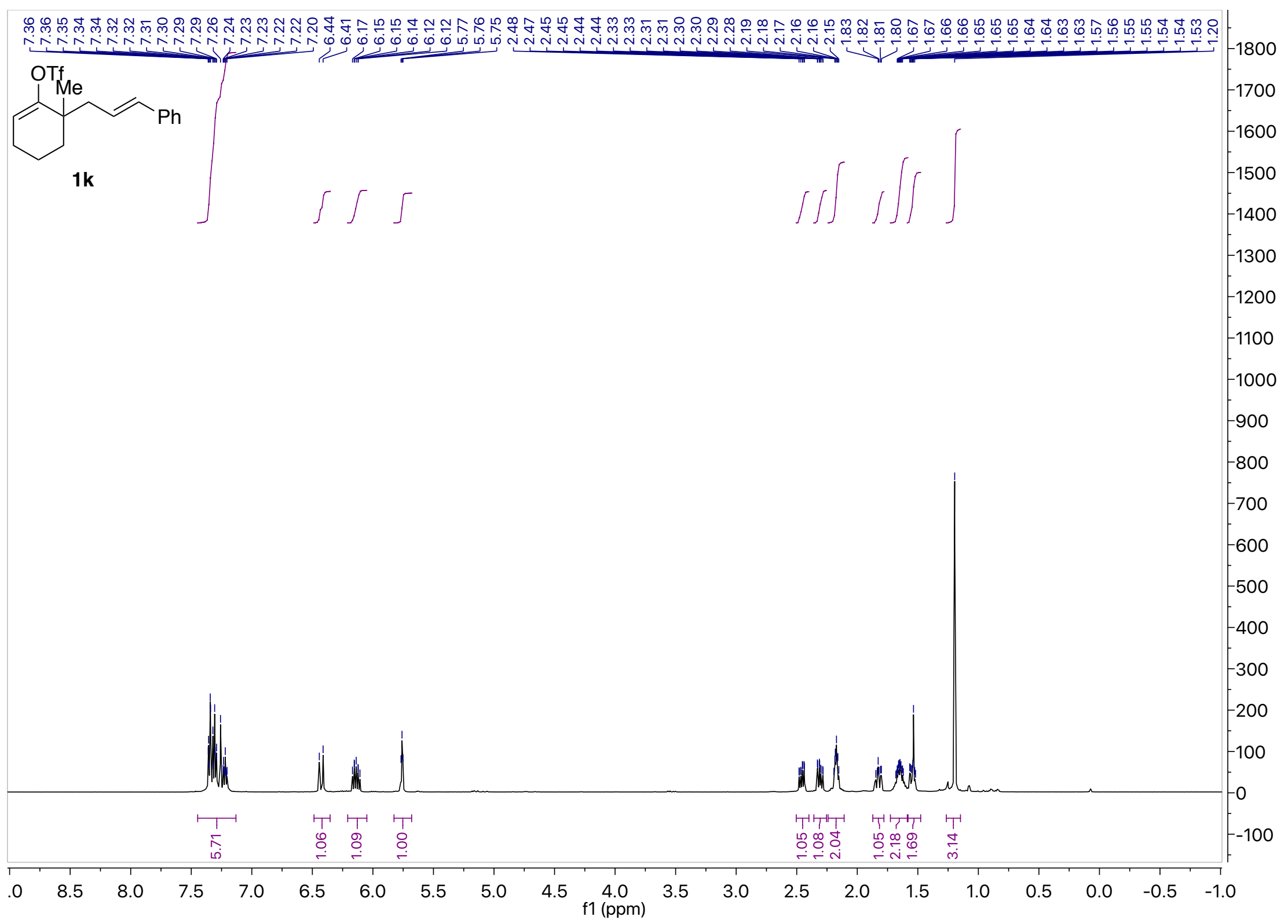




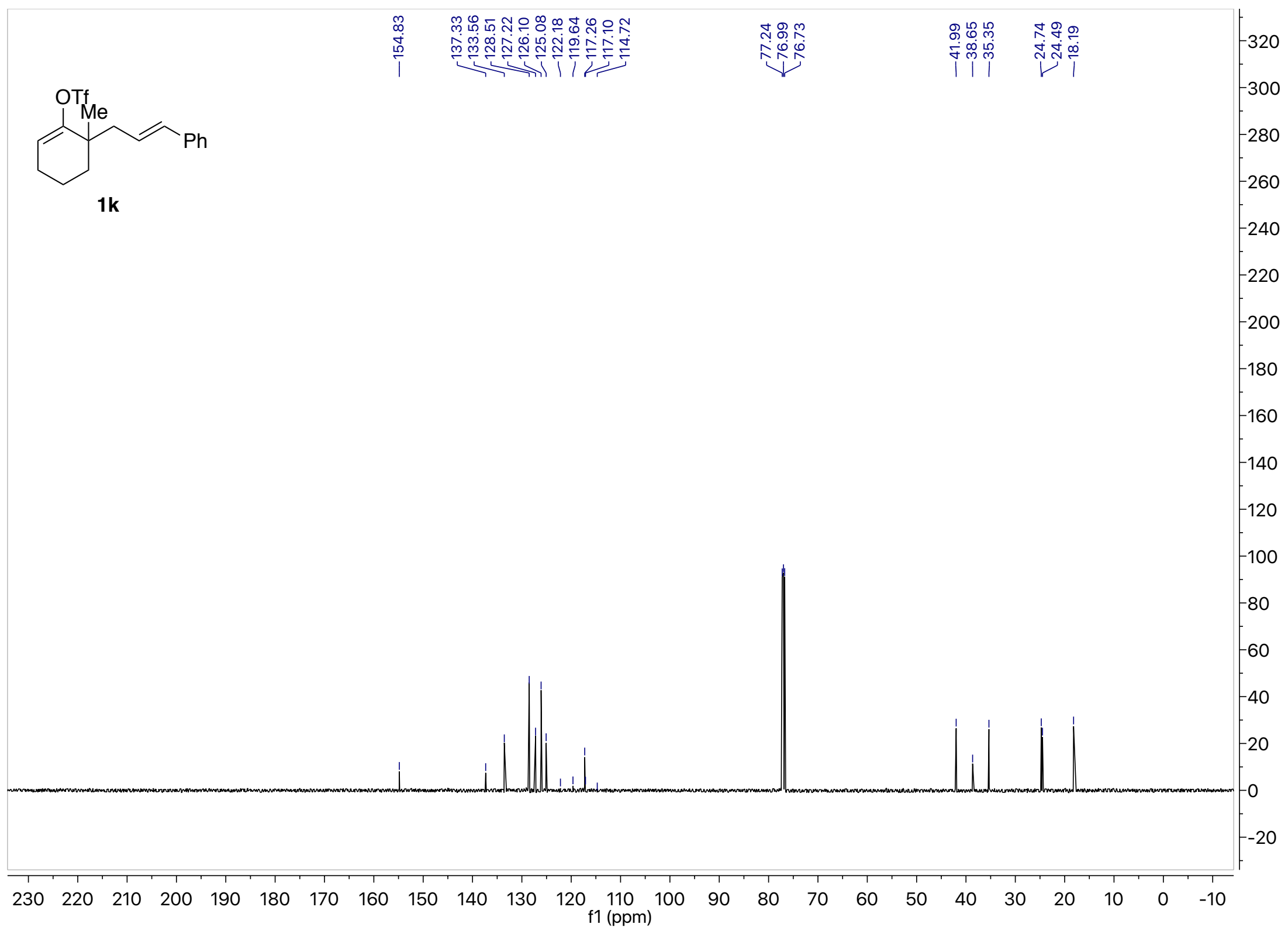




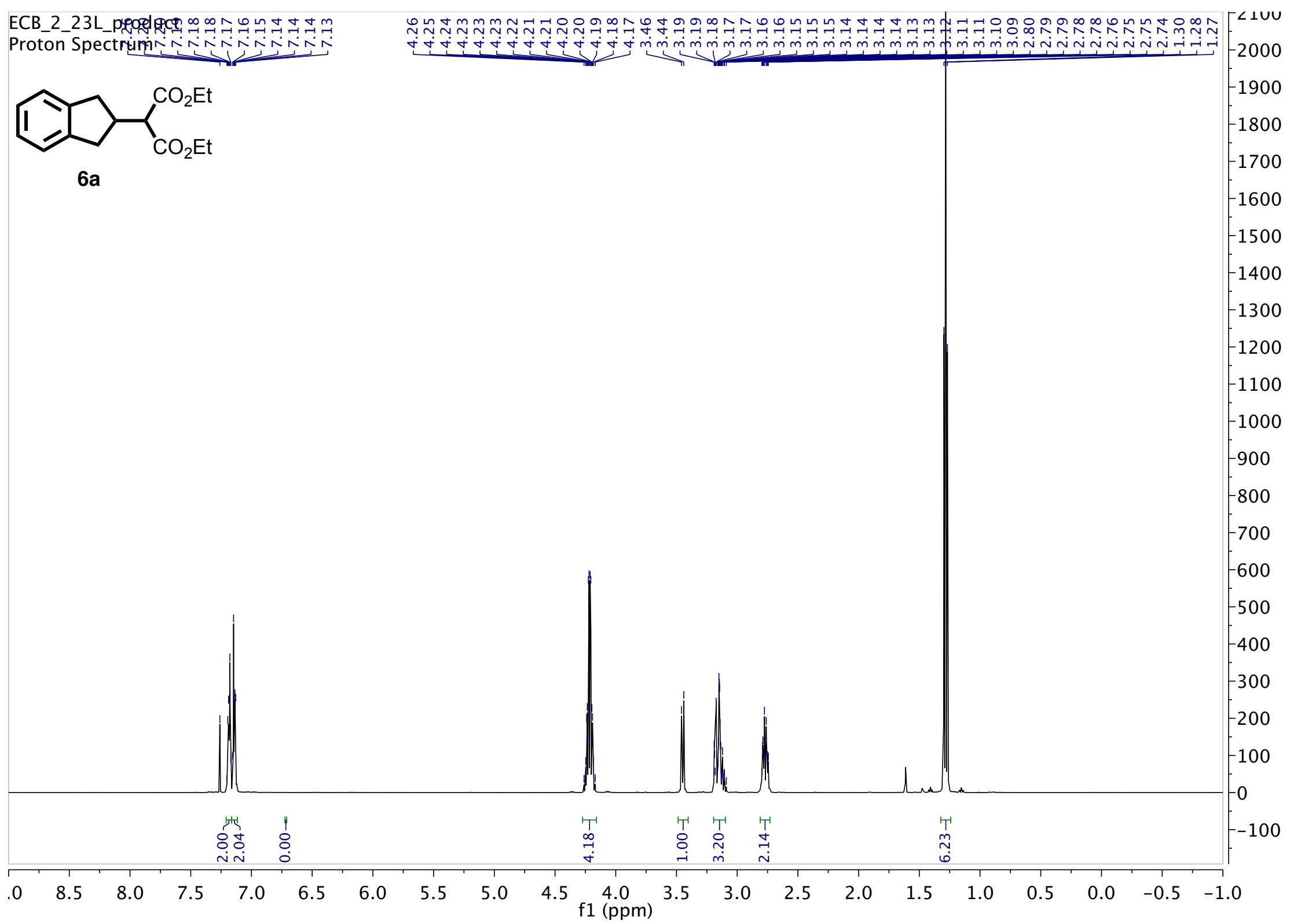




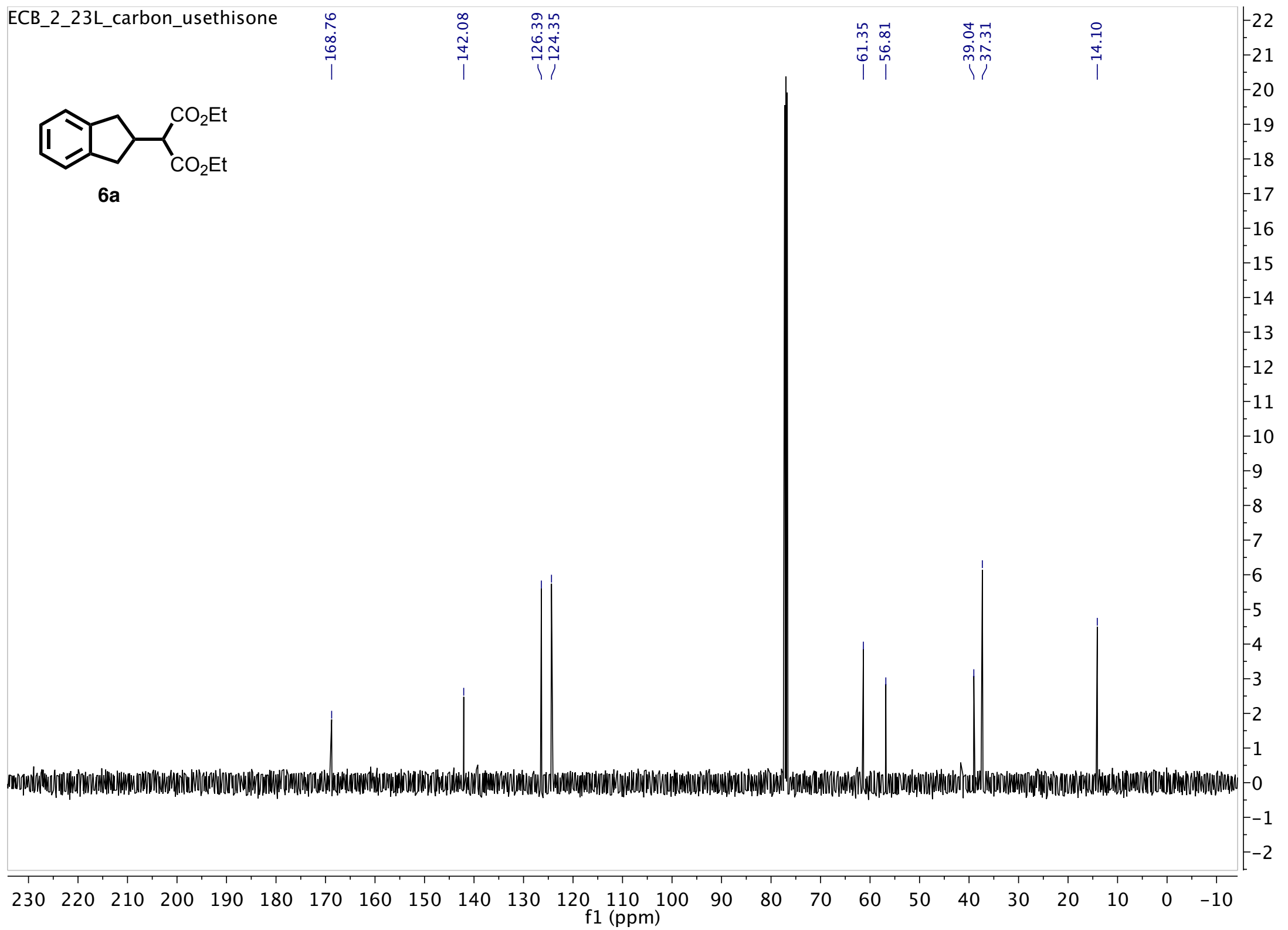




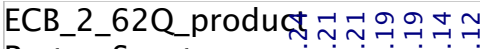

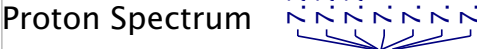

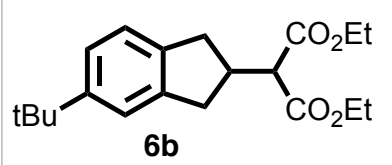

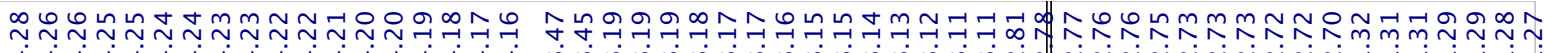

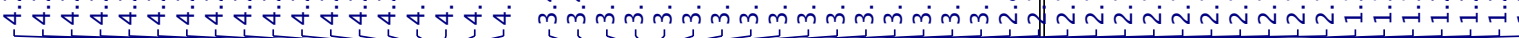

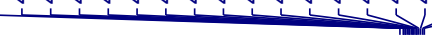

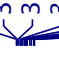

(1)

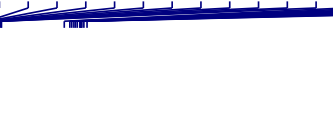

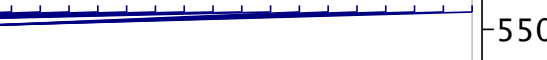

500

450

$-400$ 


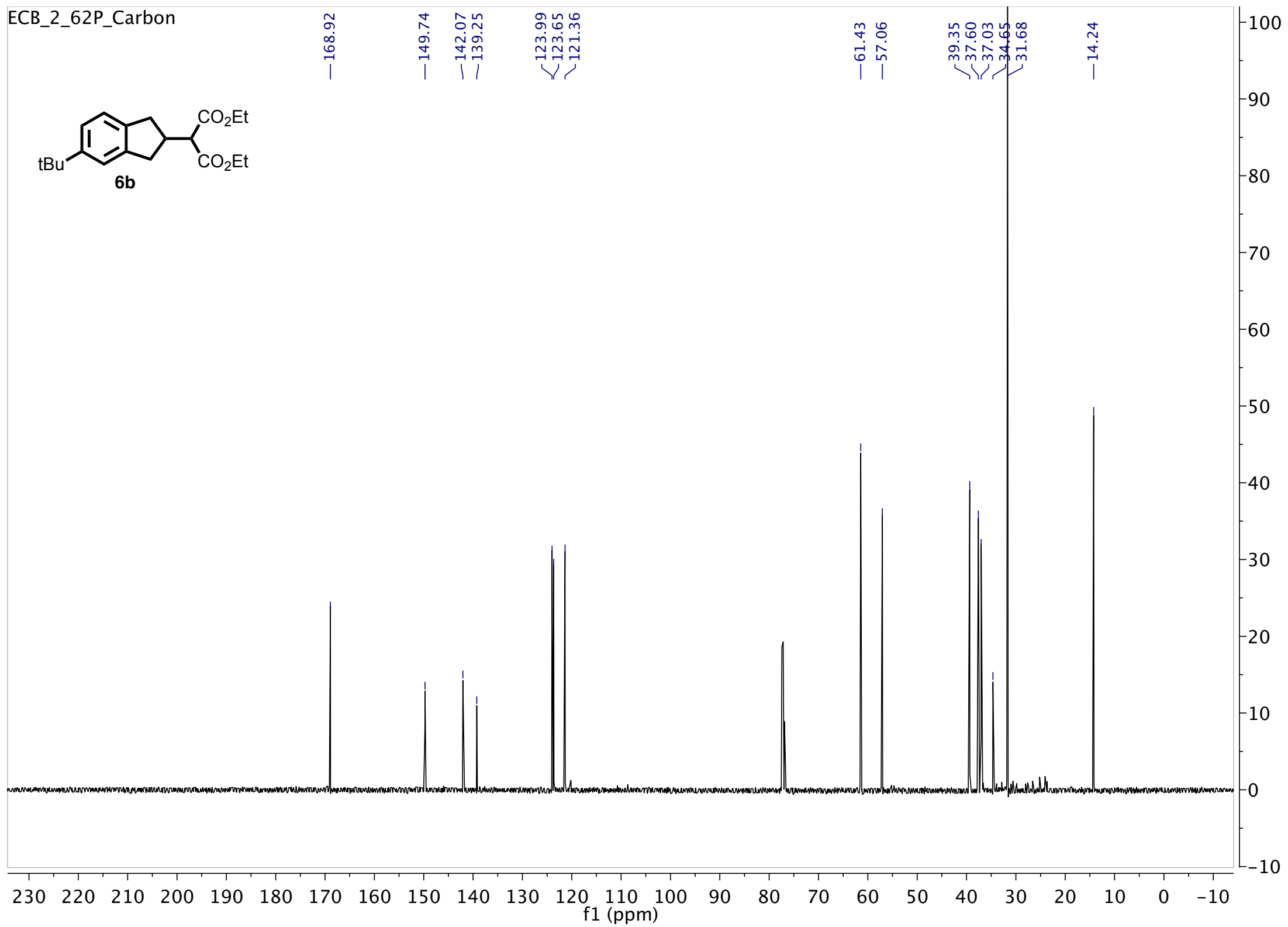




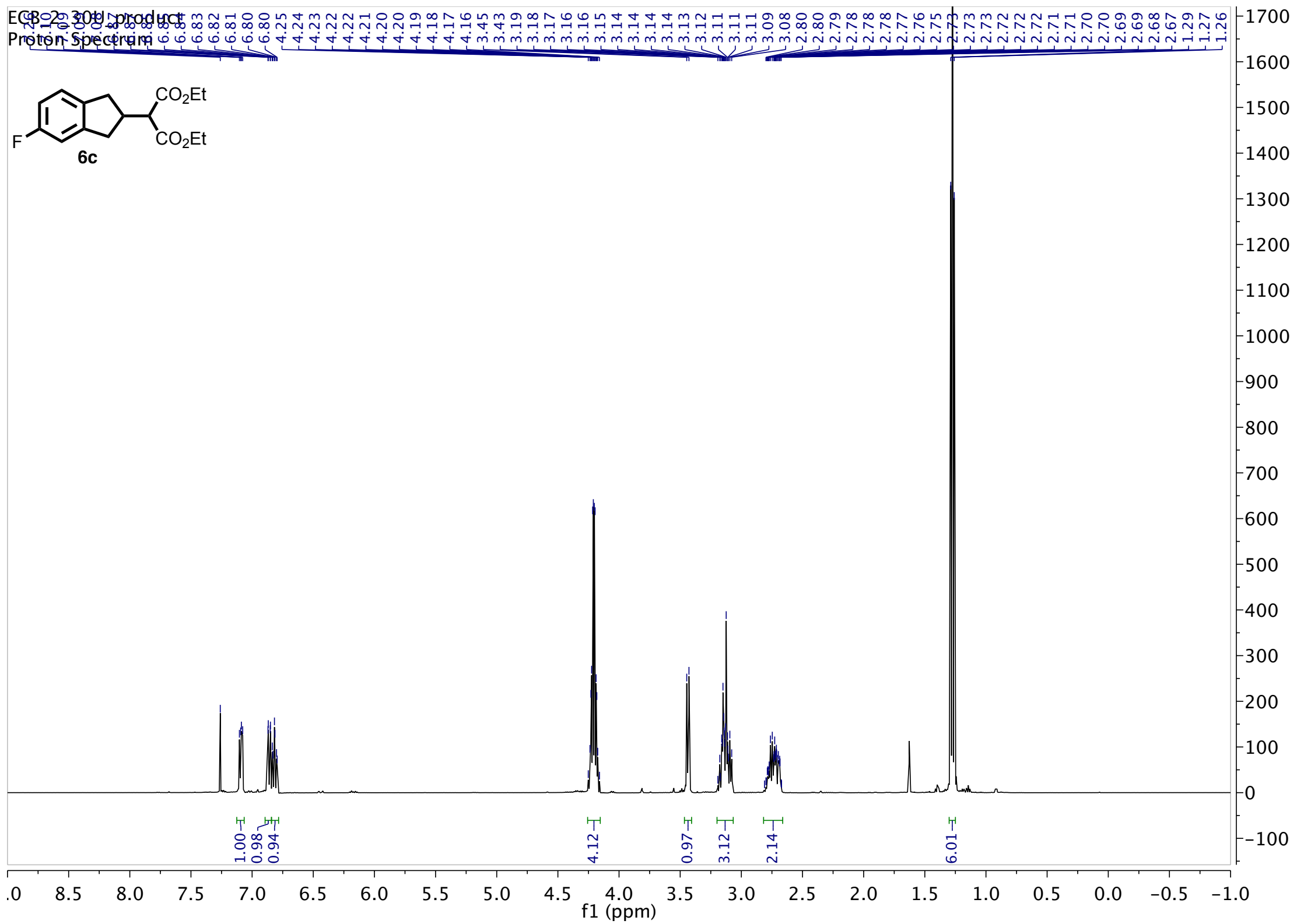




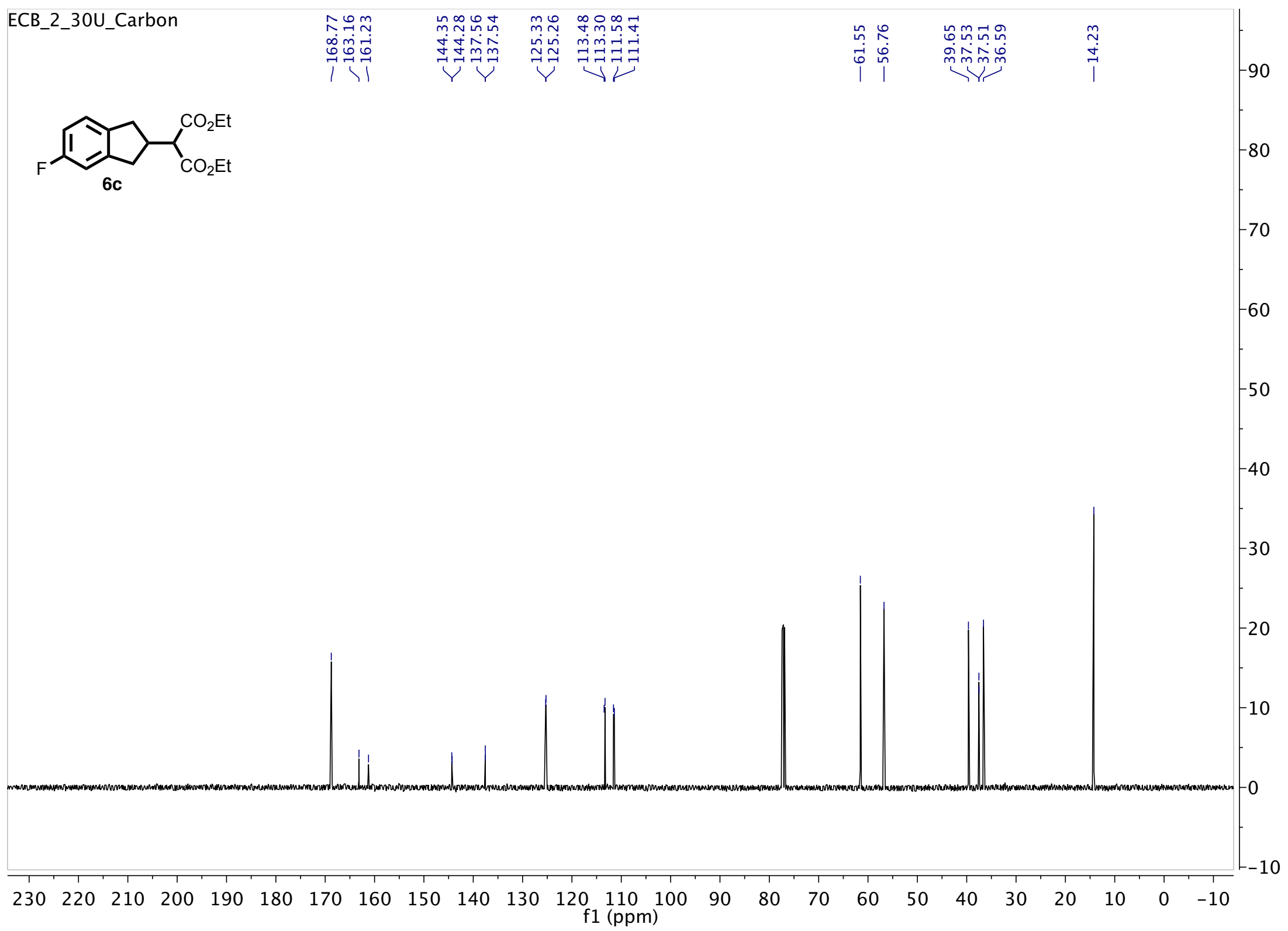




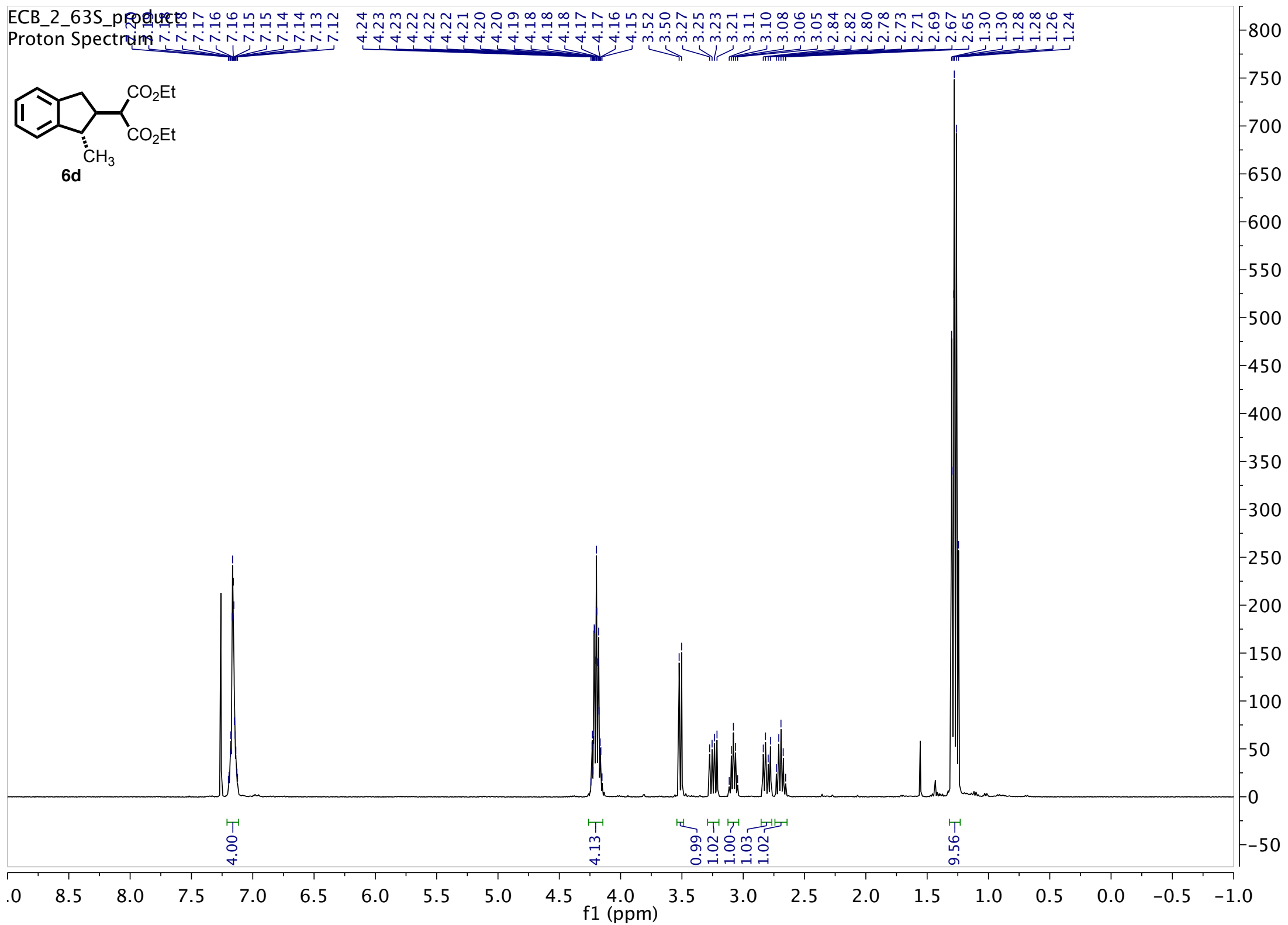




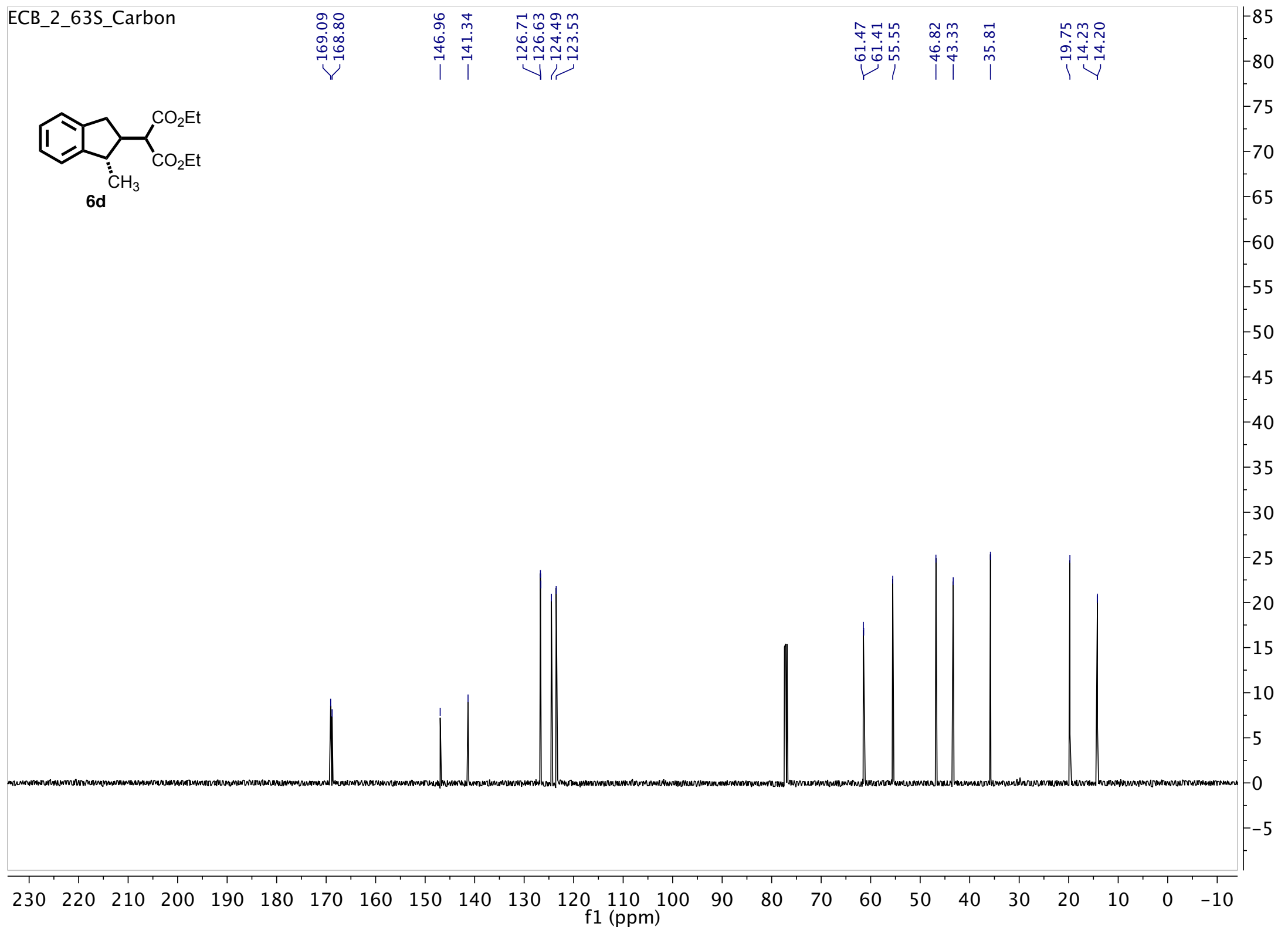




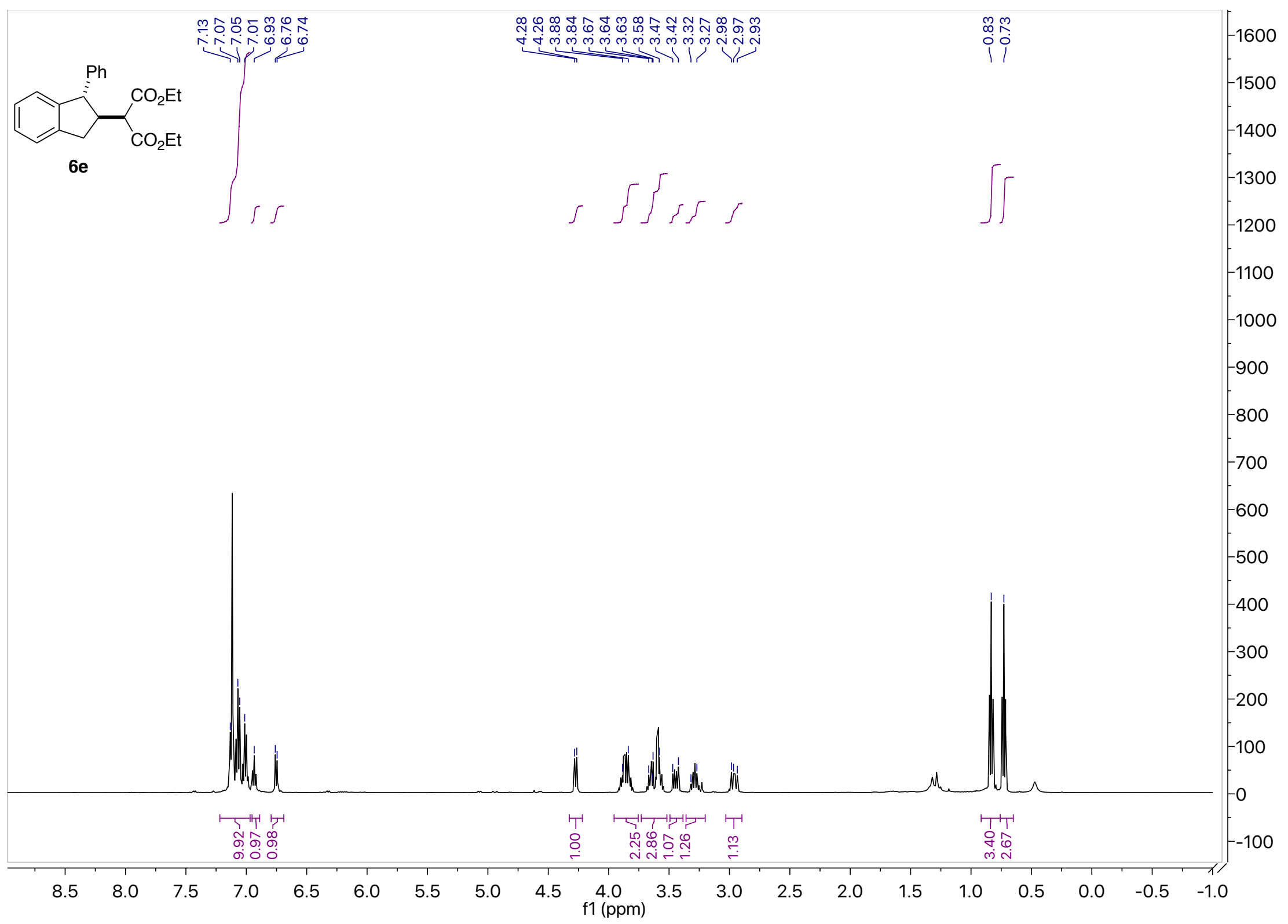




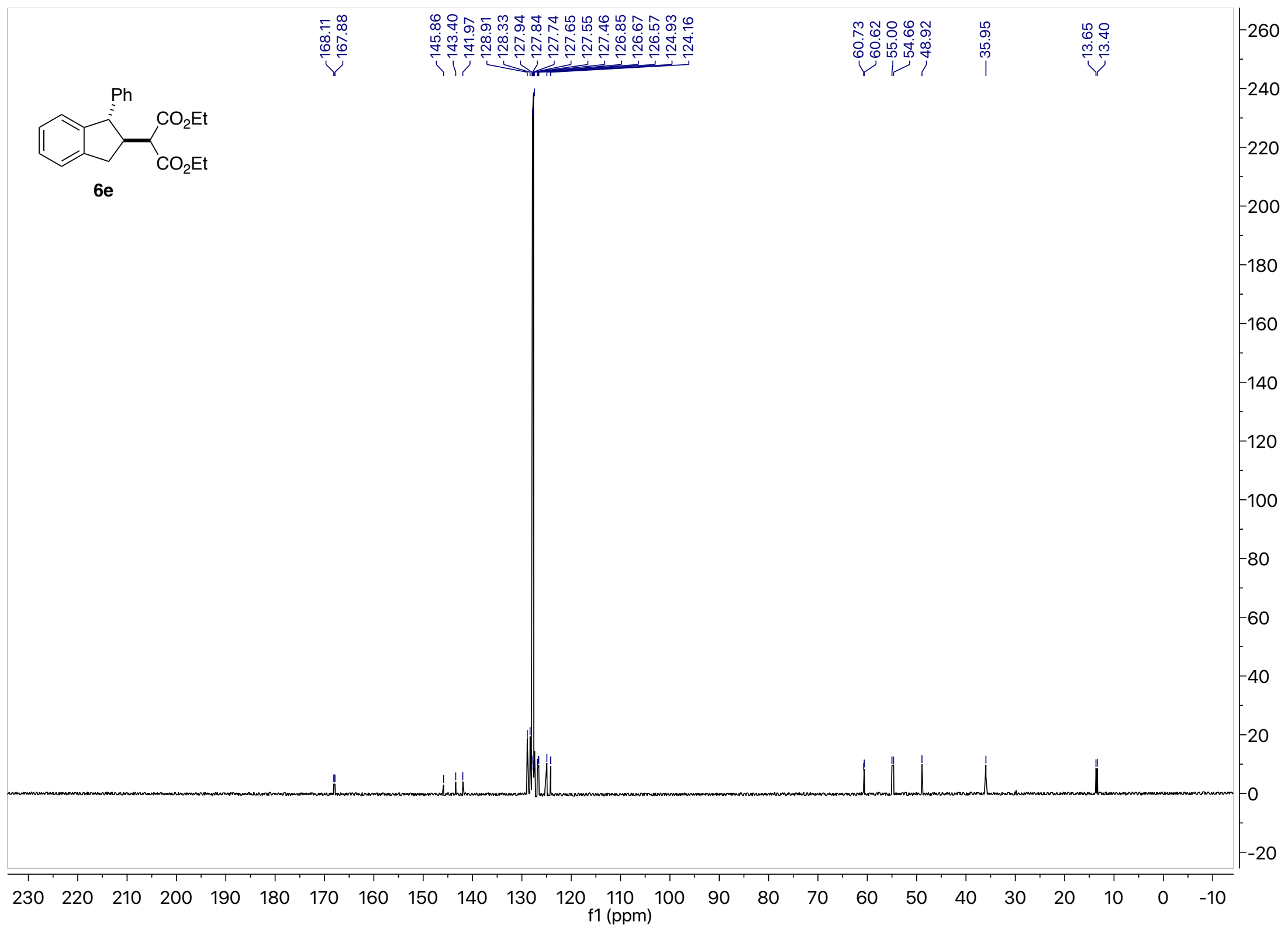




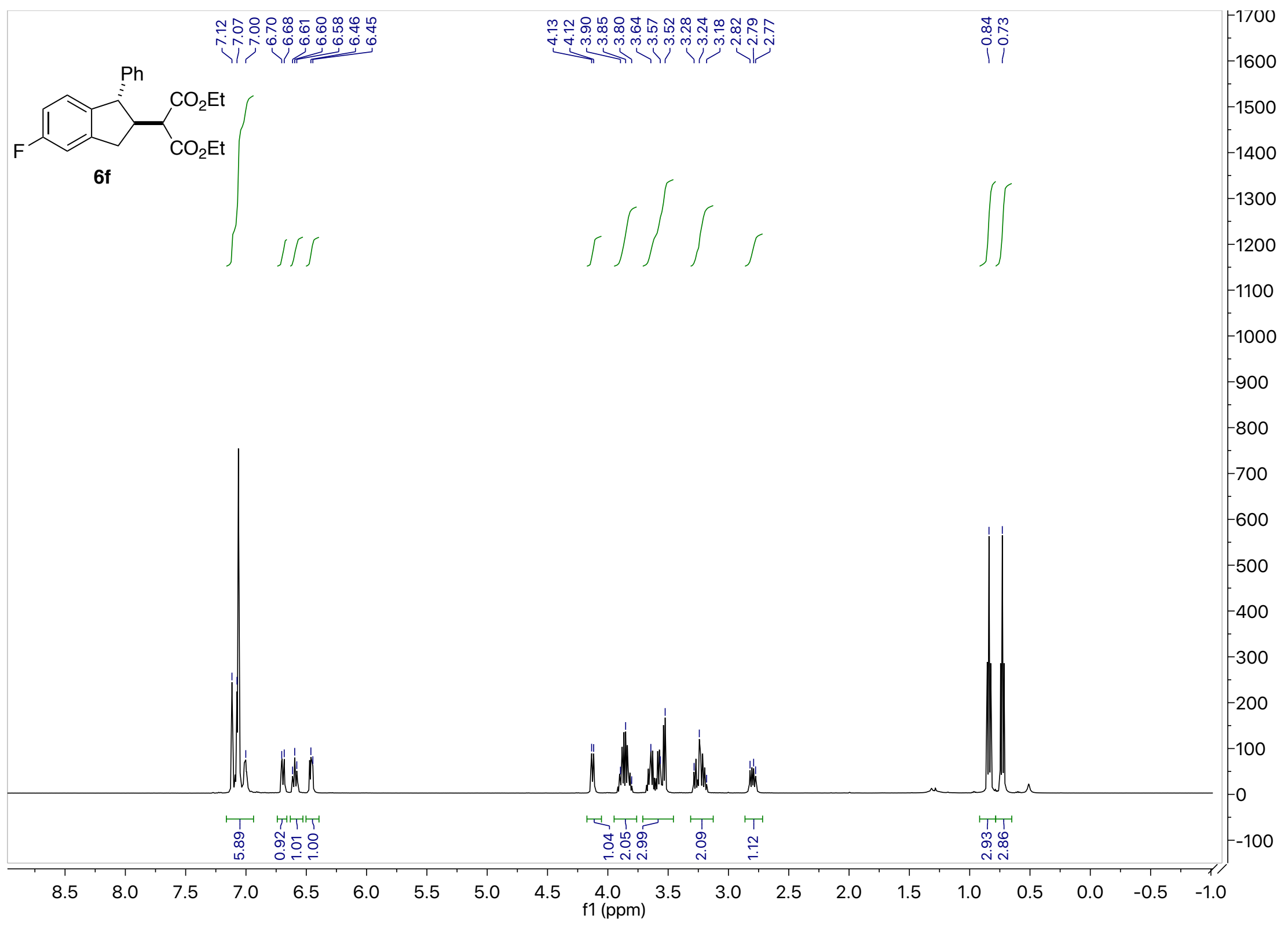




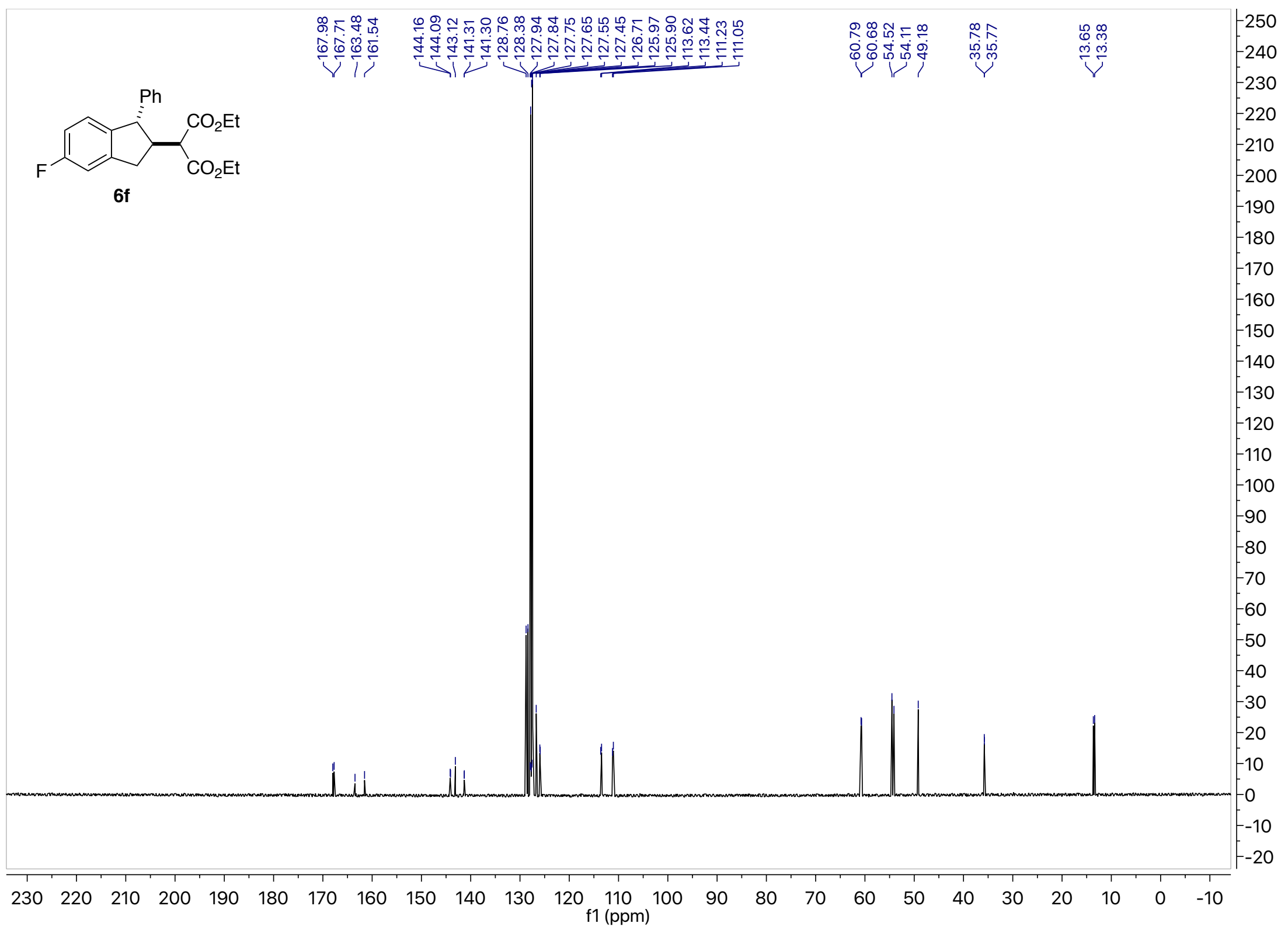




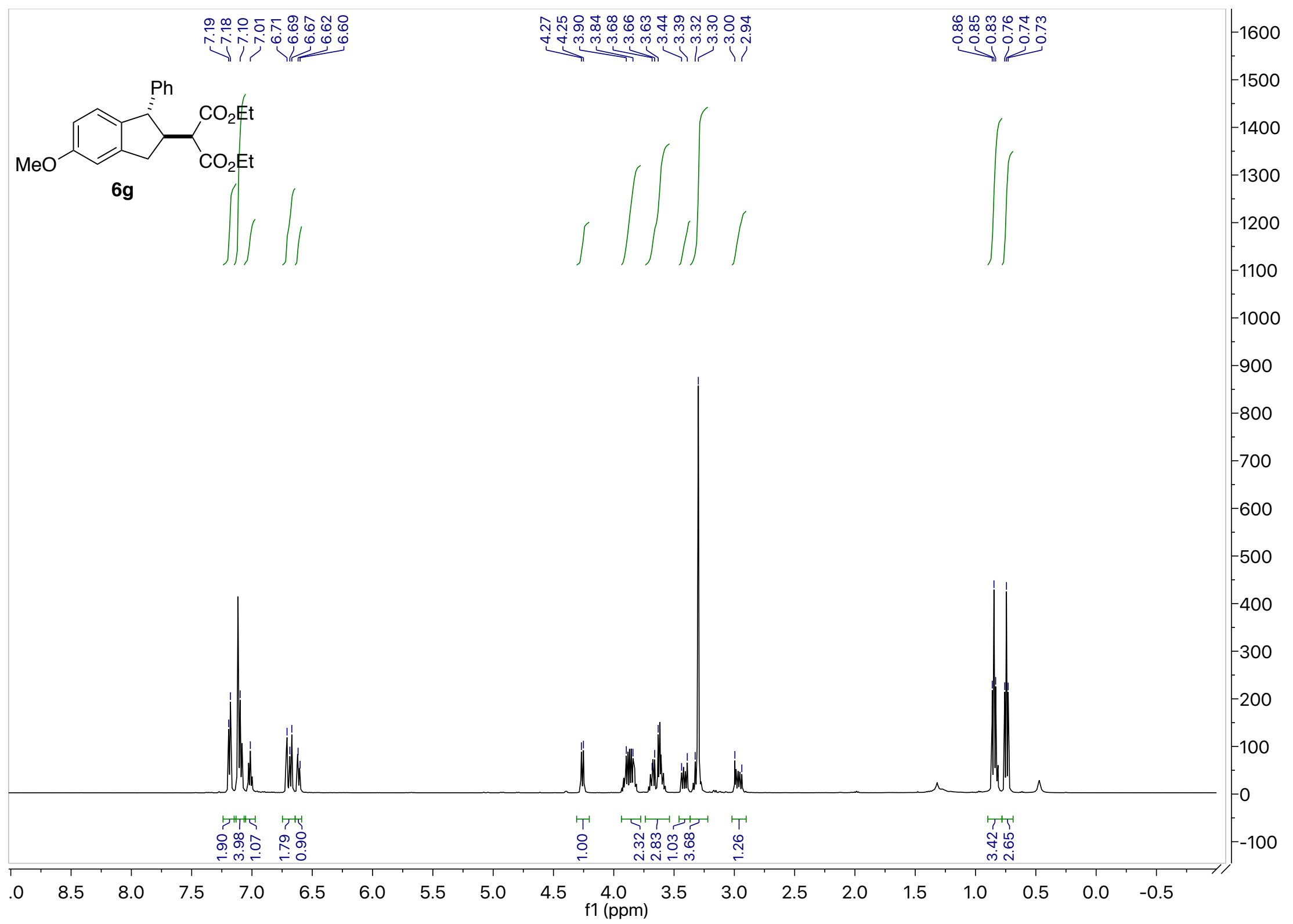




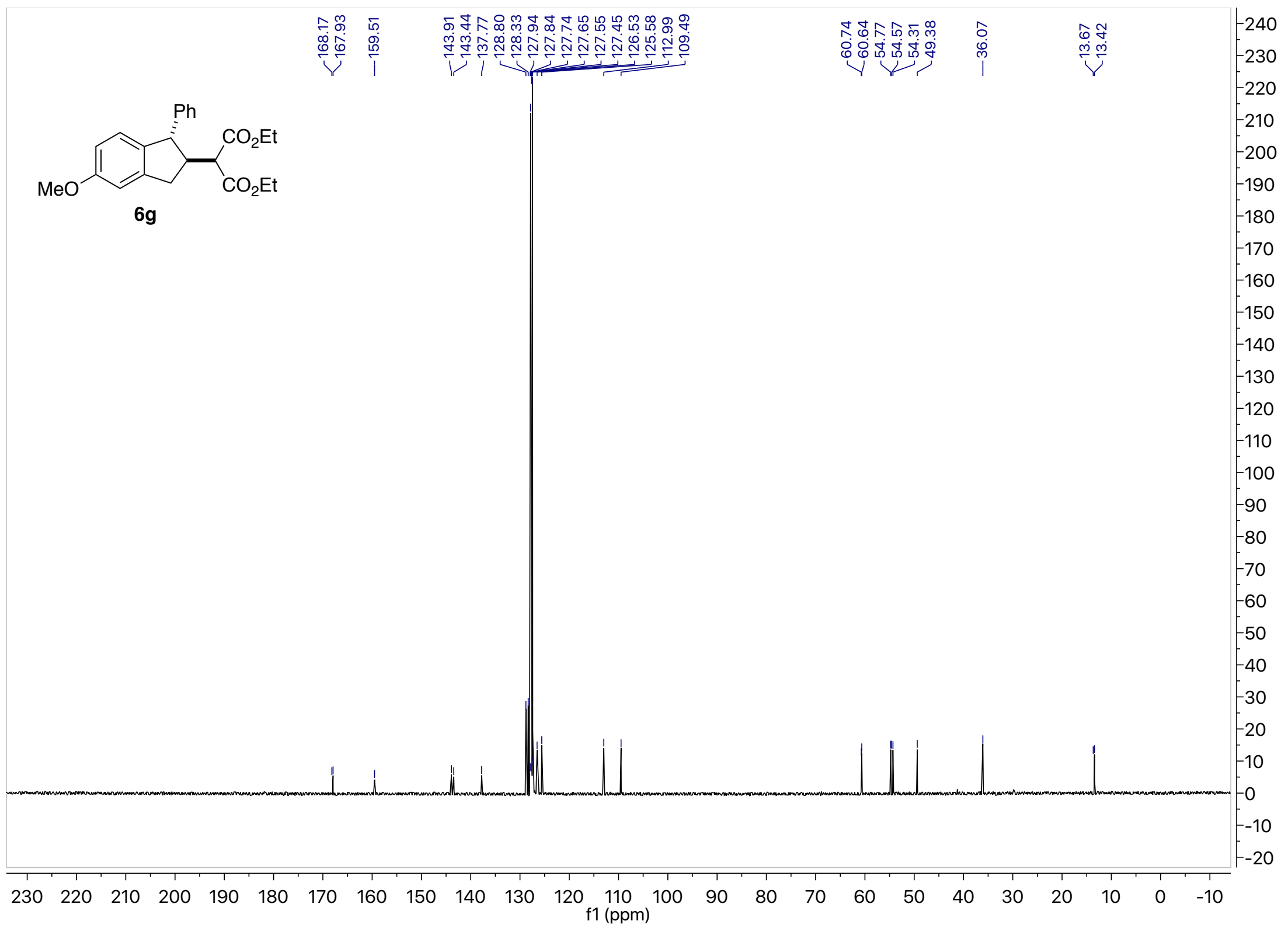




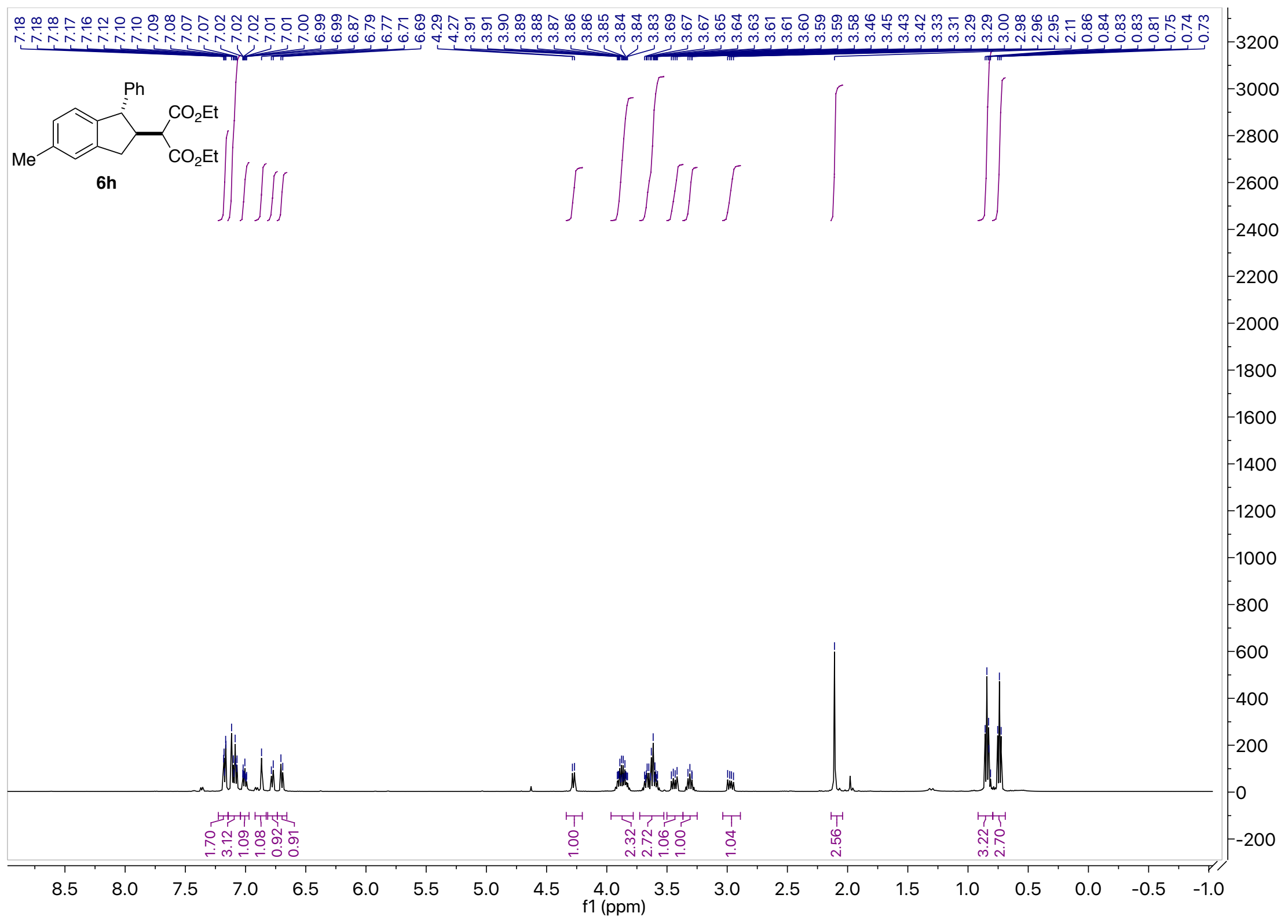




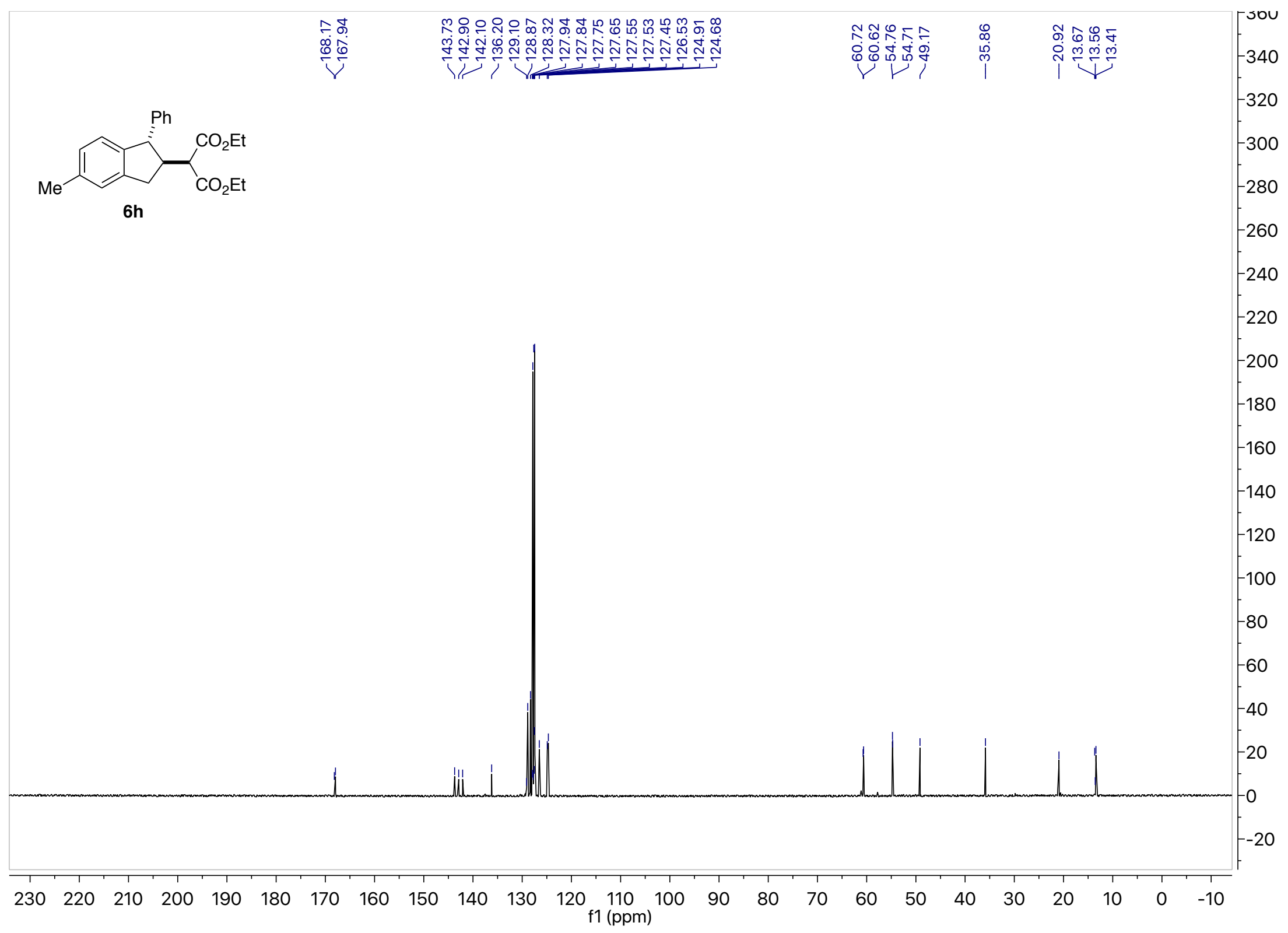




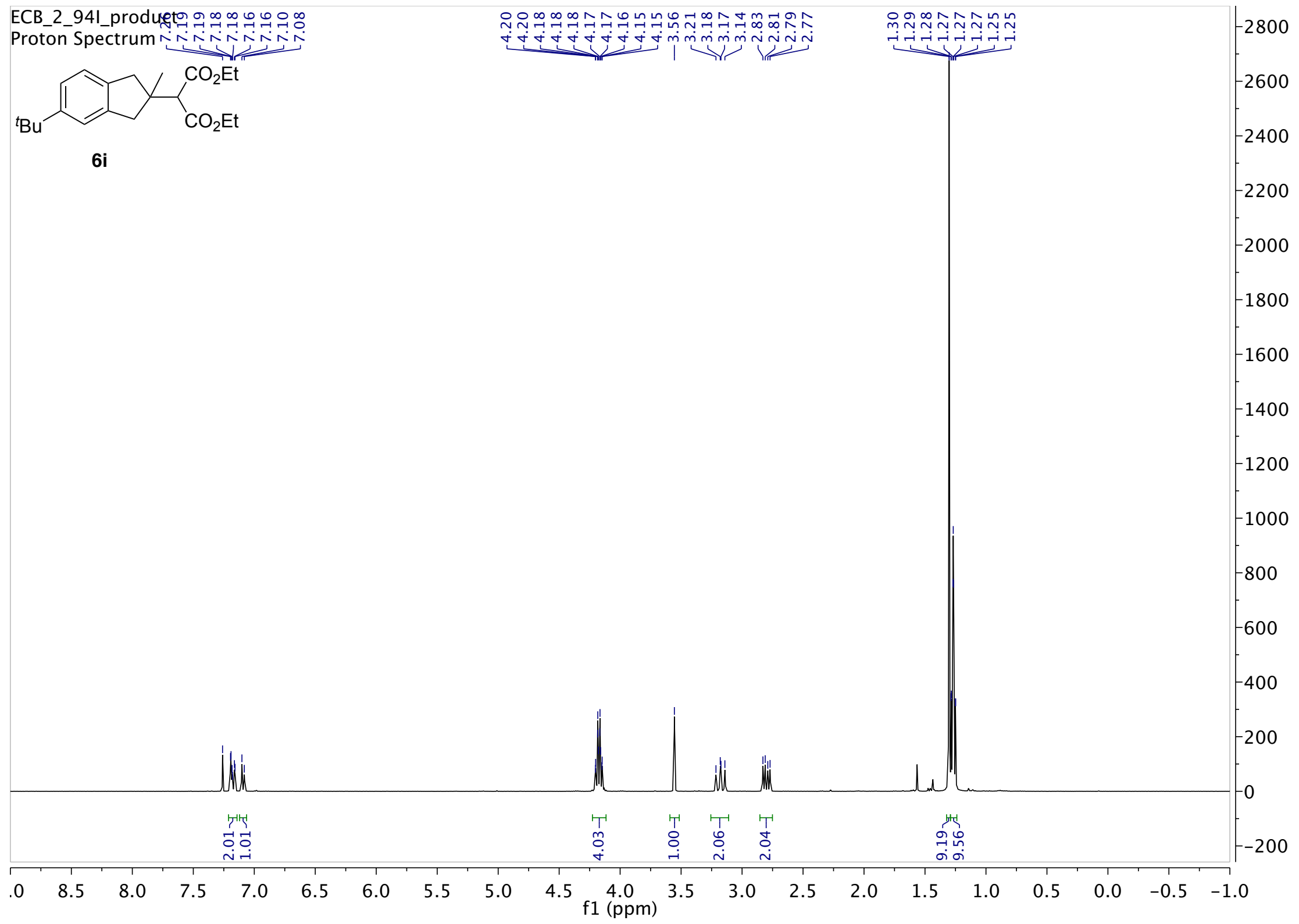




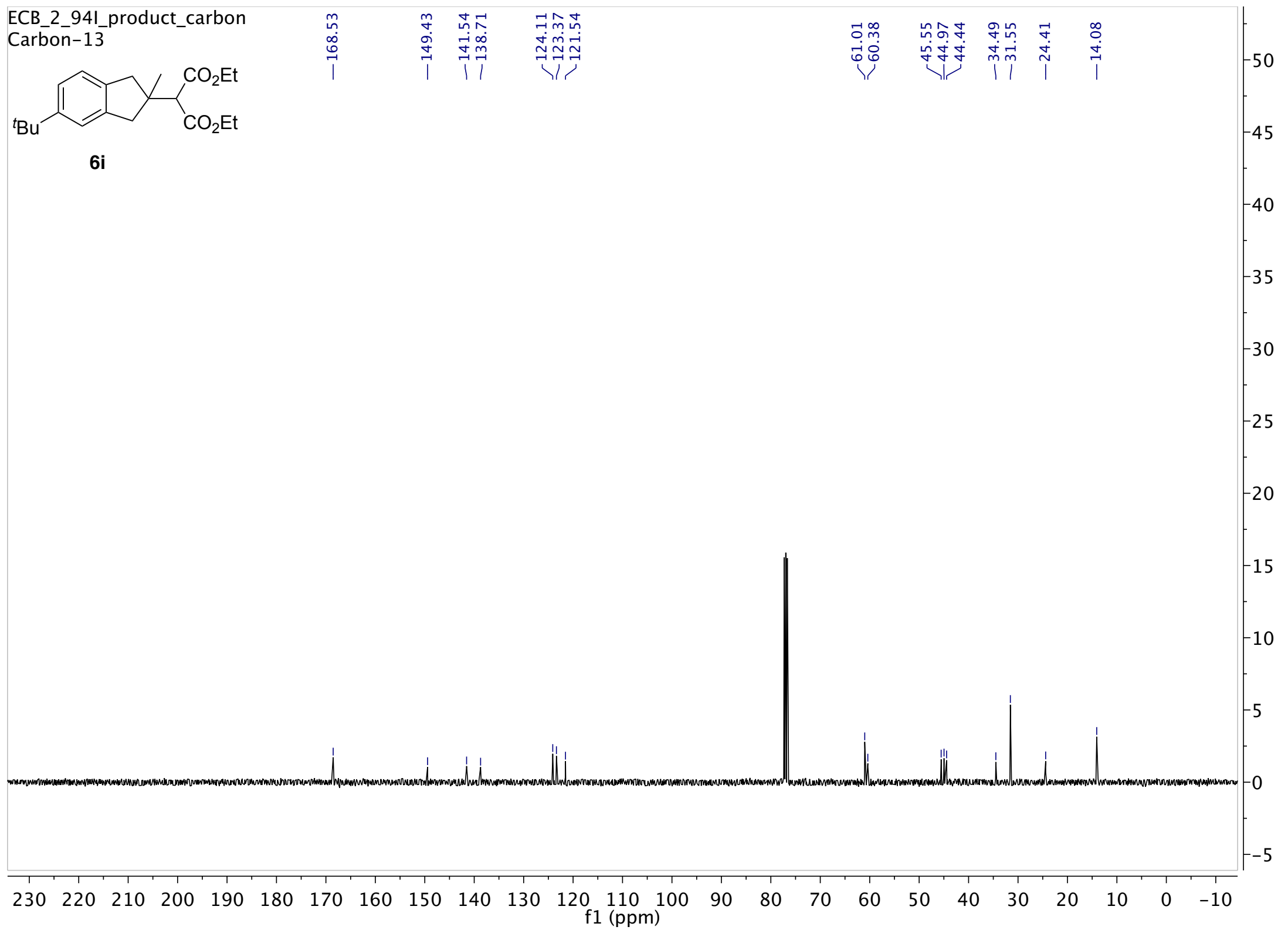




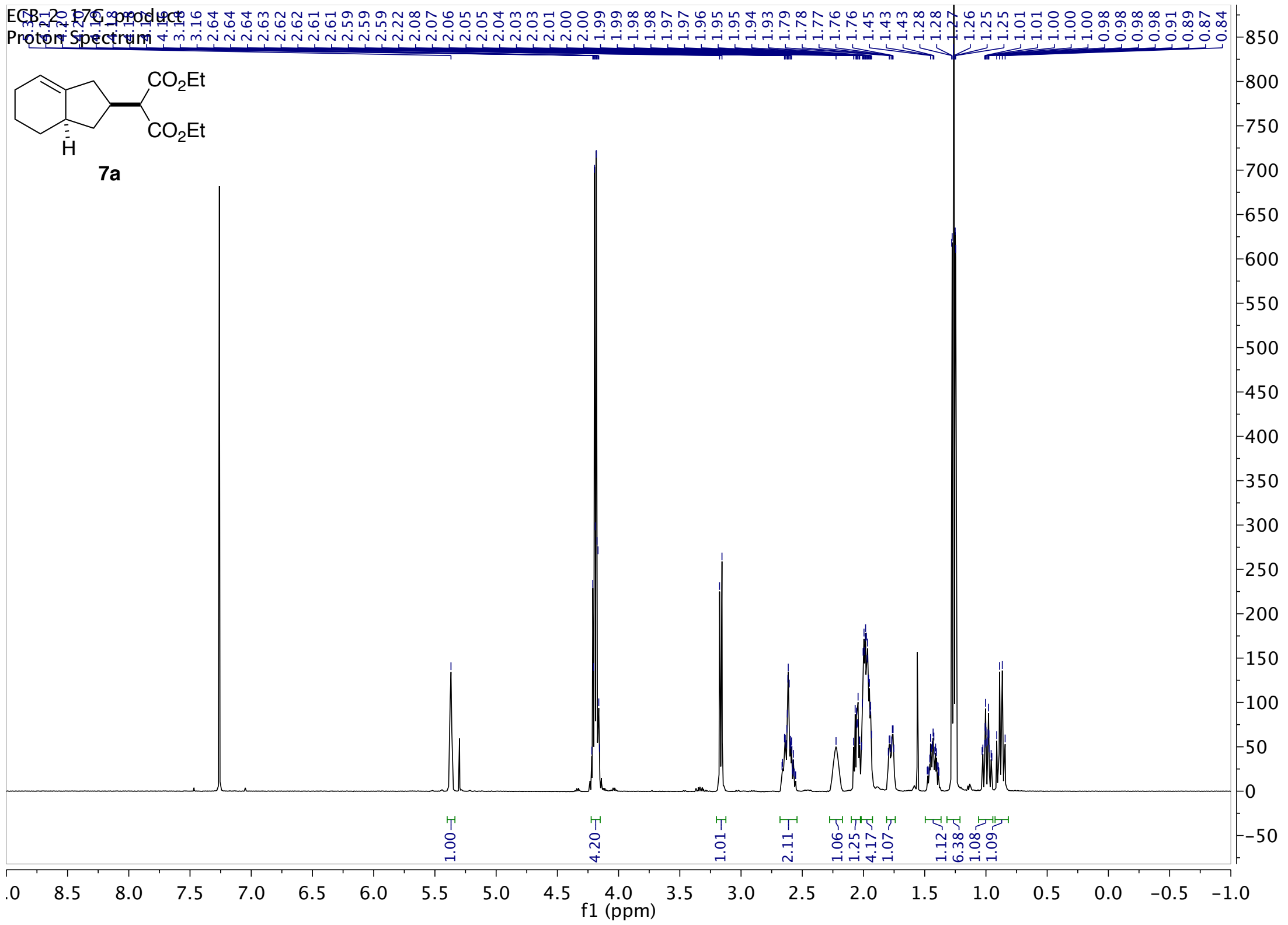




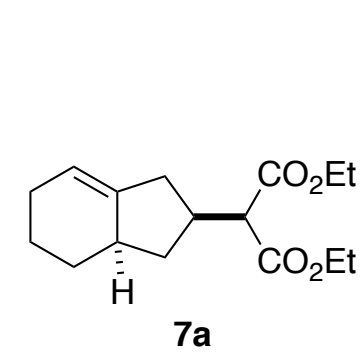

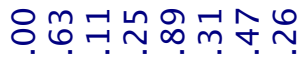

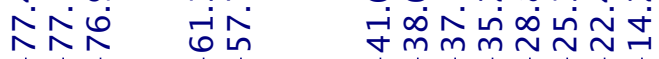
$\mathrm{O}_{2} \mathrm{Et}$

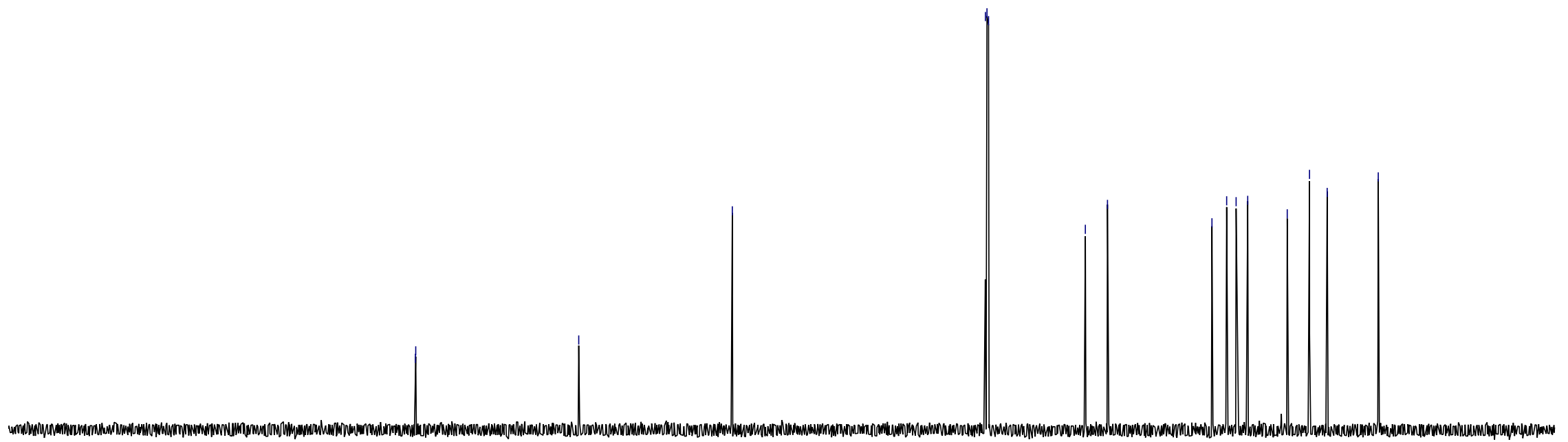

2302 $\begin{array}{llll}210 & 200 & 190 & 180\end{array}$ 


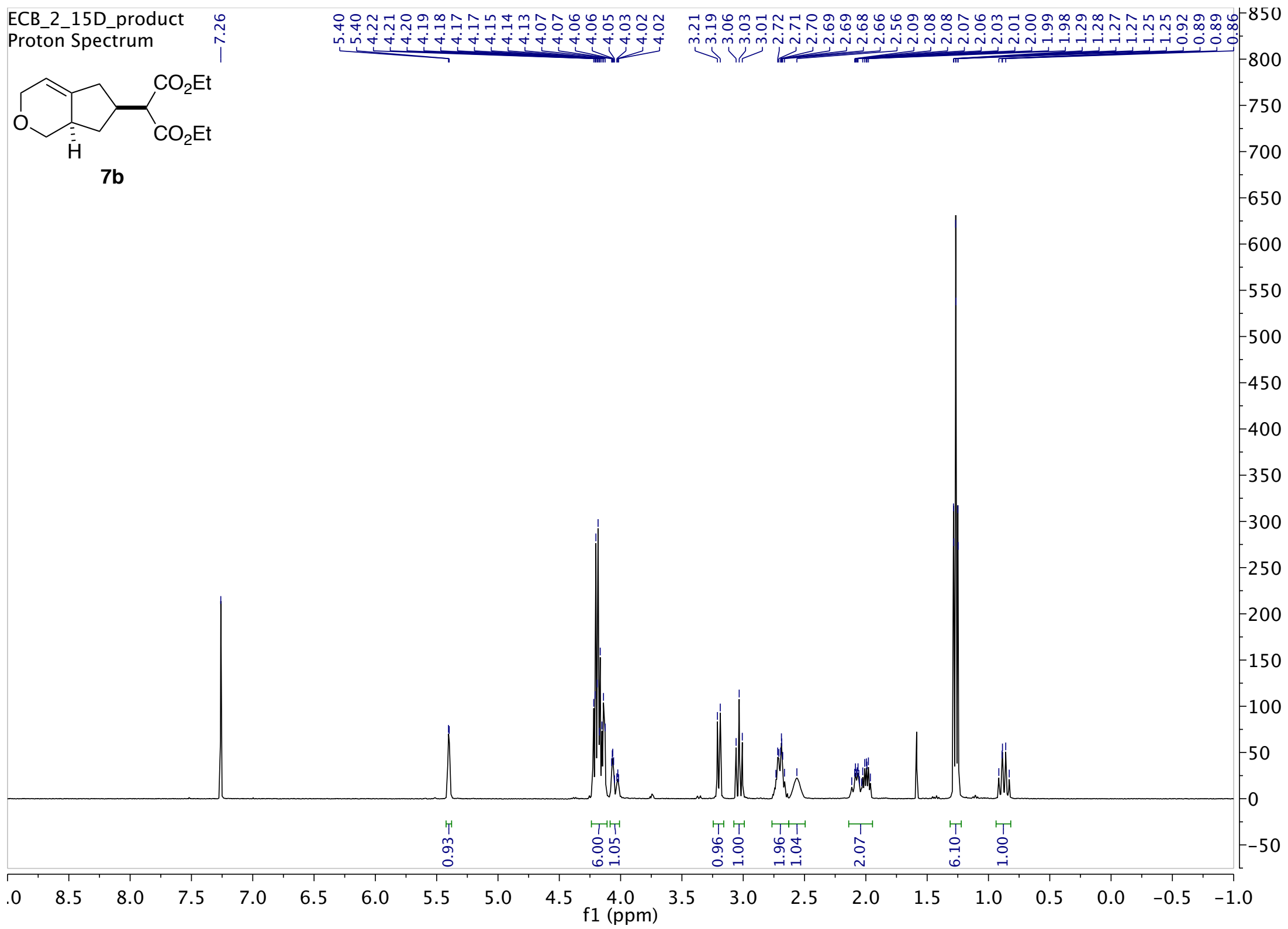




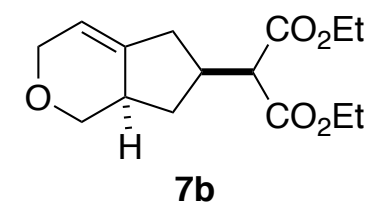

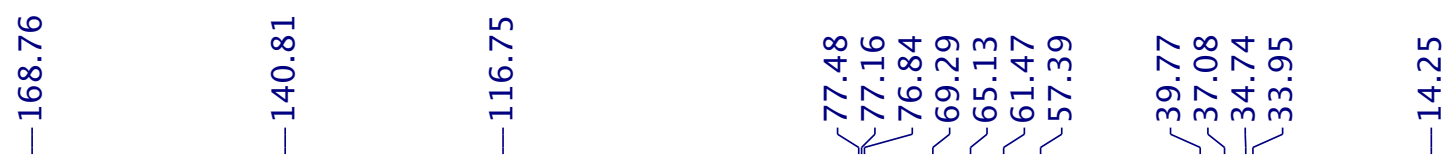

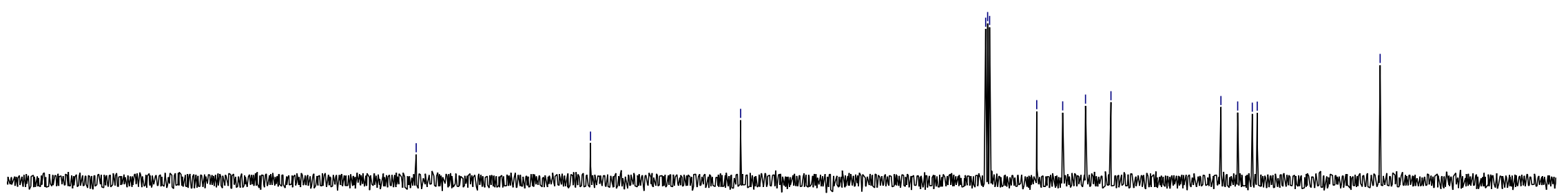
$\begin{array}{lllllllllllllllllllllllllllllllll}230 & 220 & 210 & 200 & 190 & 180 & 170 & 160 & 150 & 140 & 130 & 120 & 110 & 100 & 90 & 80 & 70 & 60 & 50 & 40 & 30 & 20 & 10 & 0 & -10\end{array}$ 


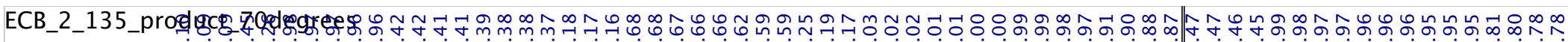
nं

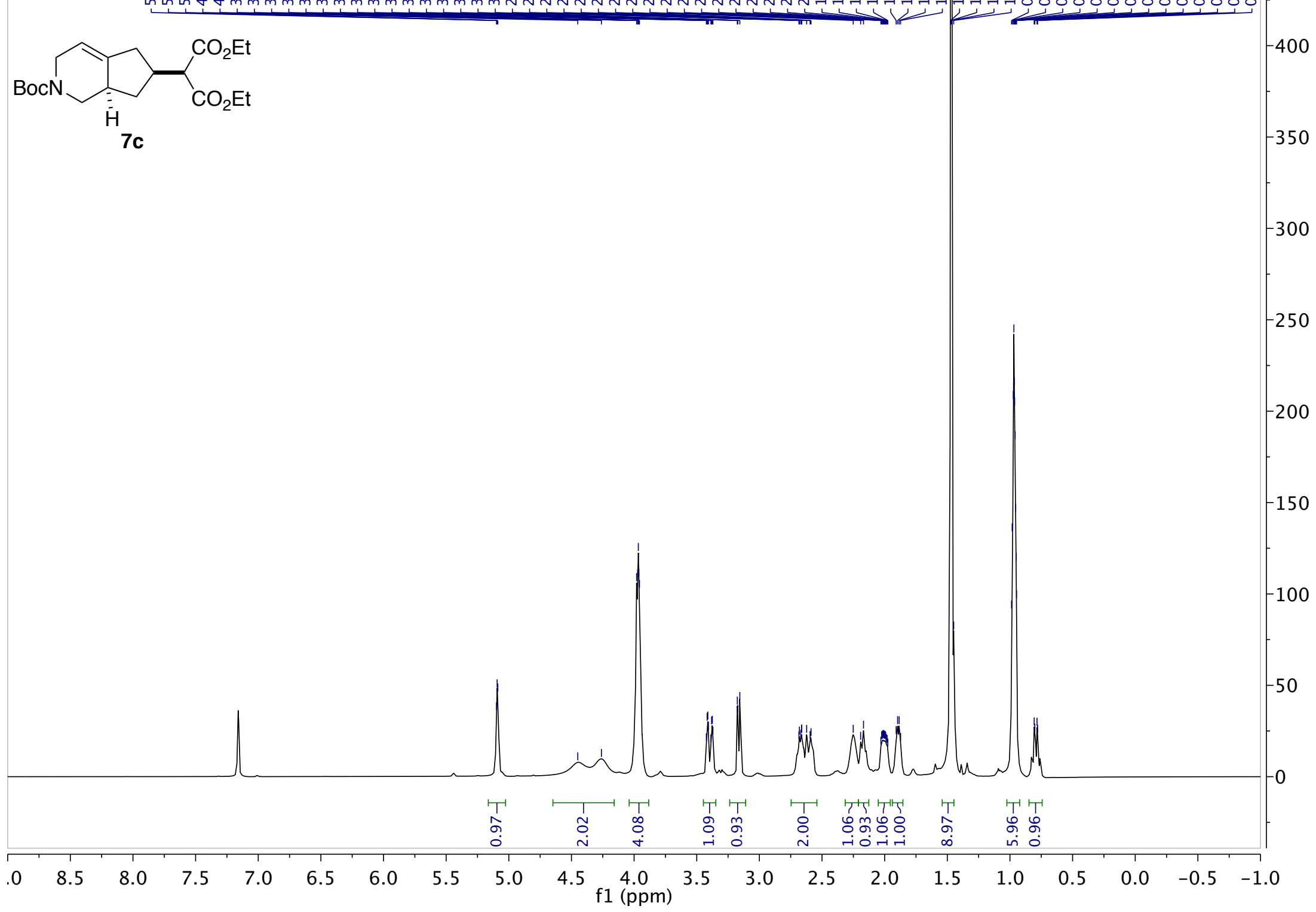




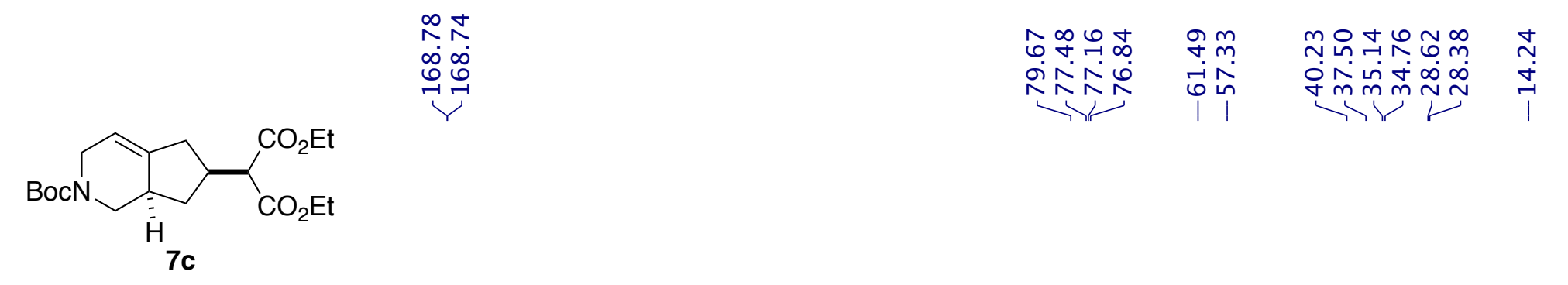

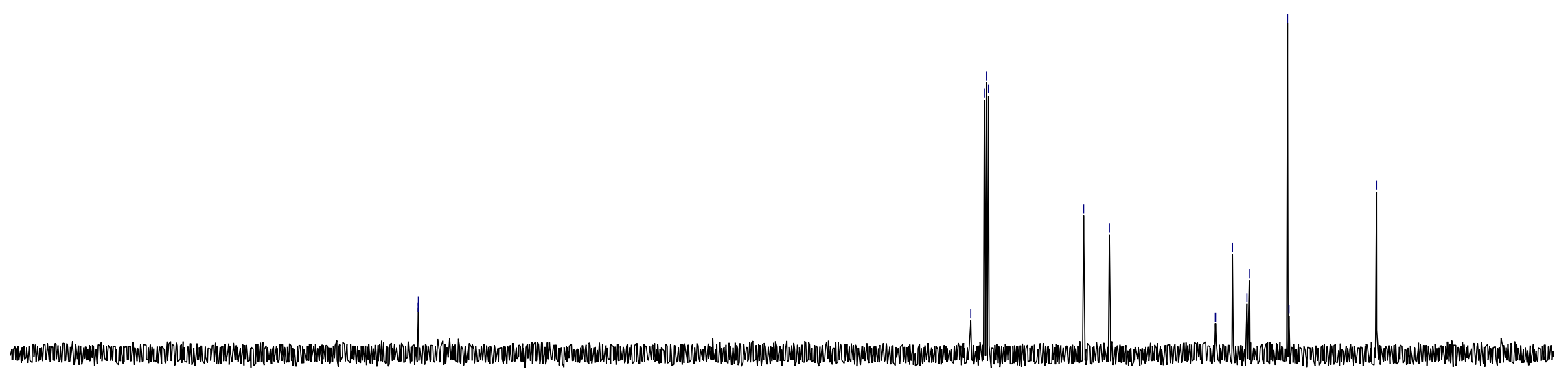

$\begin{array}{lllllllllllllllllllllllllllllllllll}230 & 220 & 210 & 200 & 190 & 180 & 170 & 160 & 150 & 140 & 130 & 120 & 110 & 100 & 90 & 80 & 70 & 60 & 50 & 40 & 30 & 20 & 10 & 0 & -10\end{array}$ 


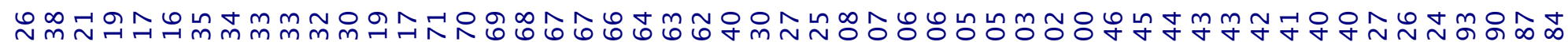

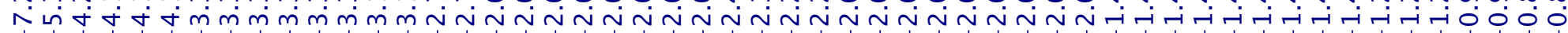
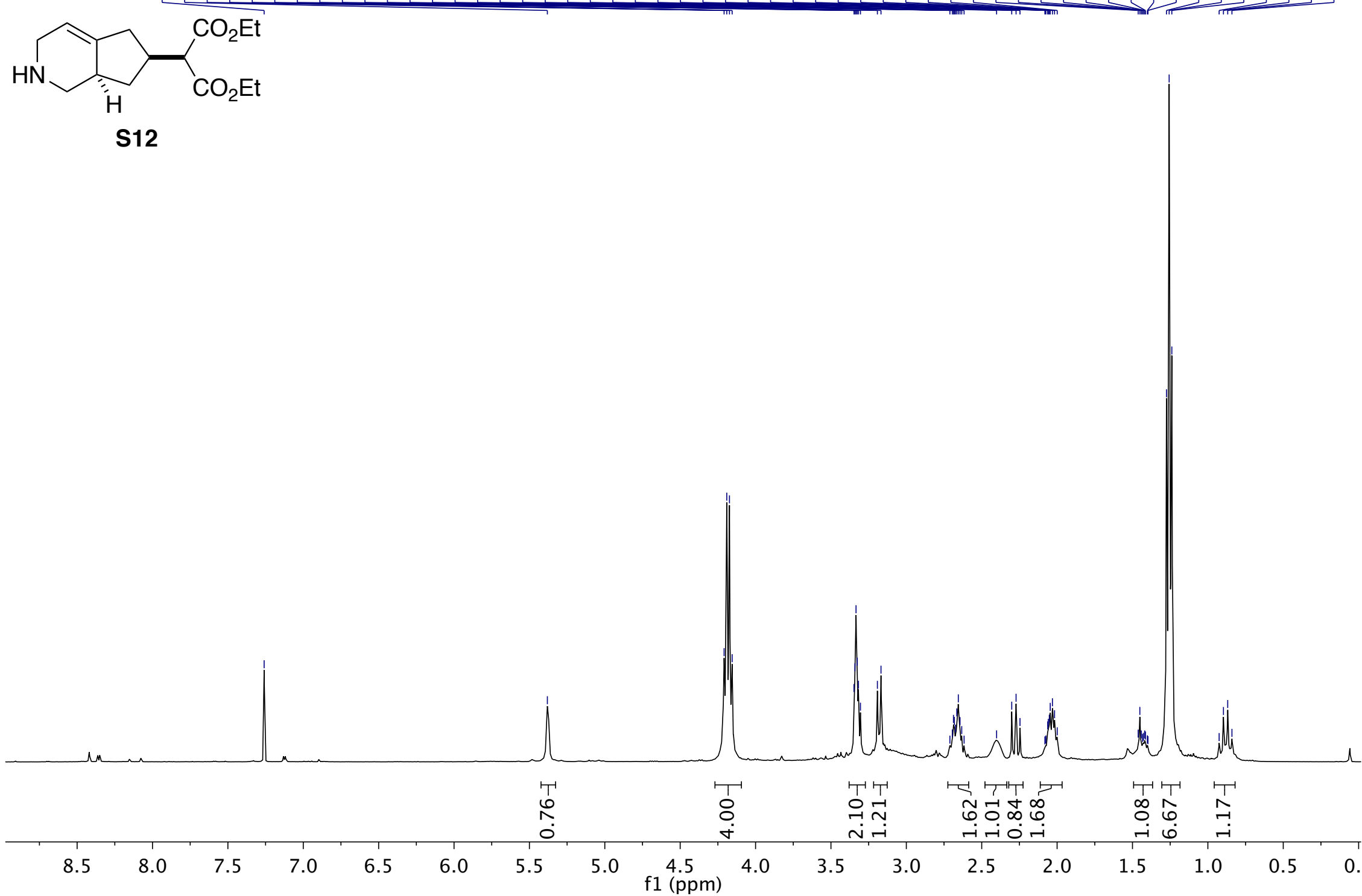

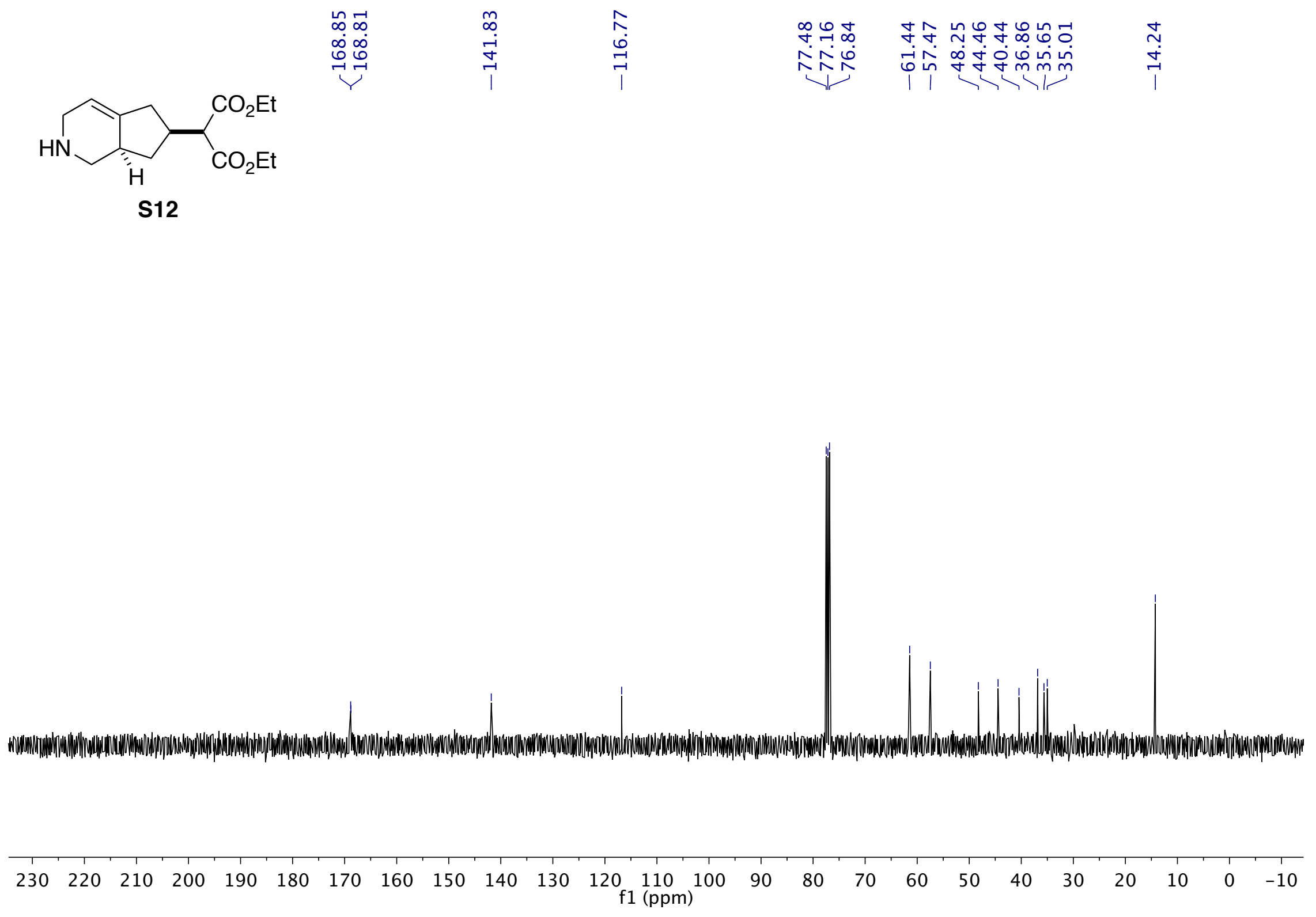


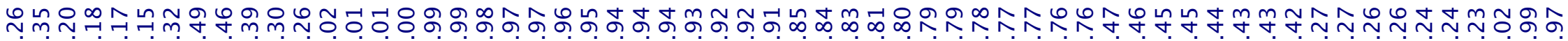
Nं

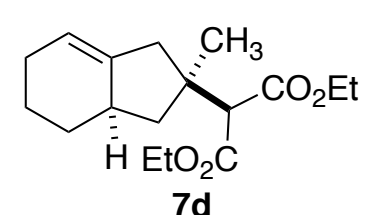

7d

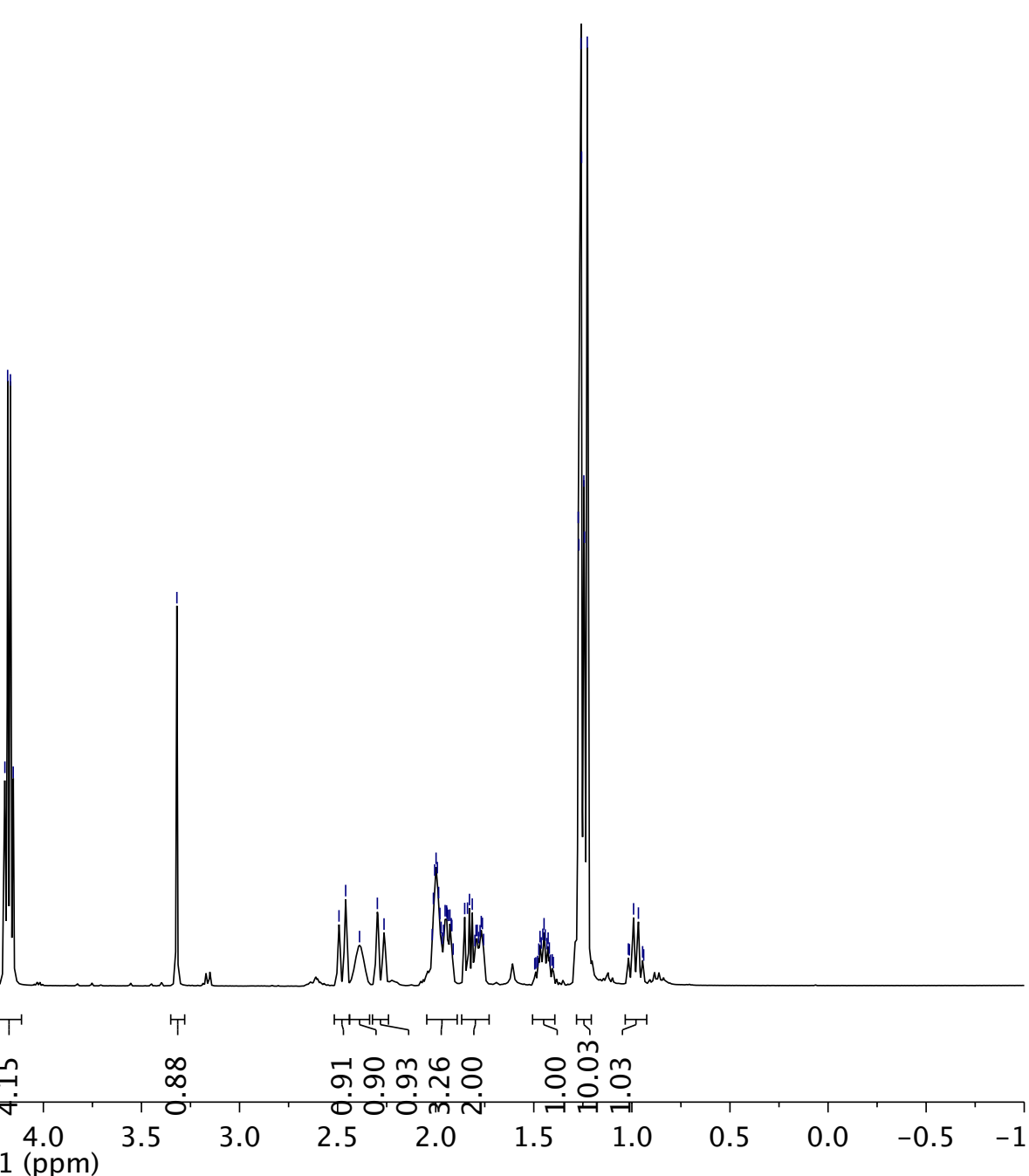



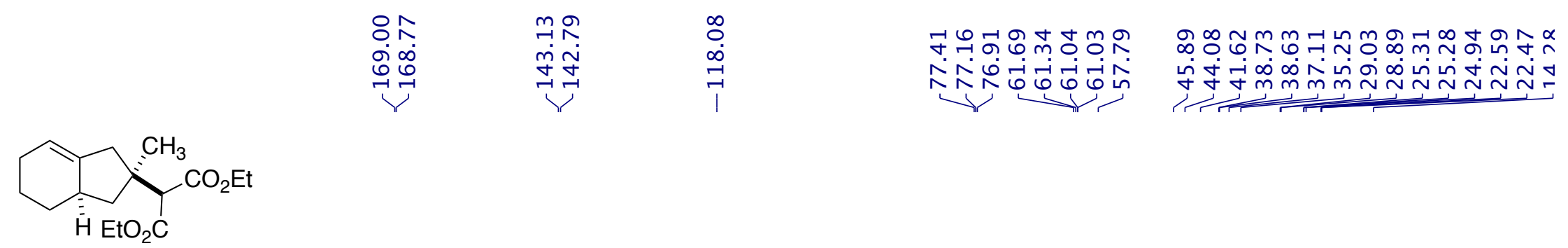

7d

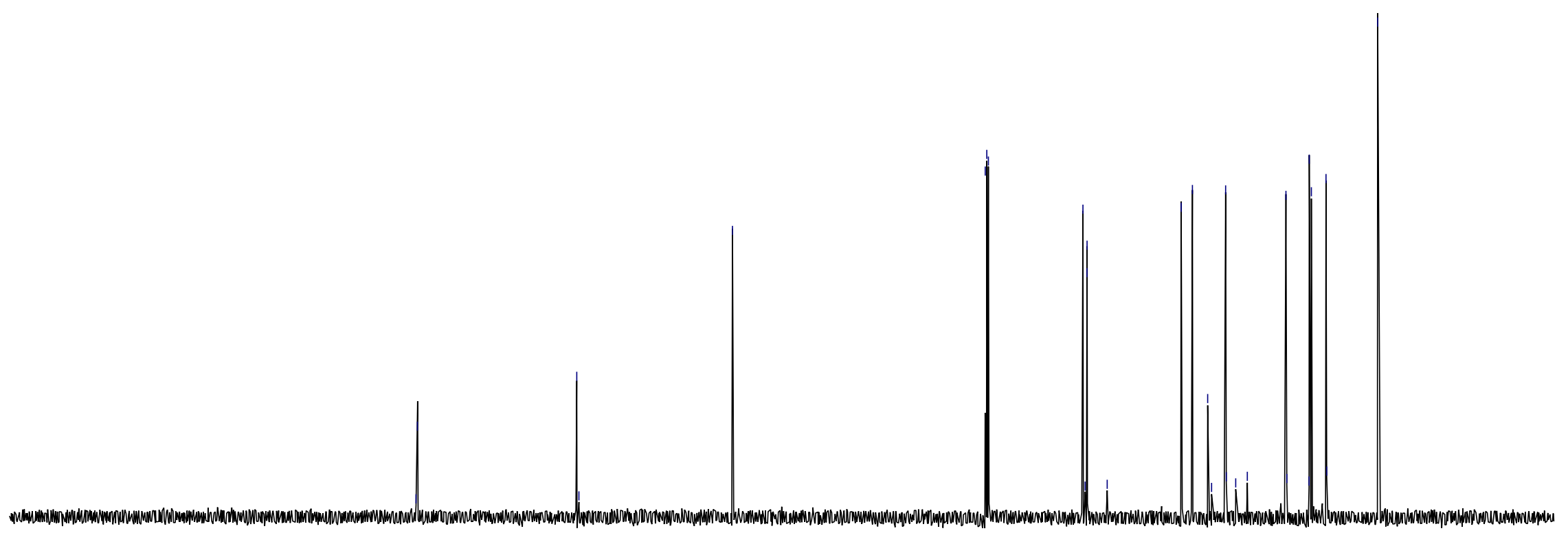




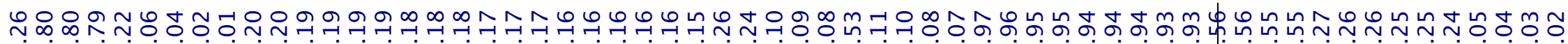

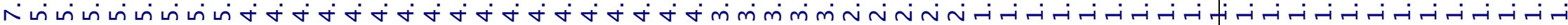
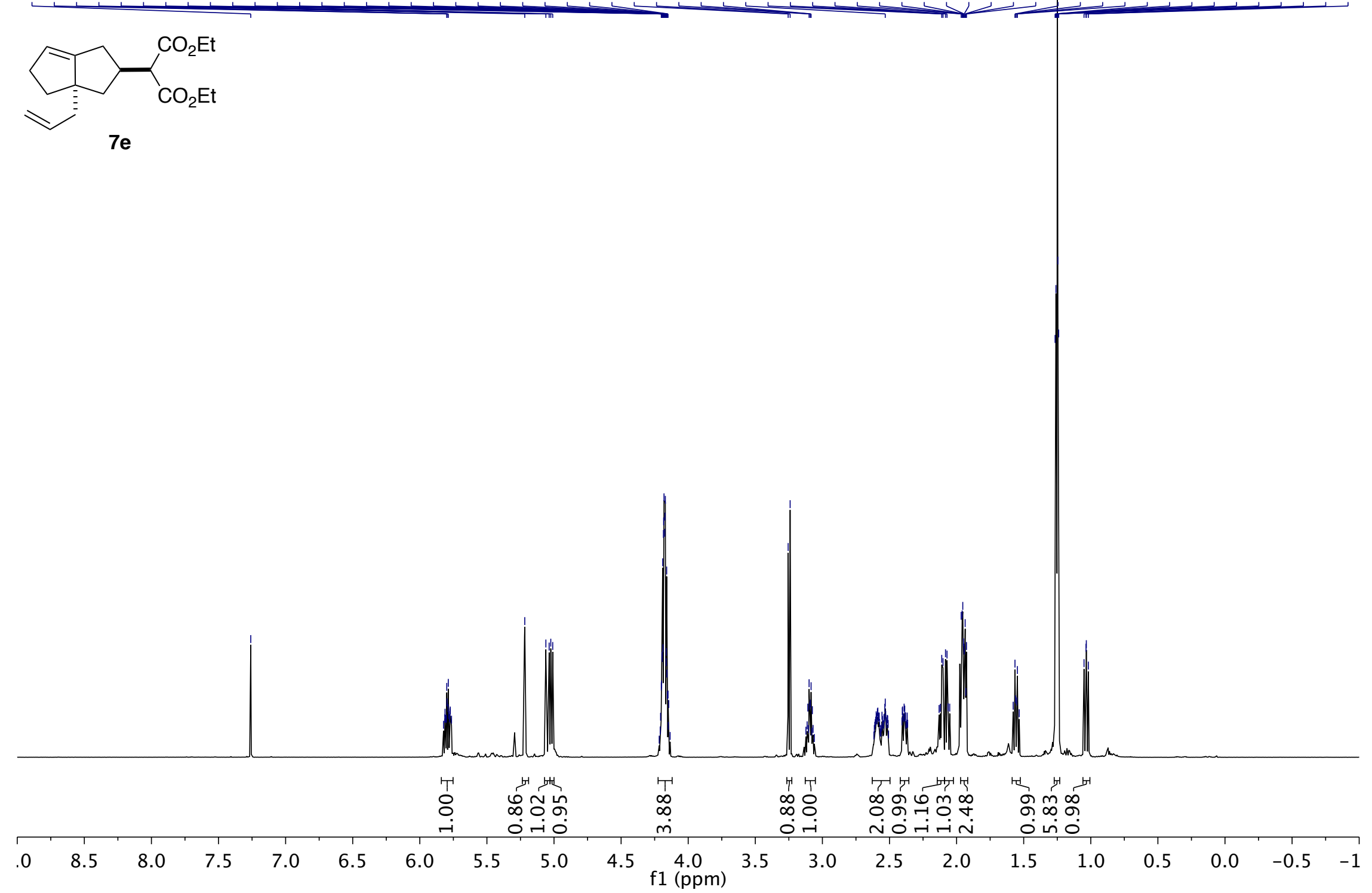

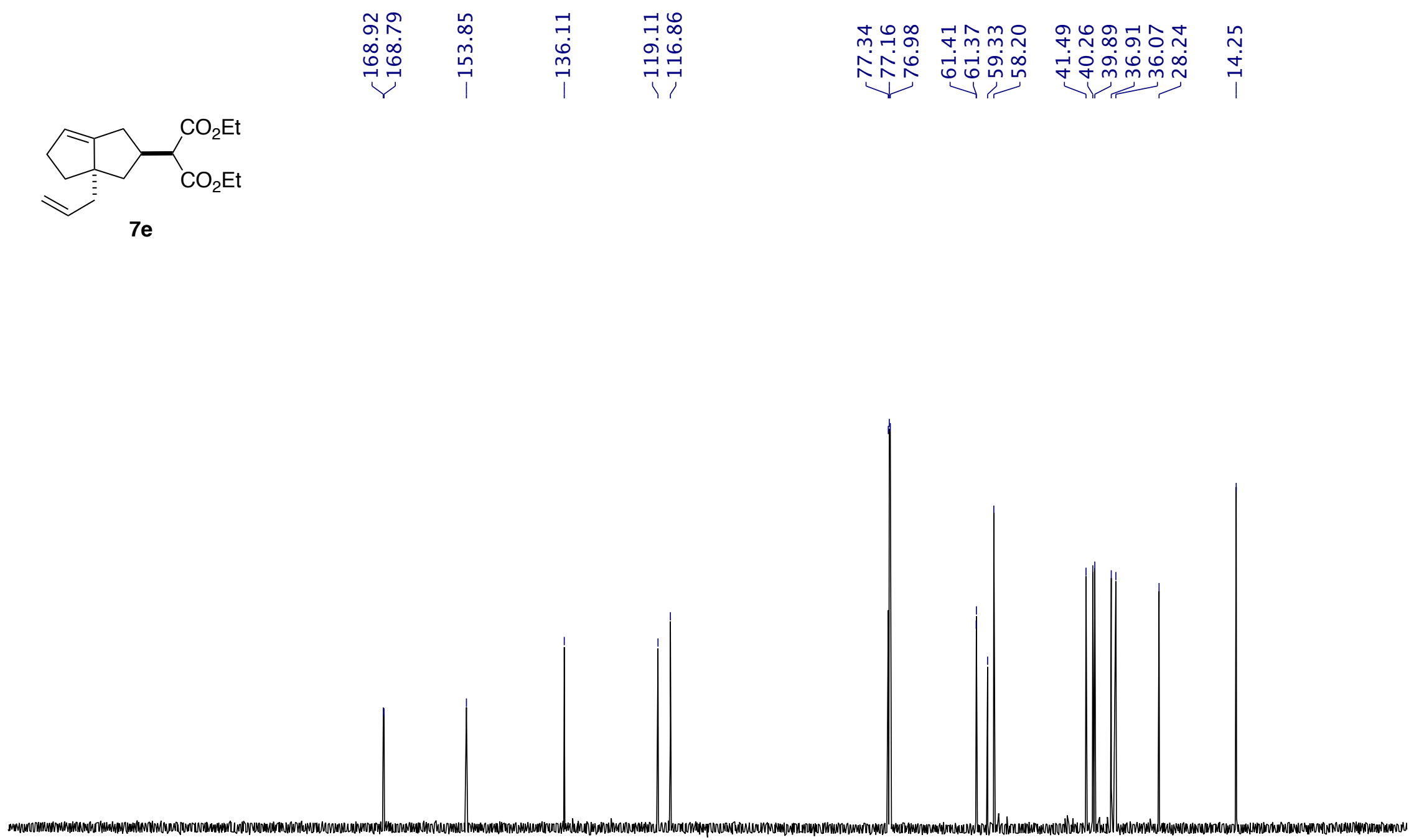

$\begin{array}{lllllllllllllllllllllllllllll}230 & 220 & 210 & 200 & 190 & 180 & 170 & 160 & 150 & 140 & 130 & 120 & 110 & 100 & 90 & 80 & 70 & 60 & 50 & 40 & 30 & 20 & 10 & 0 & -10\end{array}$ 


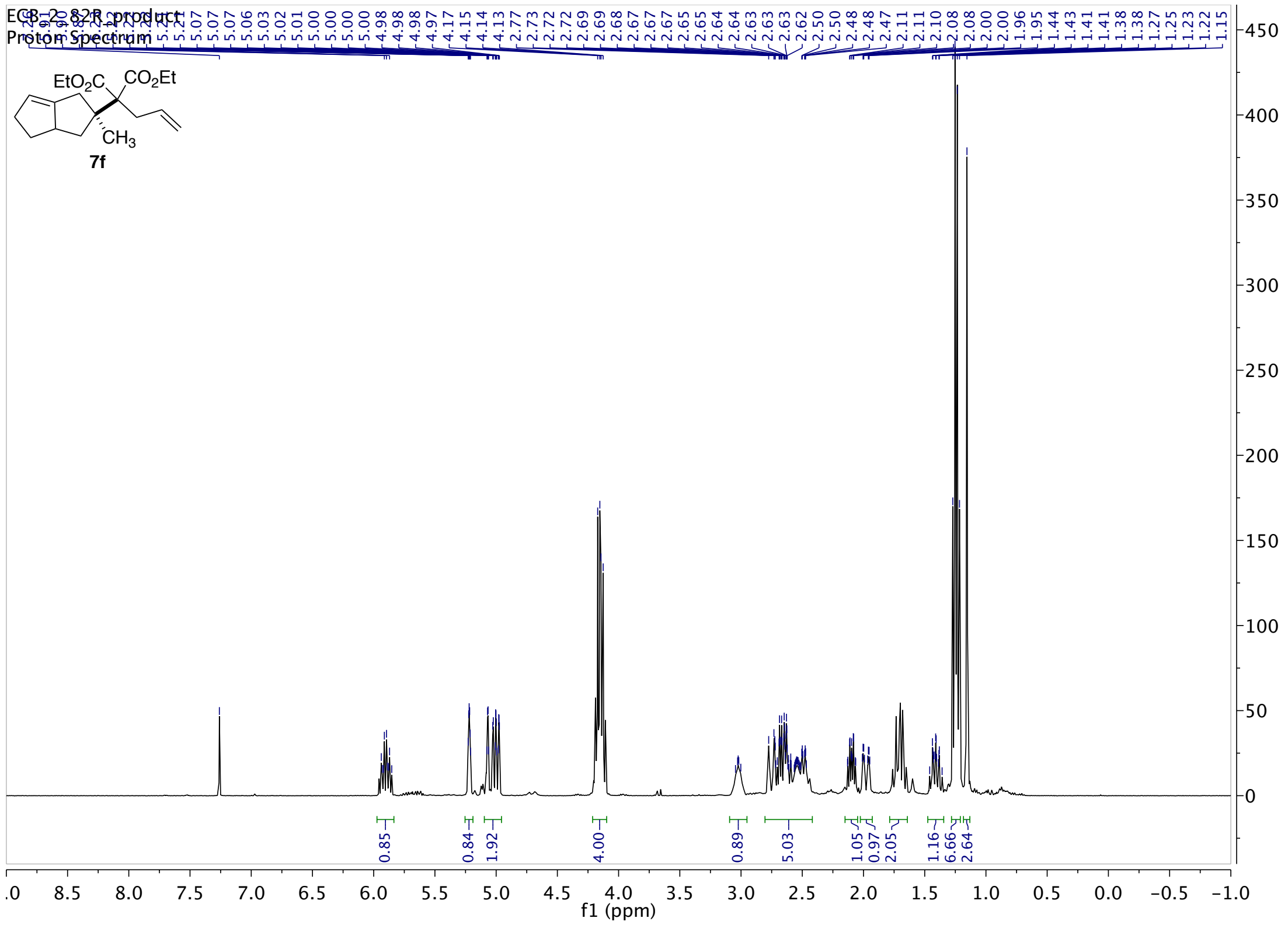




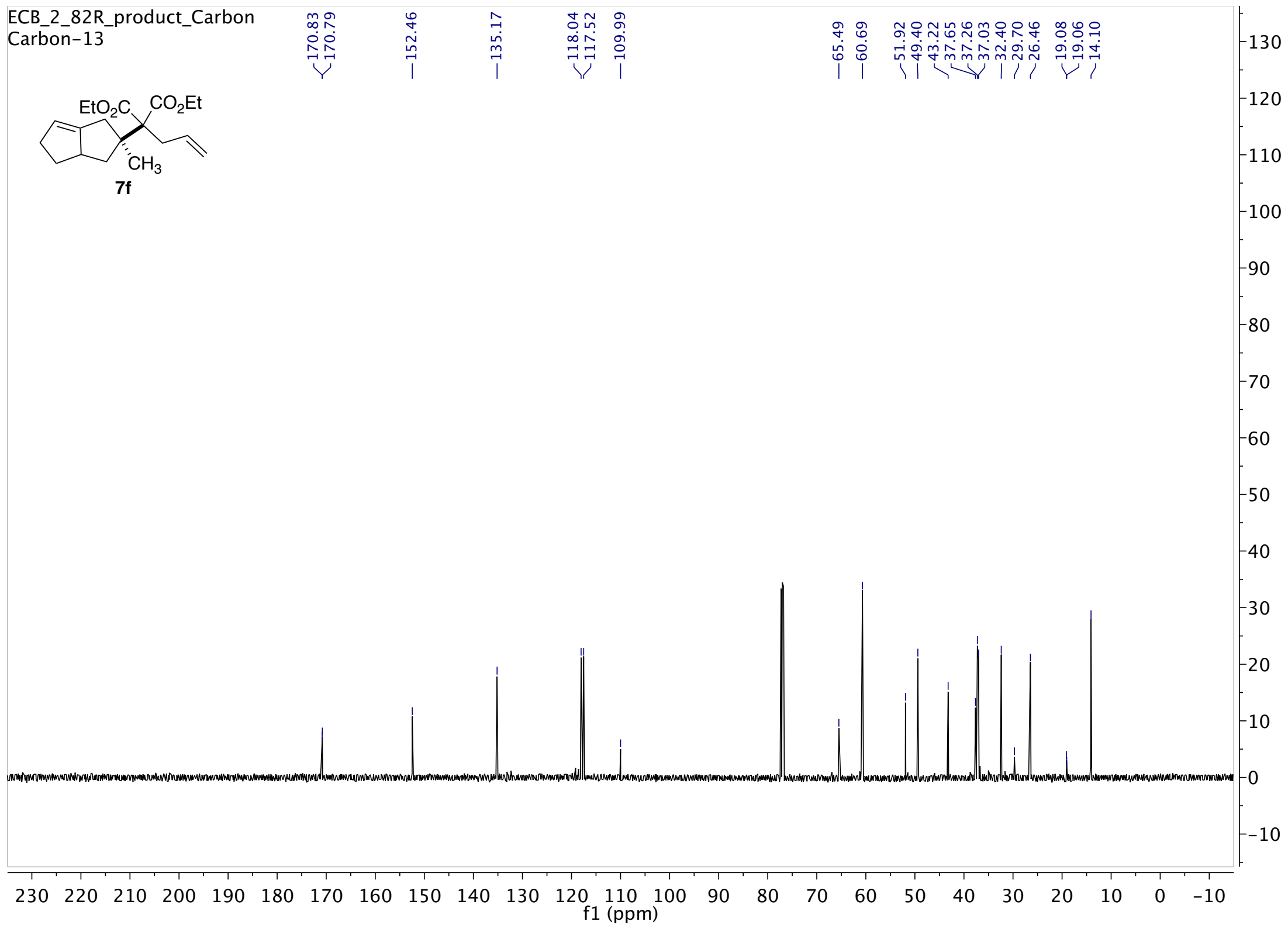




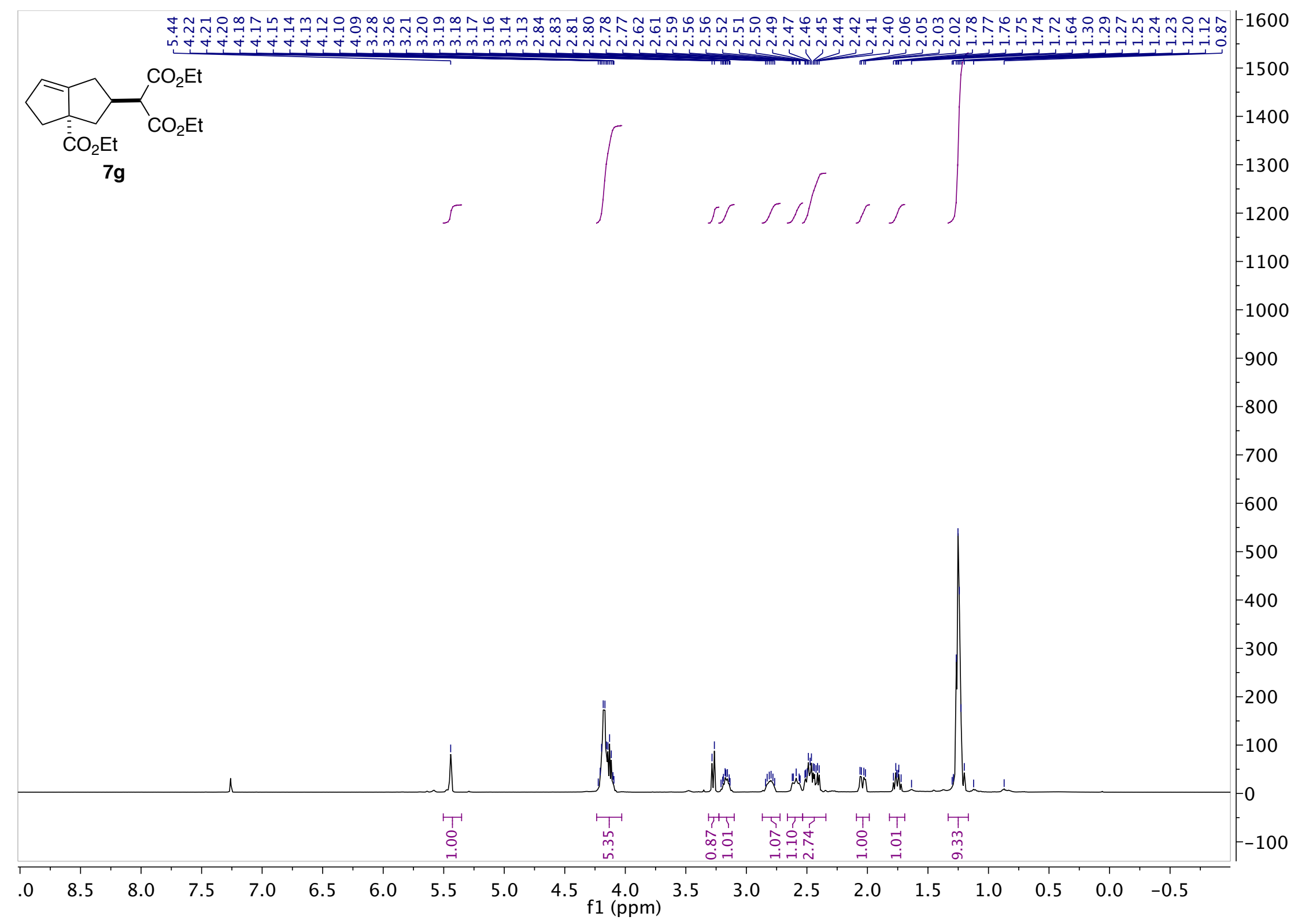




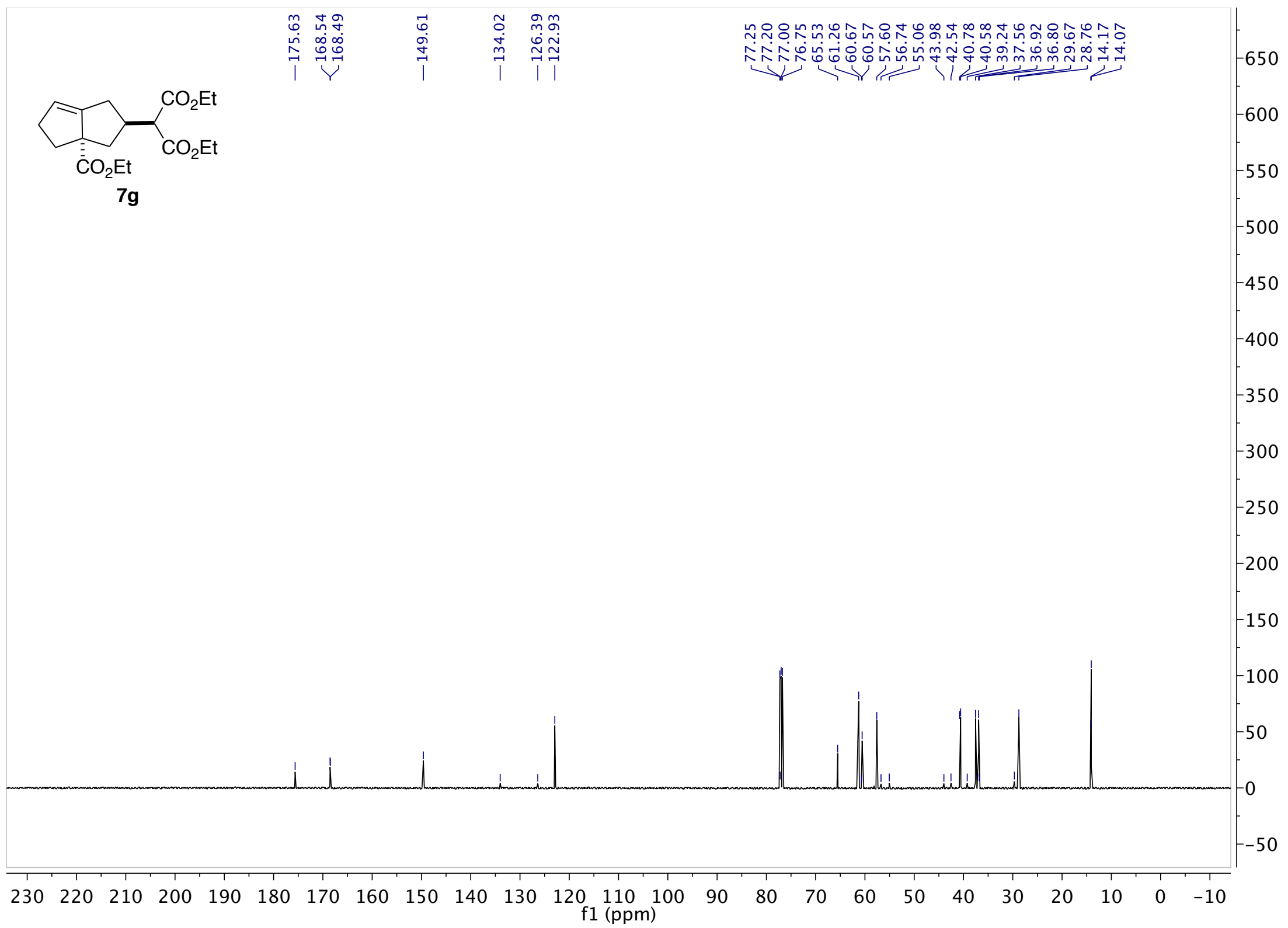




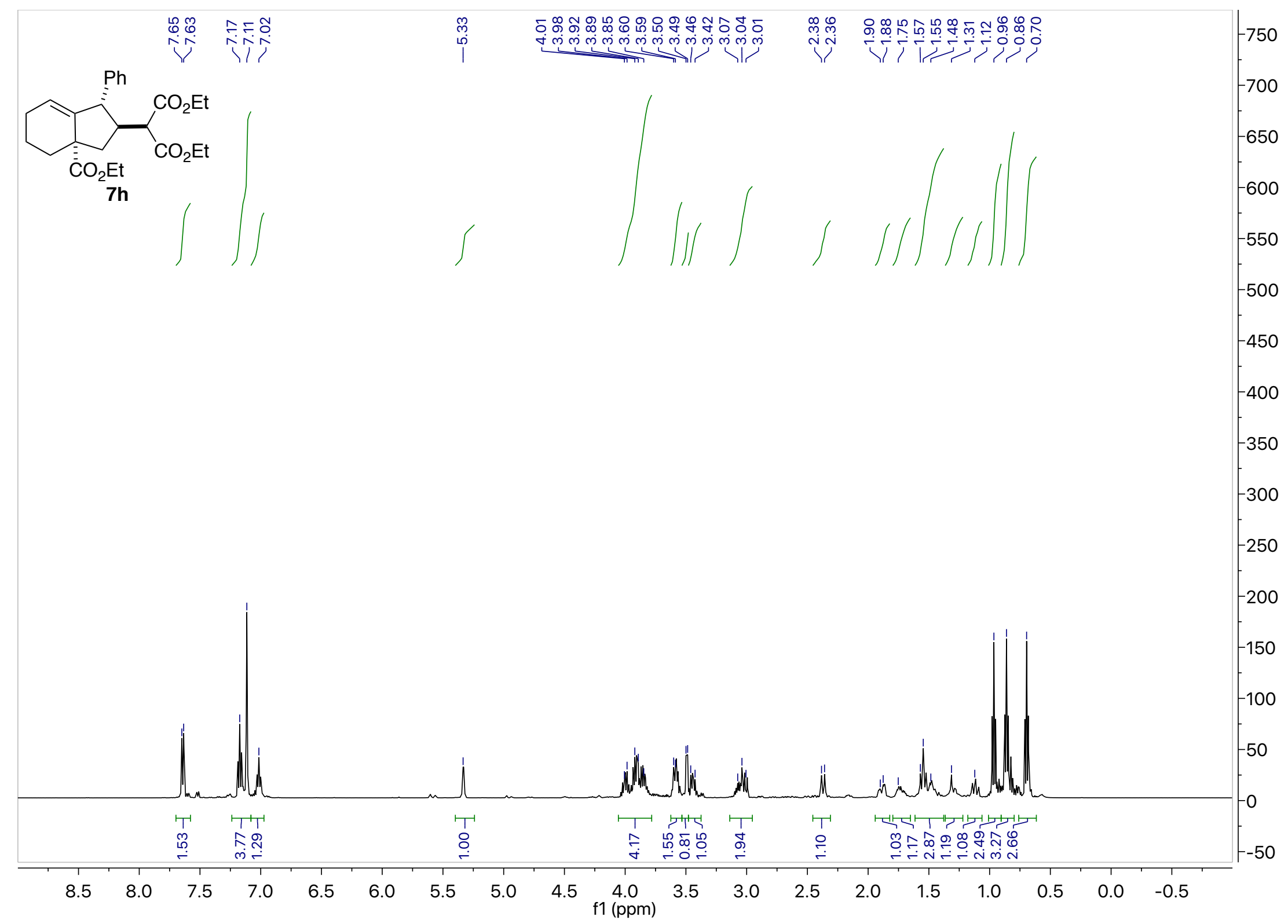




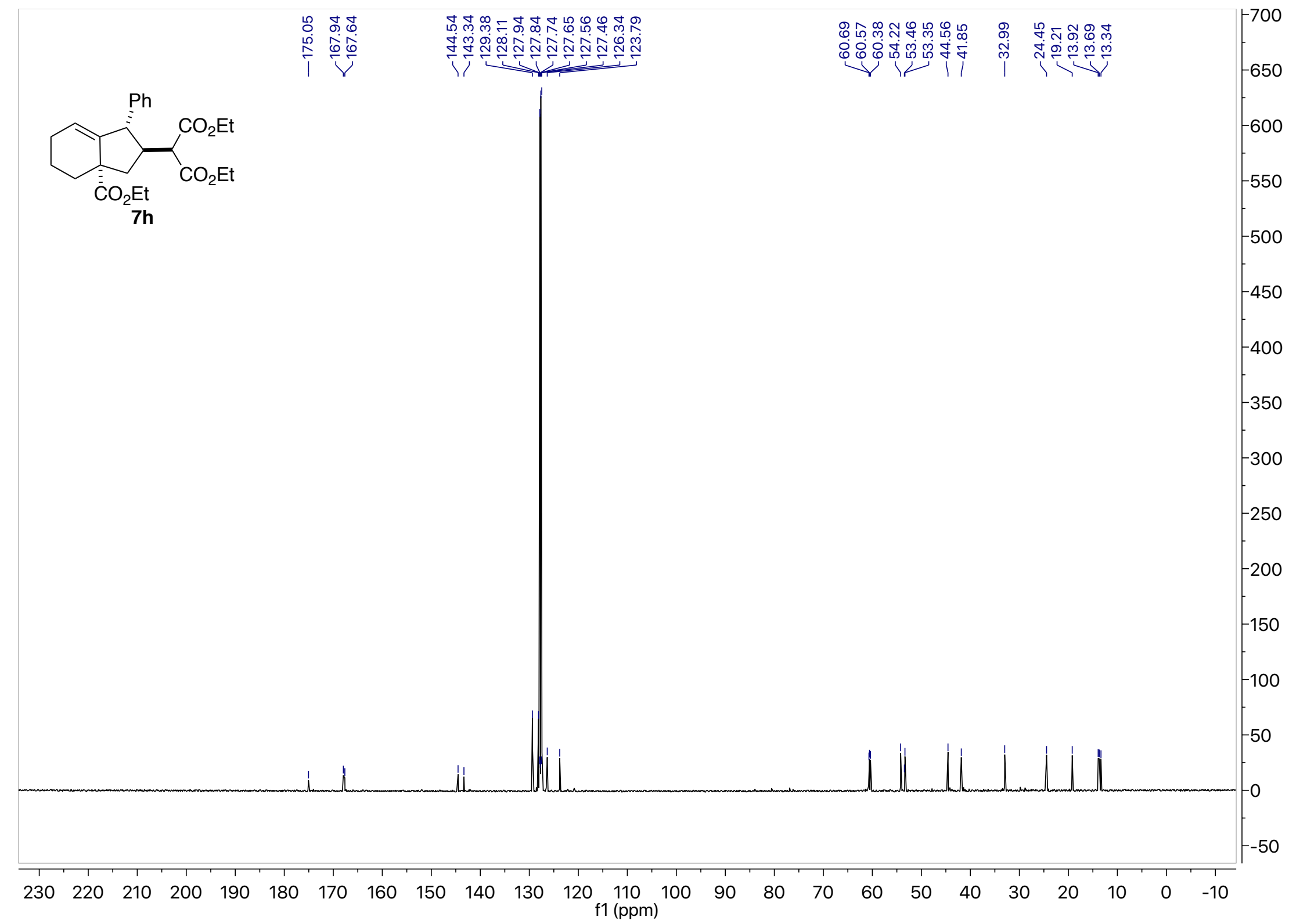




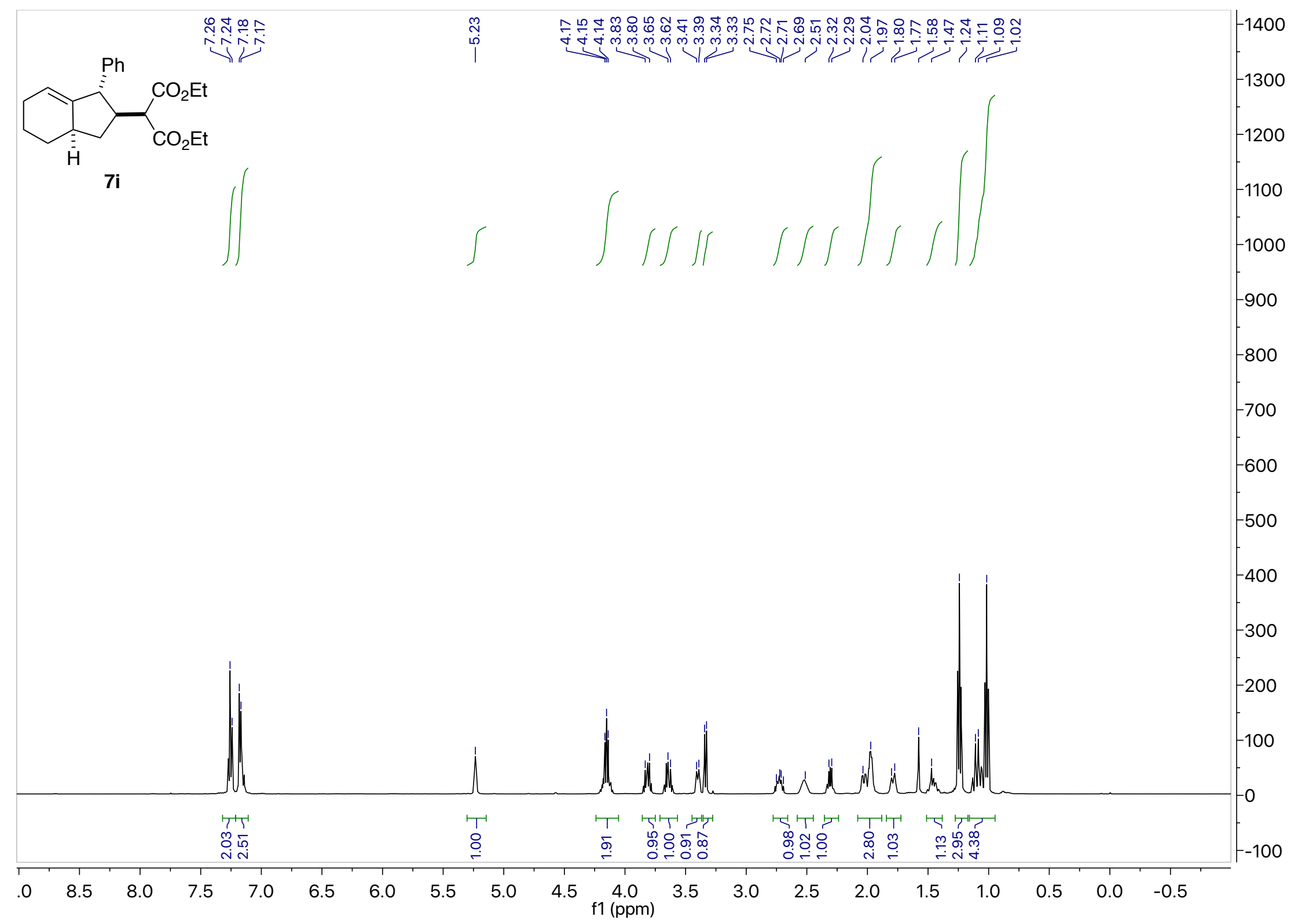




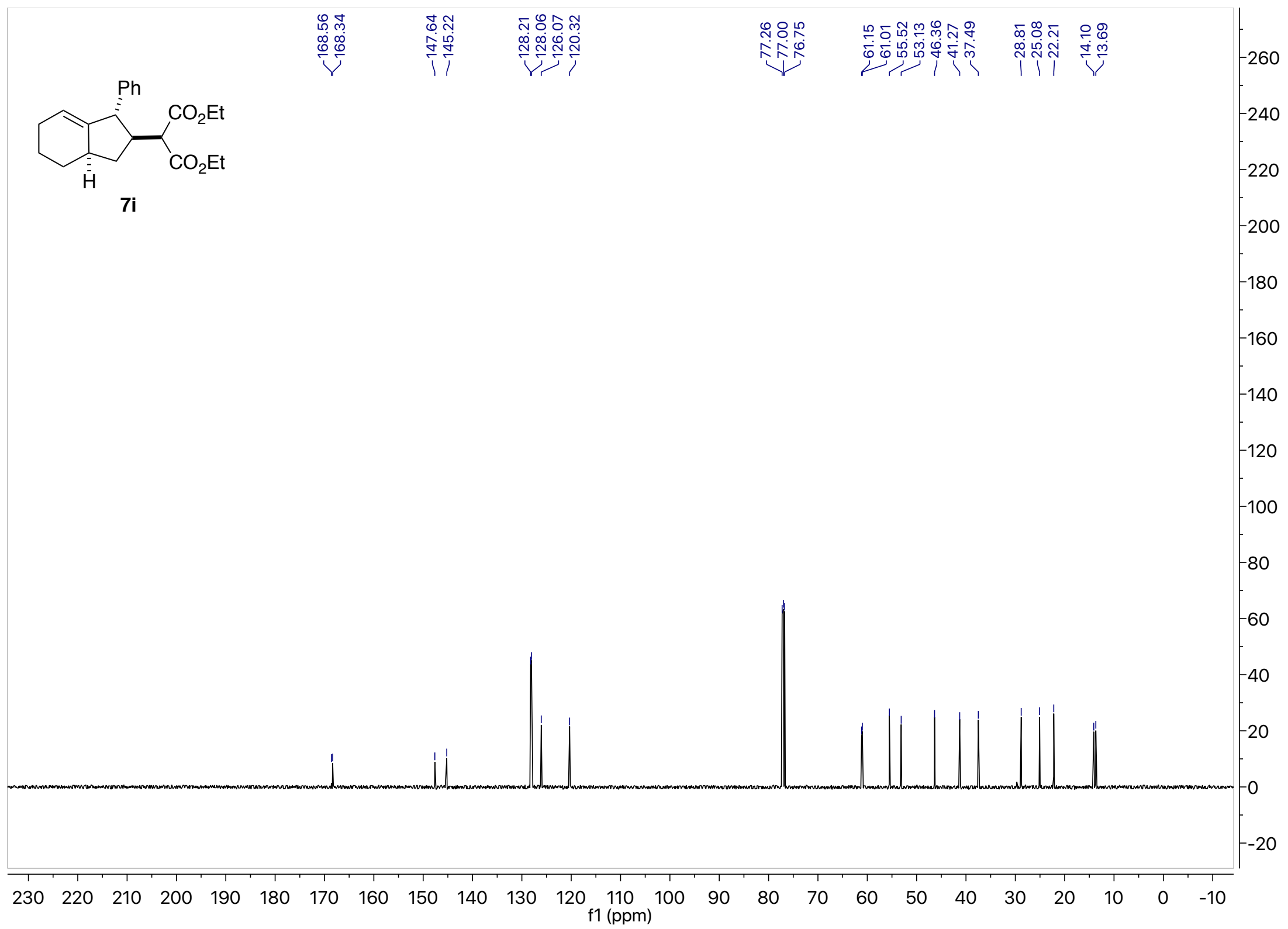




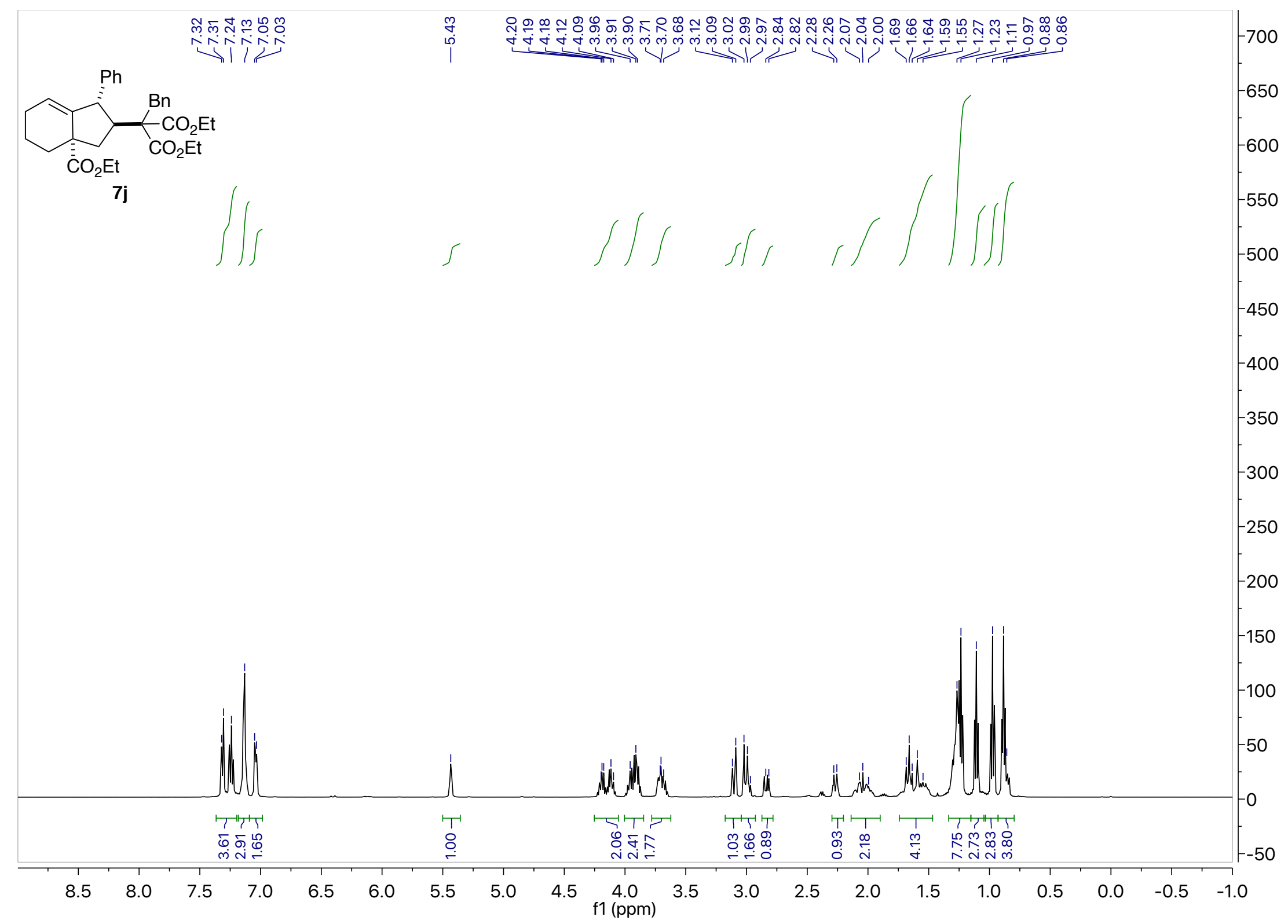




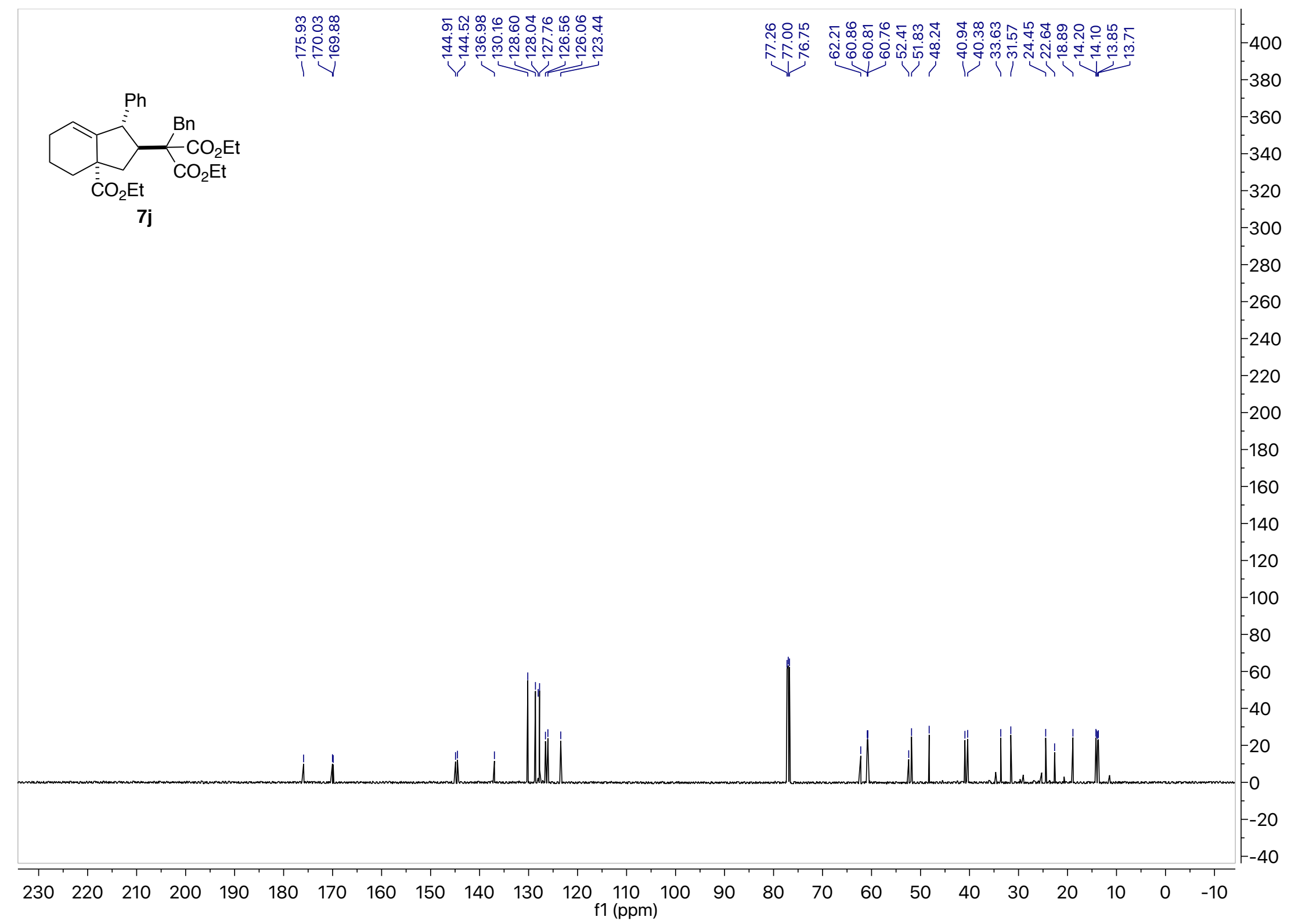




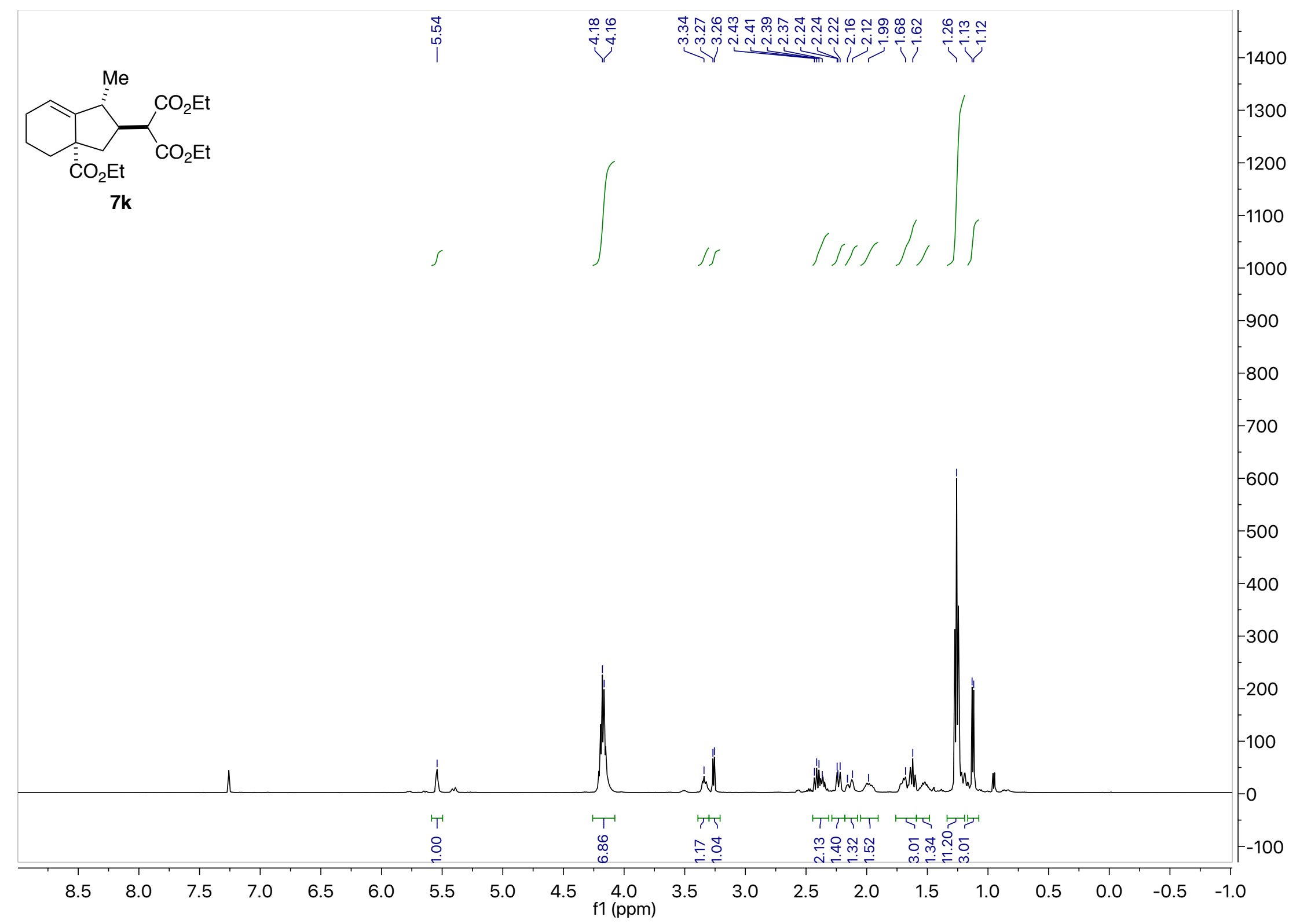




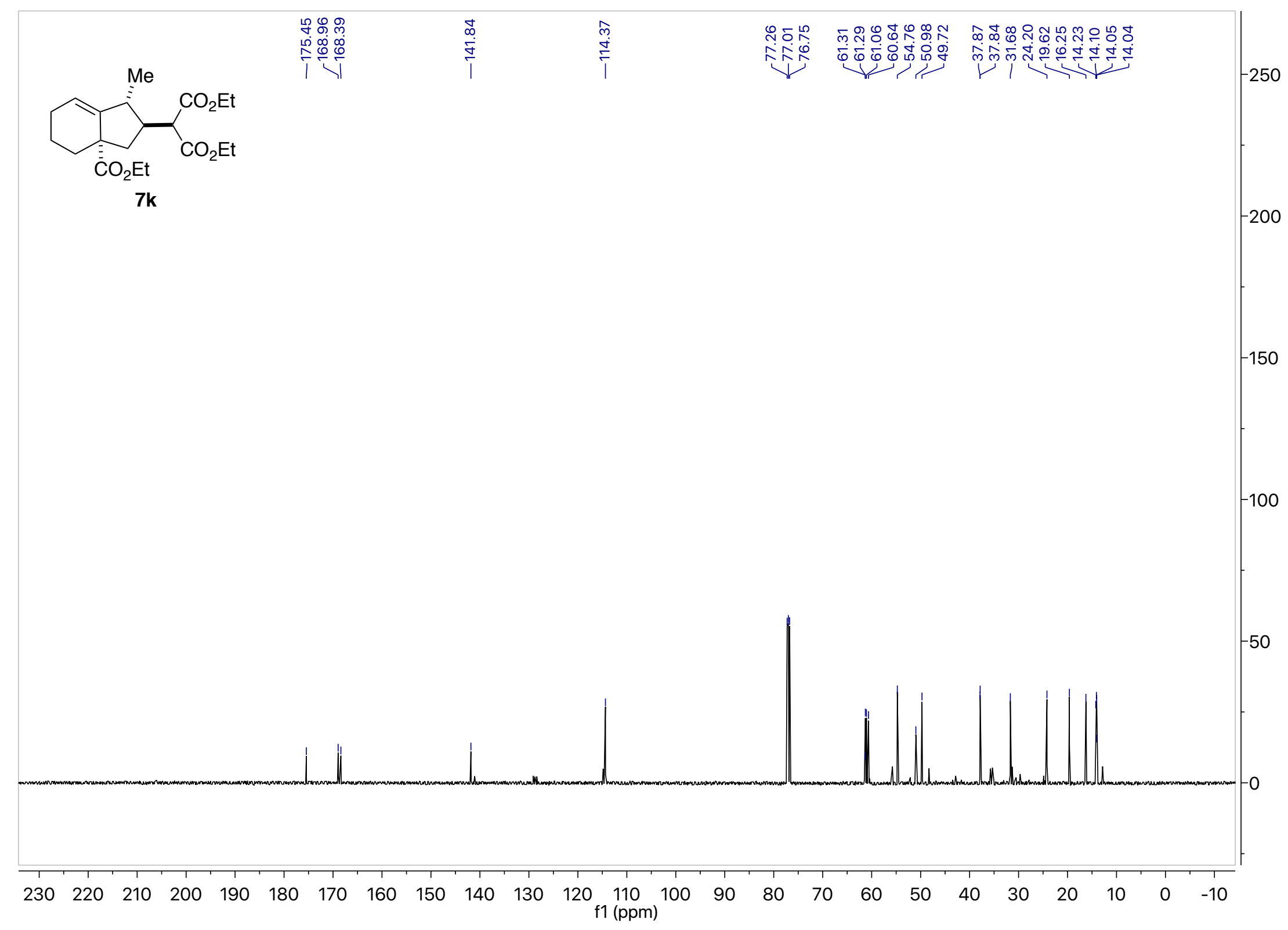




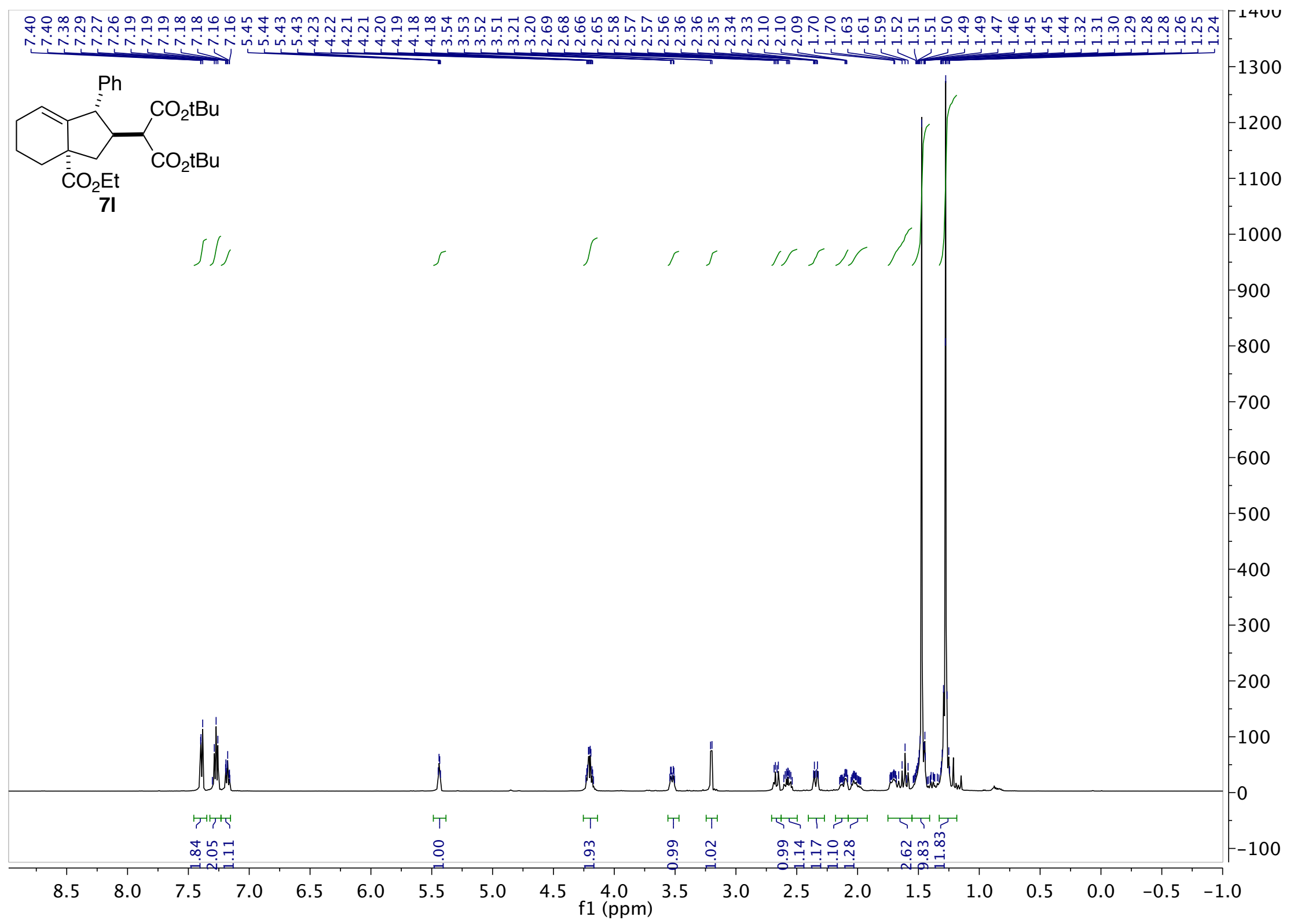




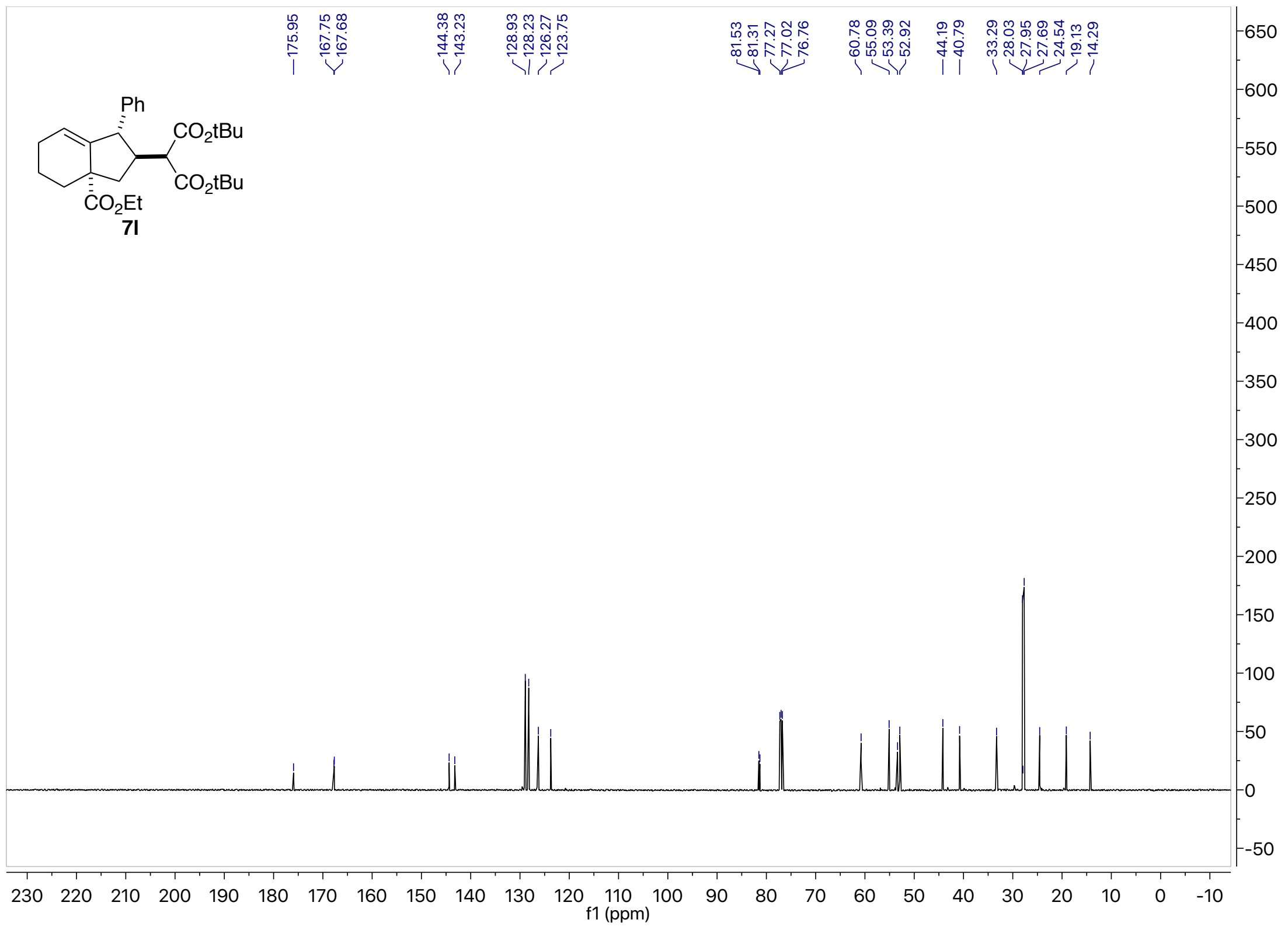




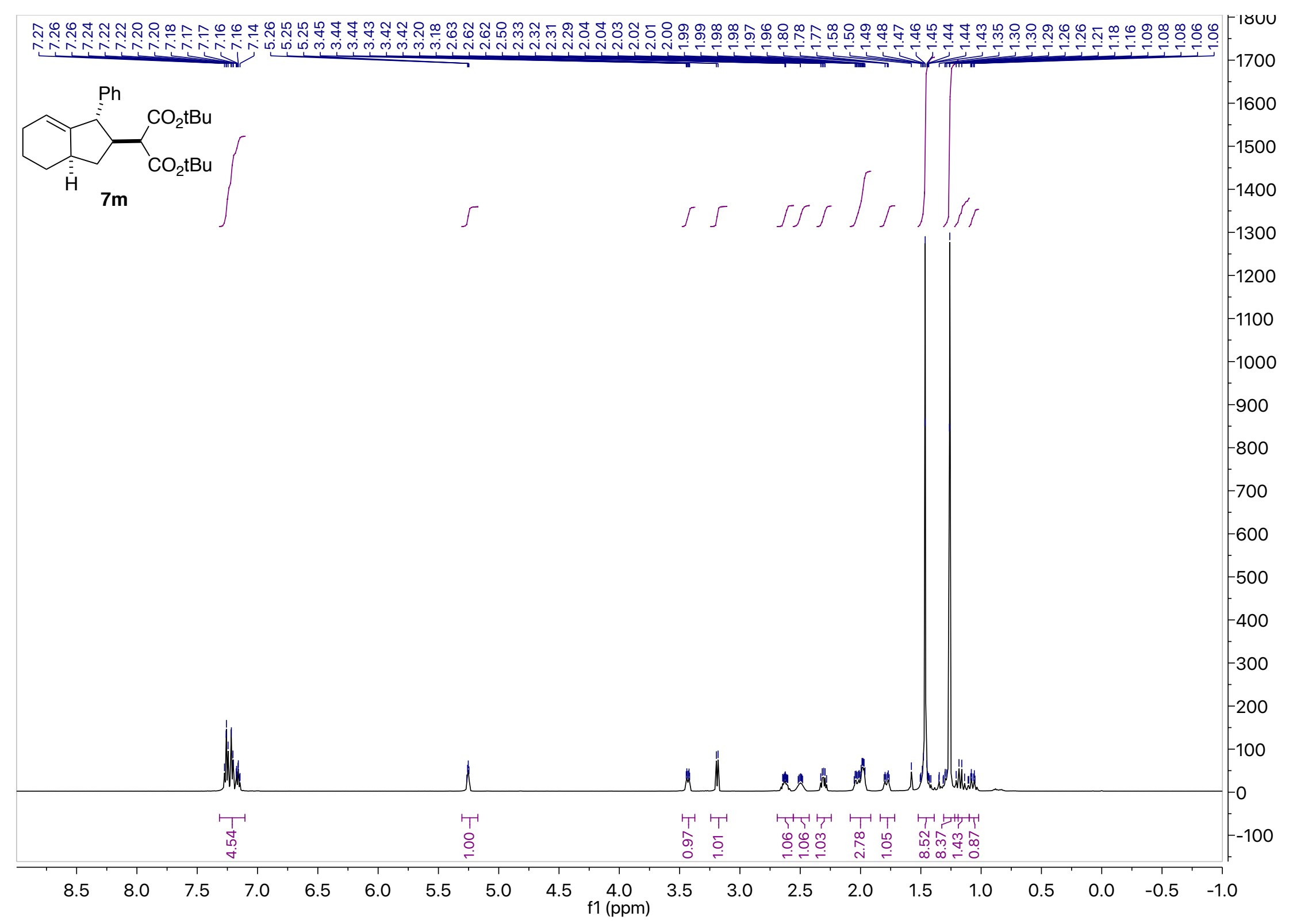




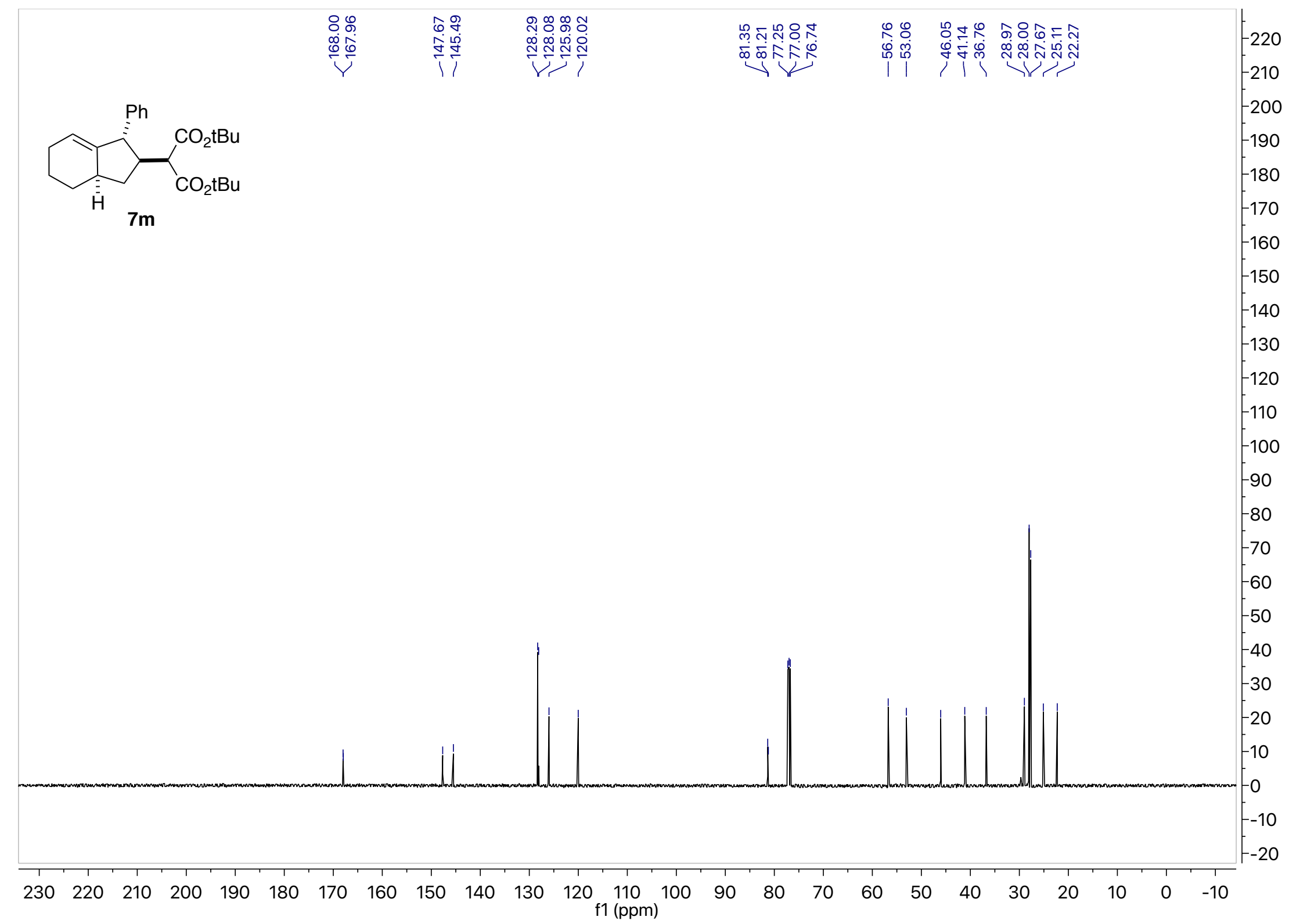




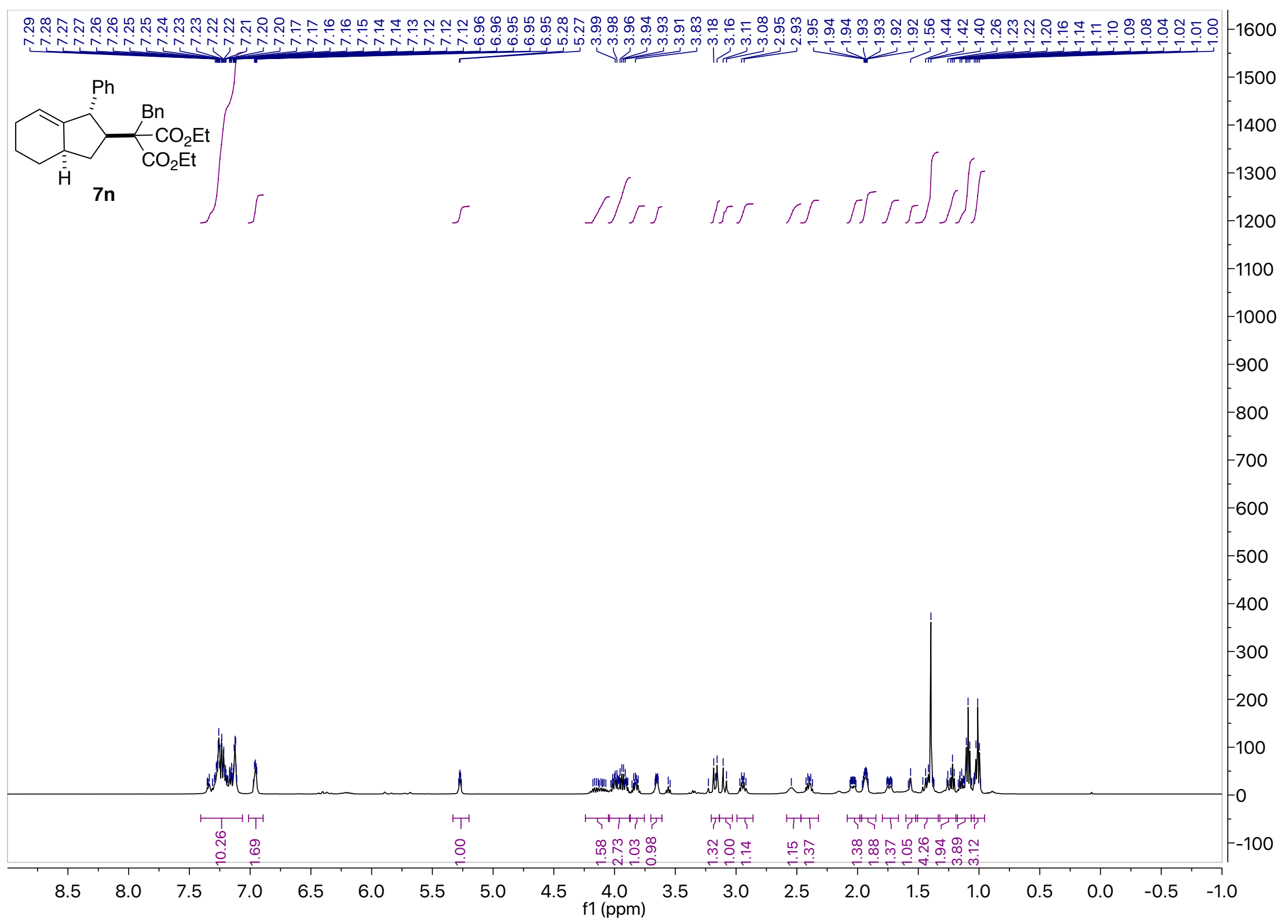




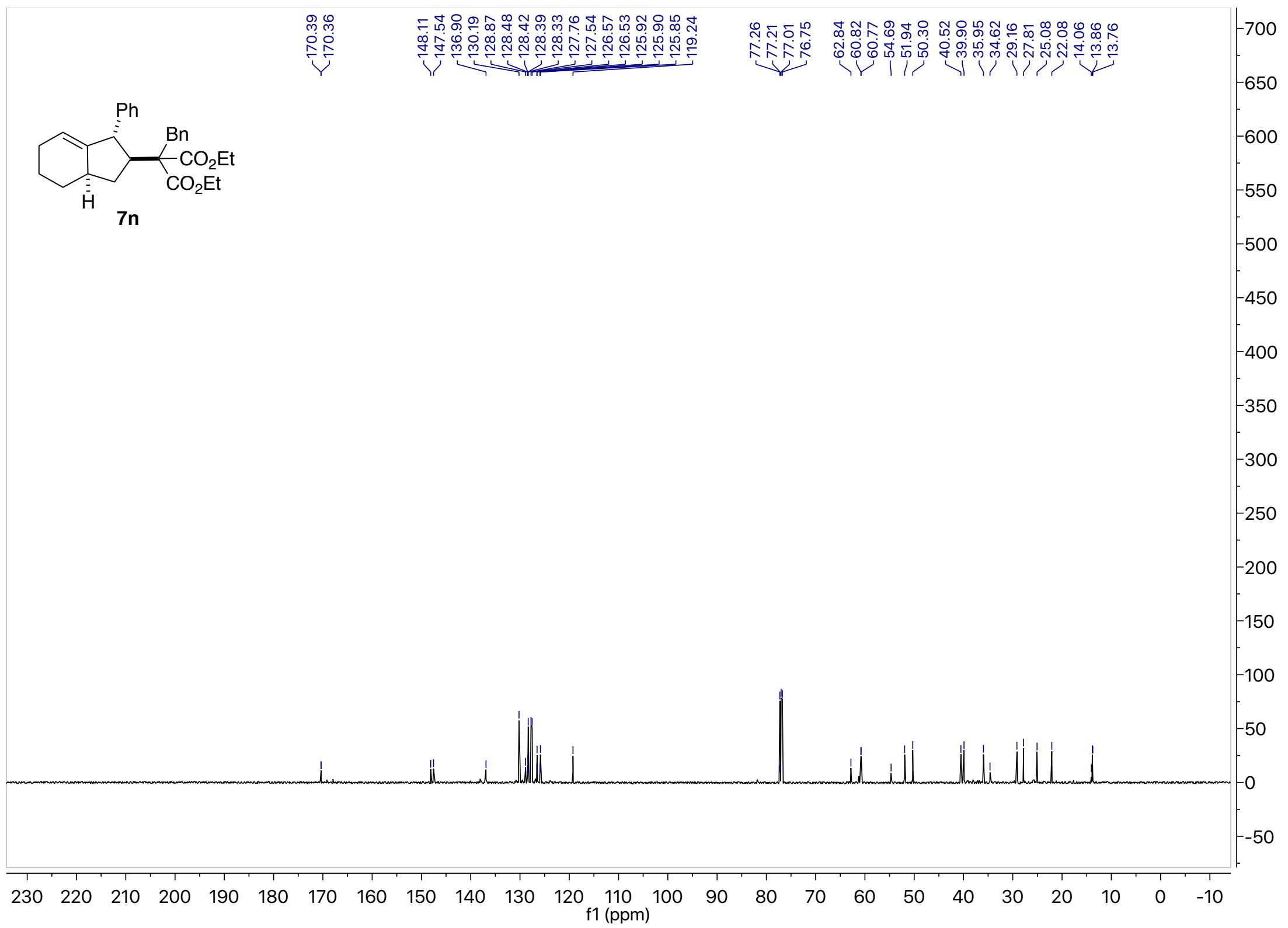




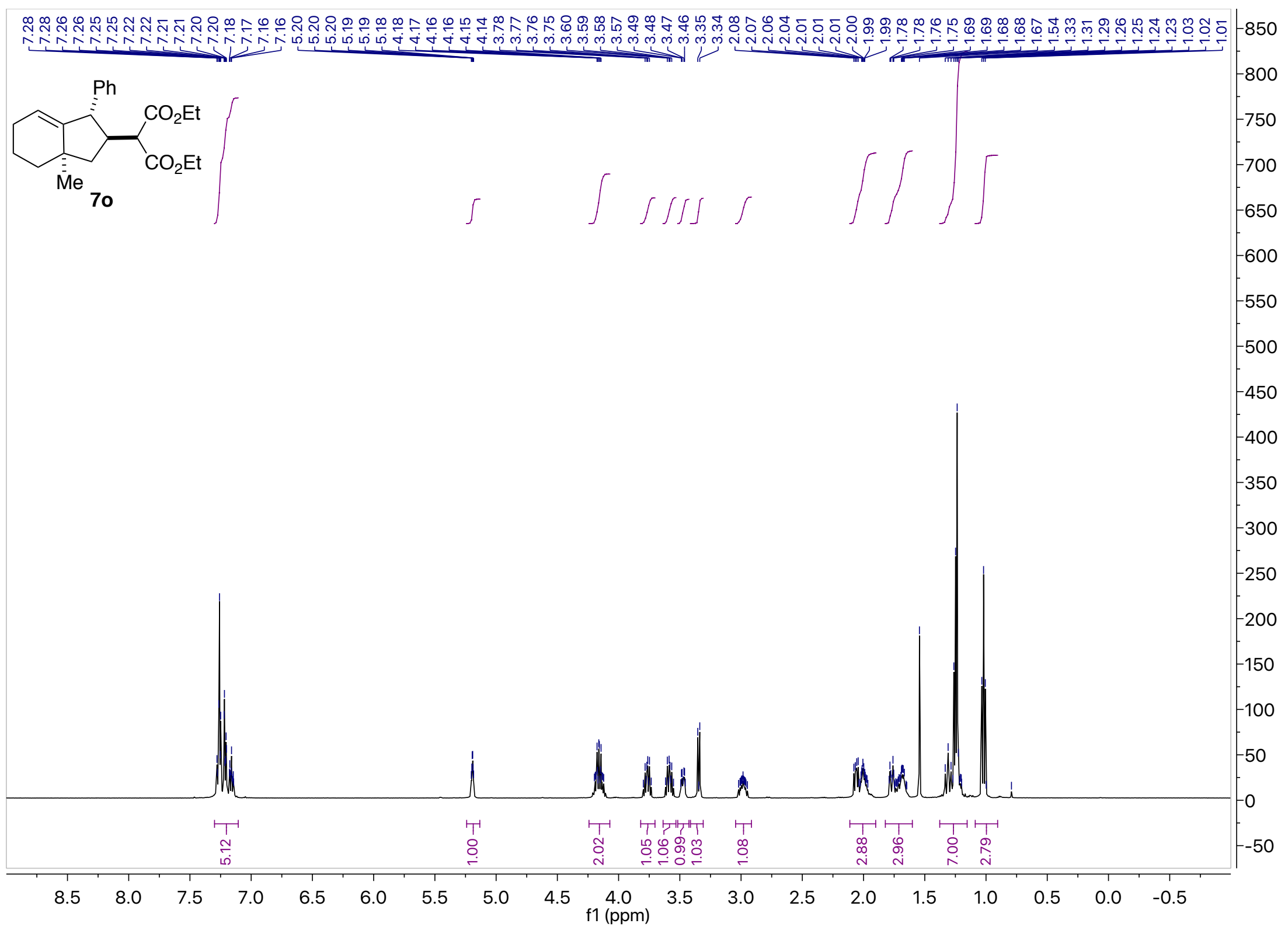




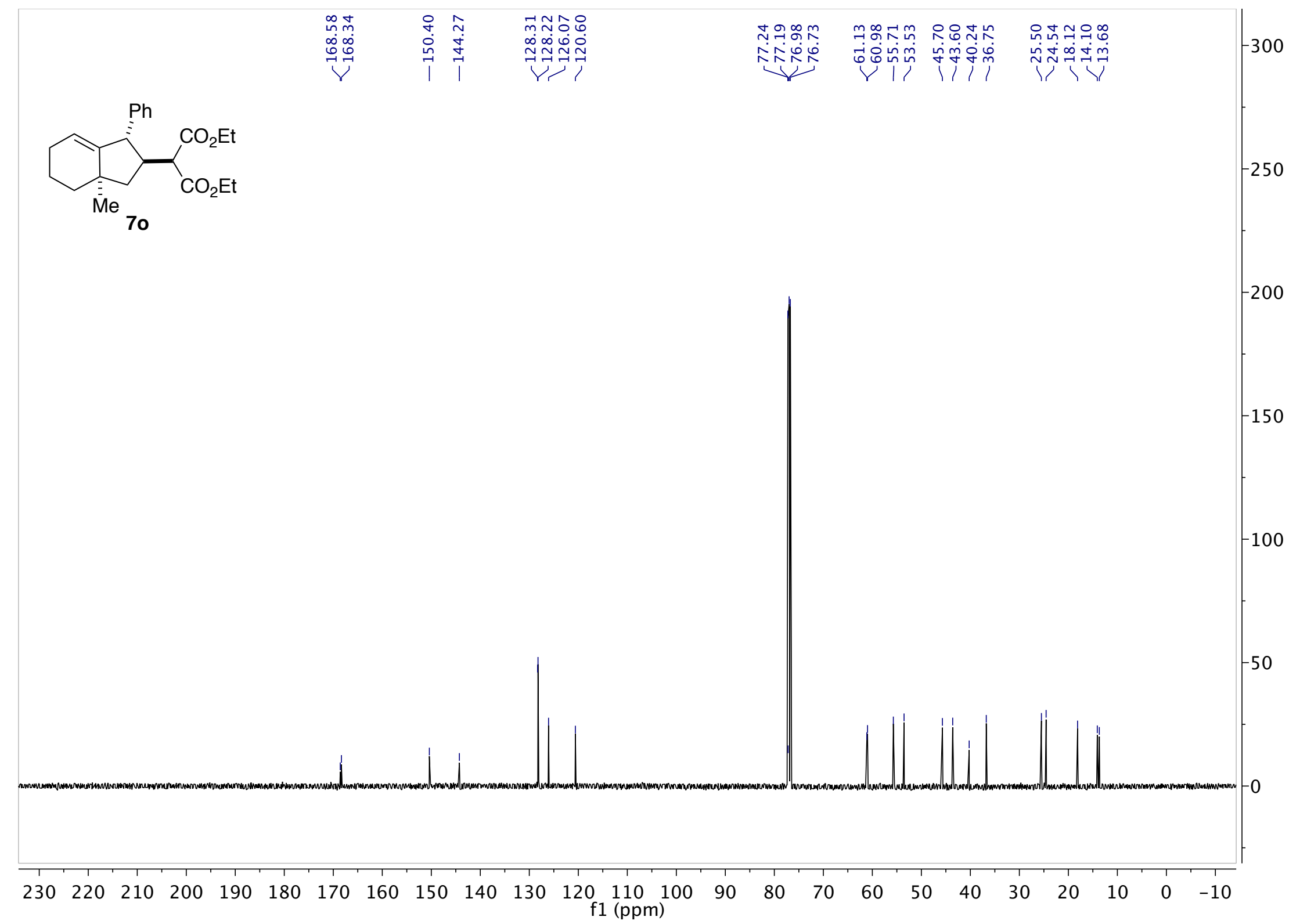




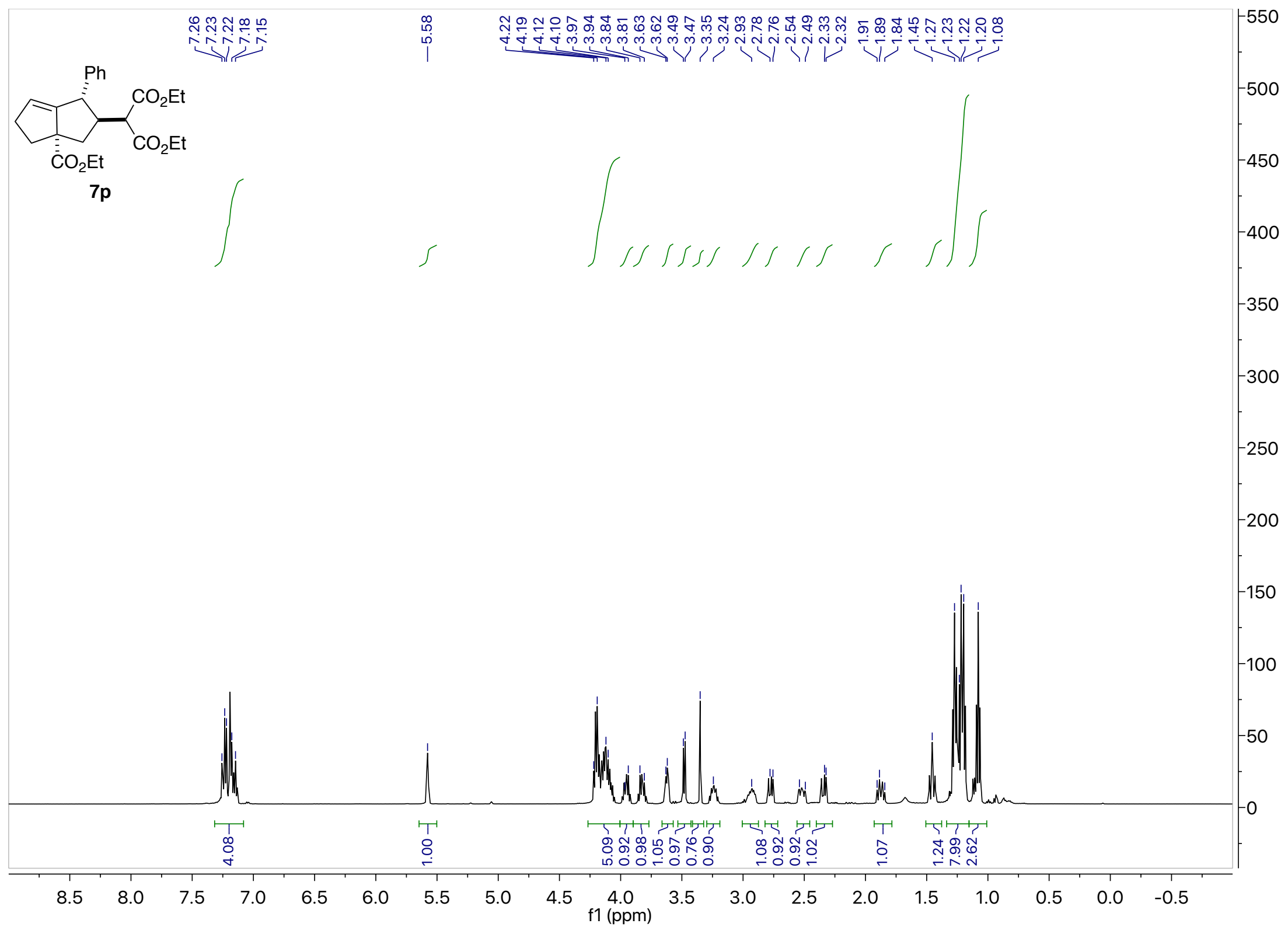




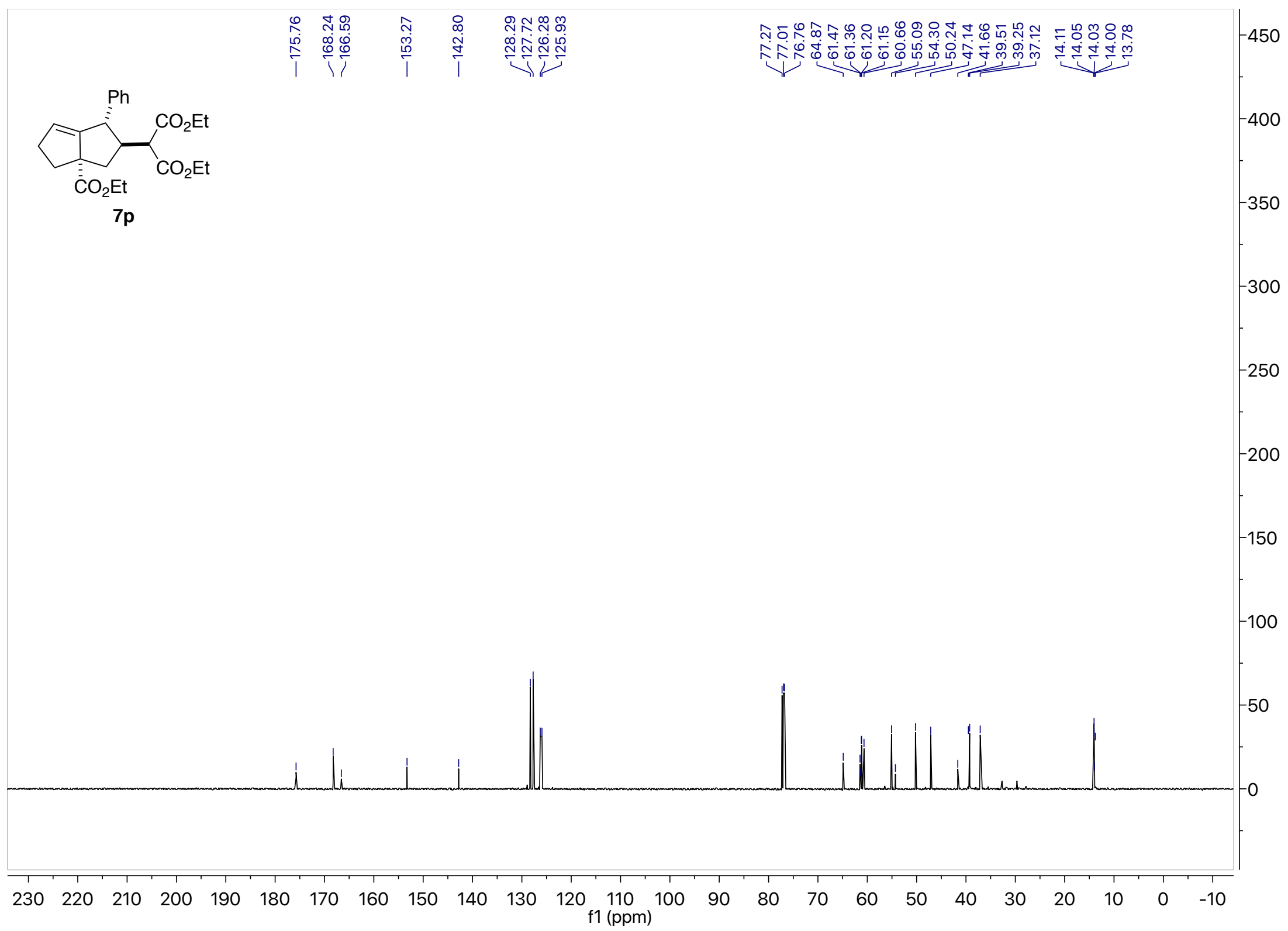




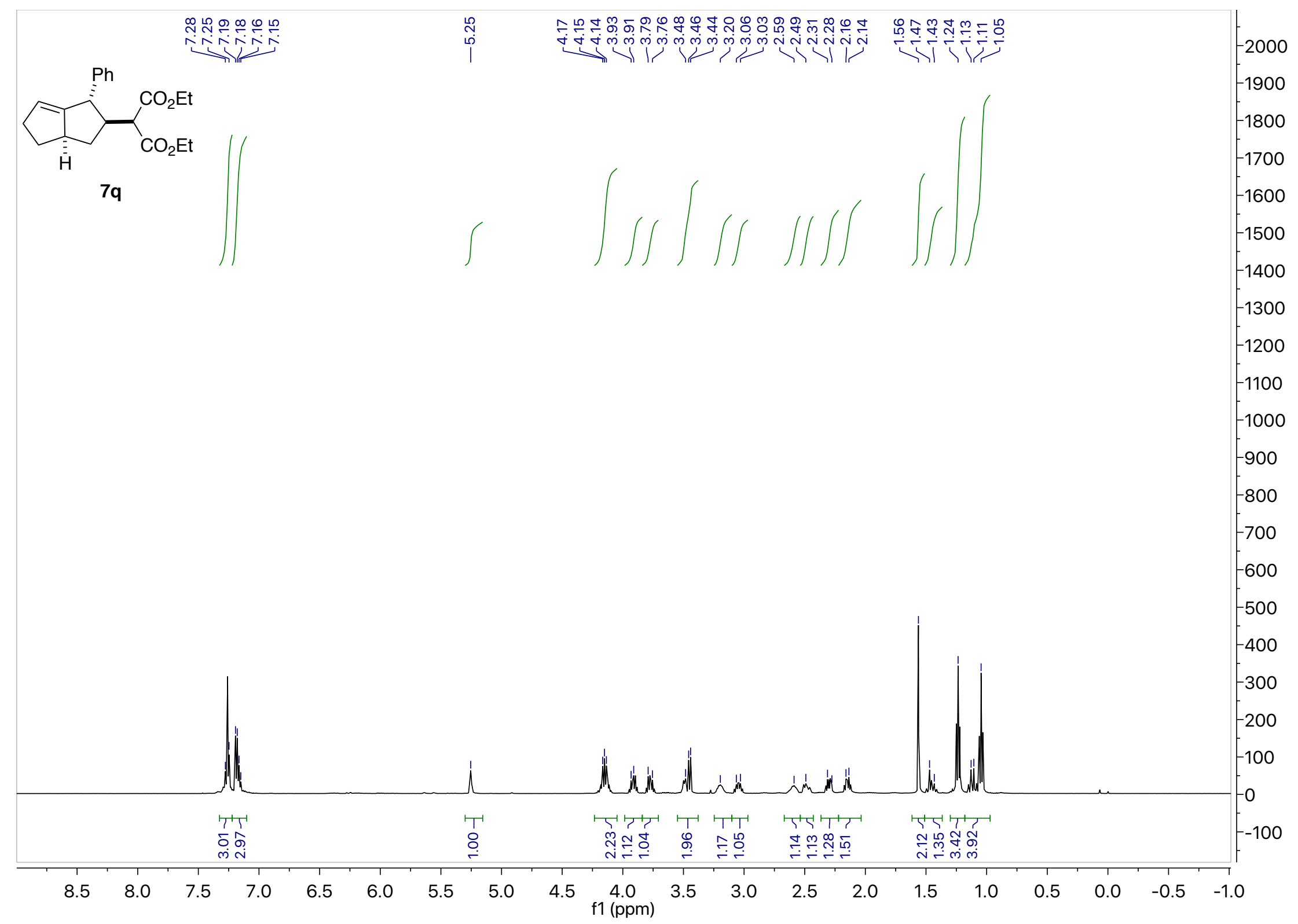




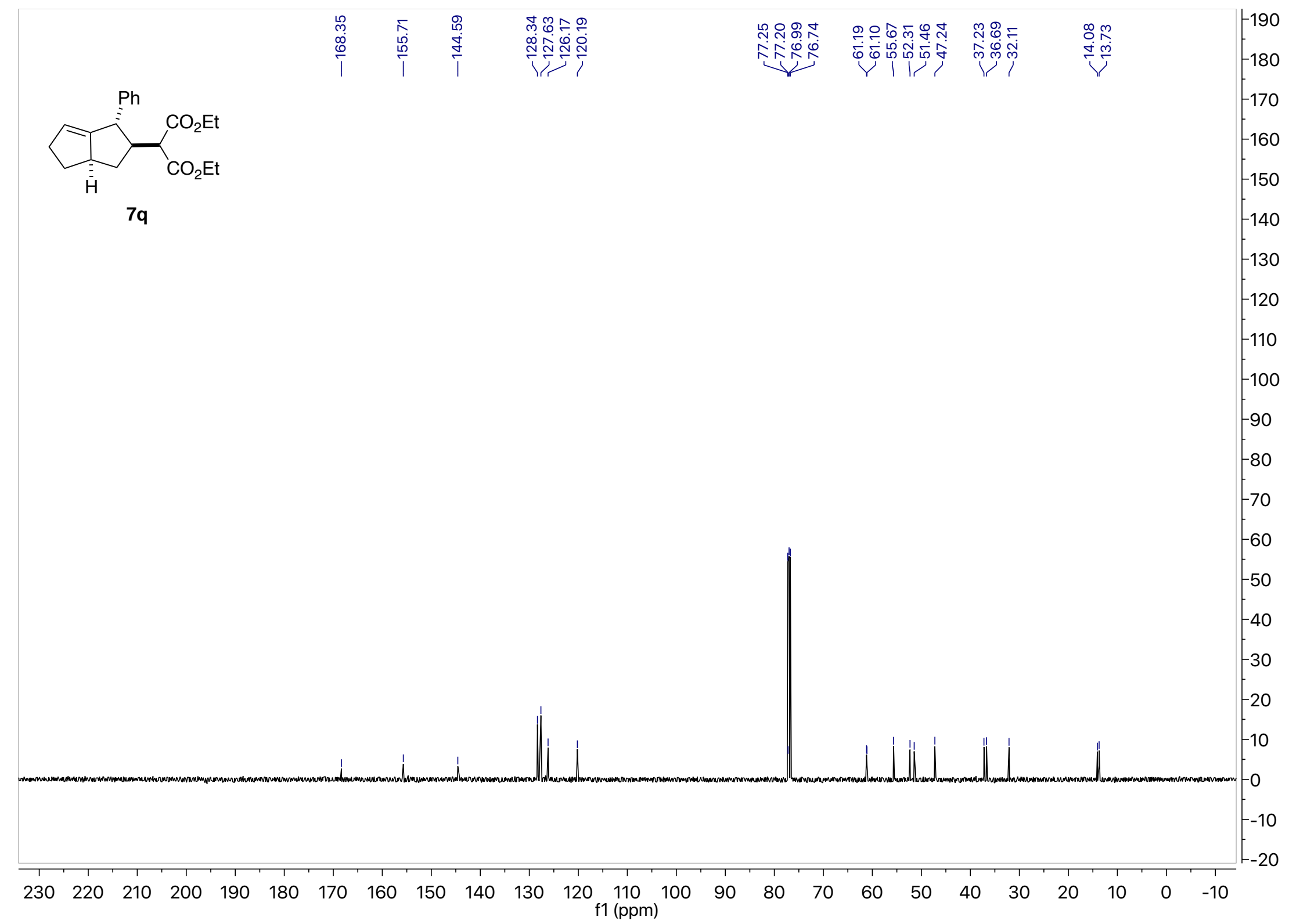




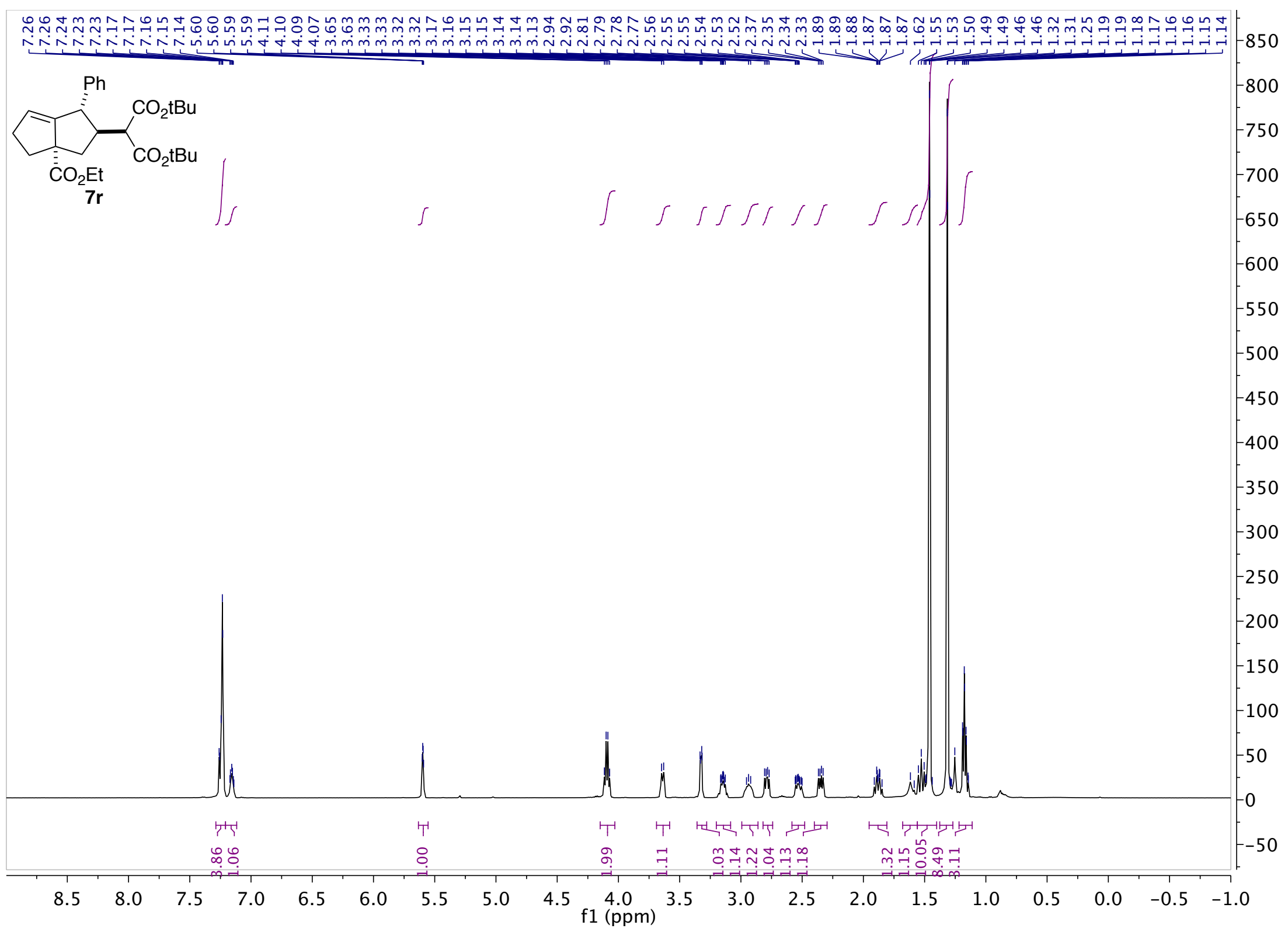




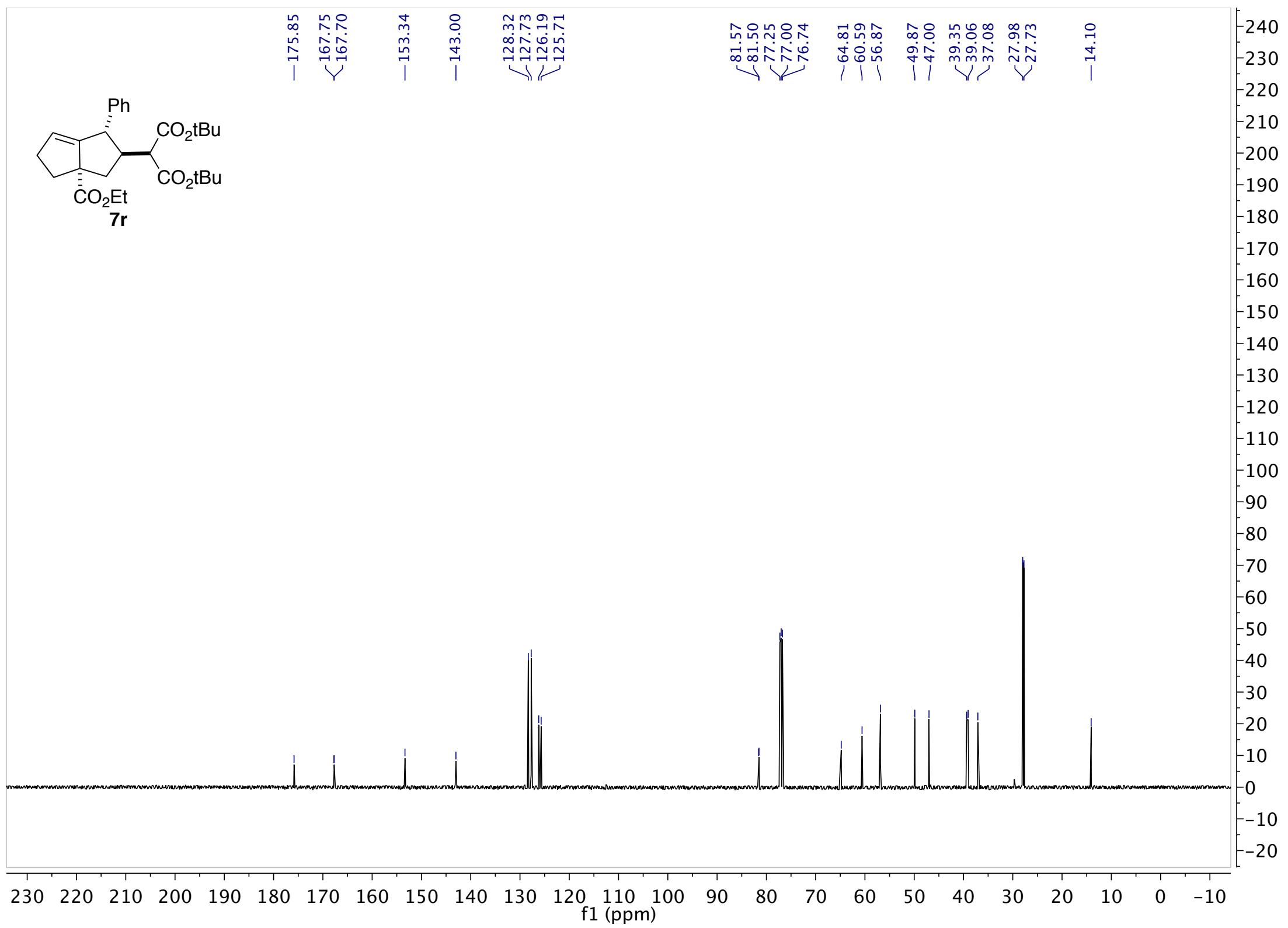




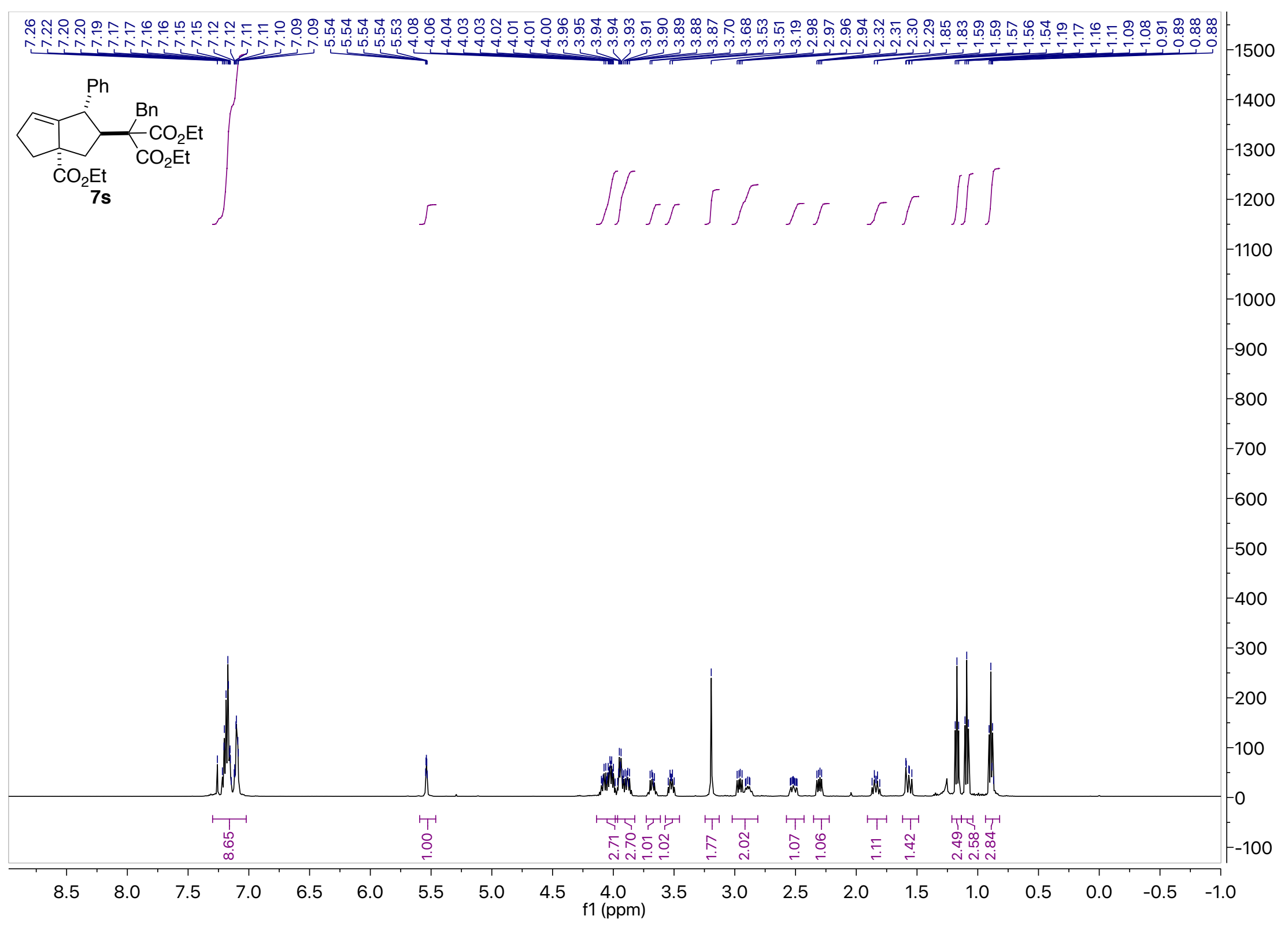




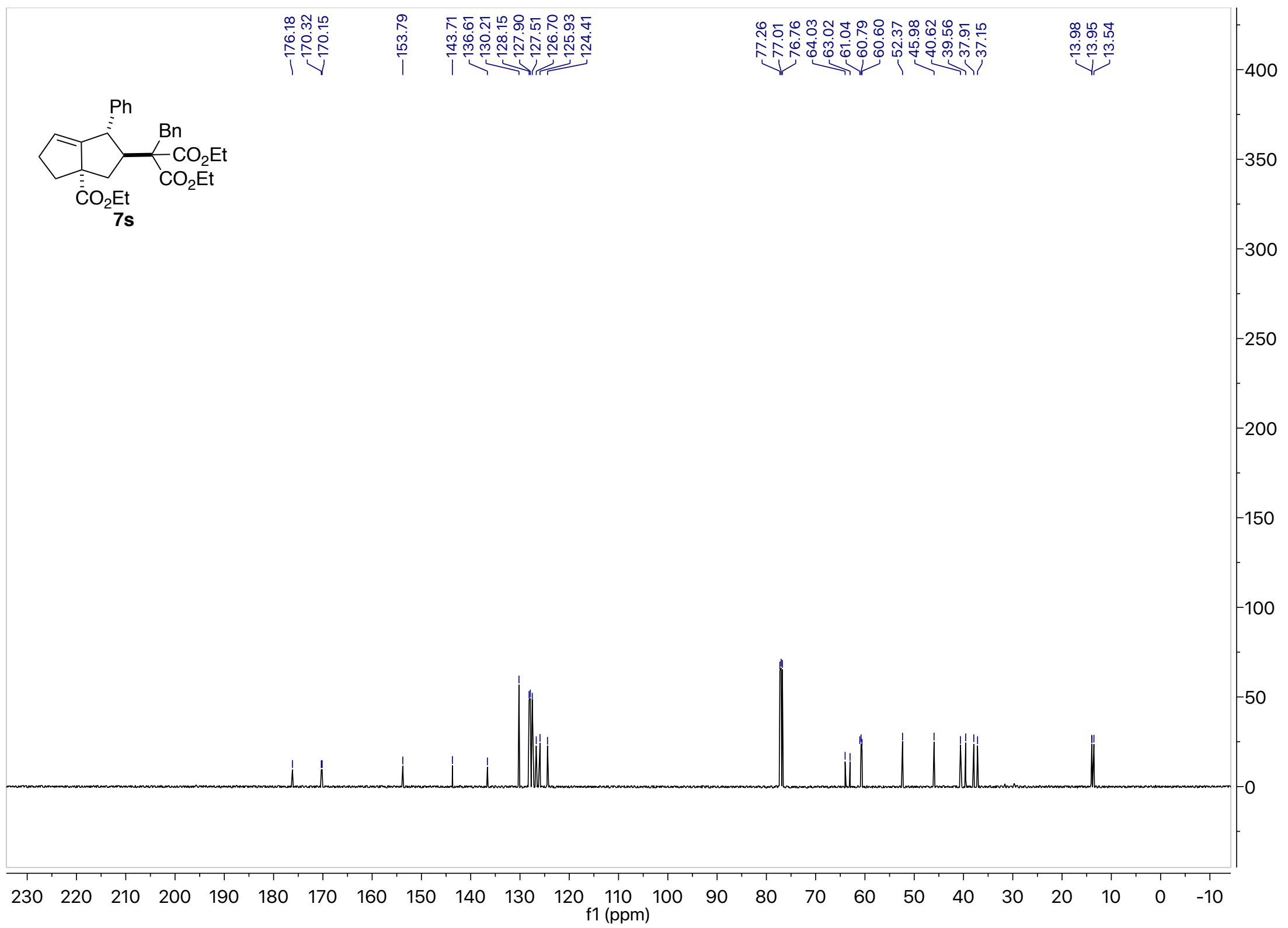




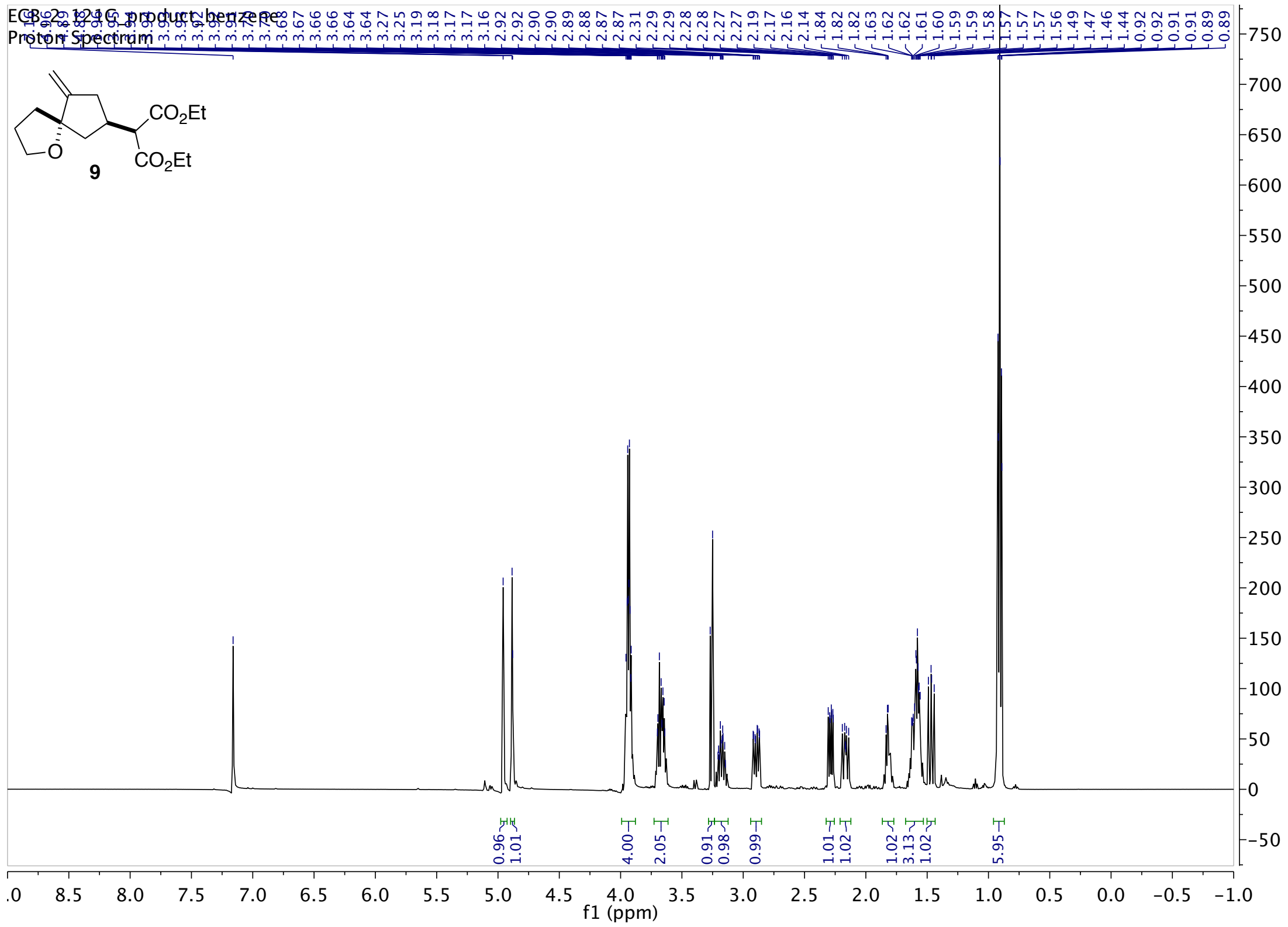




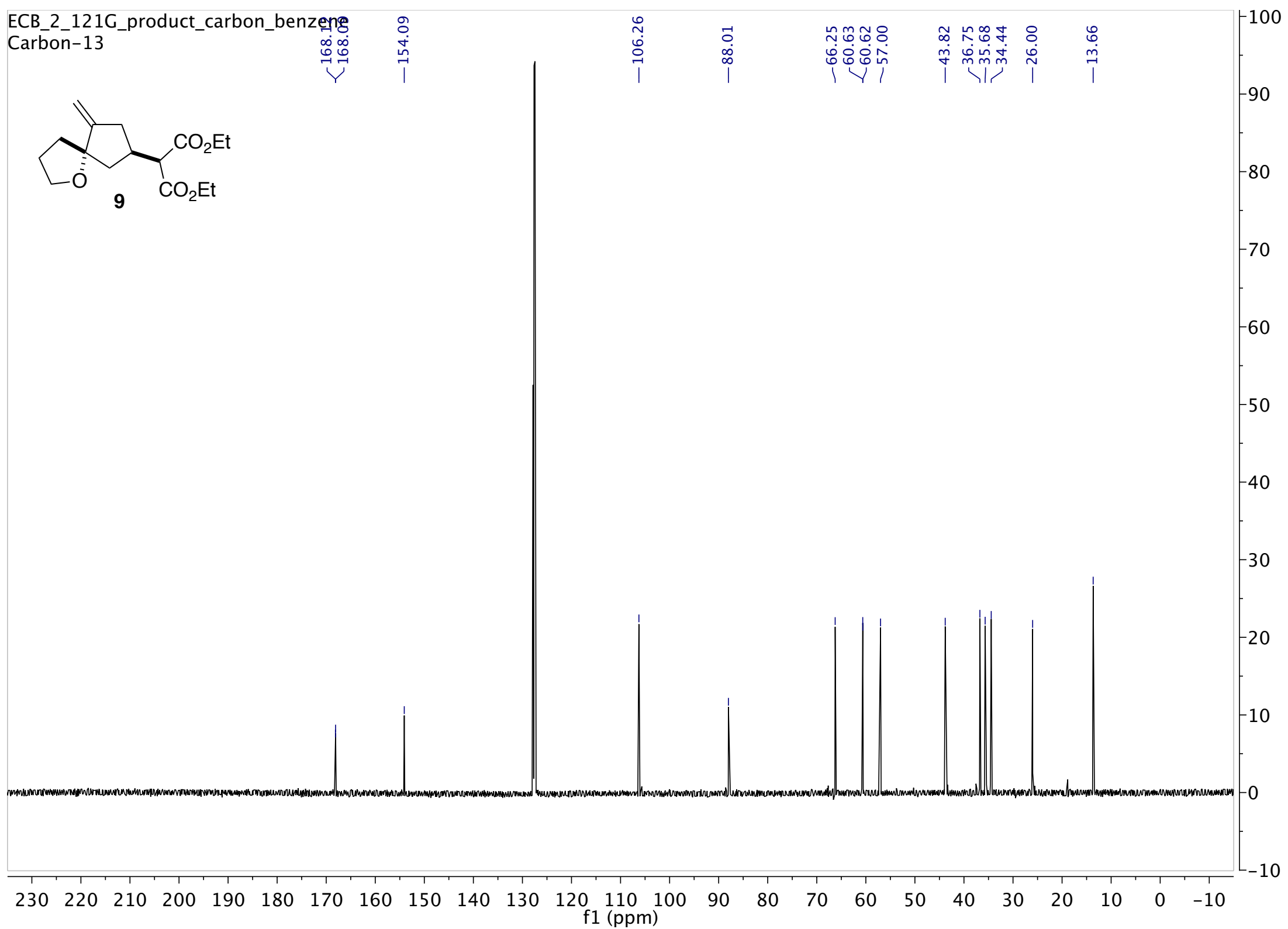




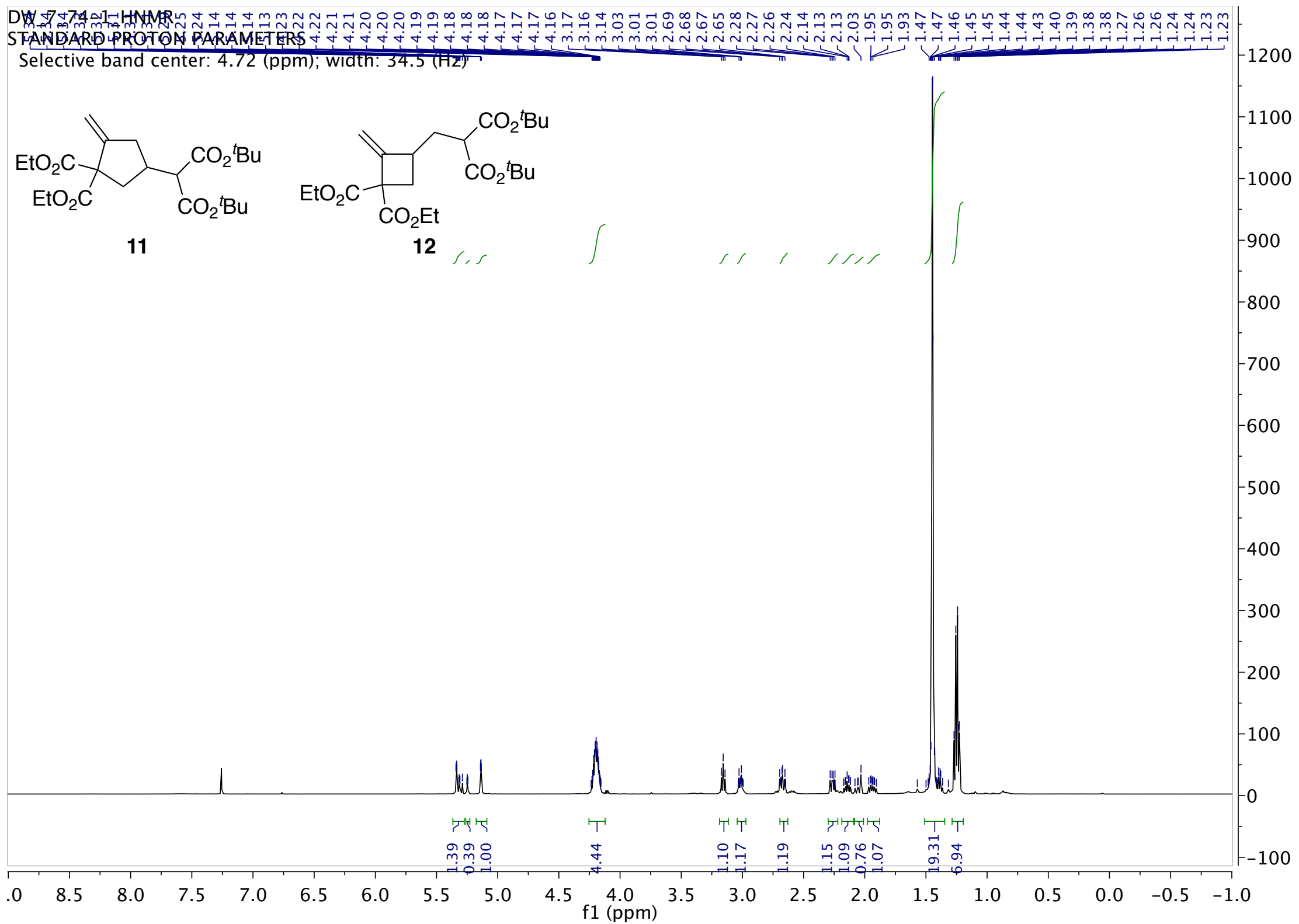




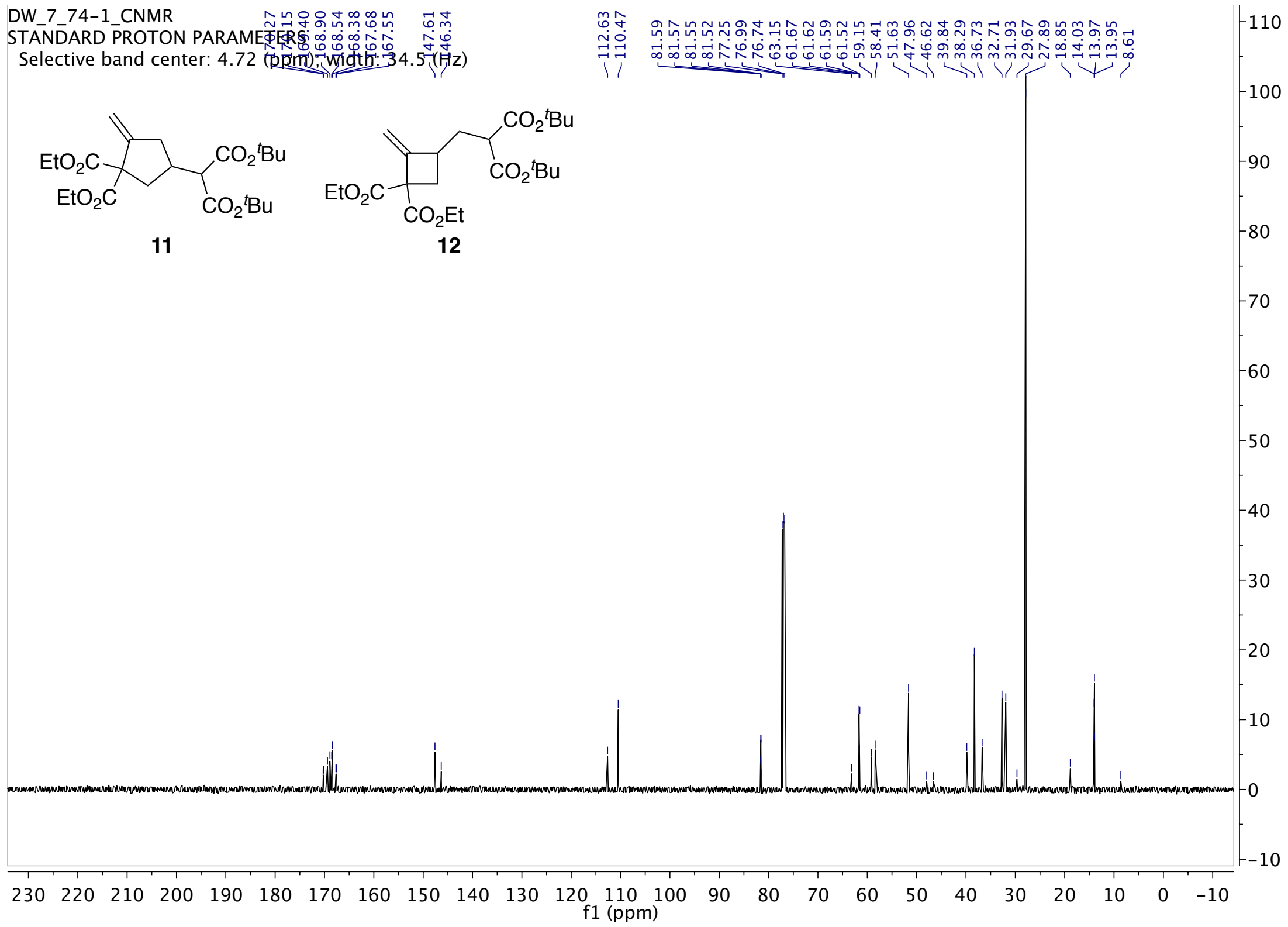




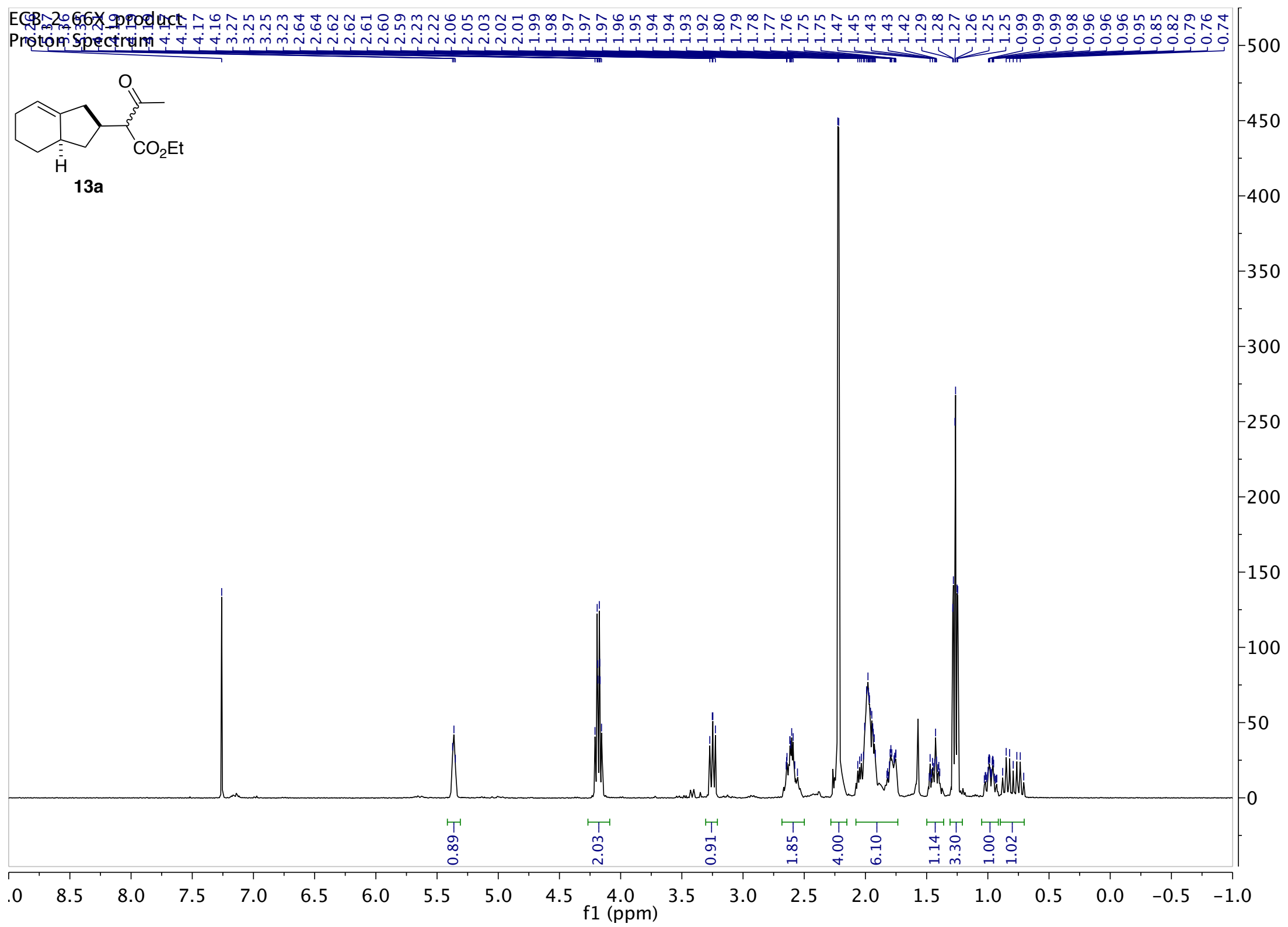



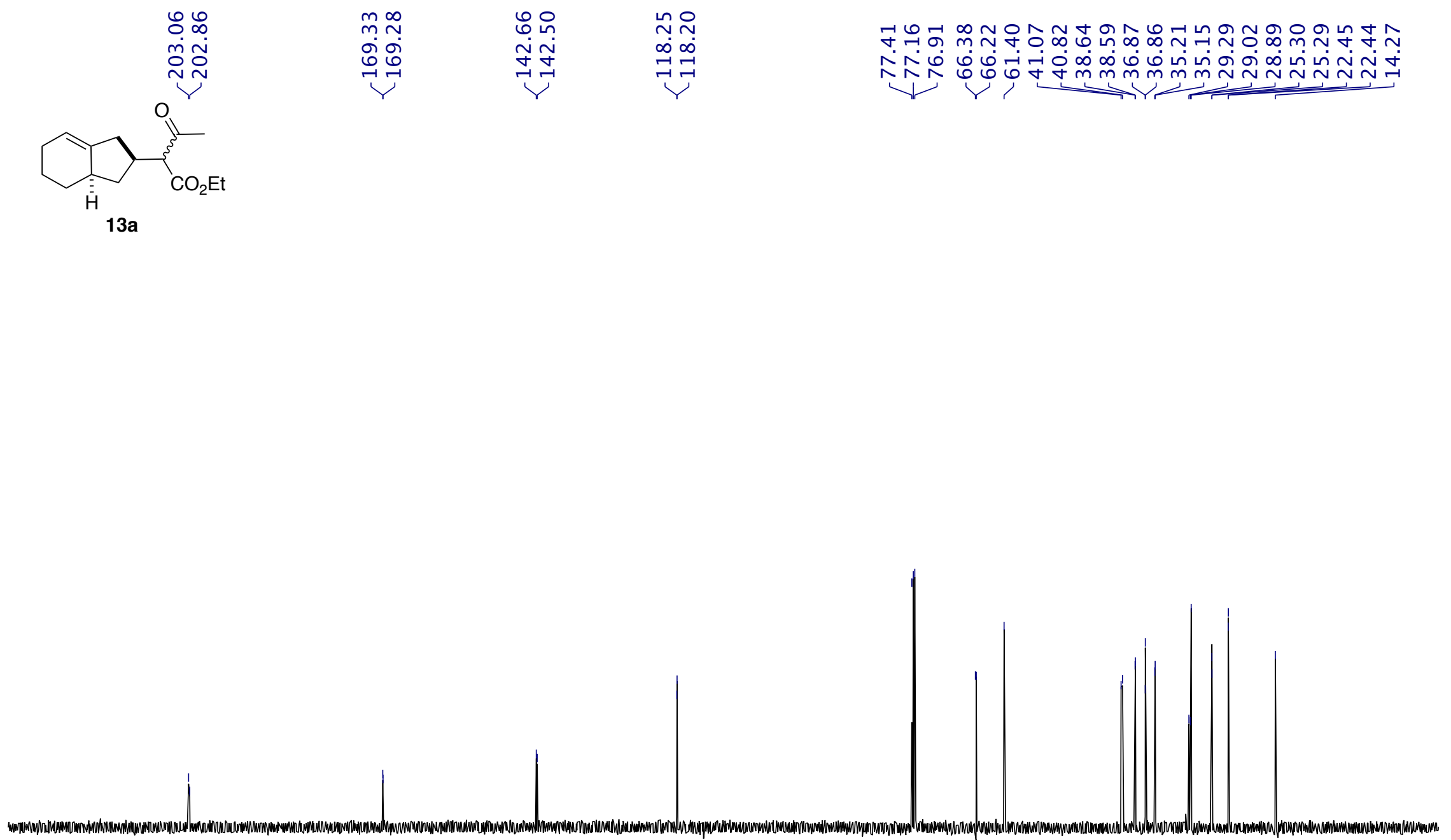


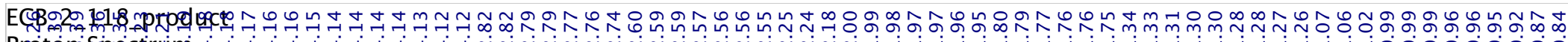

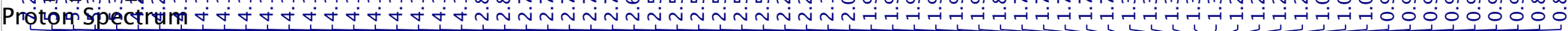

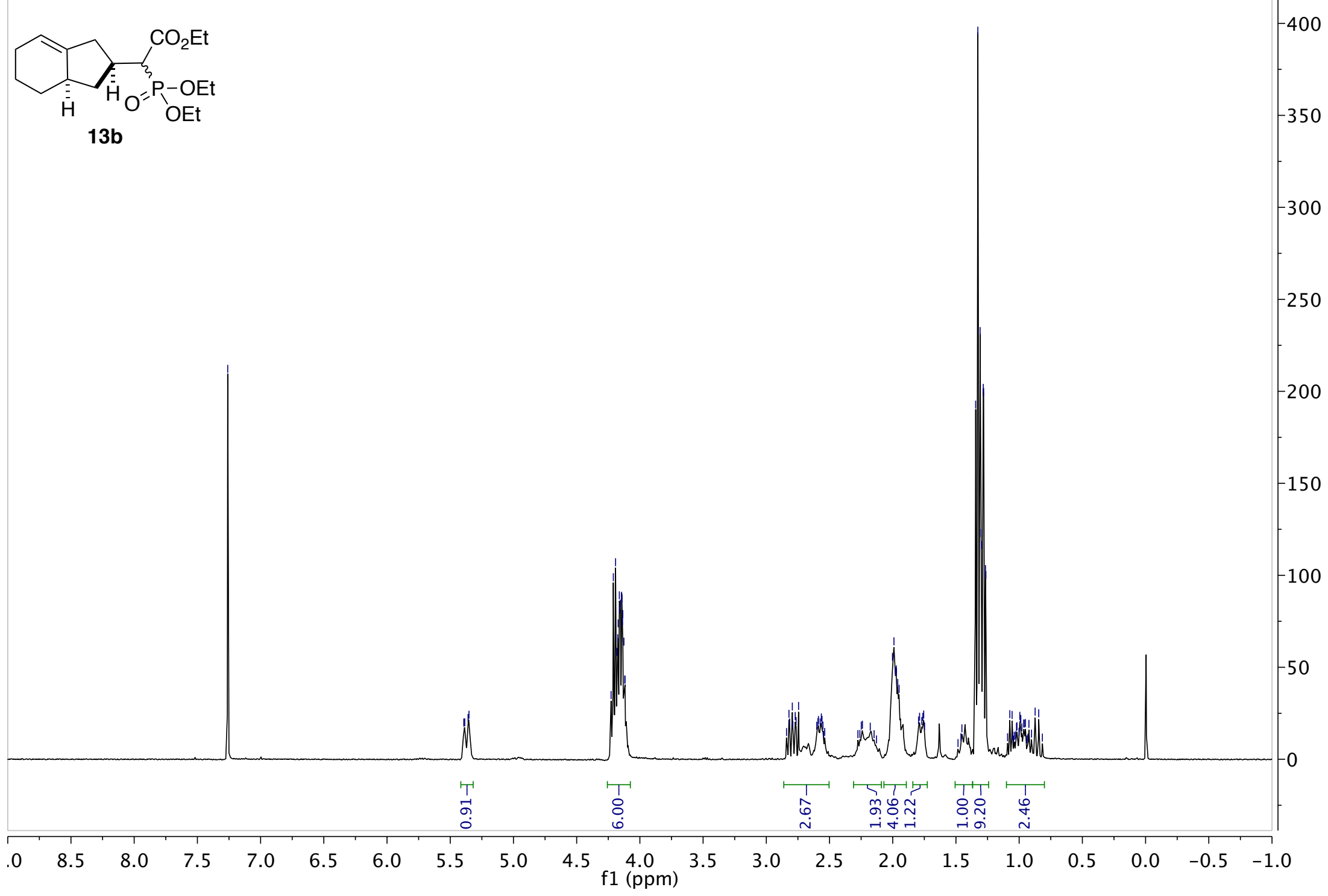




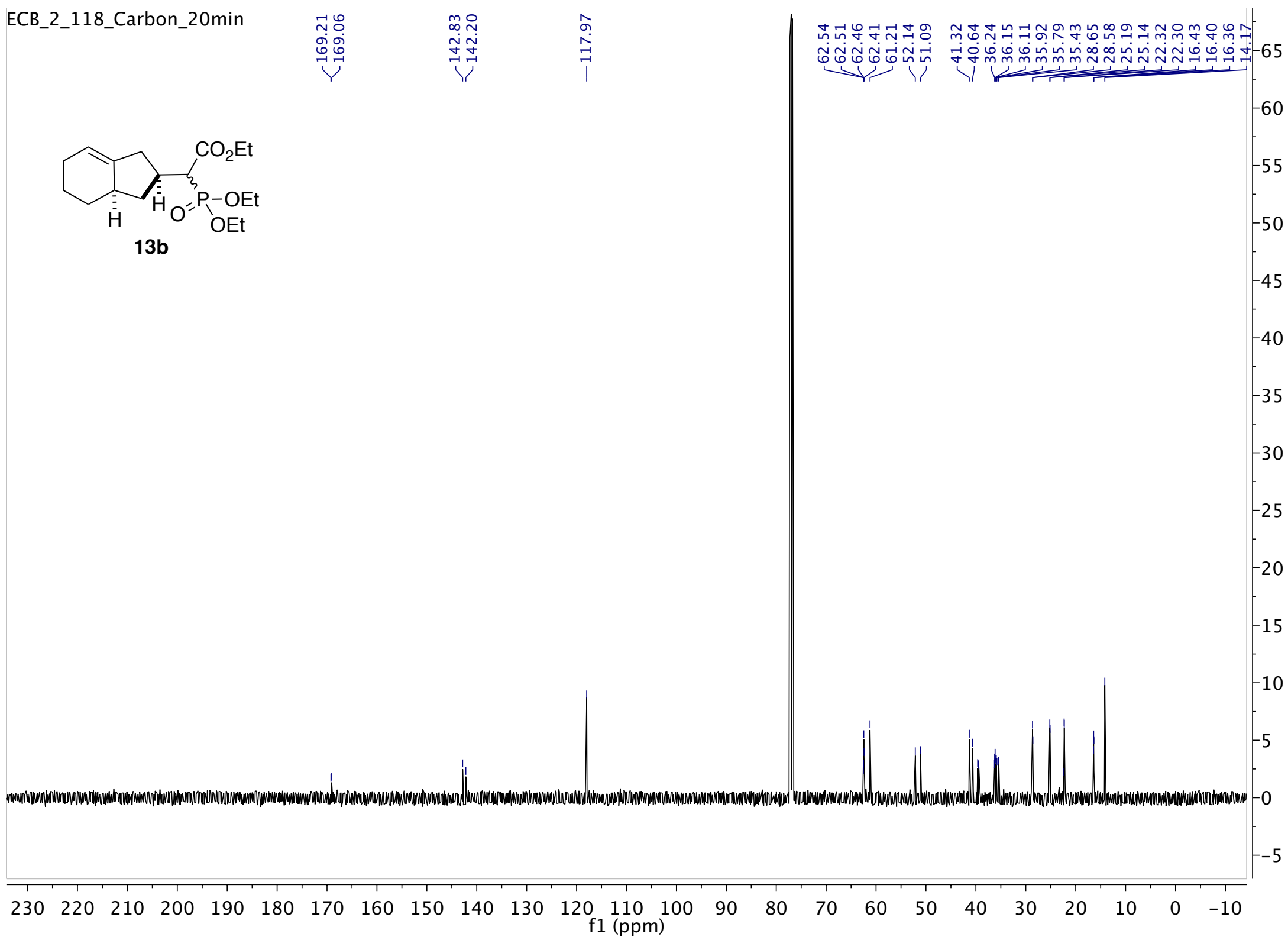




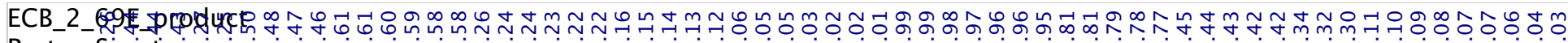

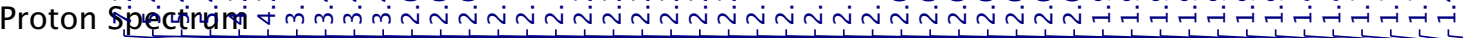

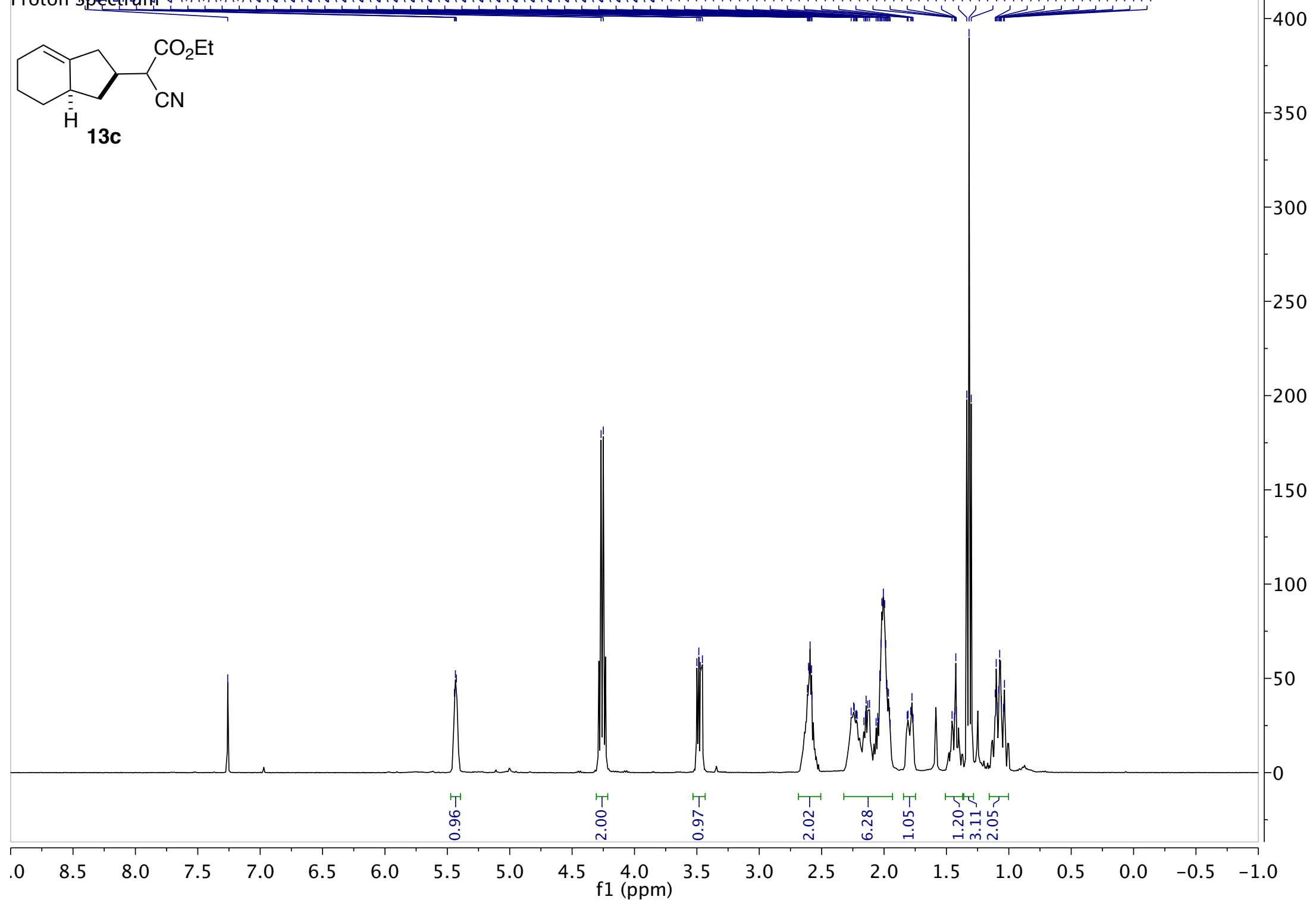




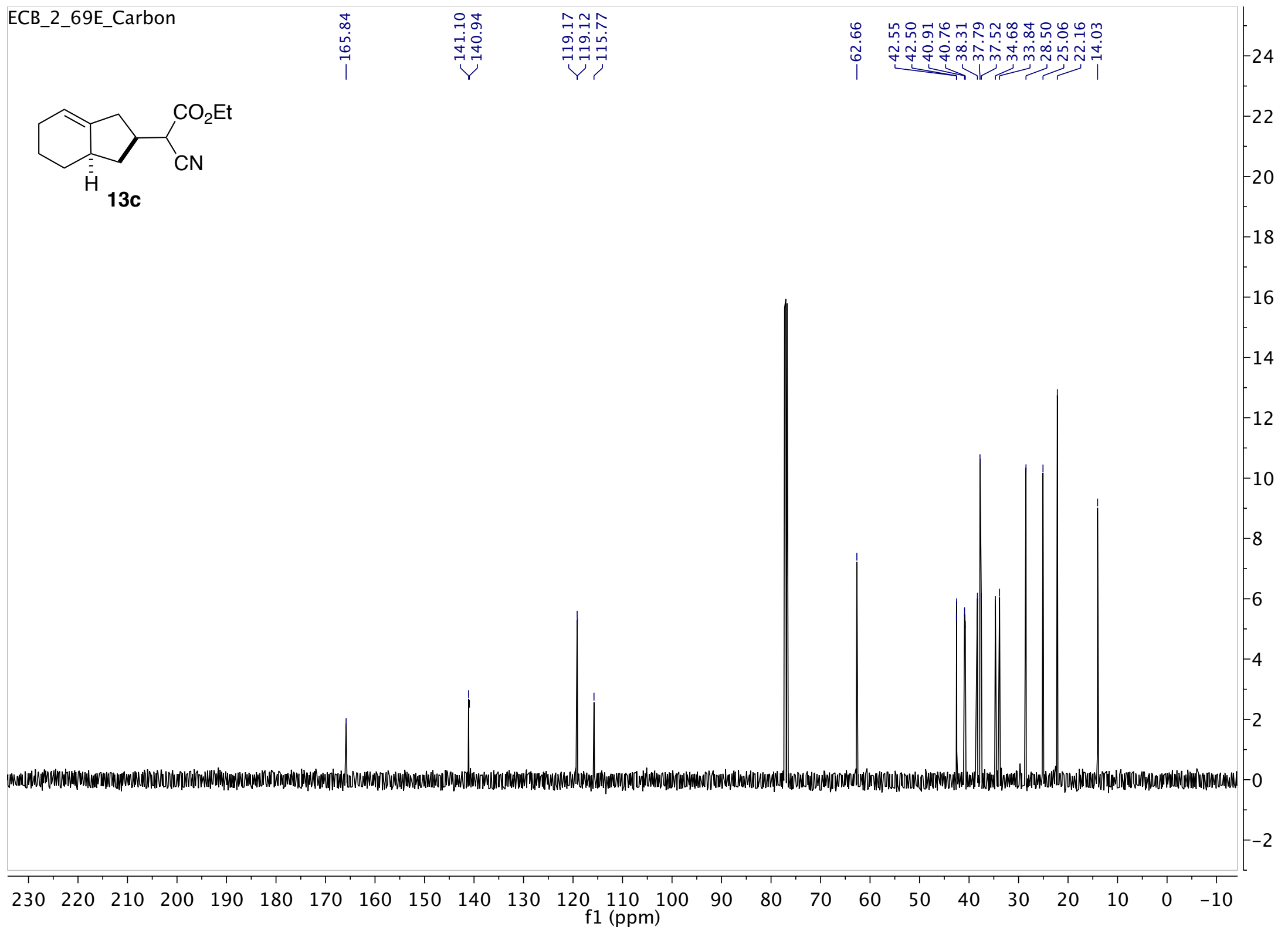




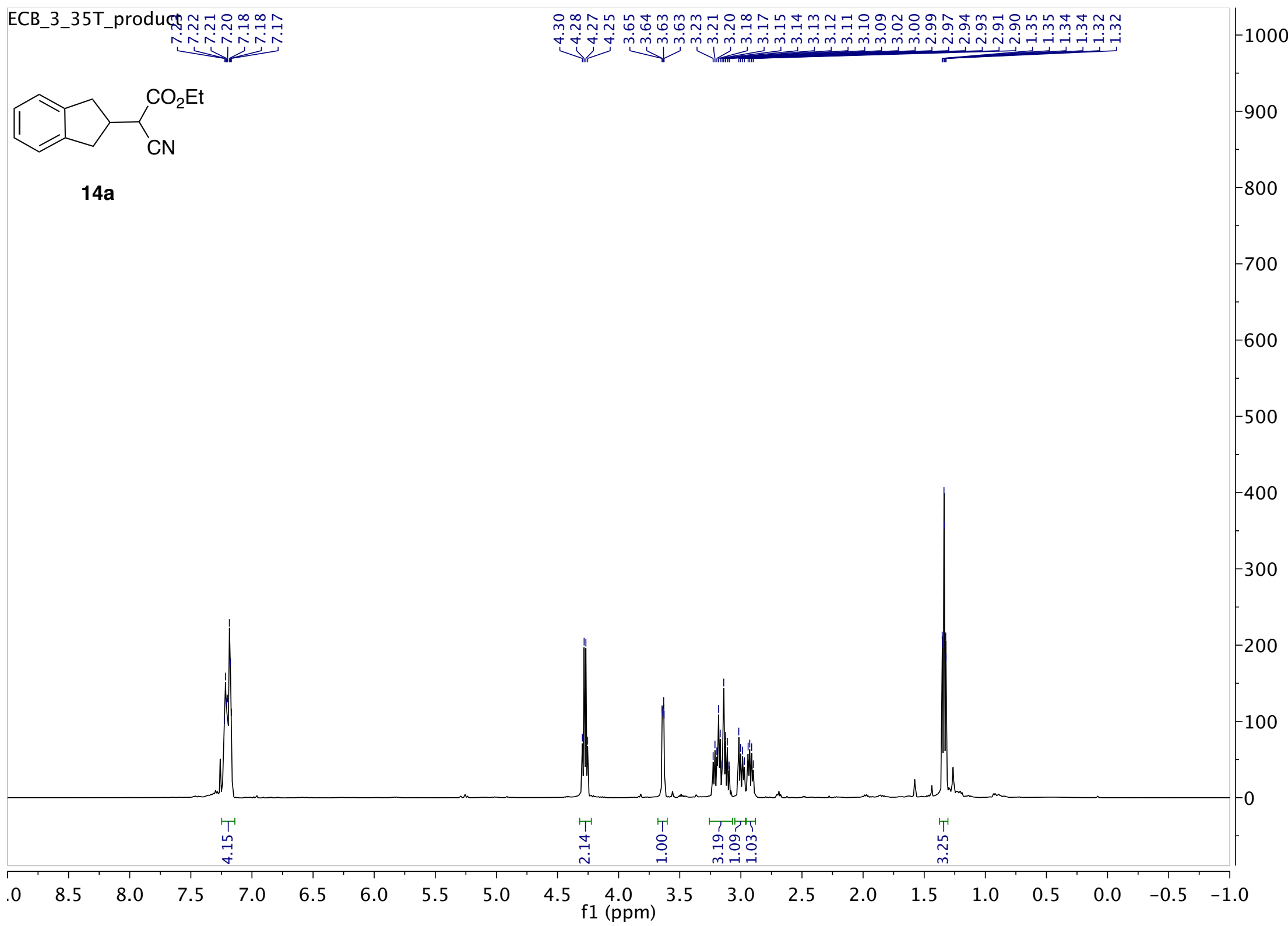




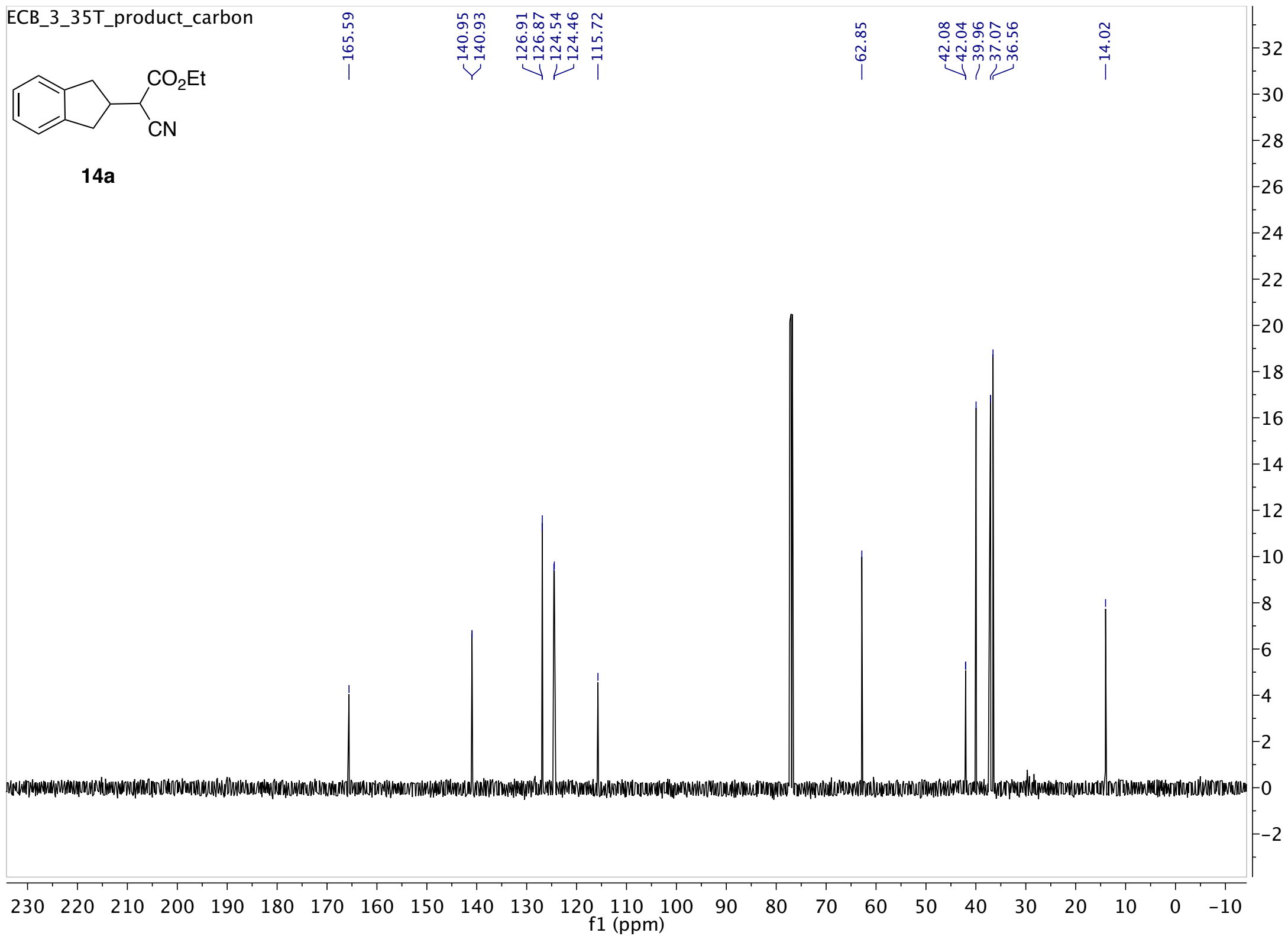




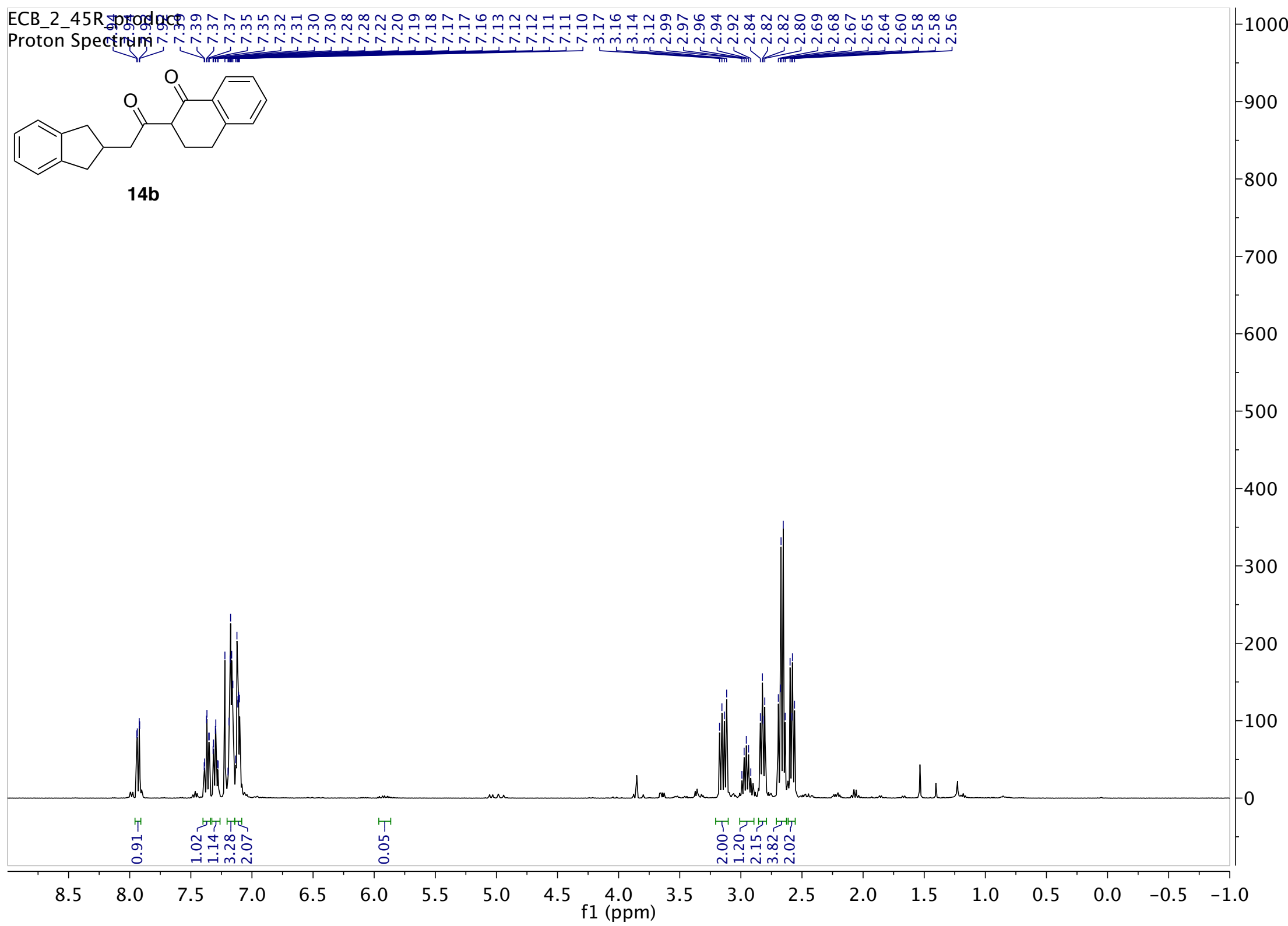




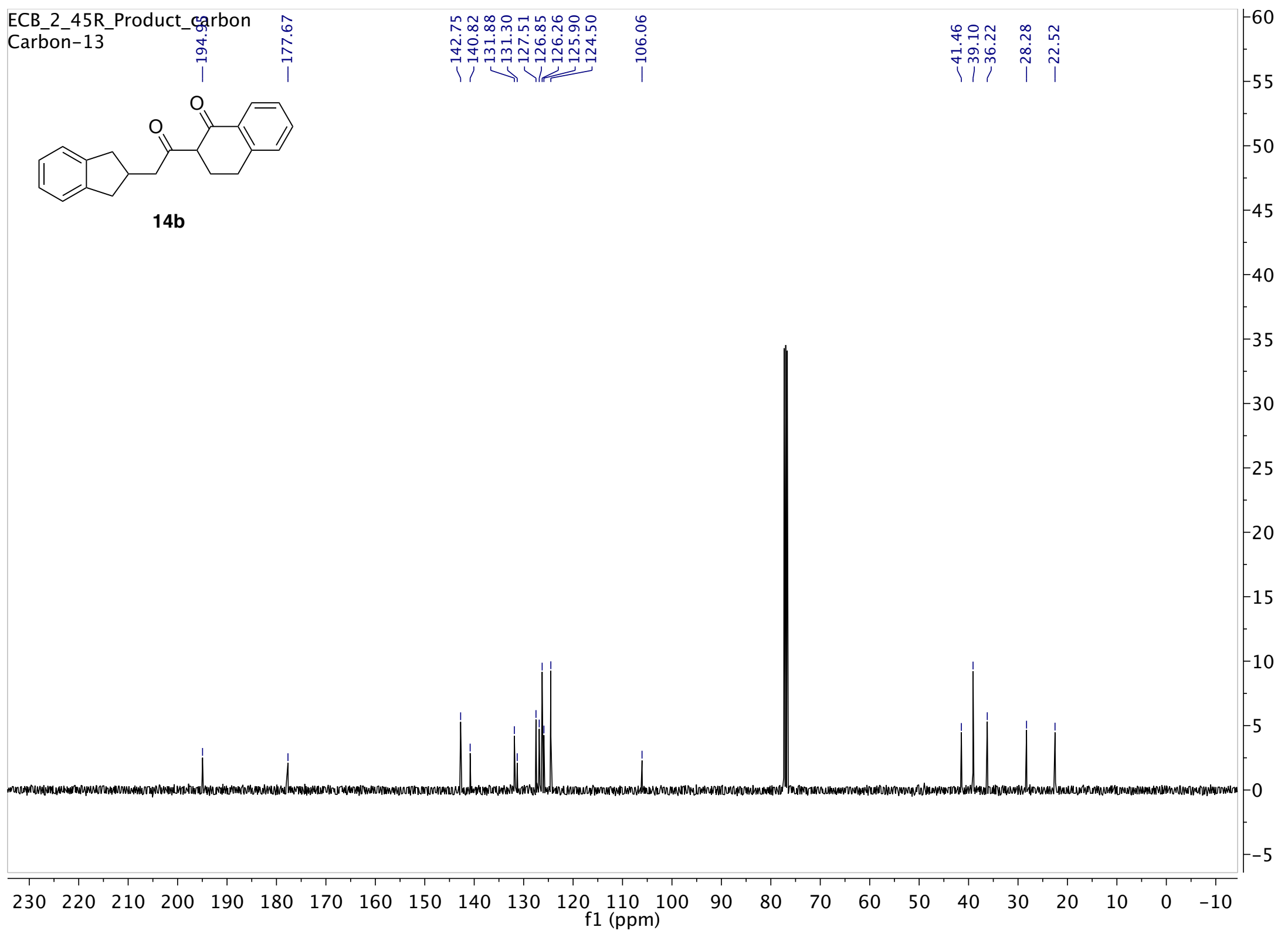




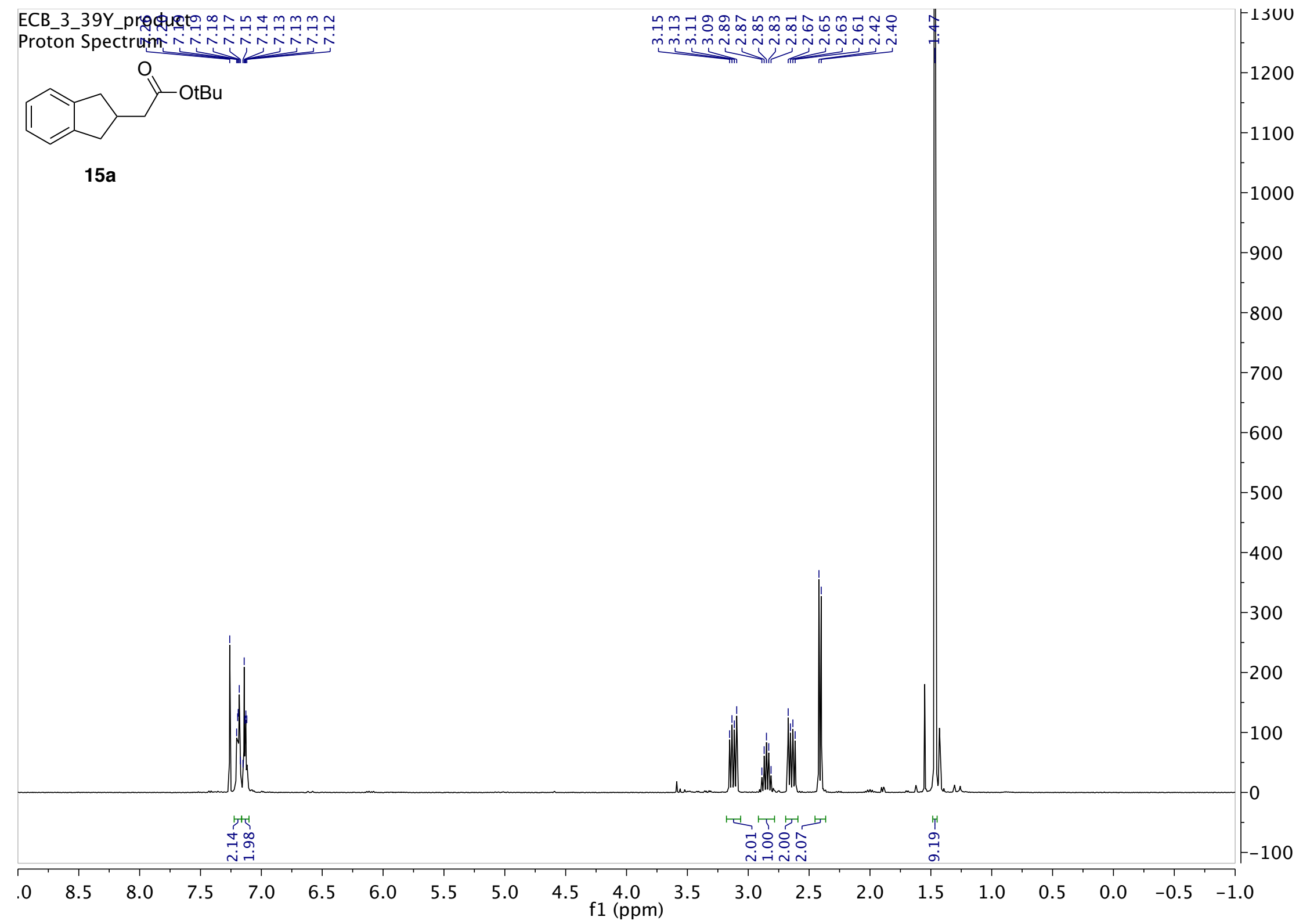




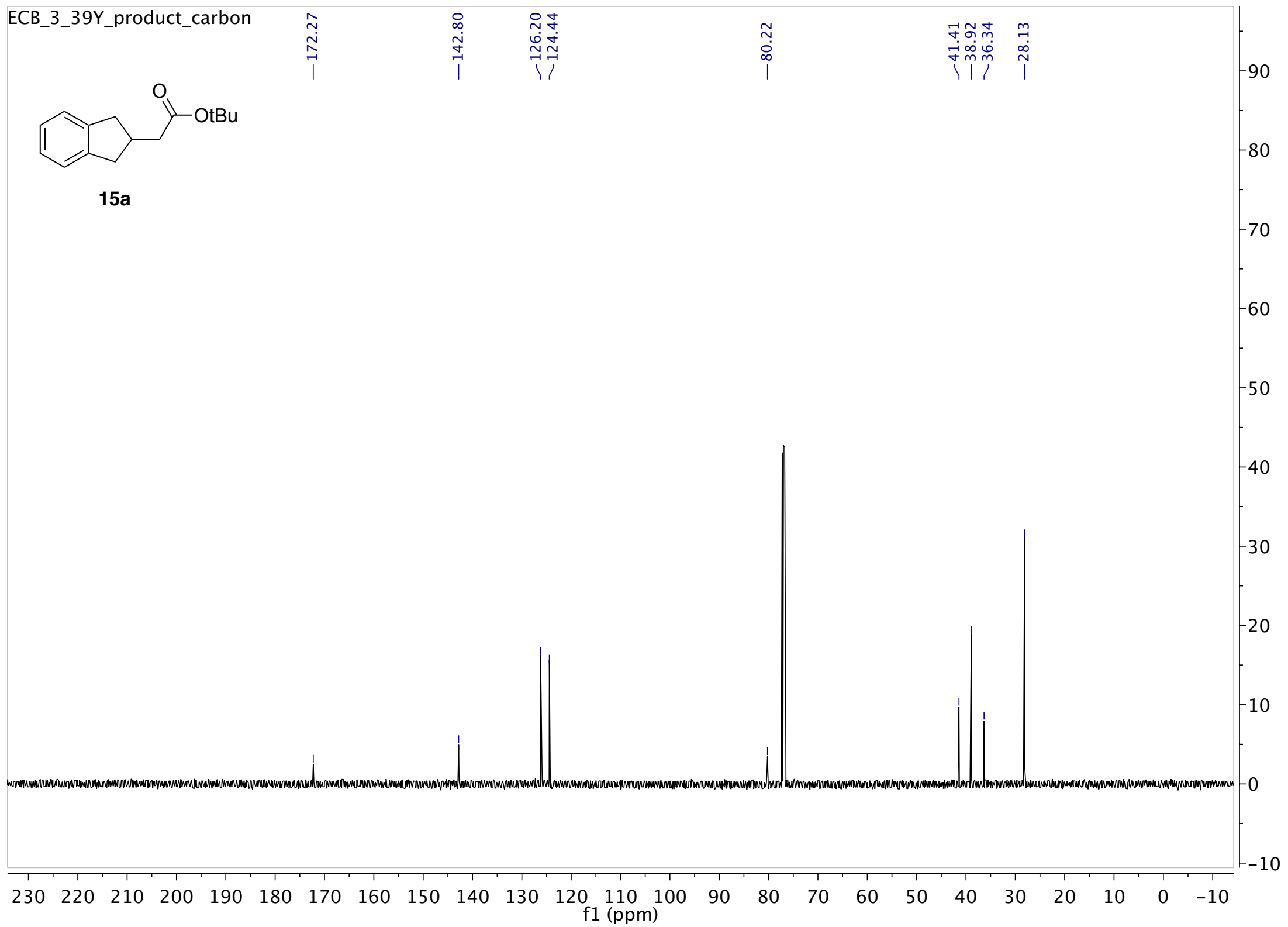




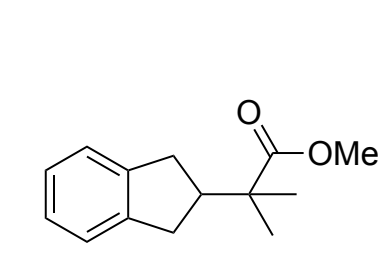

$15 b$

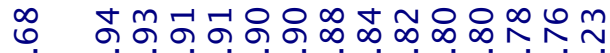

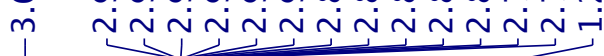

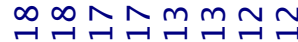

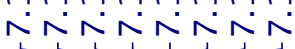

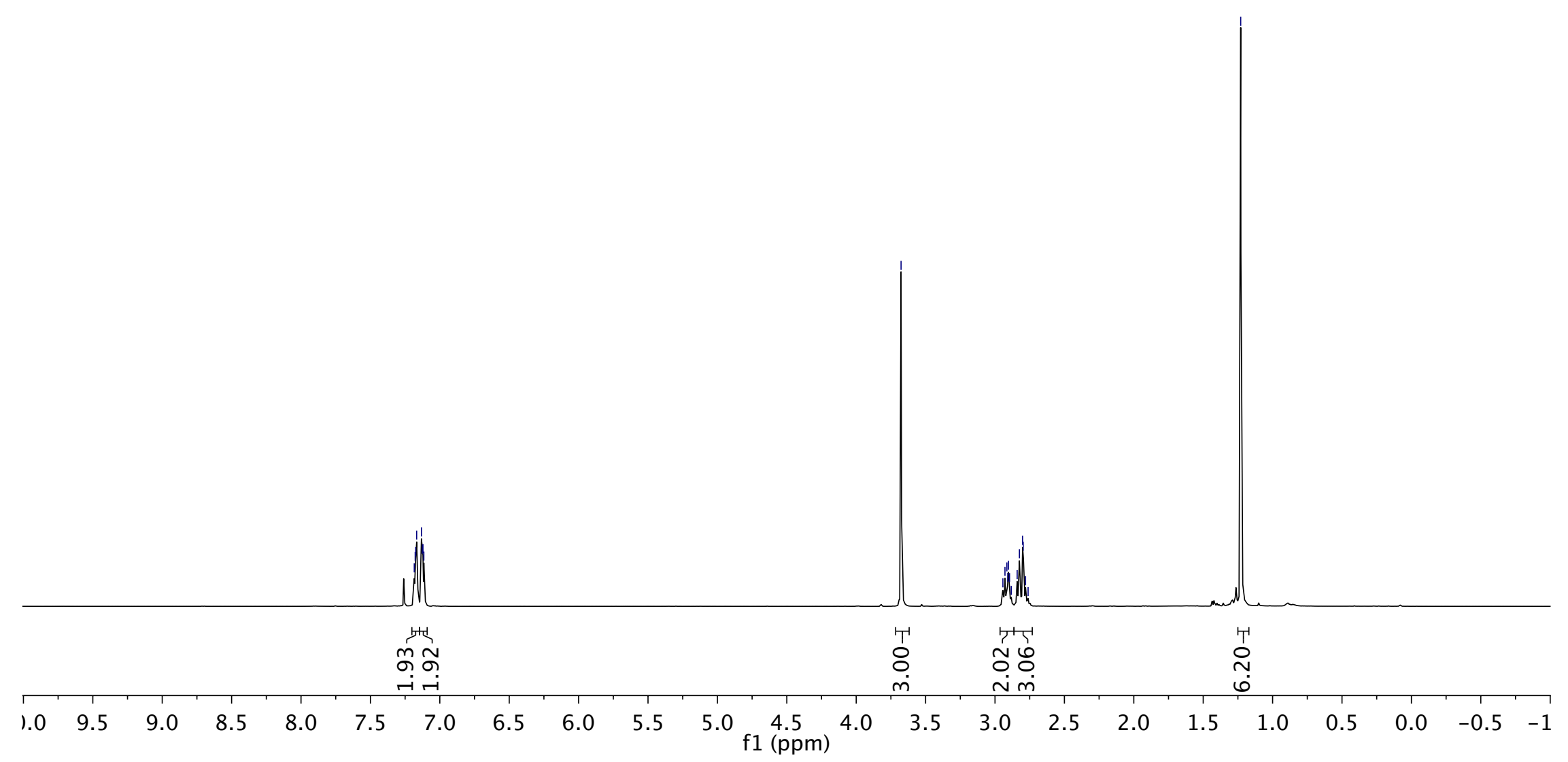




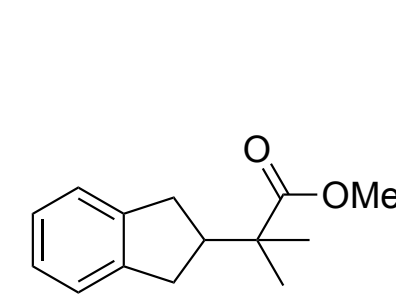

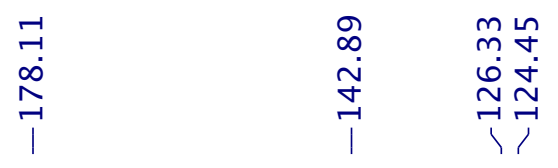

감두

송

Lొm $\infty$ กิ

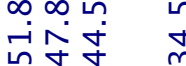

$\begin{array}{ll}0 & 9 \\ \stackrel{n}{*} & \stackrel{n}{\sim} \\ 1 & 1\end{array}$

$15 b$

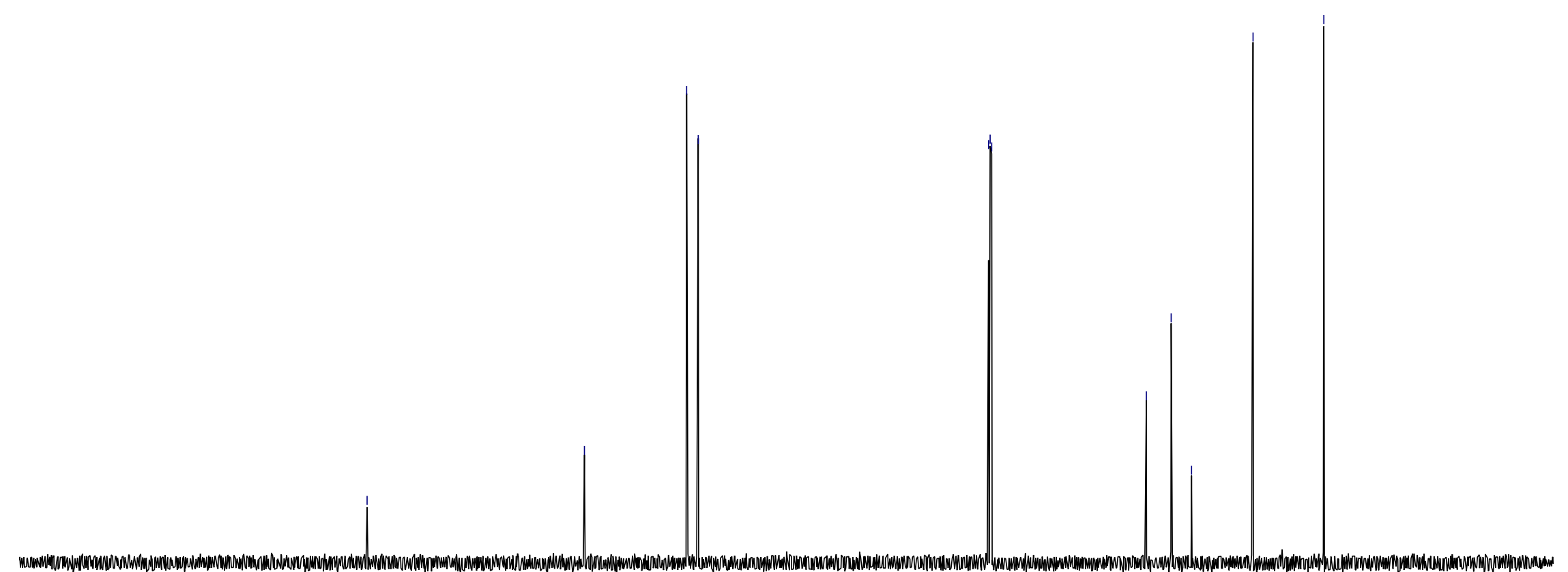

150140

$120 \quad 110 \quad 100$

90

80

$70 \quad 60$

50

40

30

20

10

$0-10$ 


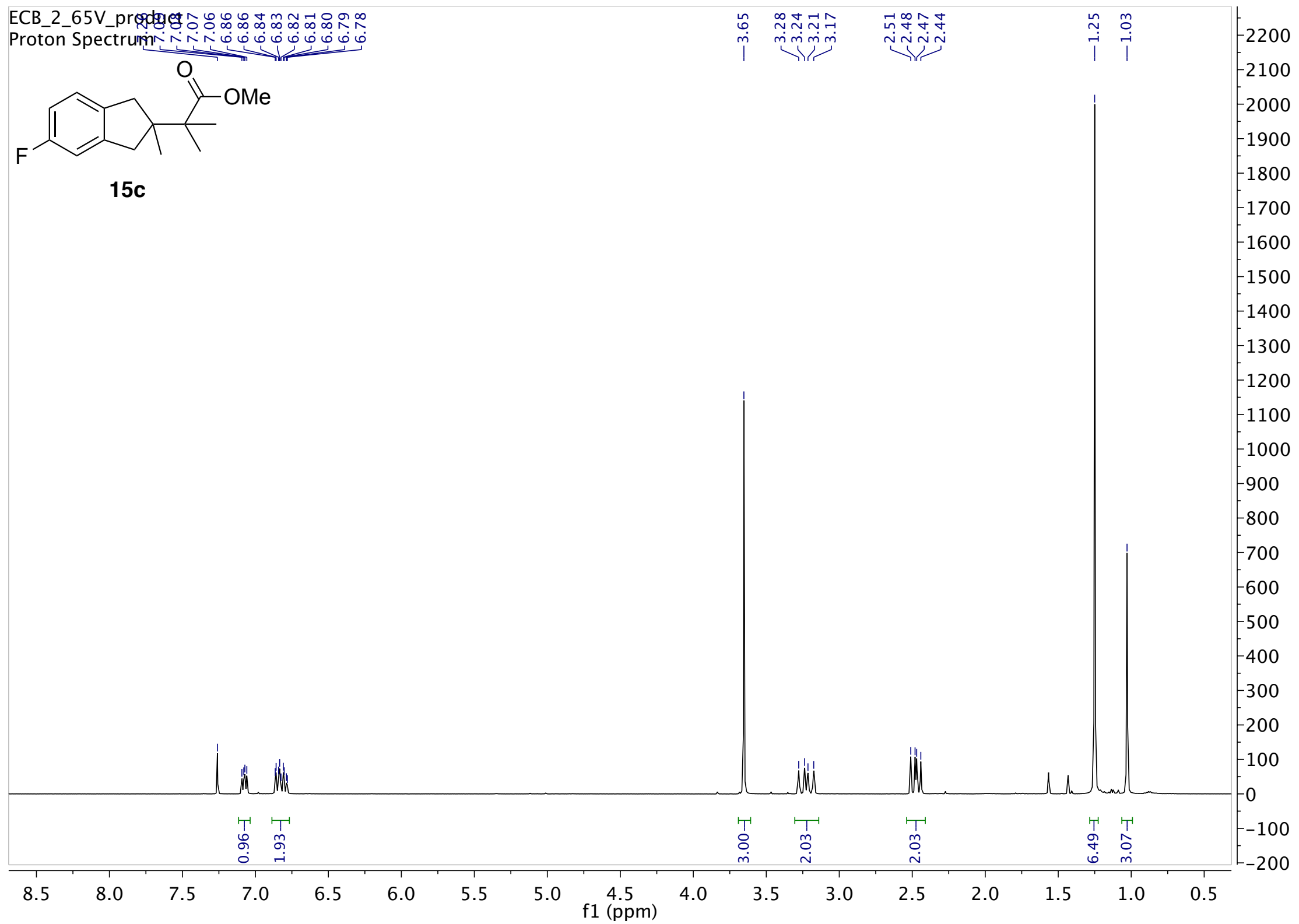




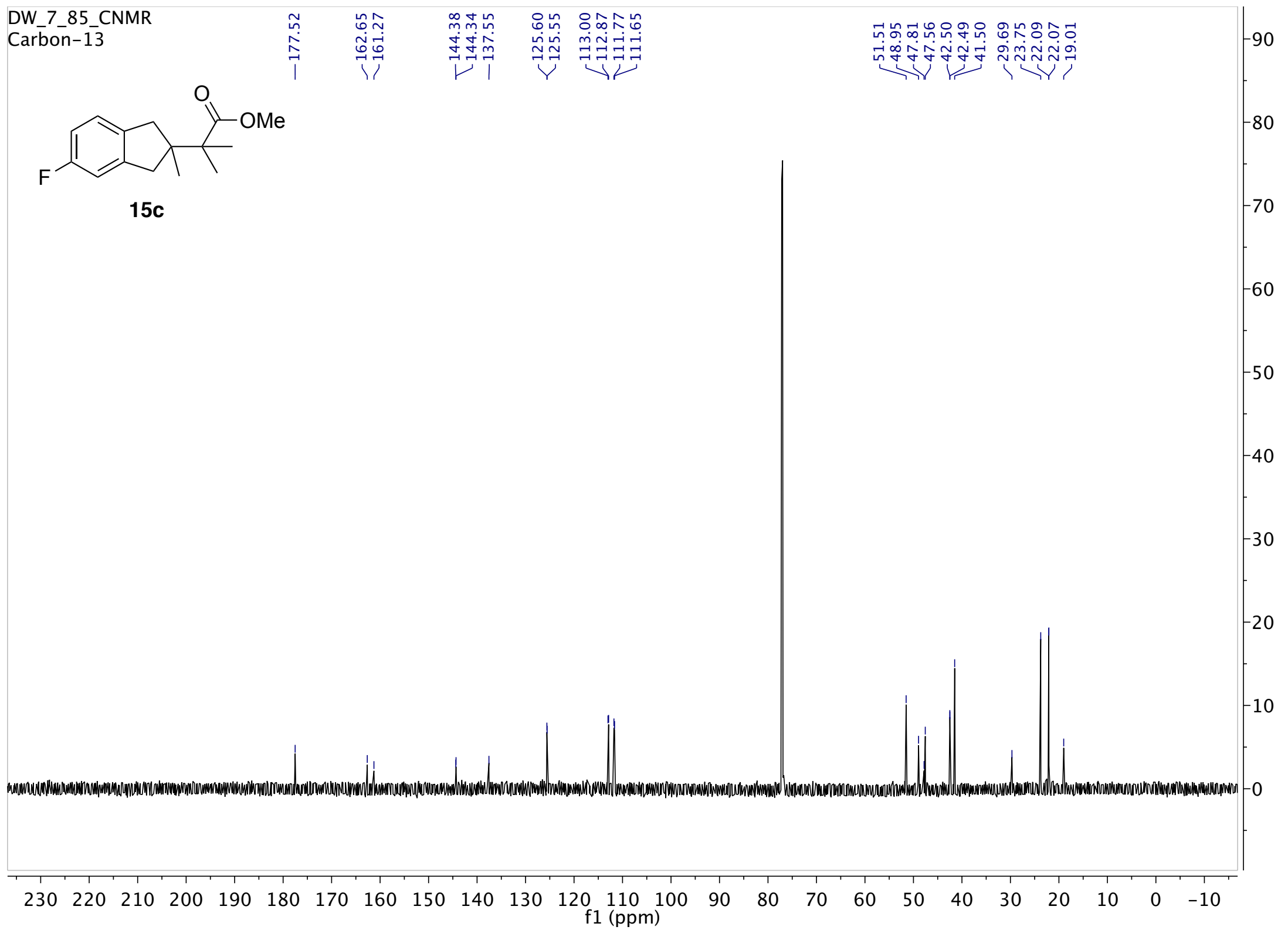




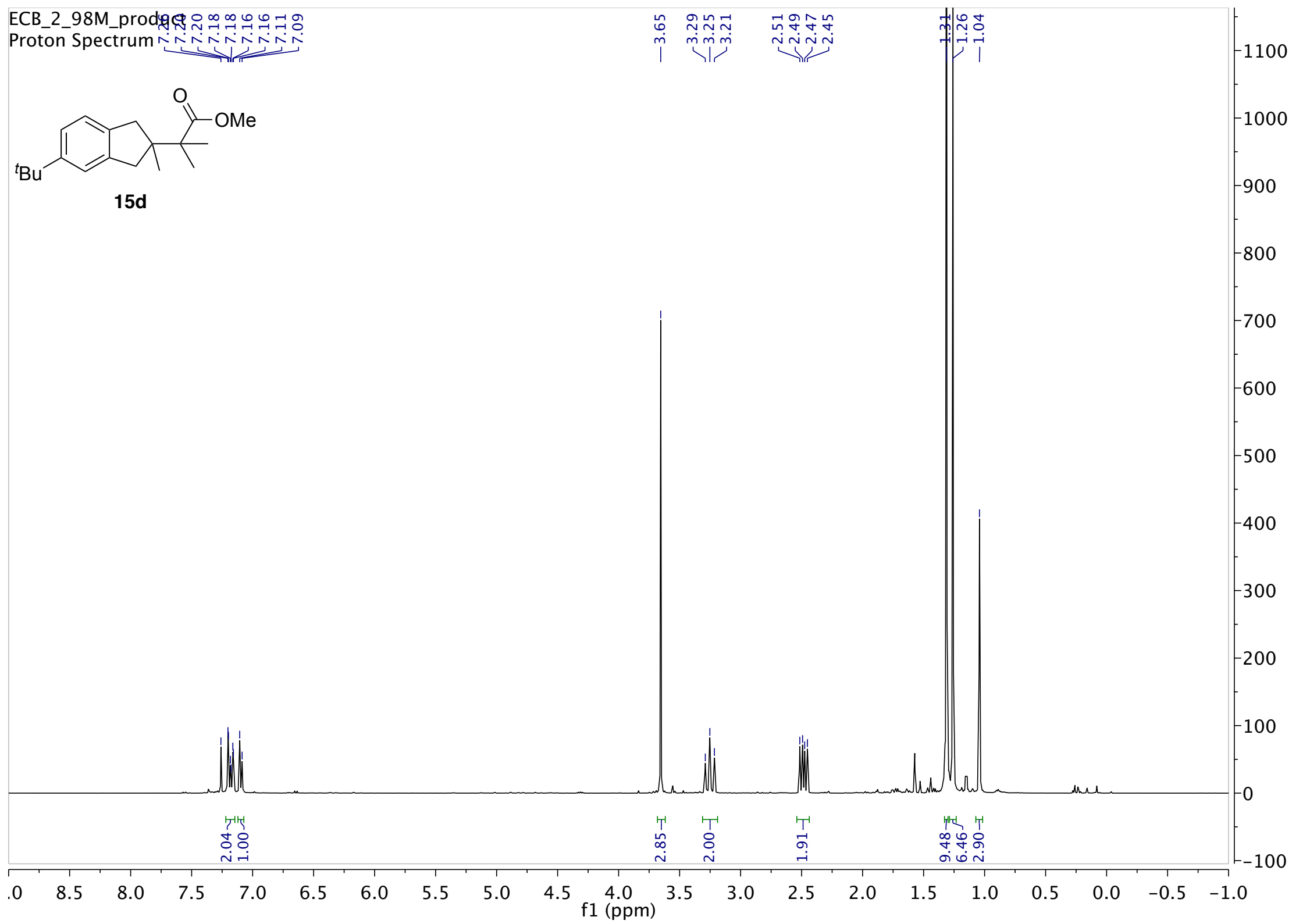




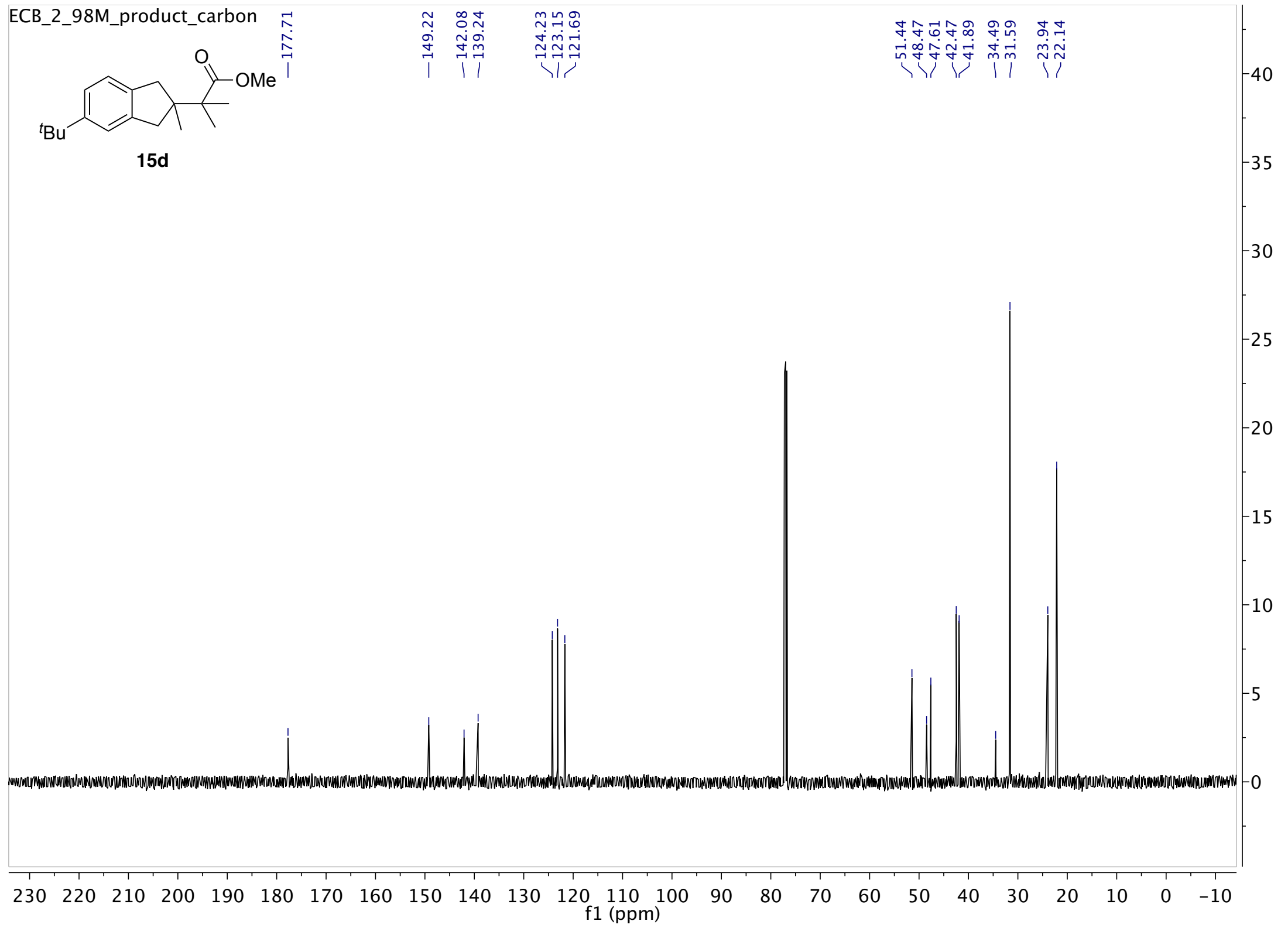




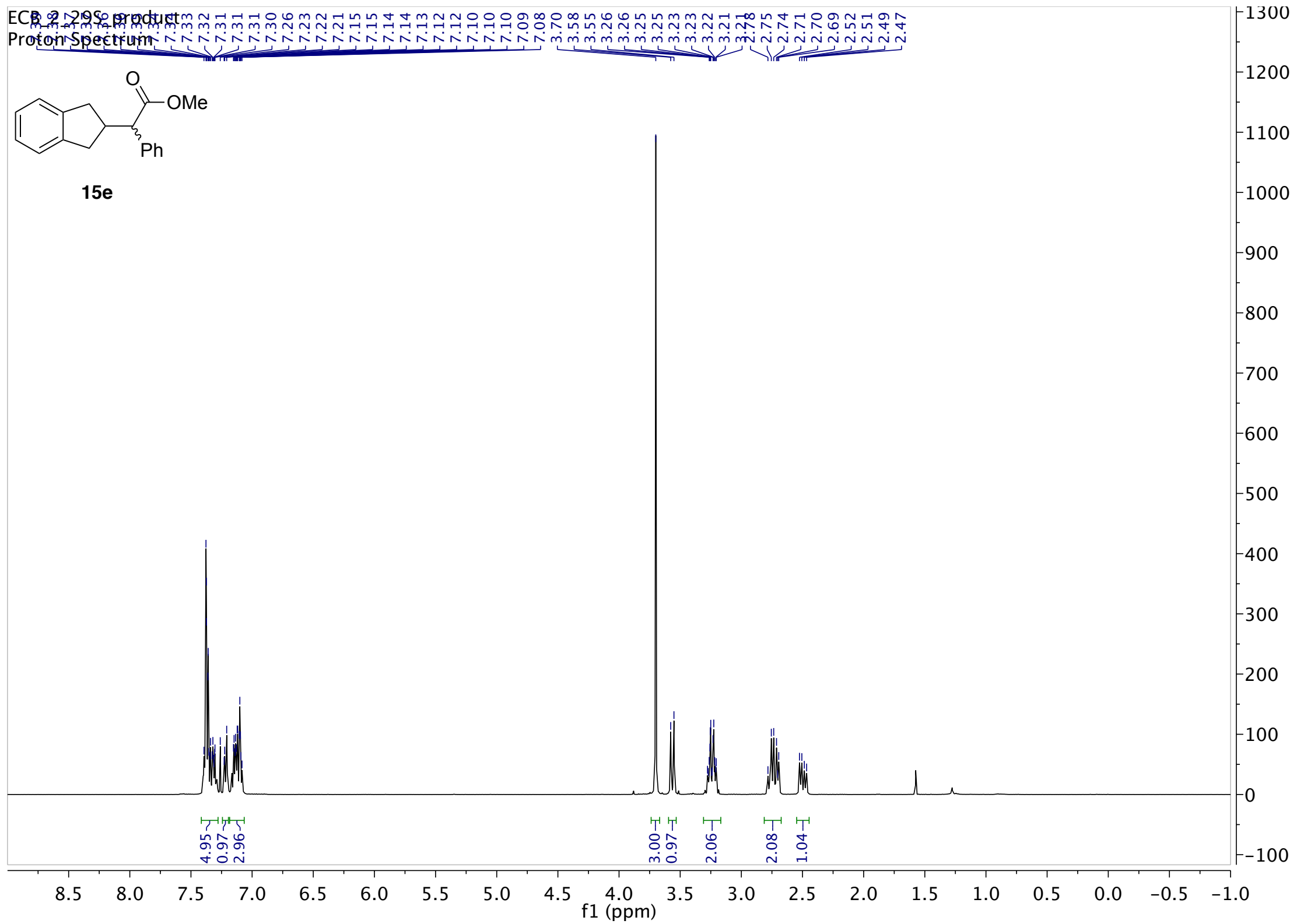




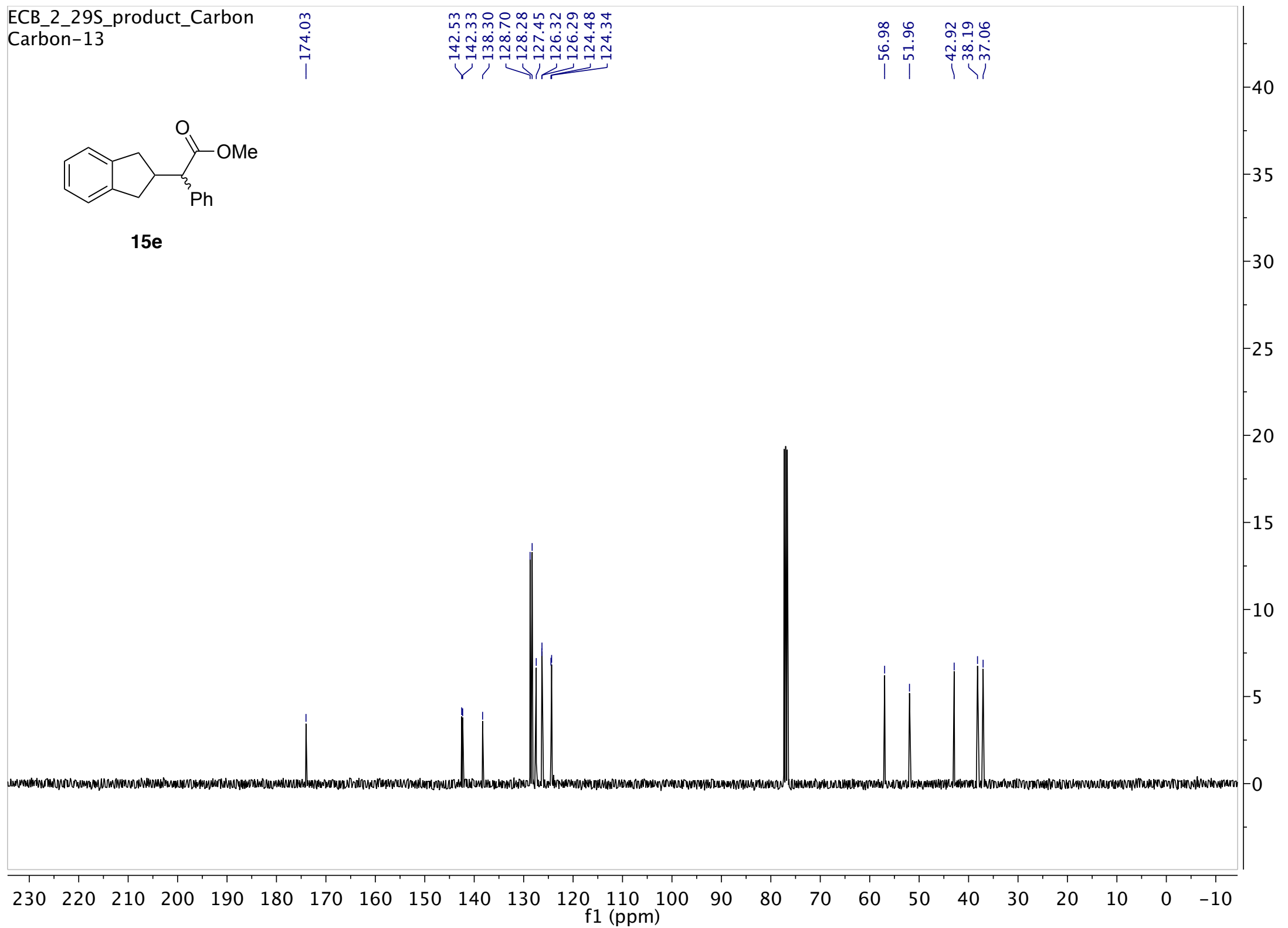




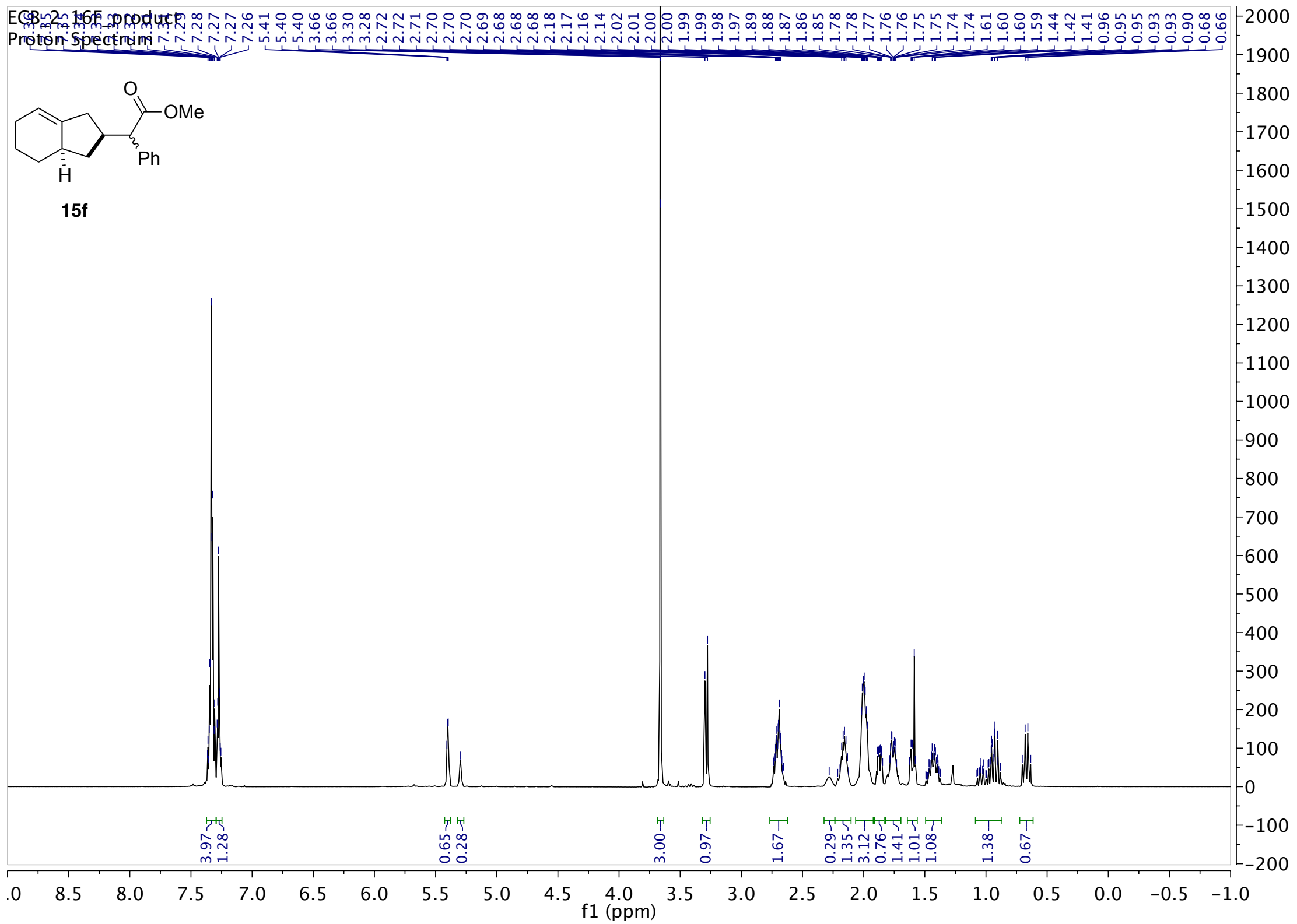




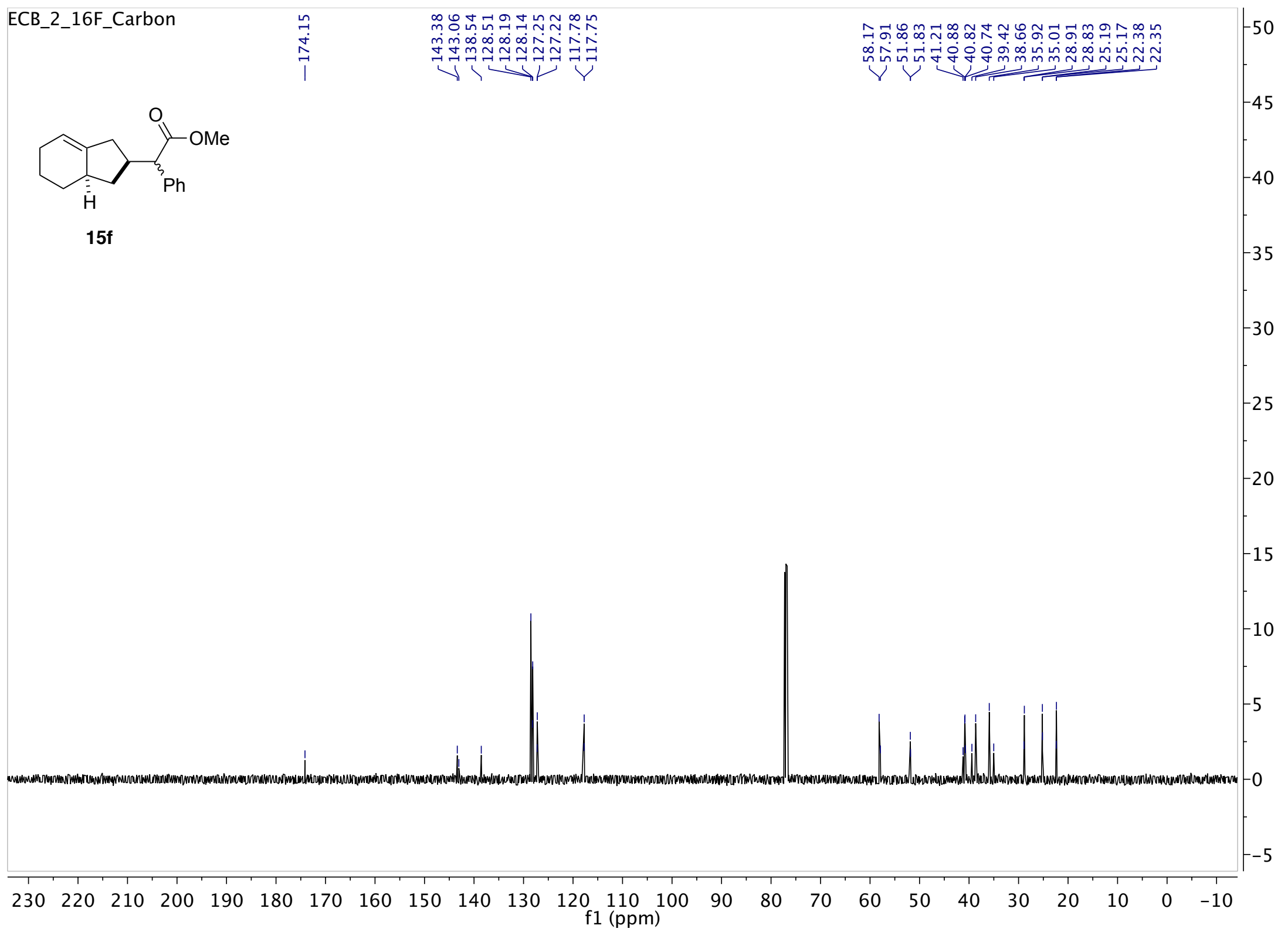




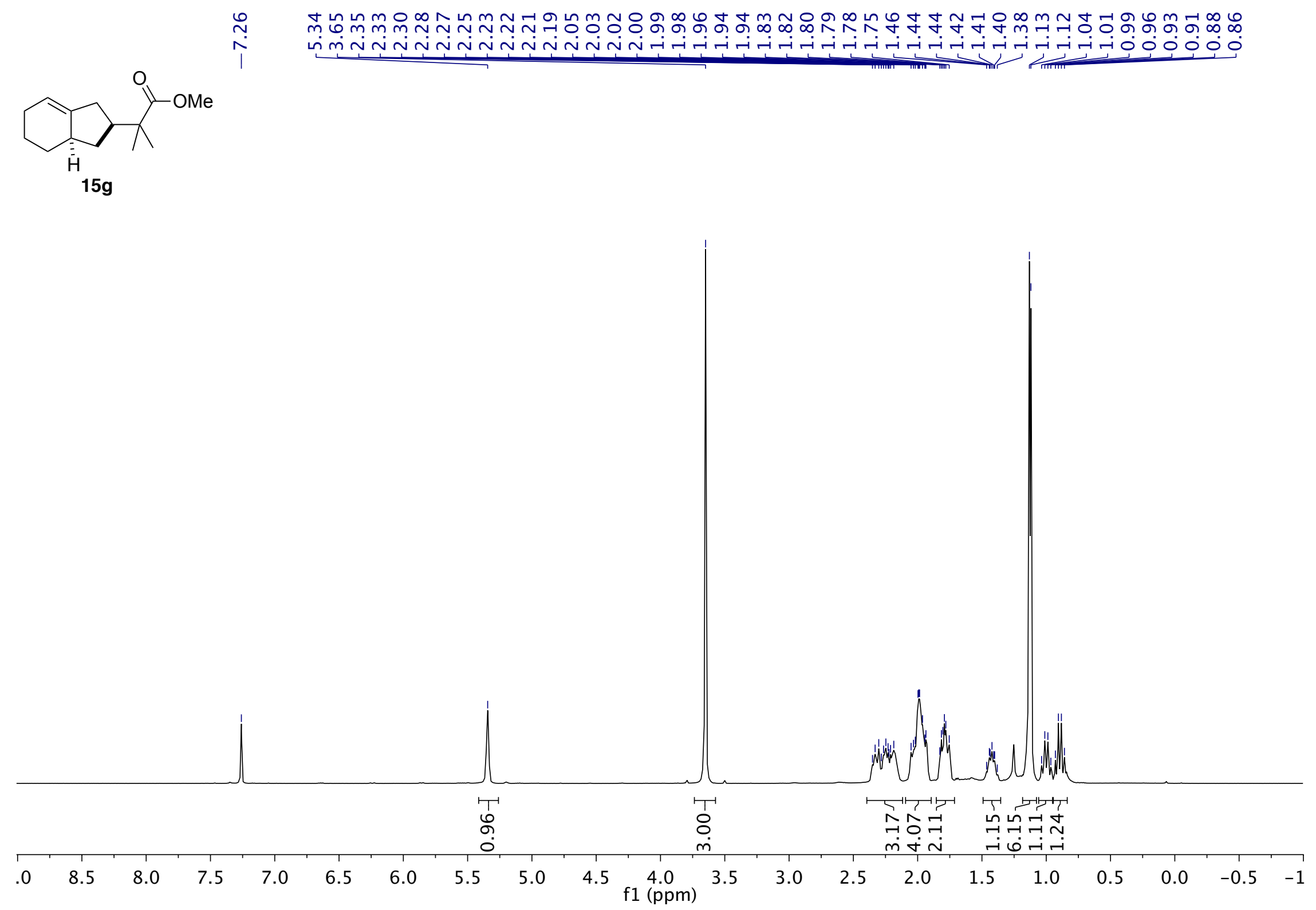




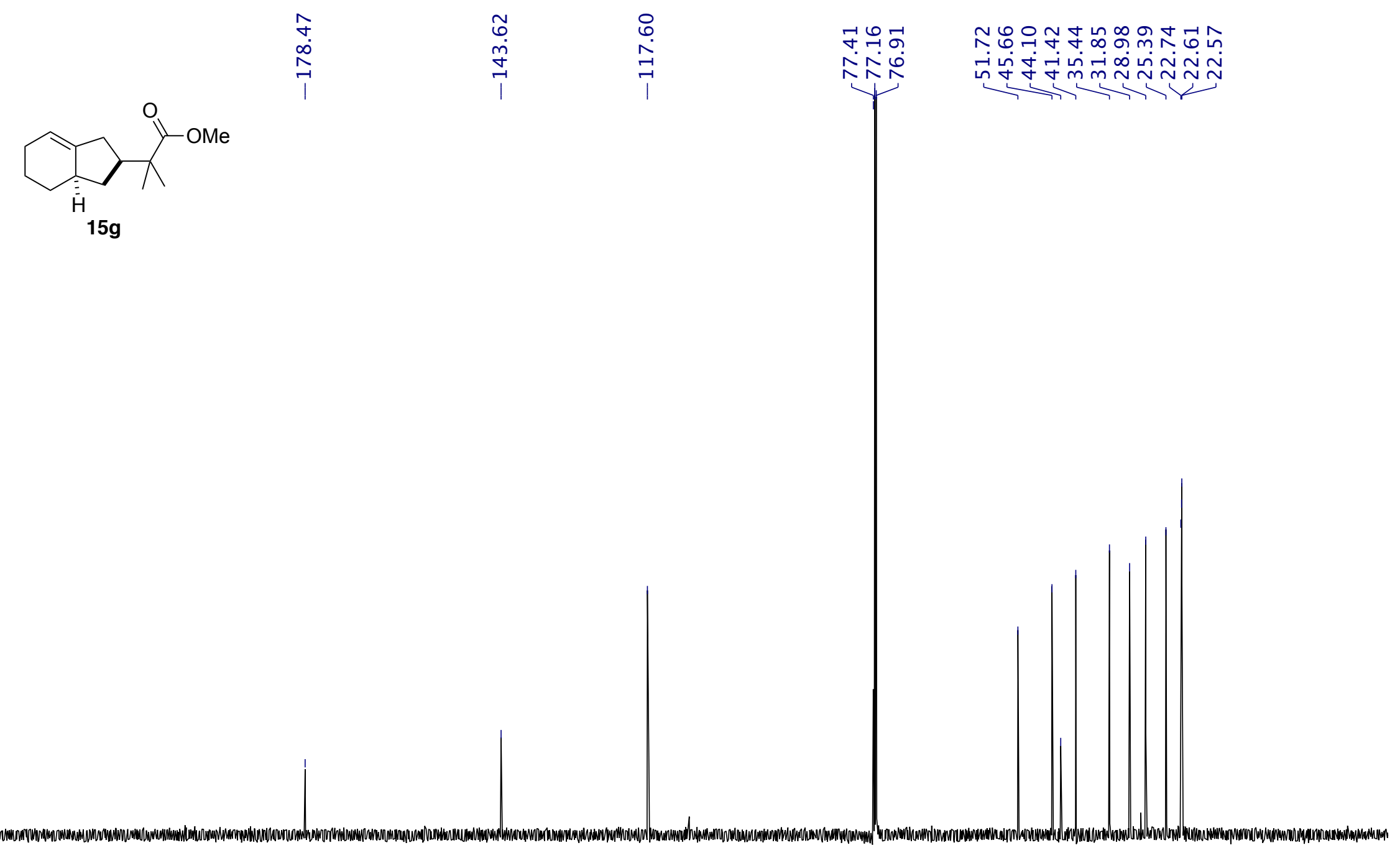

$\begin{array}{lllllllllllllllllllllllllllll}230 & 220 & 210 & 200 & 190 & 180 & 170 & 160 & 150 & 140 & 130 & 120 & 110 & 100 & 90 & 80 & 70 & 60 & 50 & 40 & 30 & 20 & 10 & 0 & -10\end{array}$ 


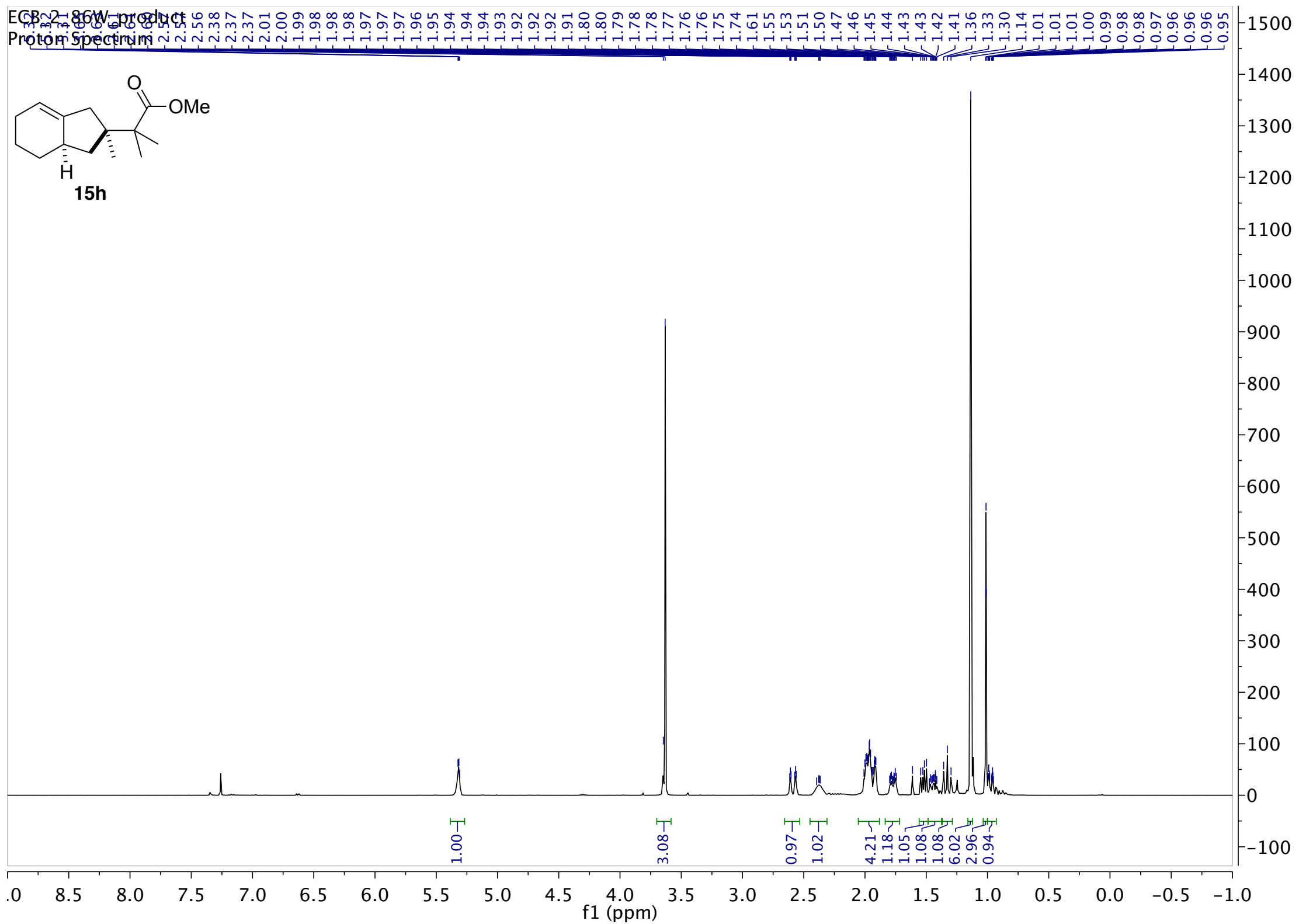




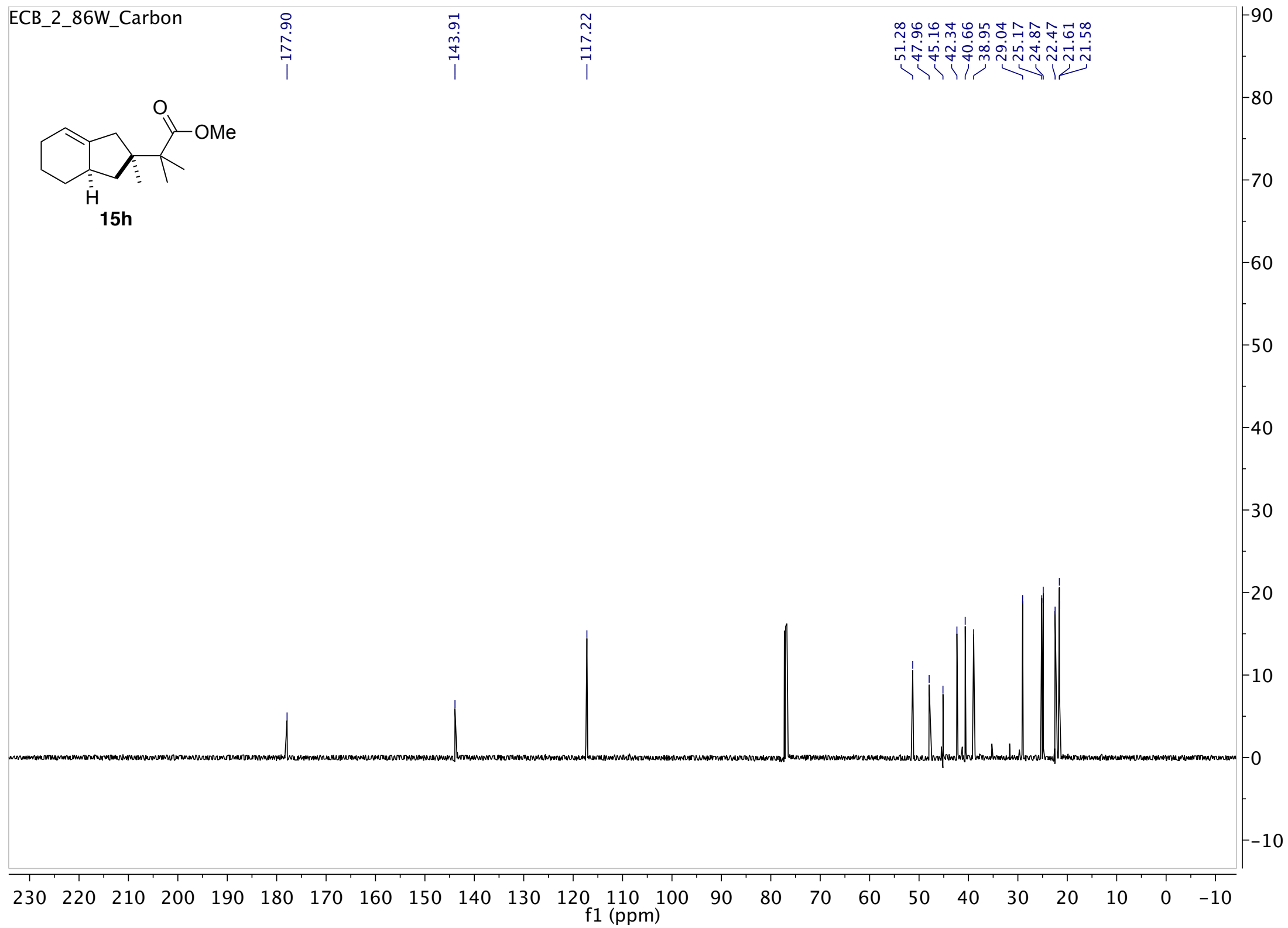




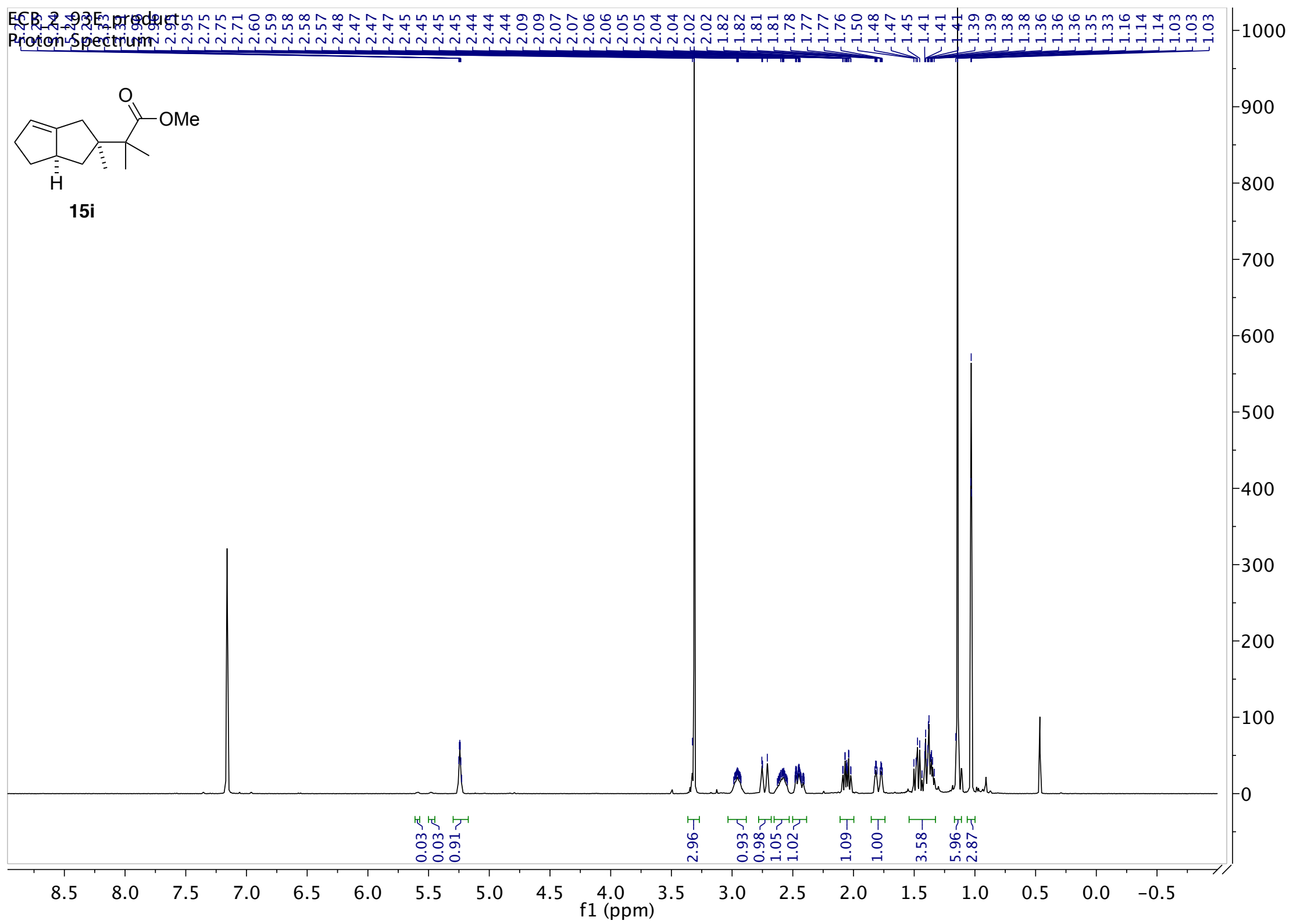




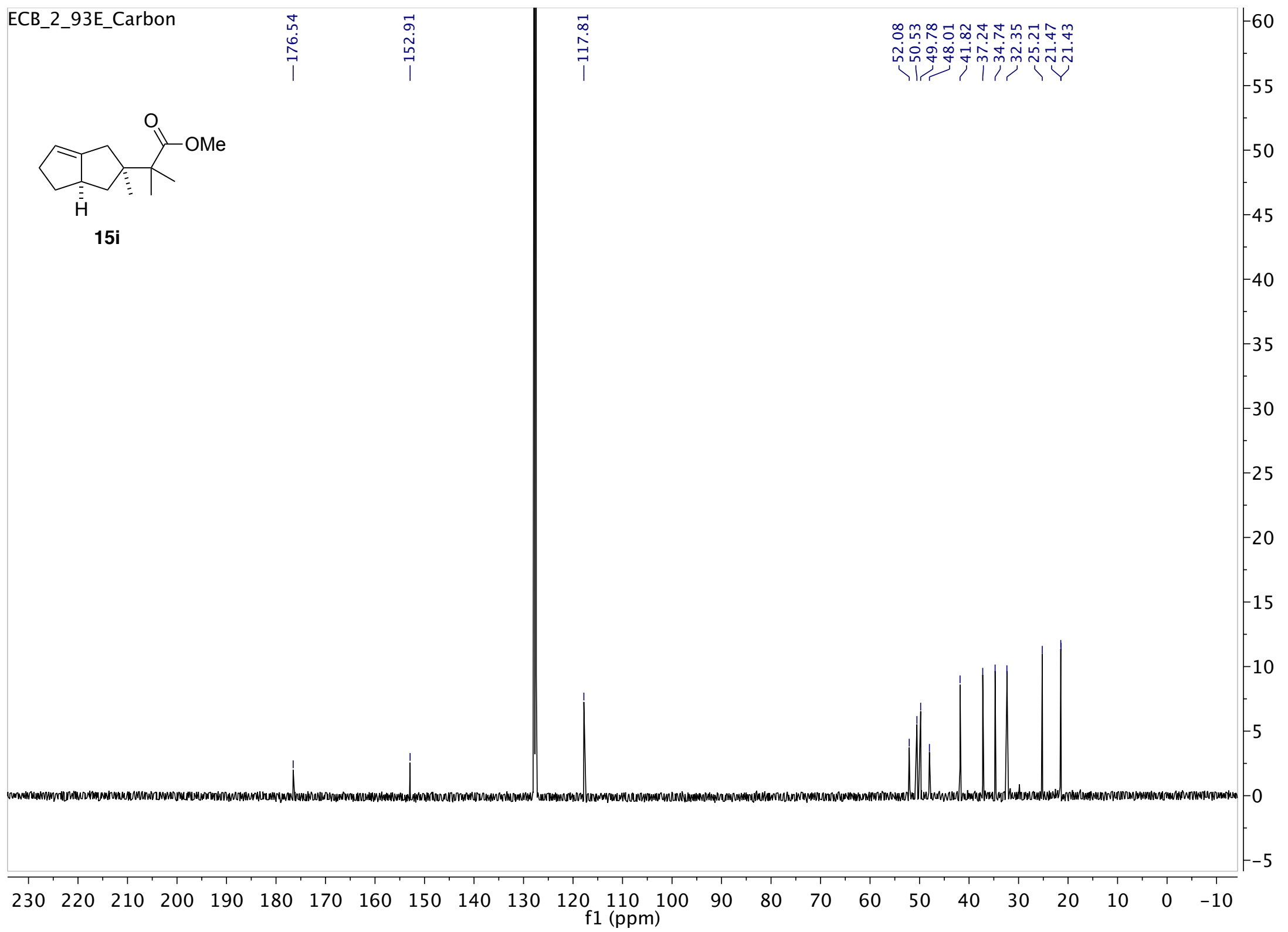




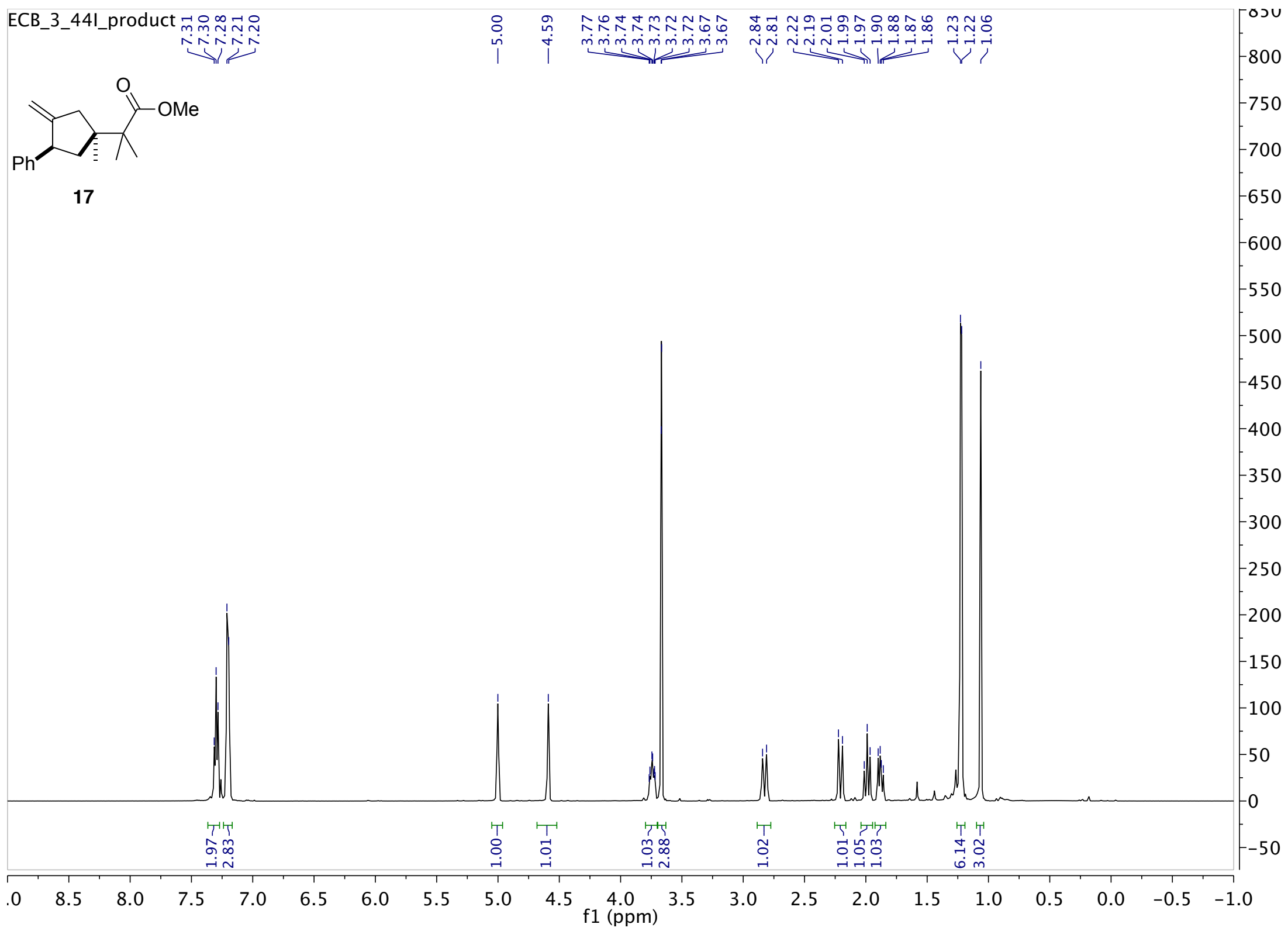




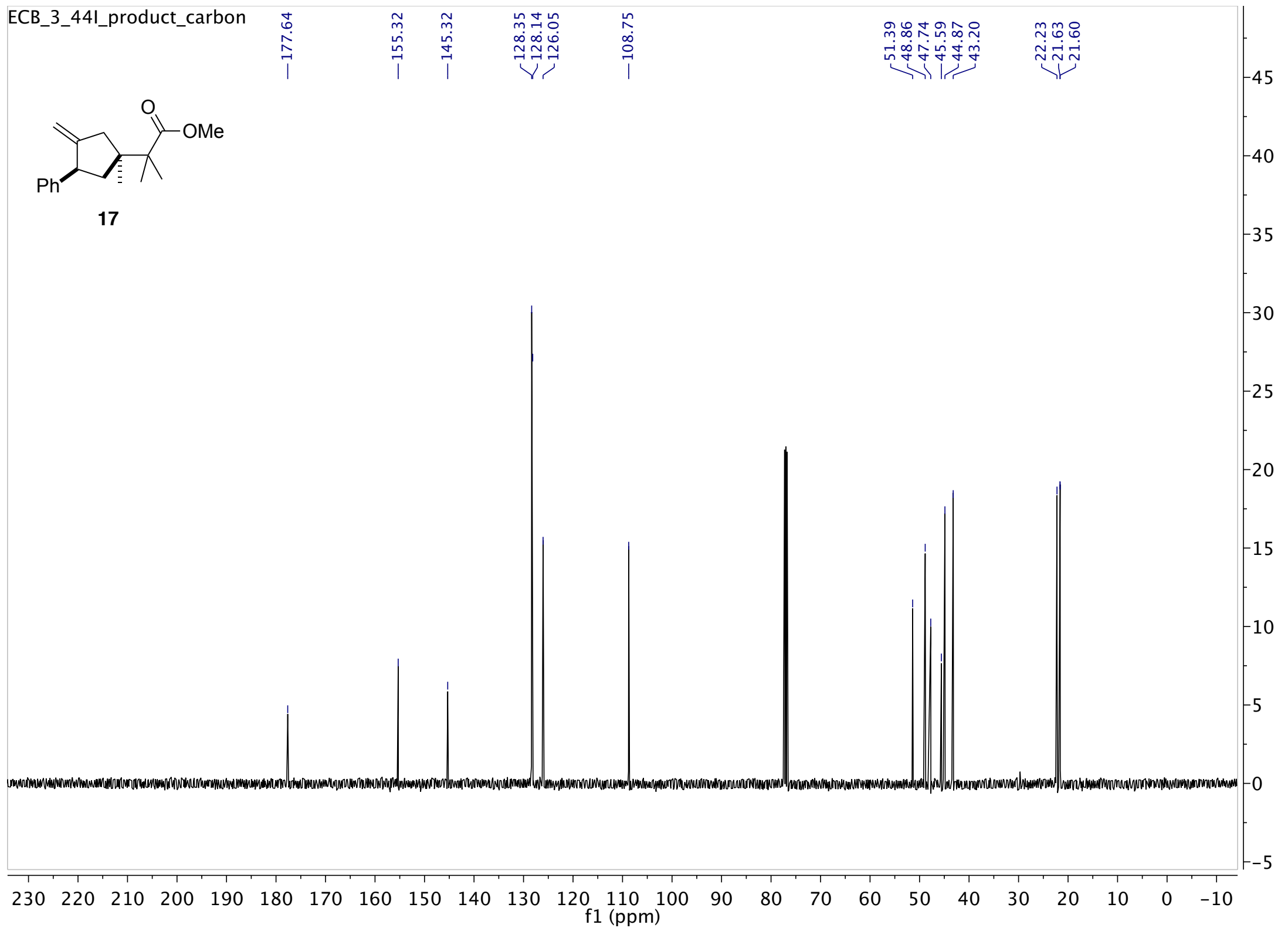




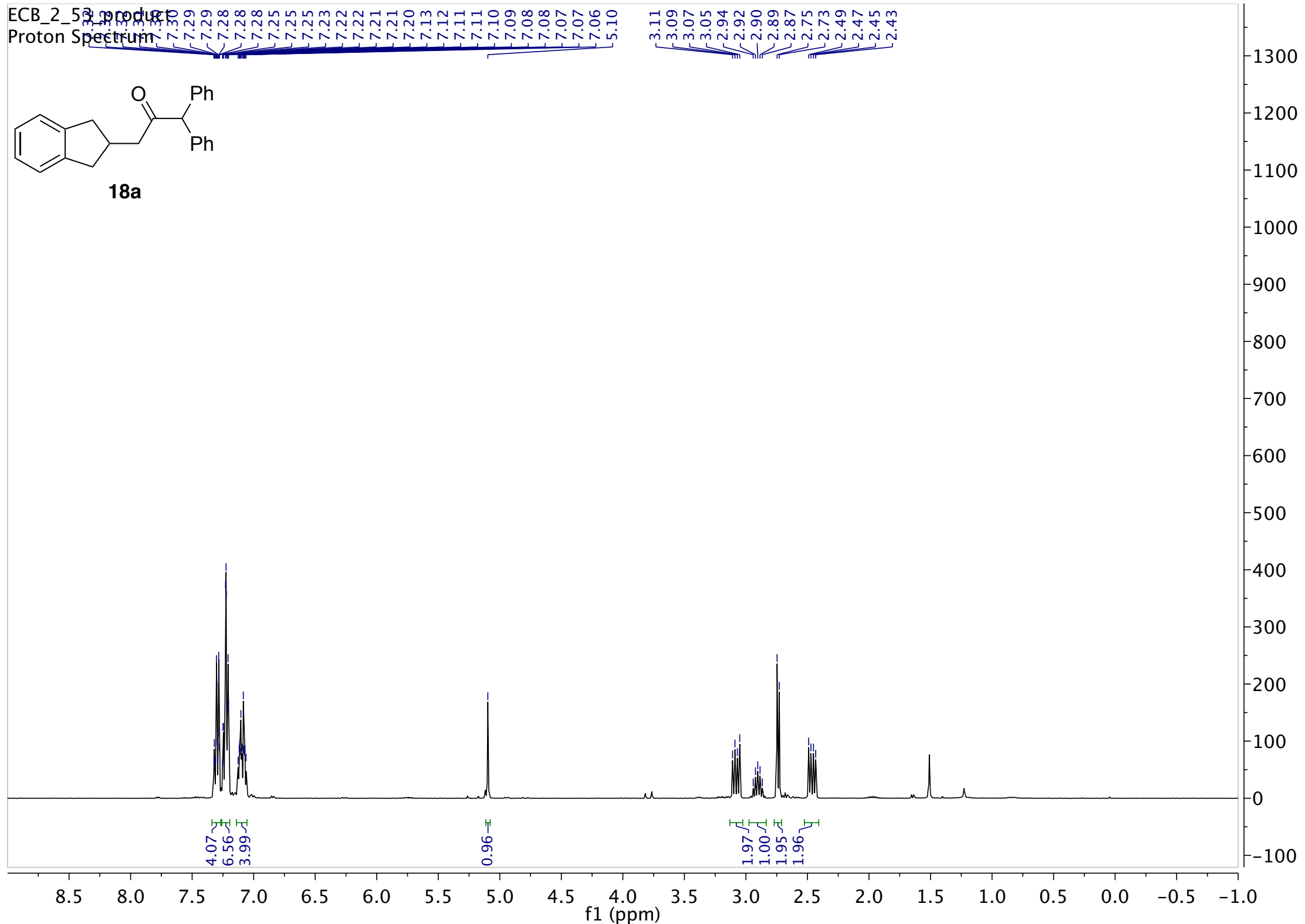




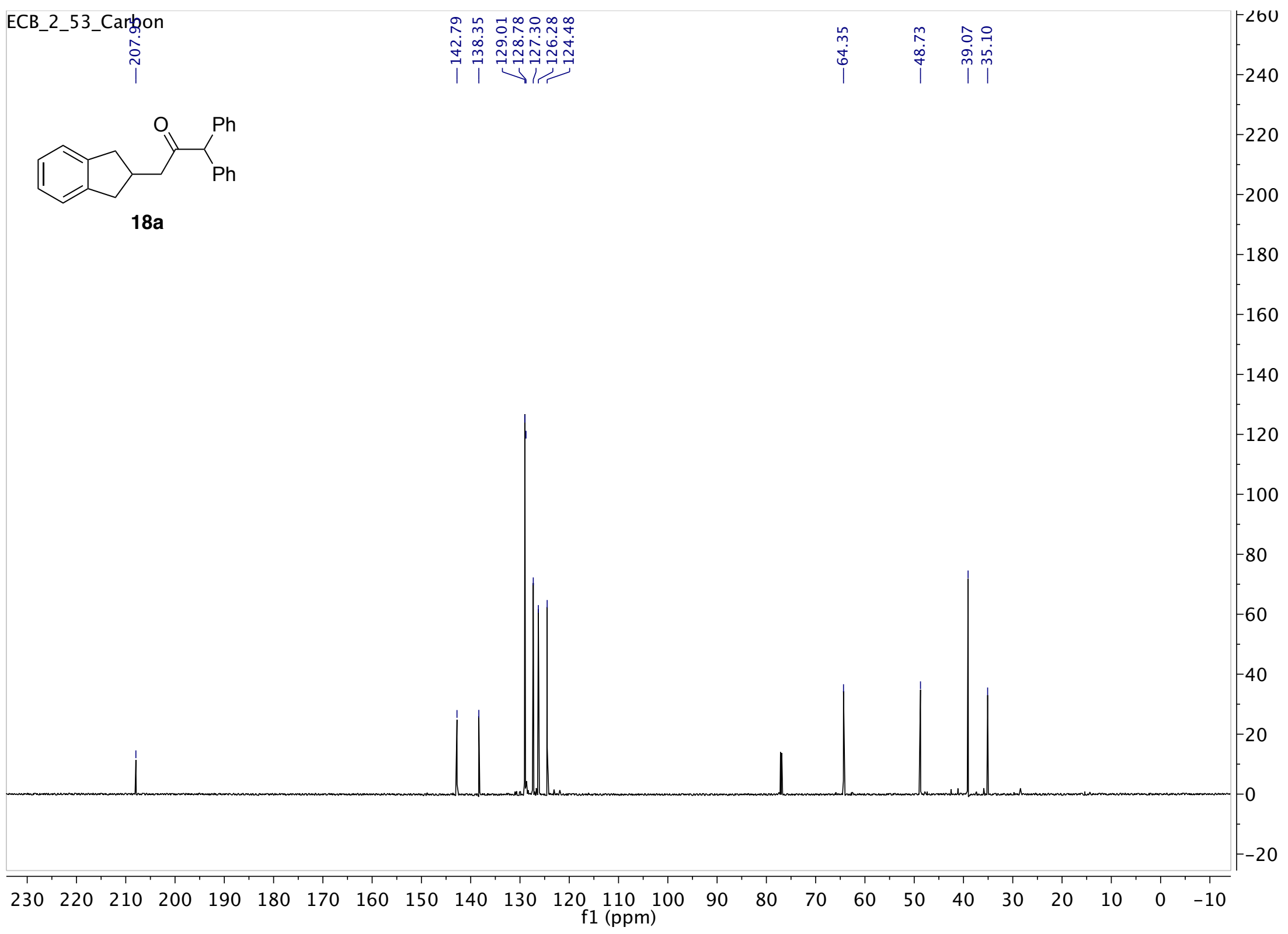


ECB_3 Protonseetrum

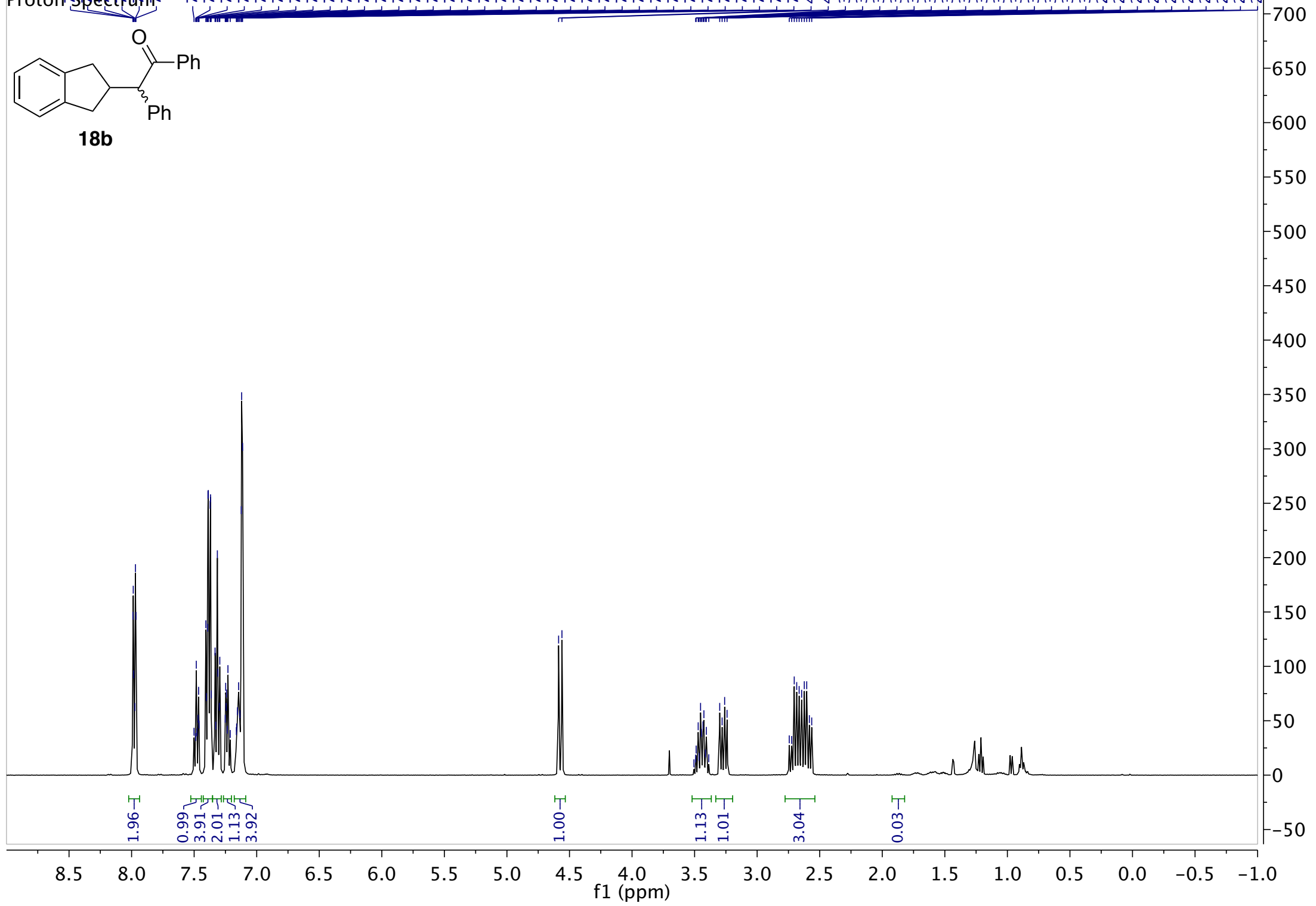




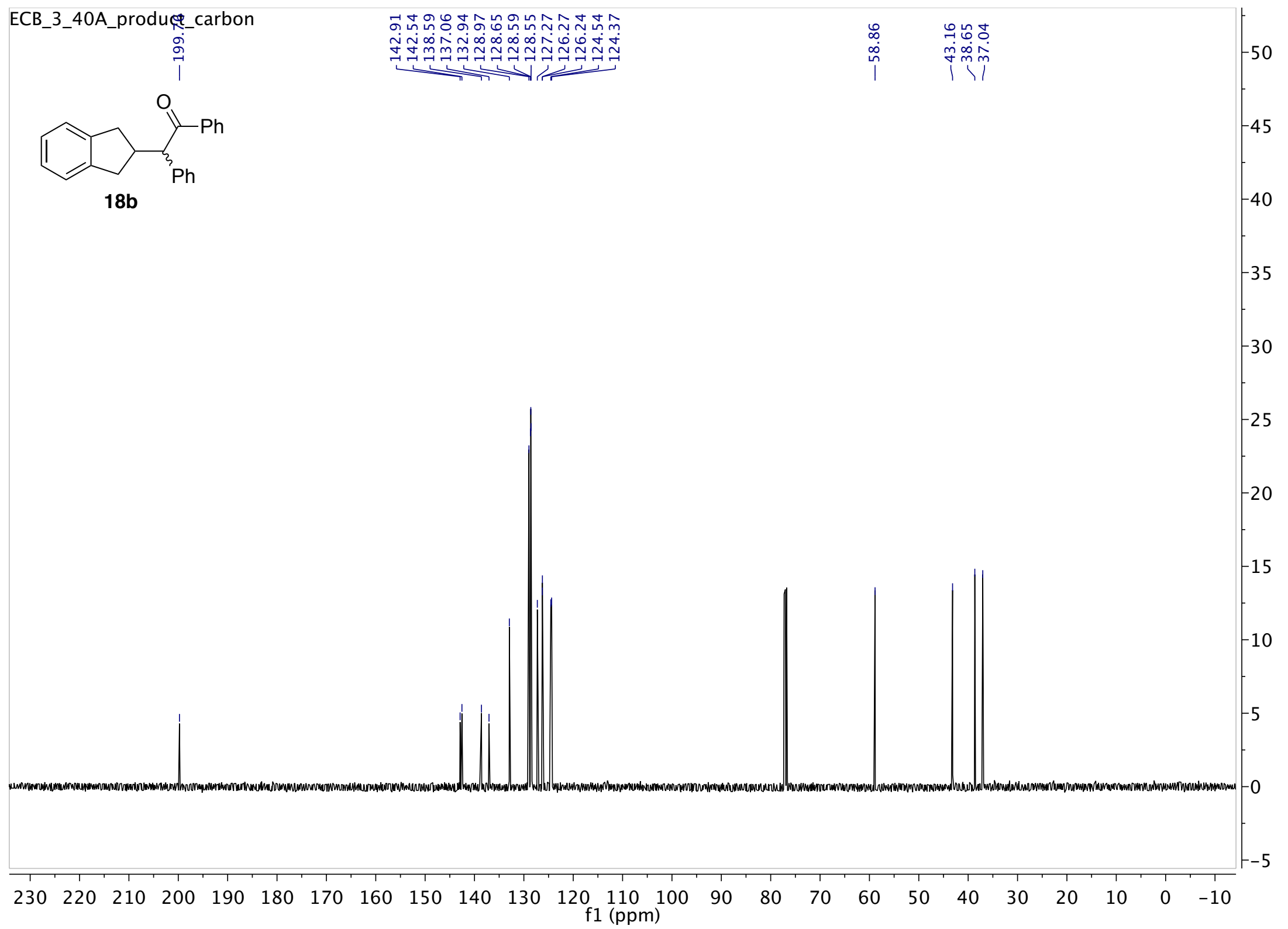




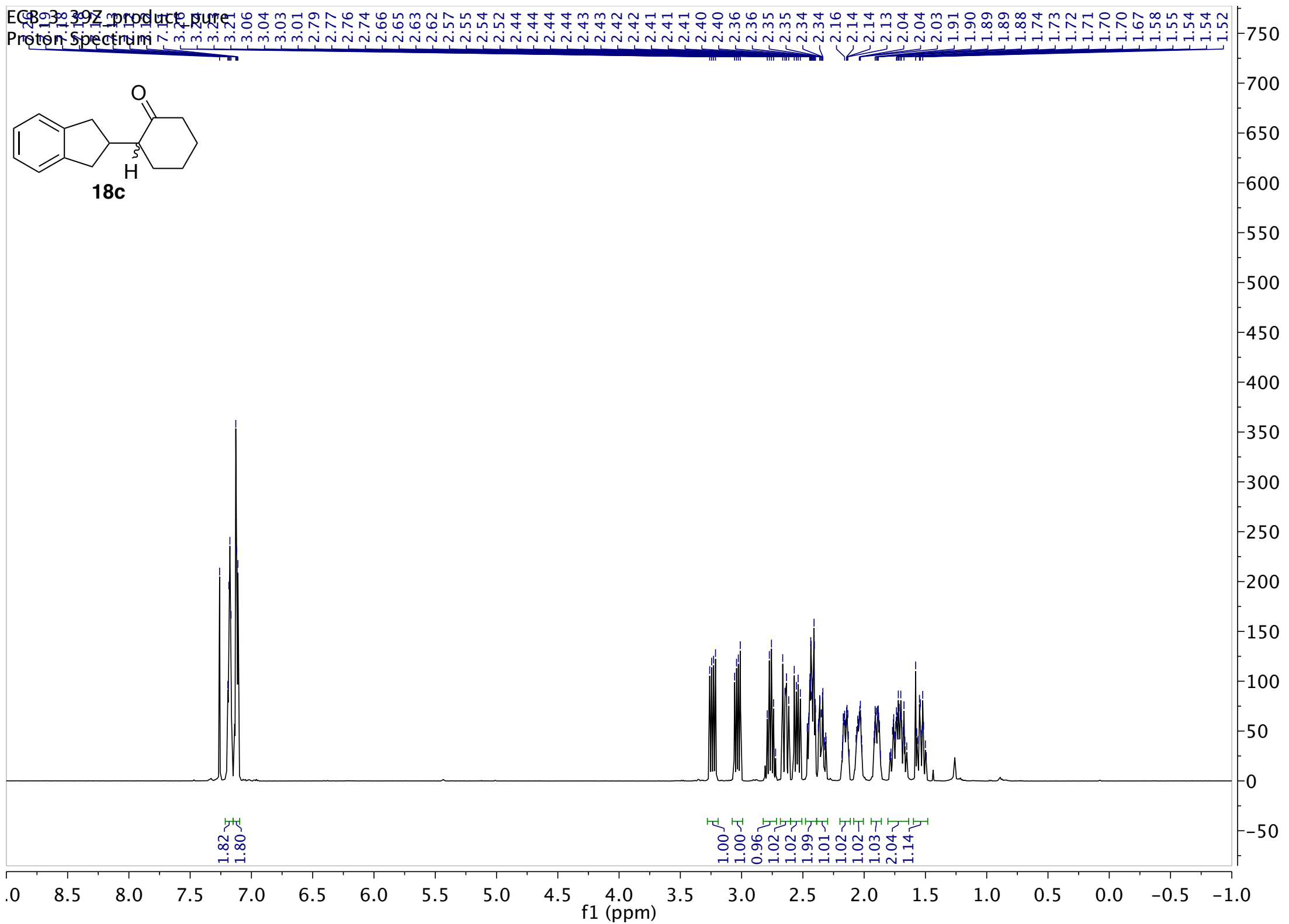




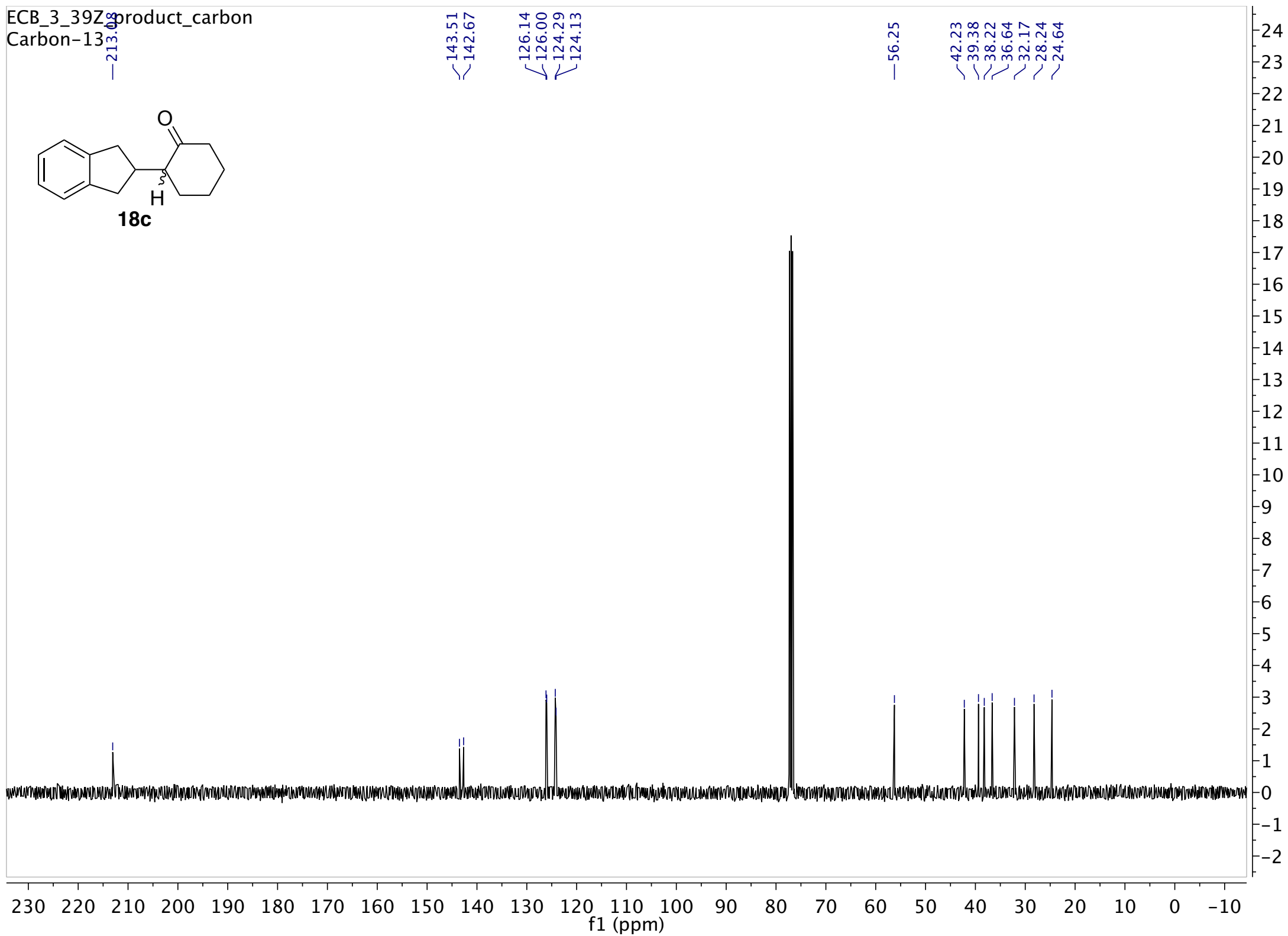




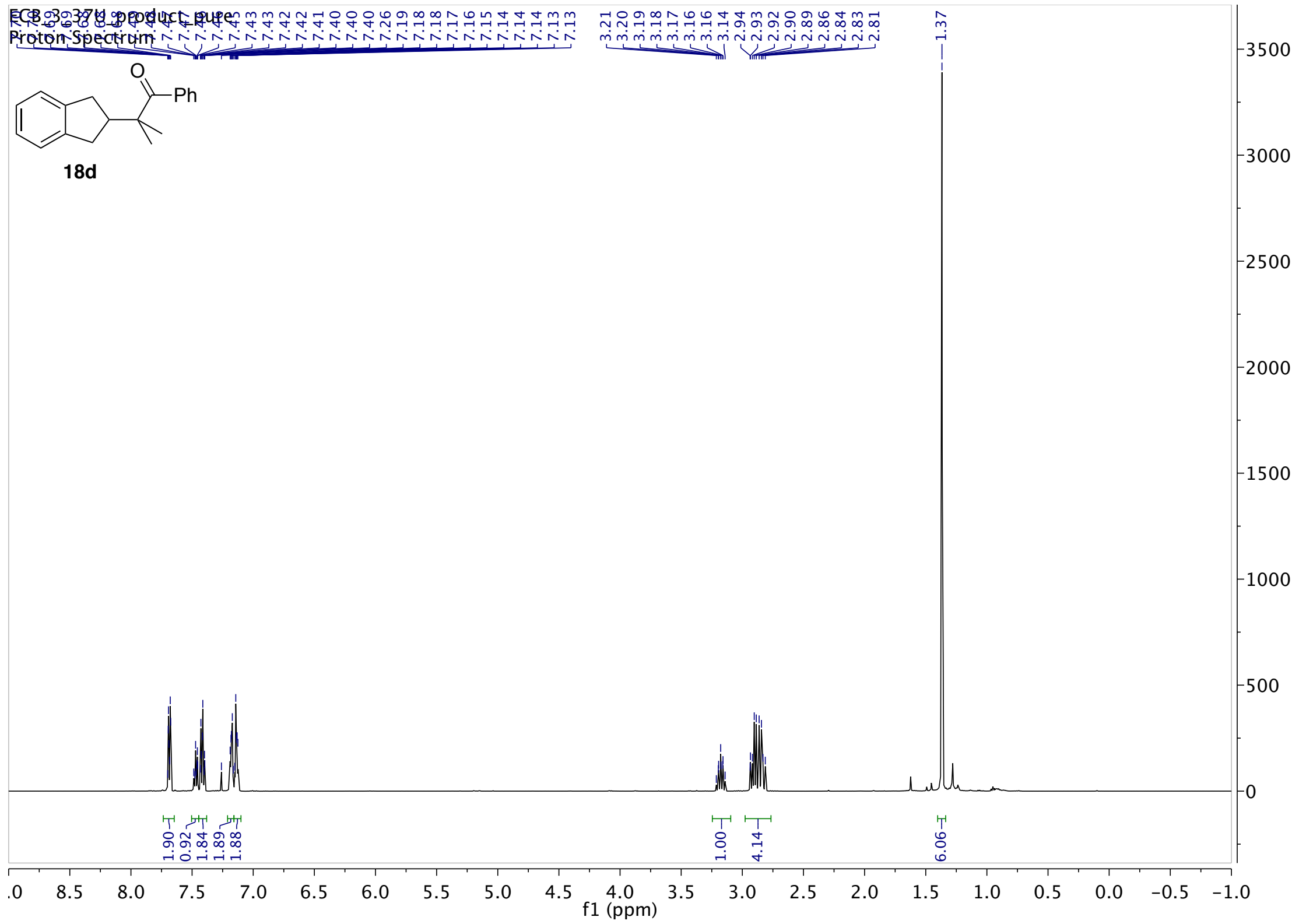




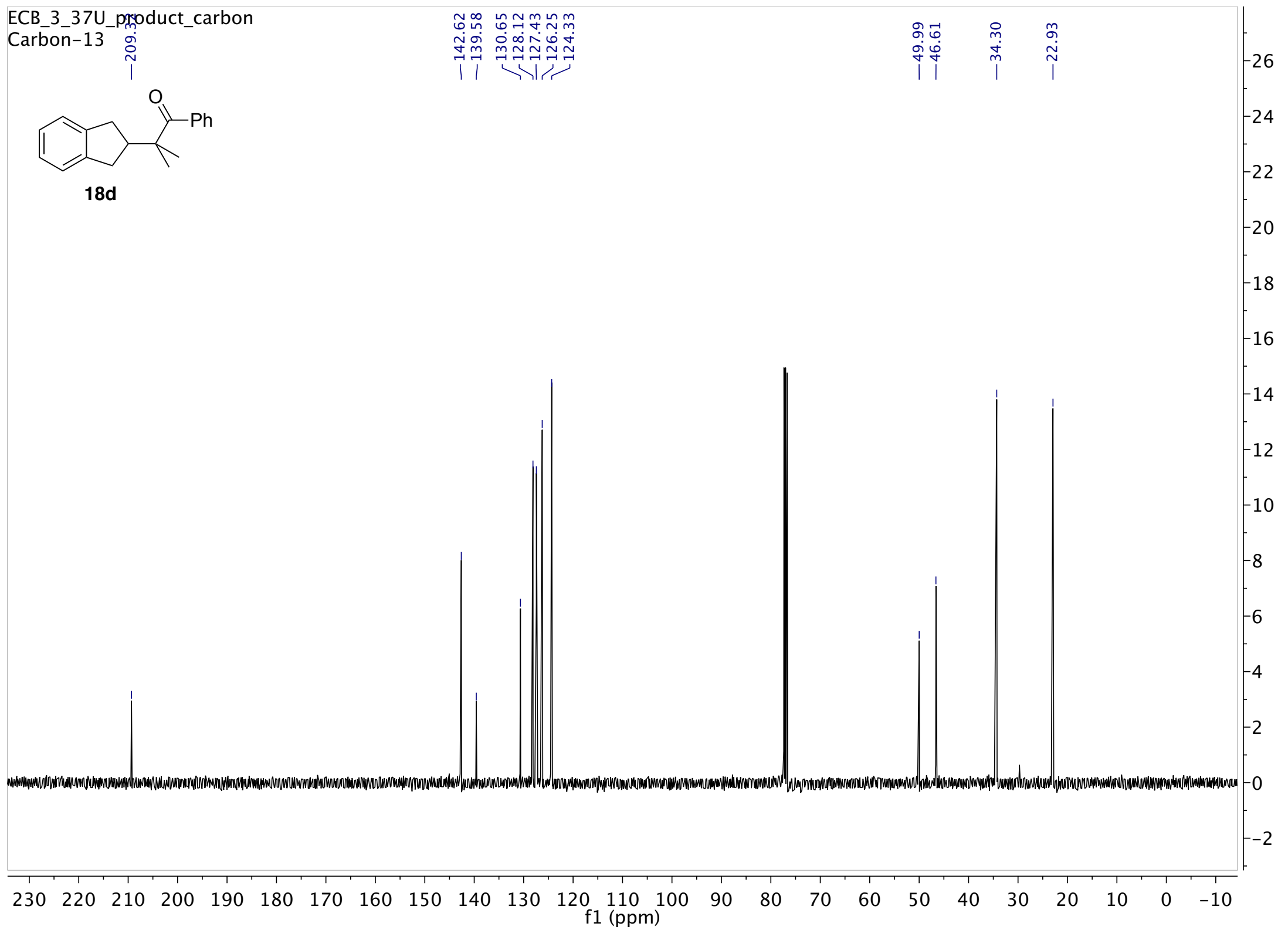




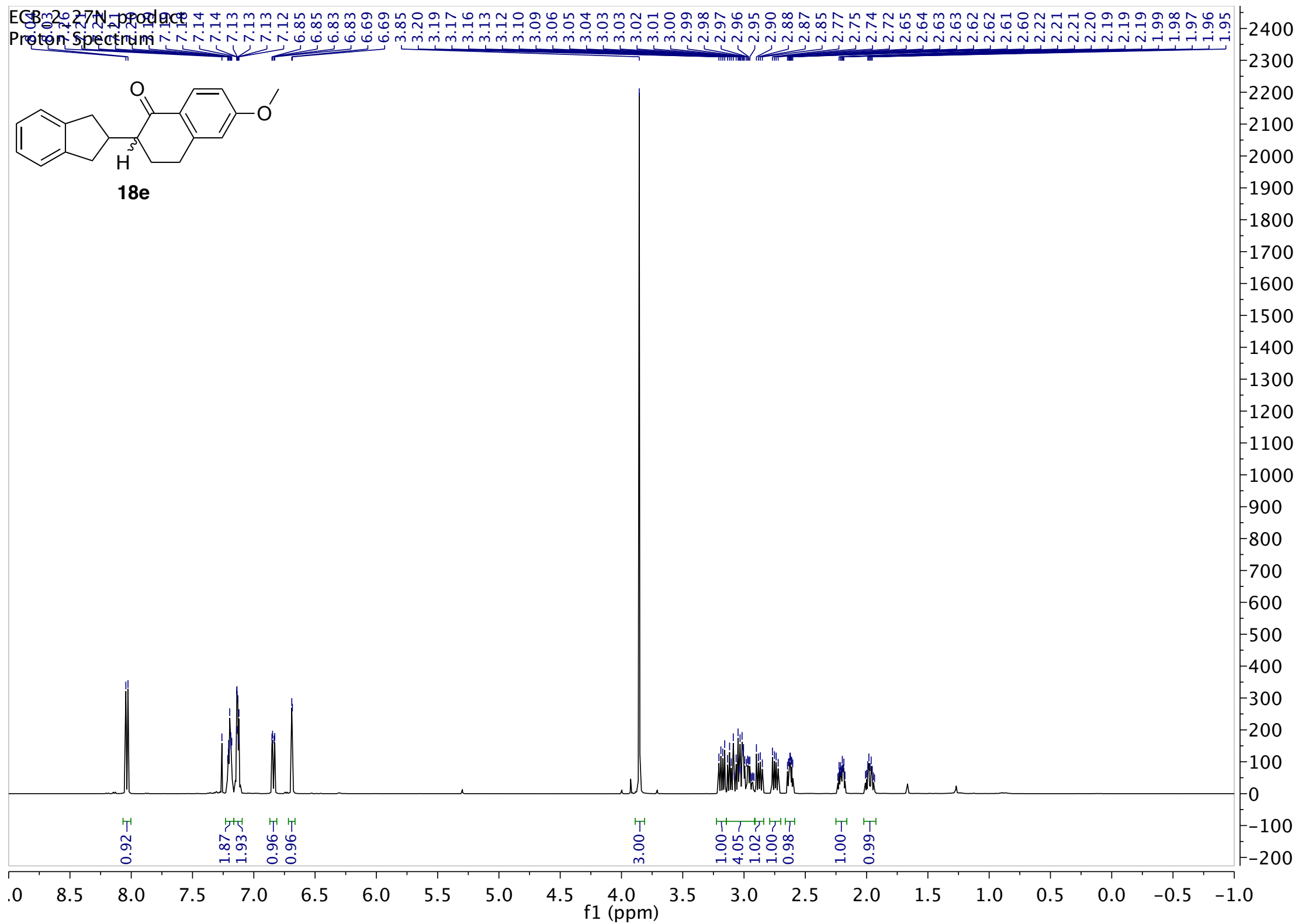




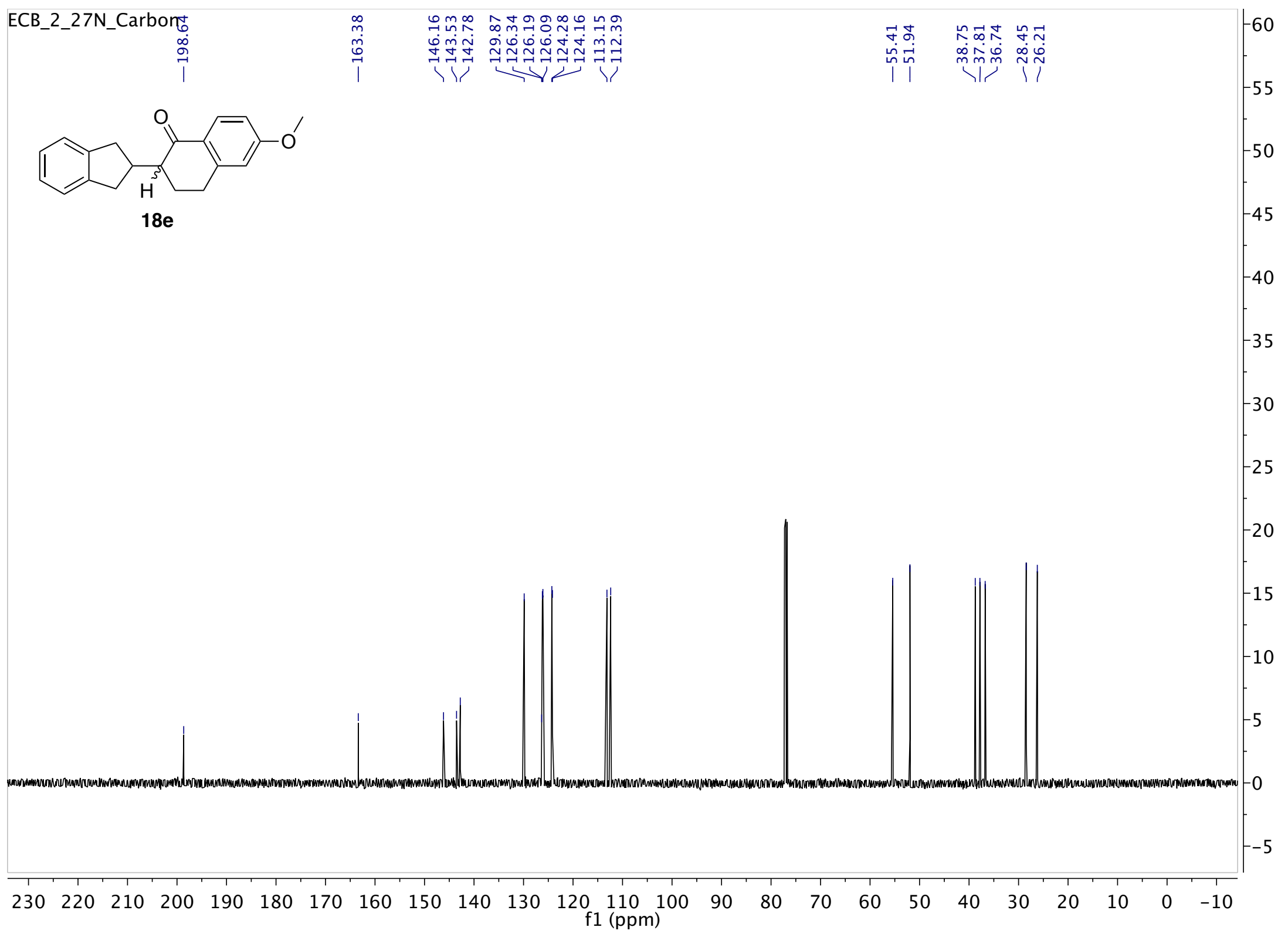




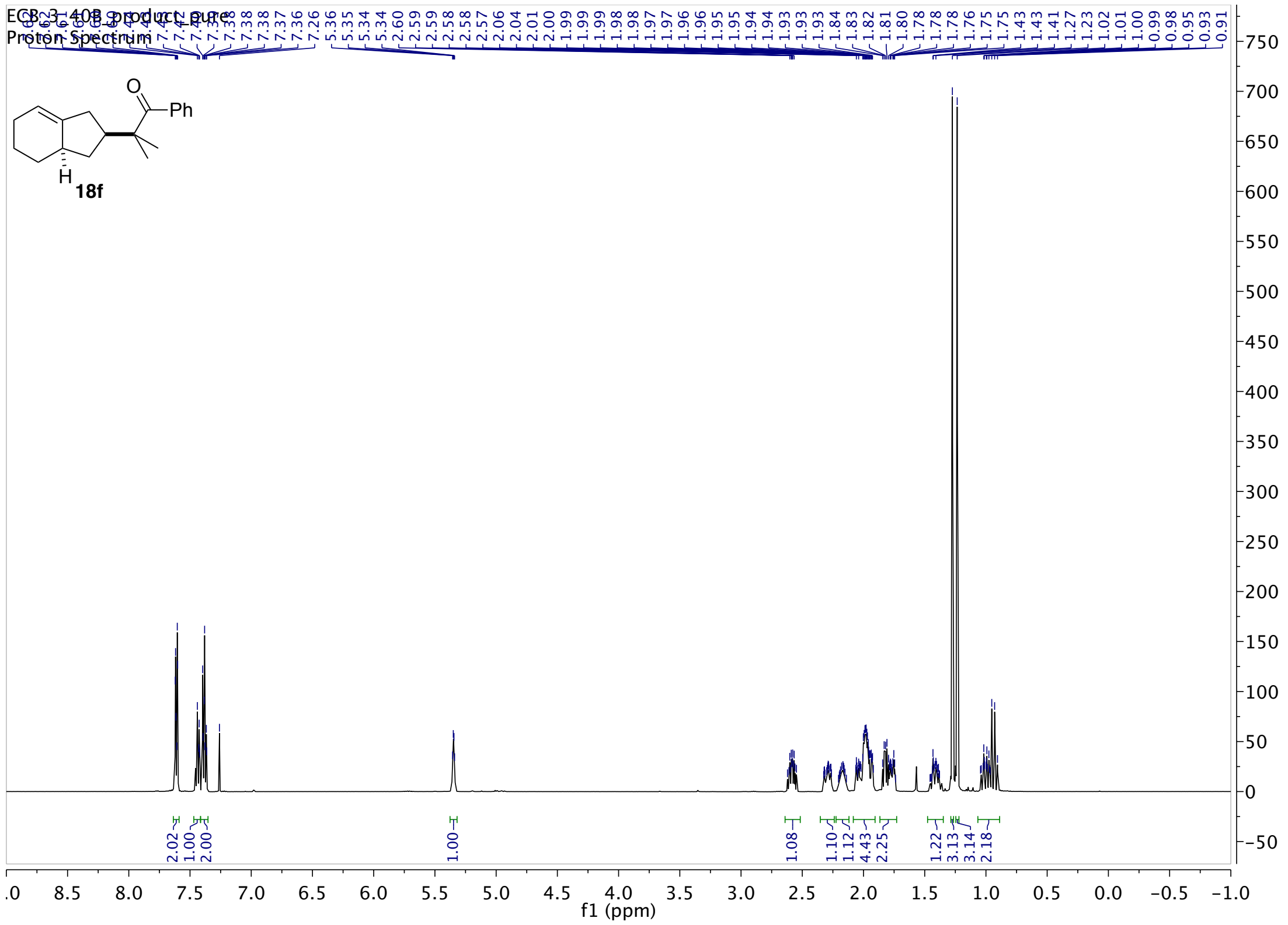




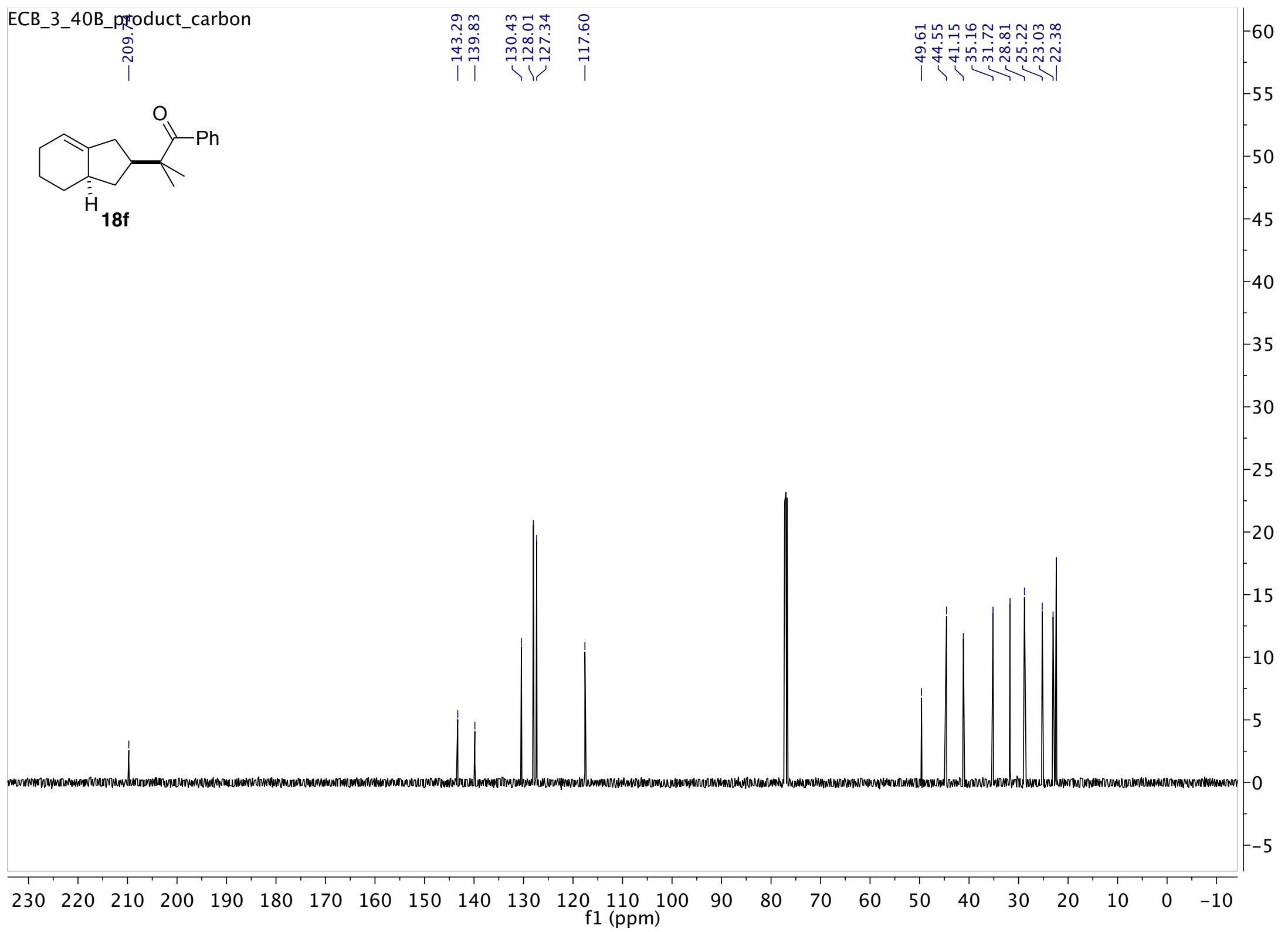




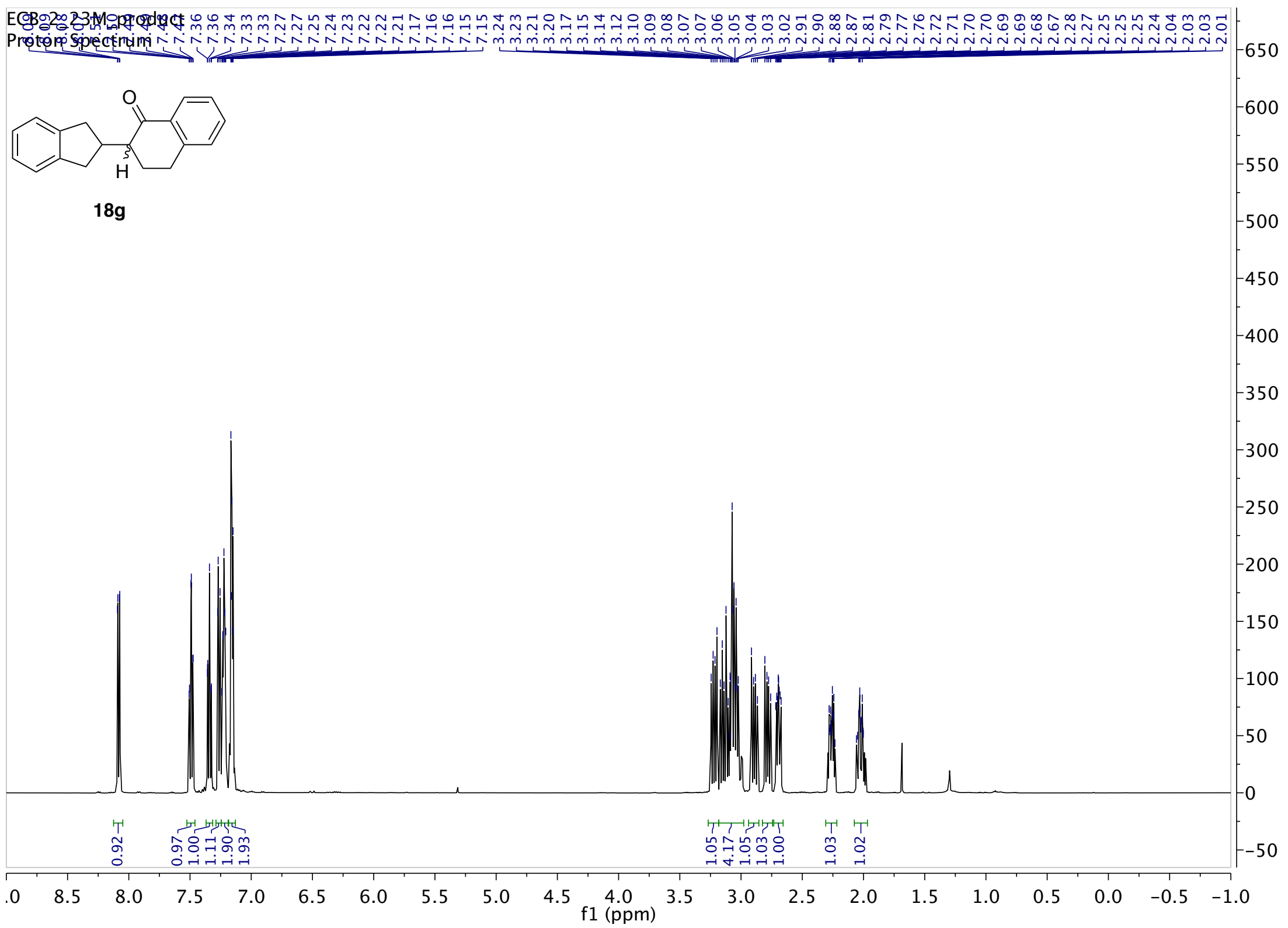




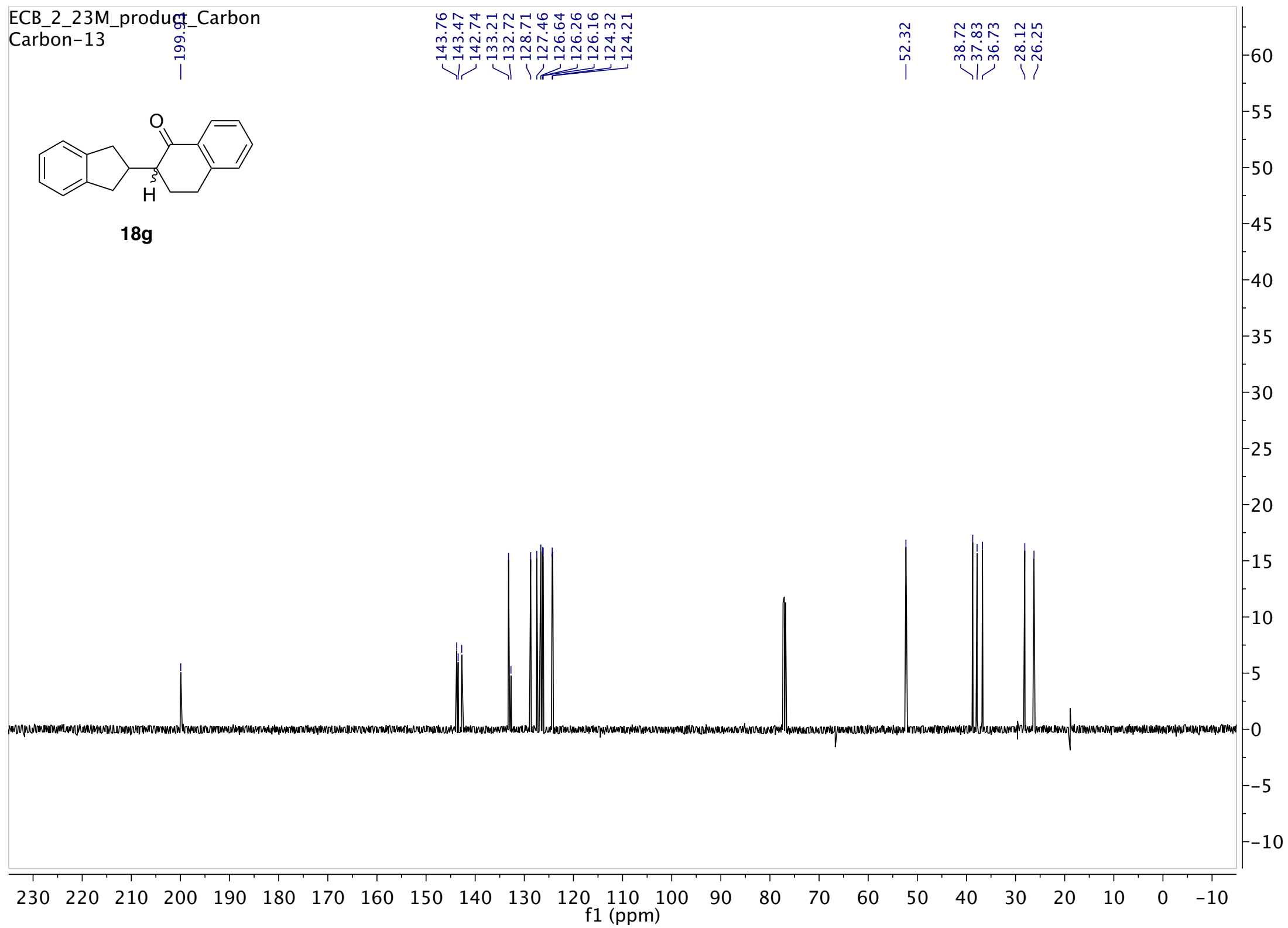




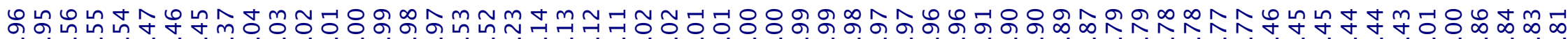

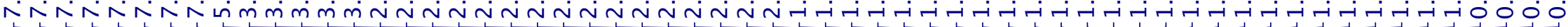
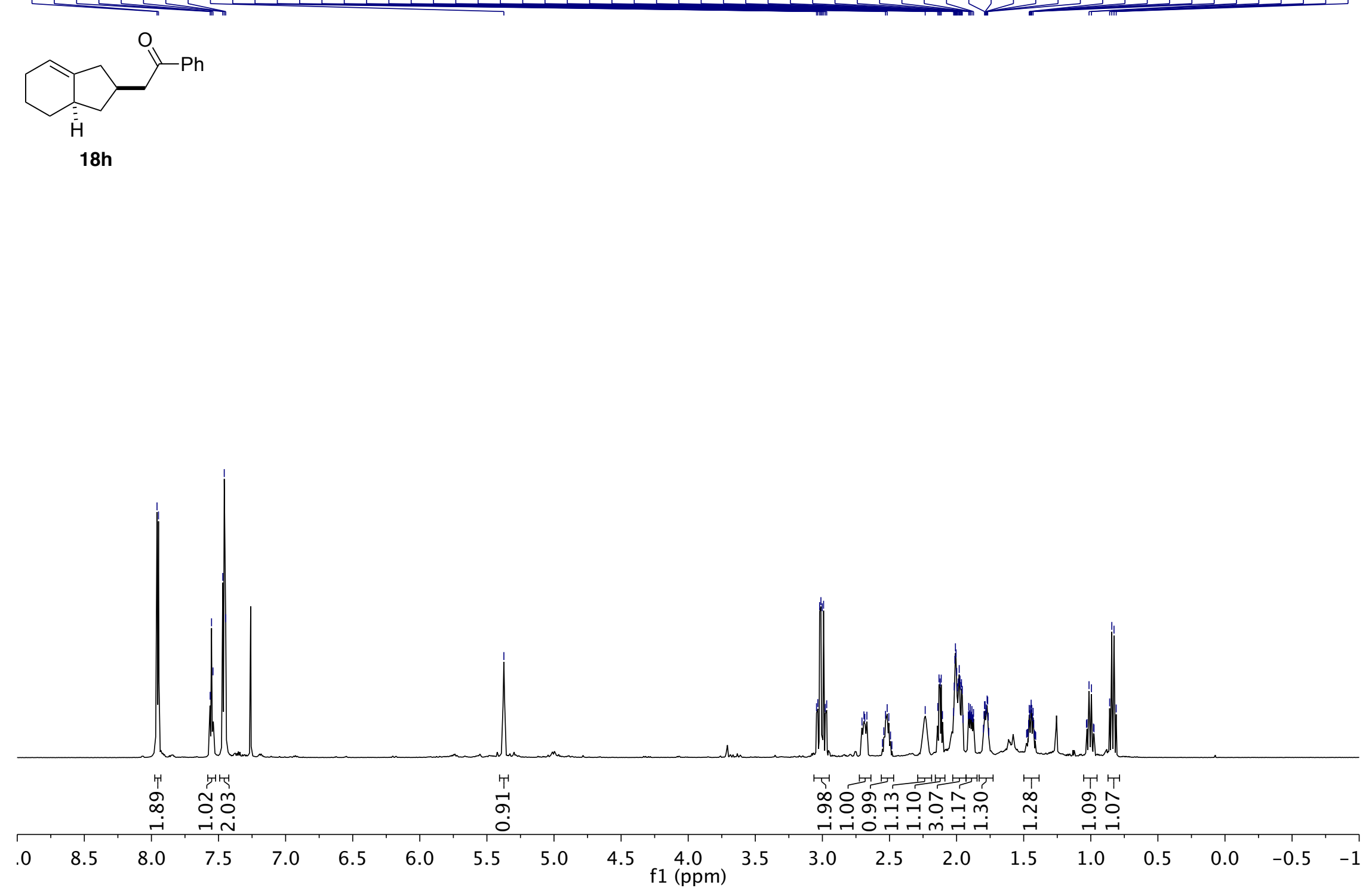

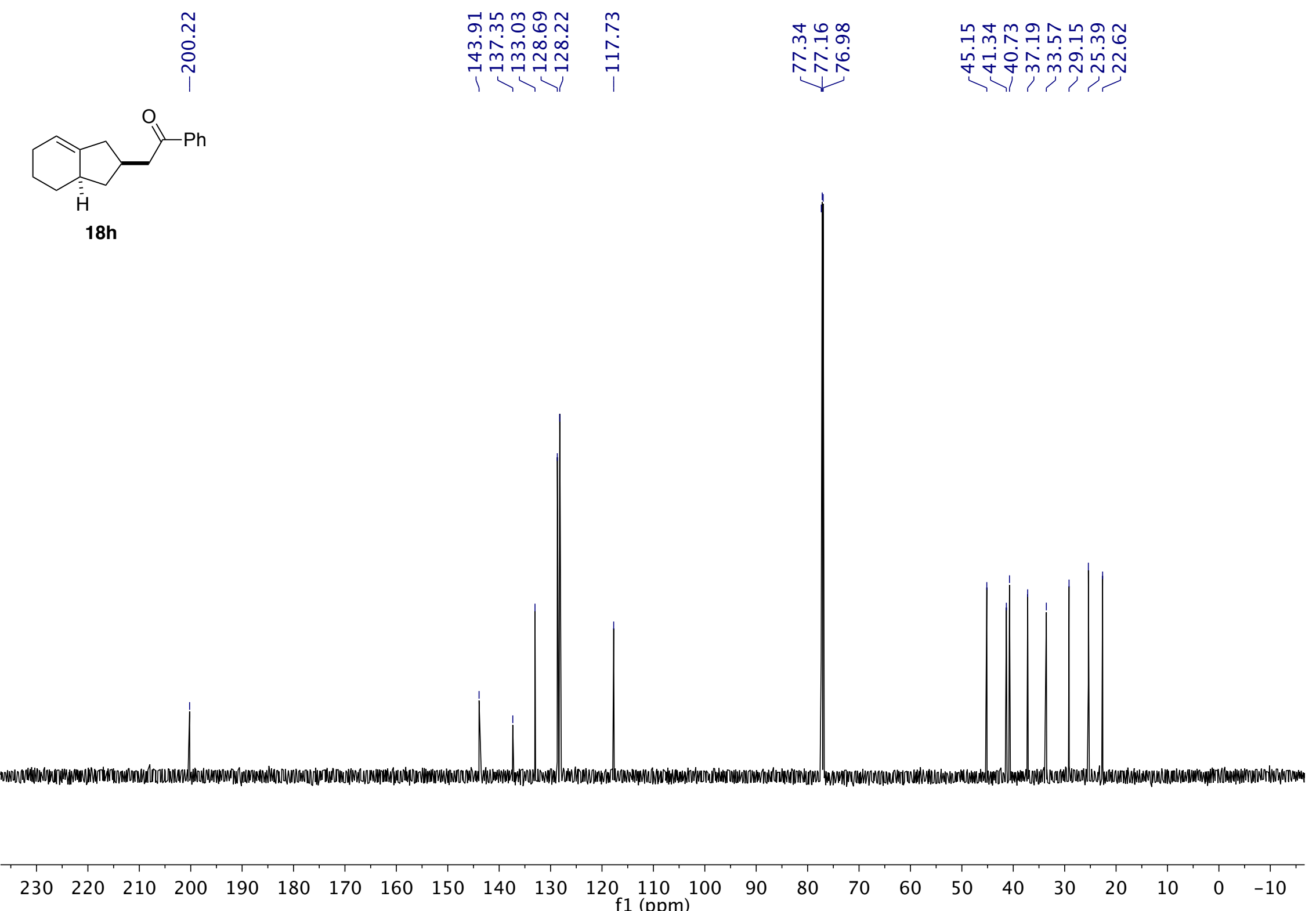


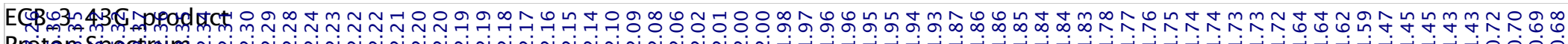

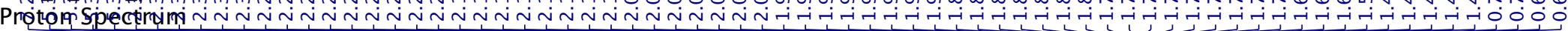

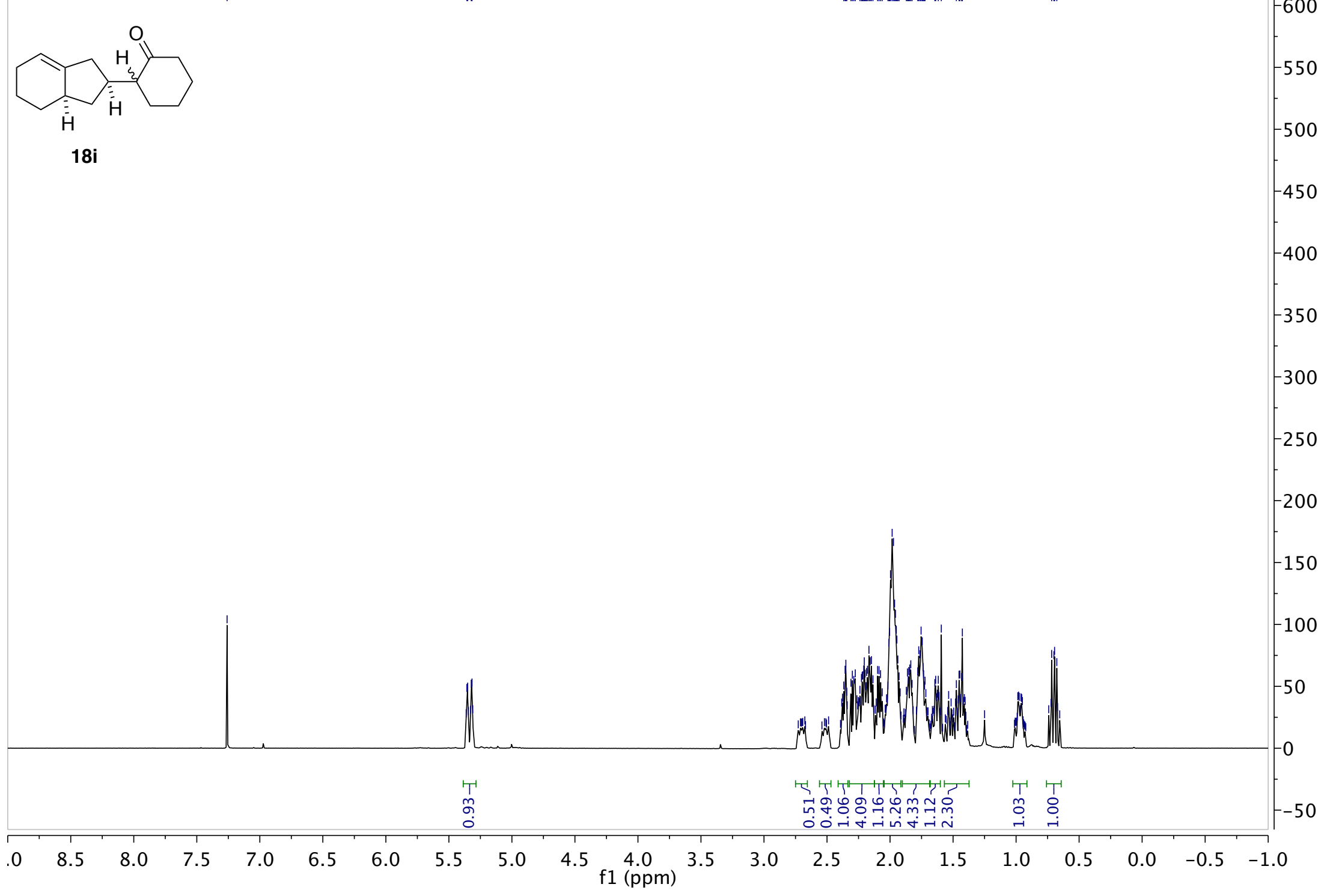




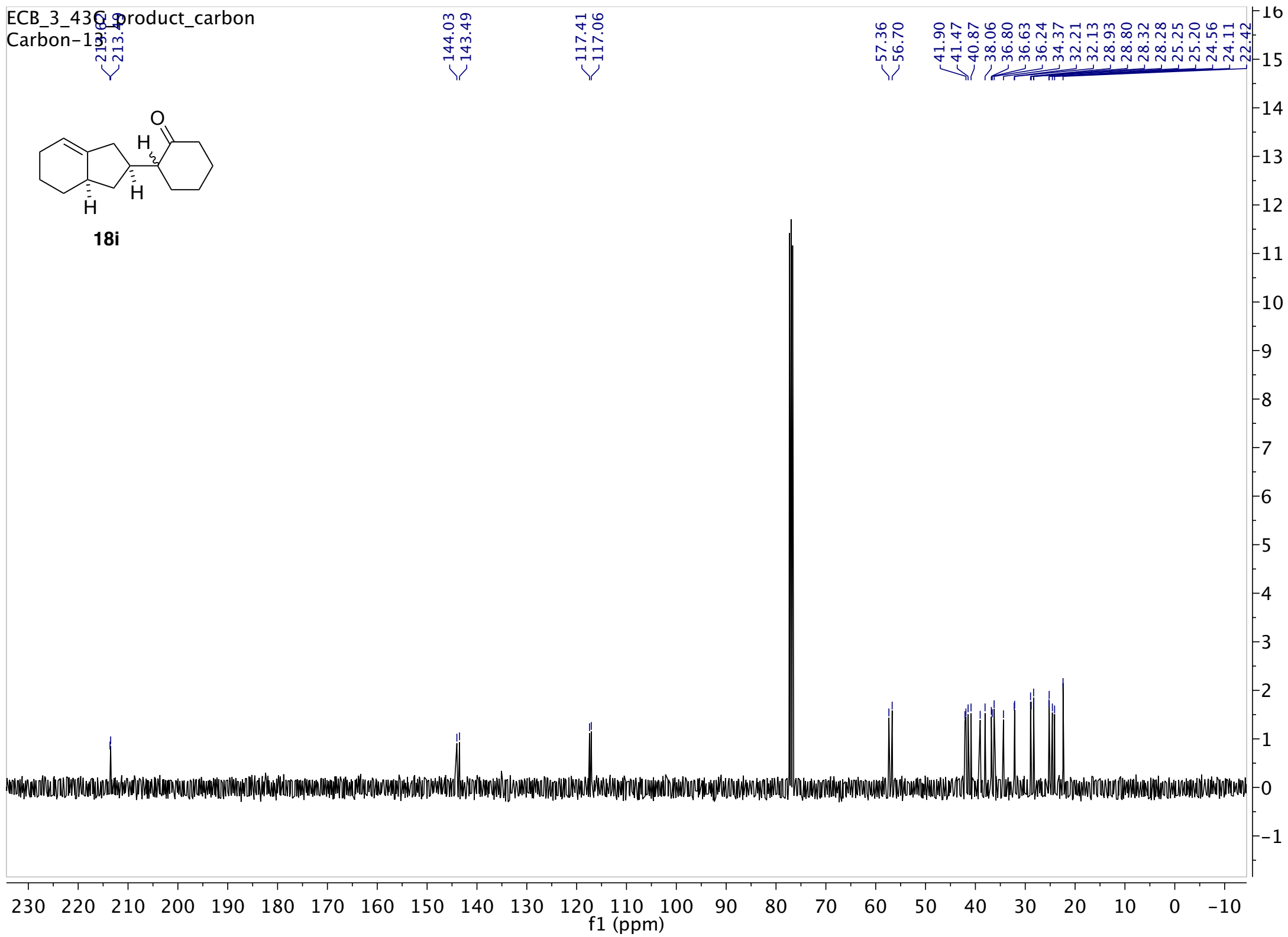




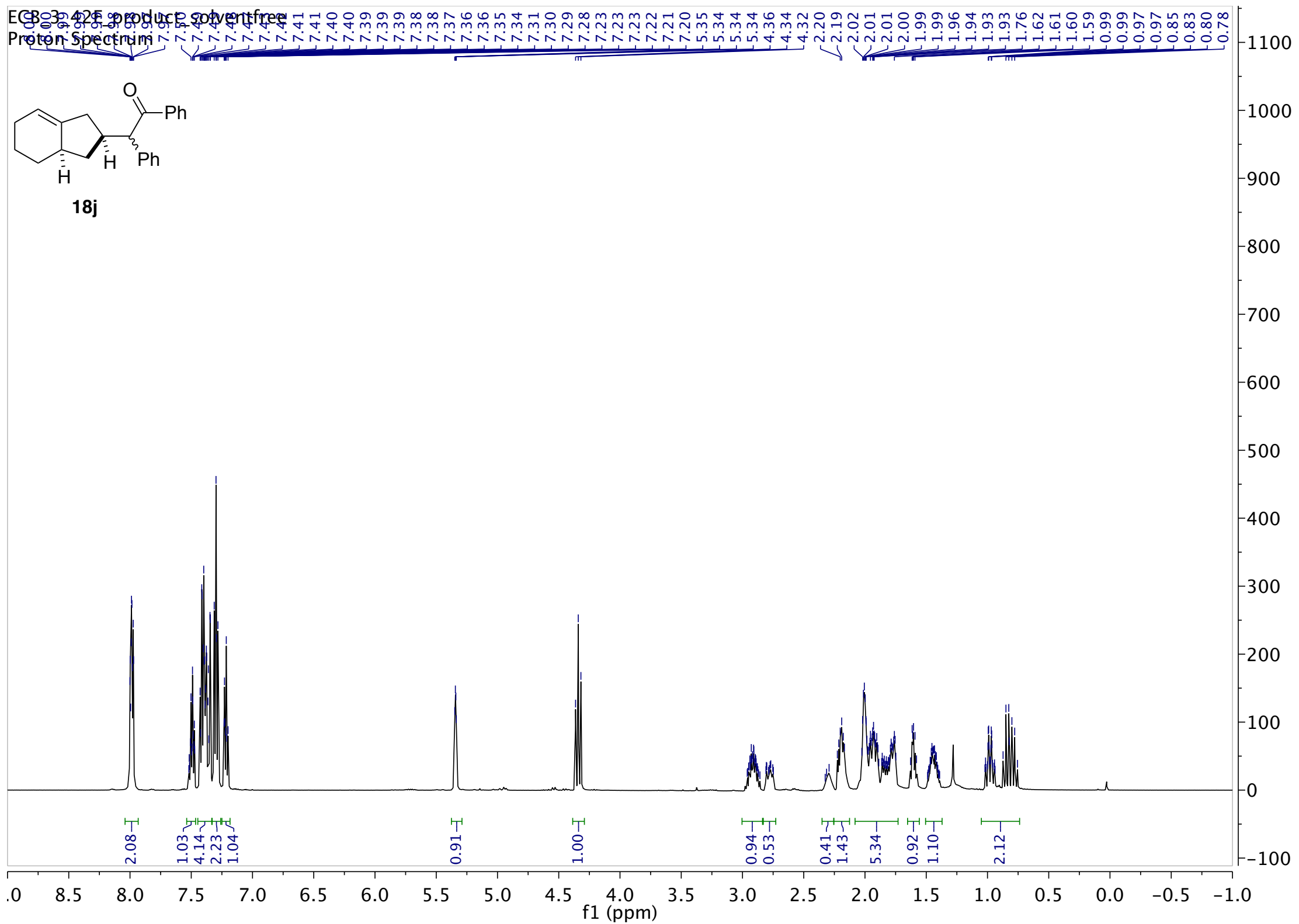




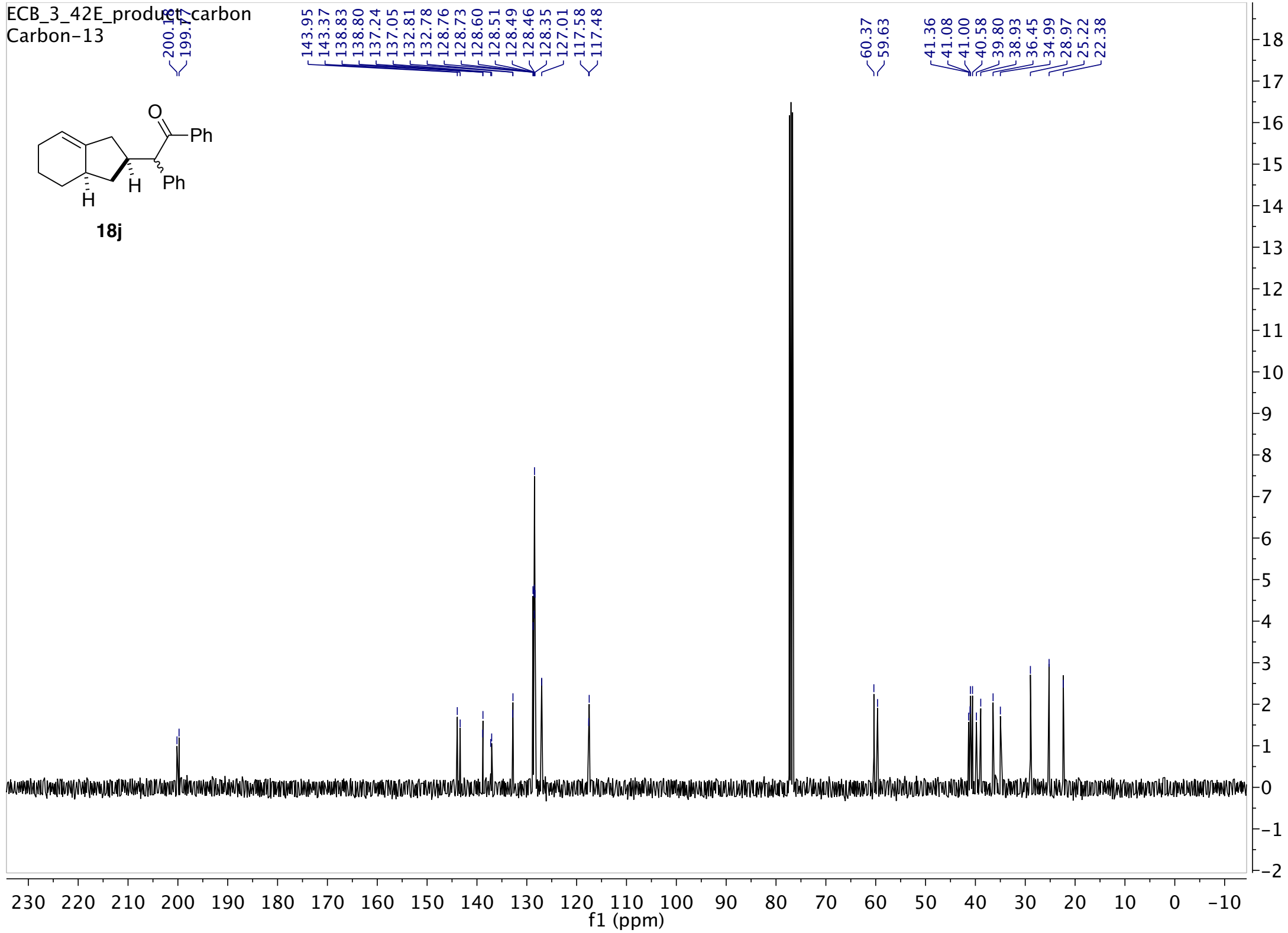




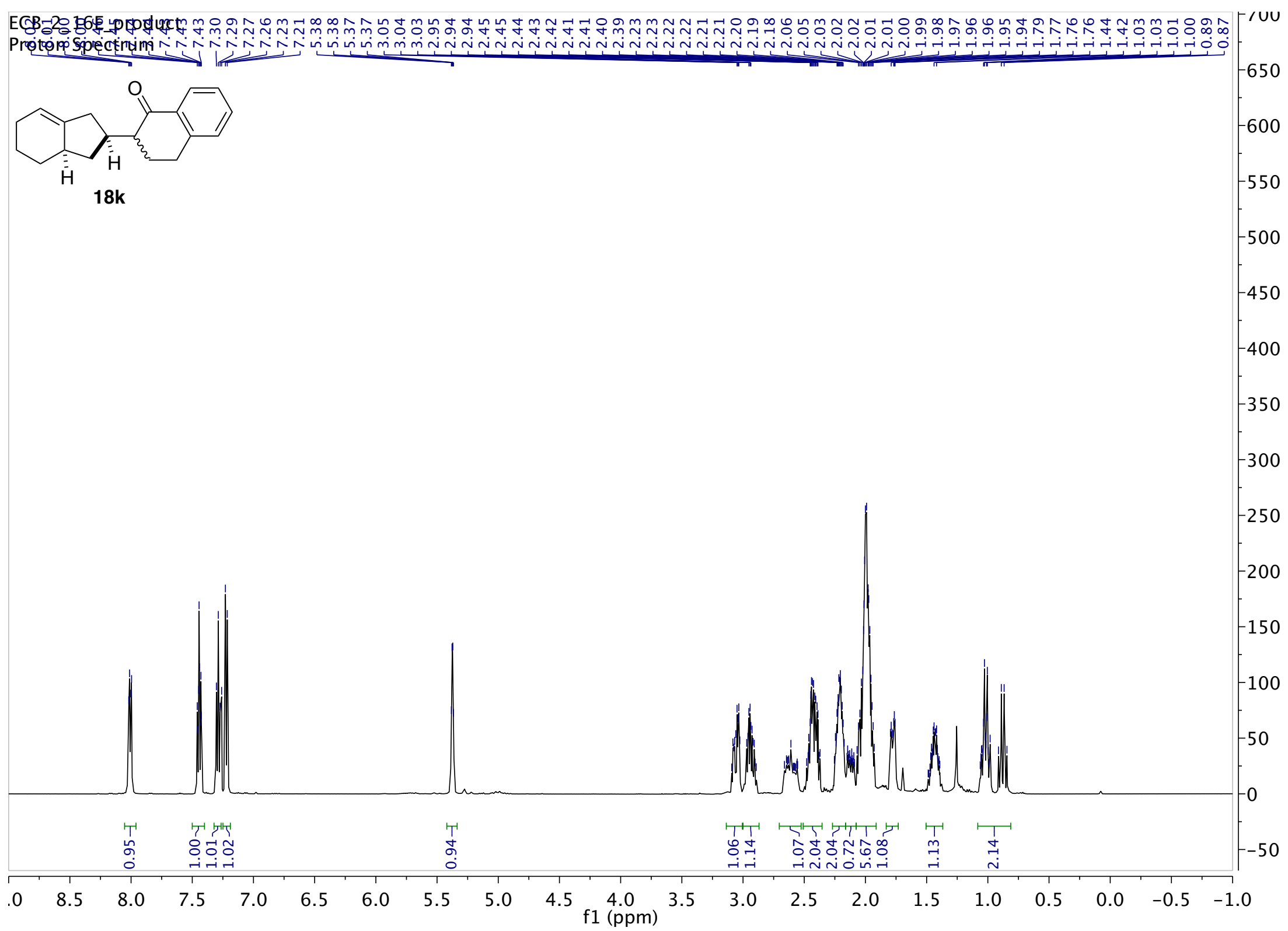




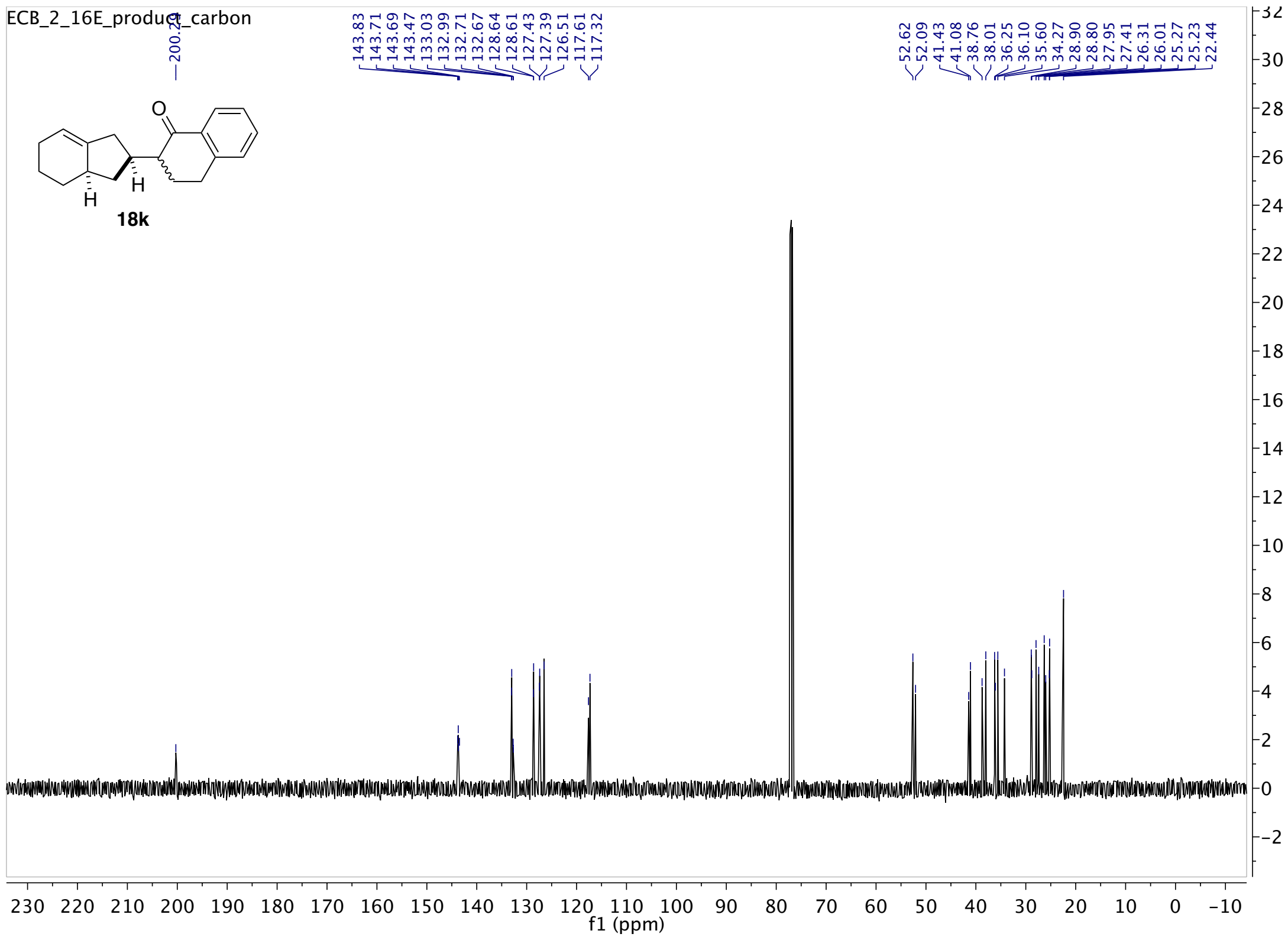




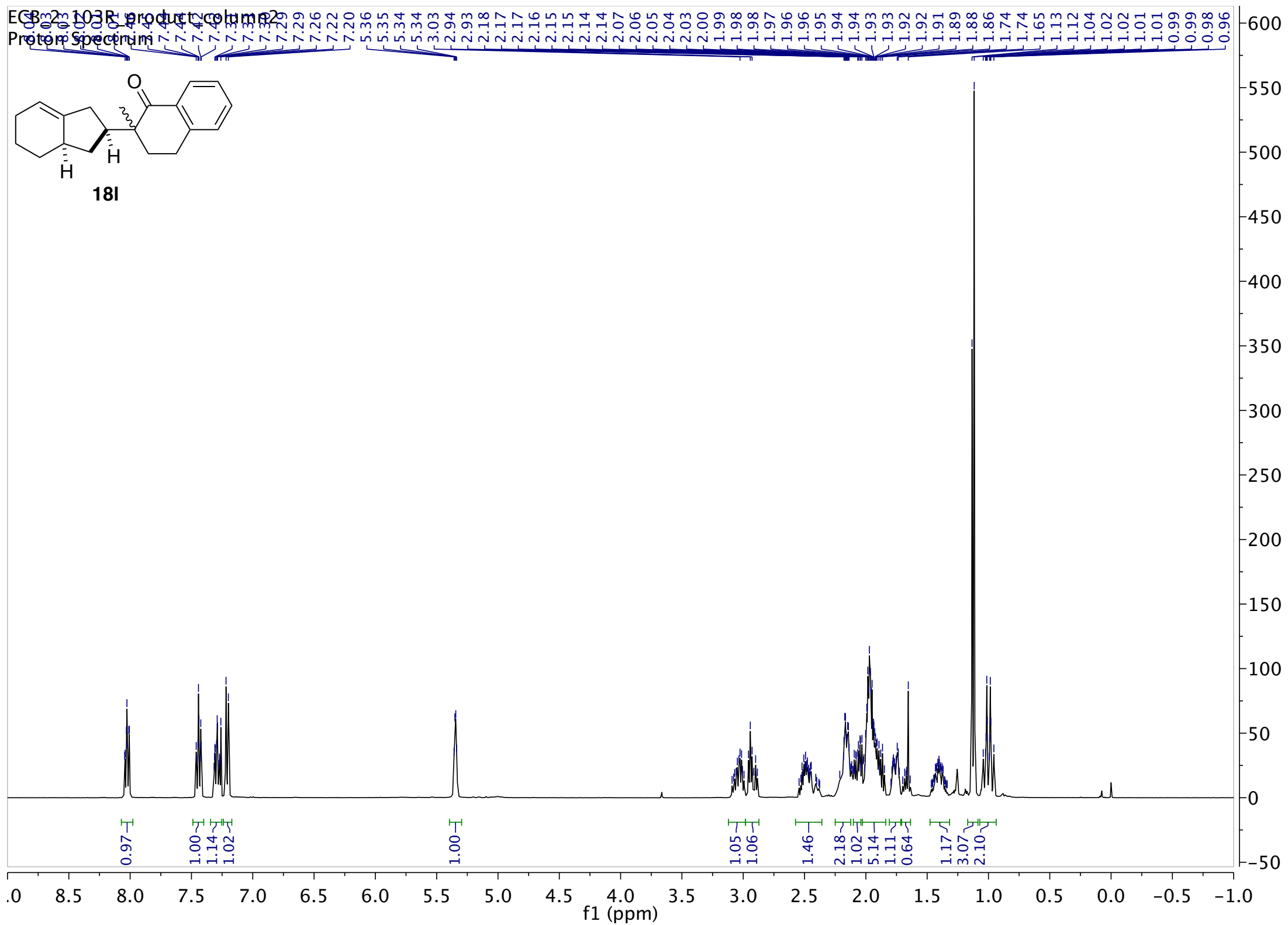




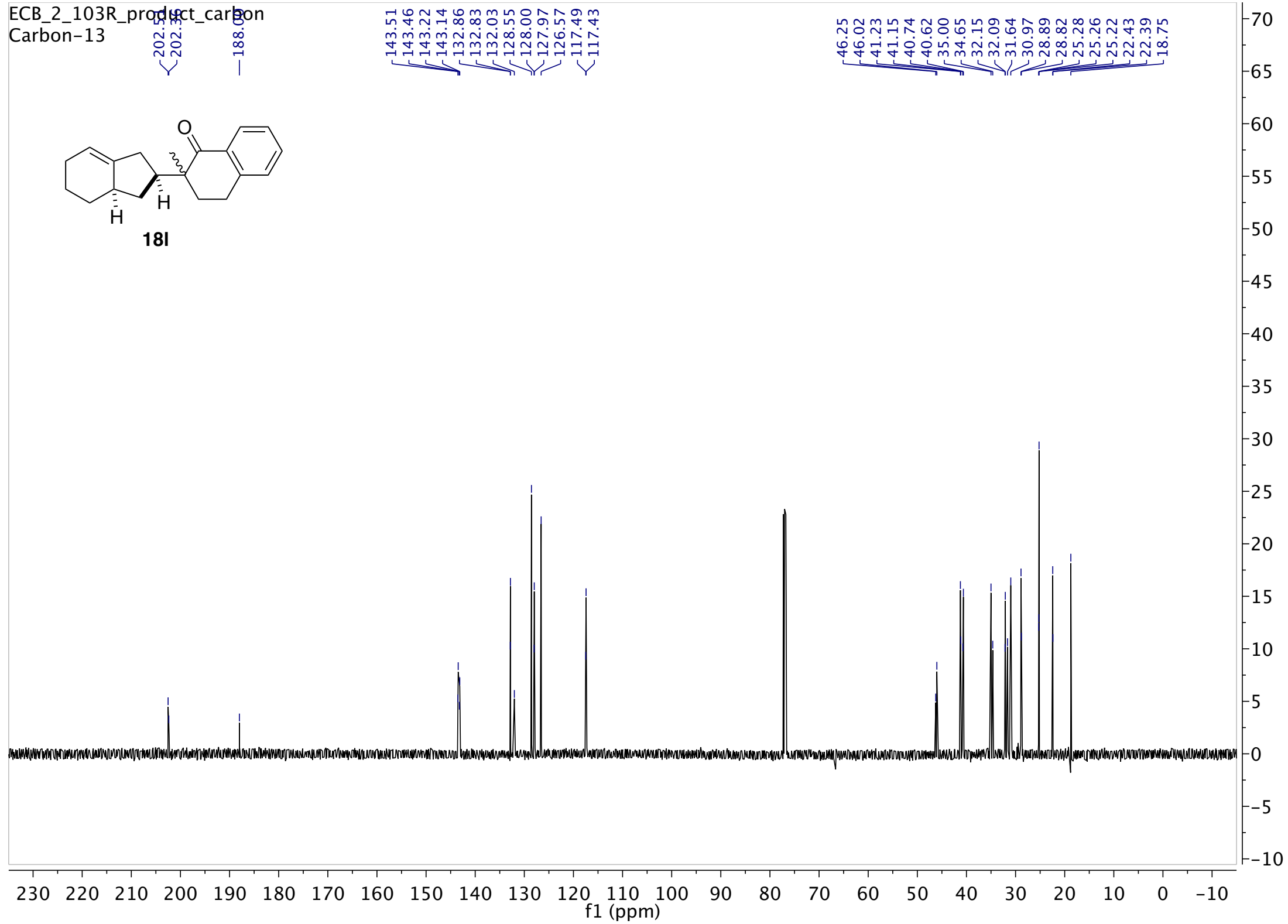

